Lucas Cardoso Laurindo

\title{
Avaliação da composição modal dinâmica do interior geostrófico dos oceanos
}

Dissertação apresentada ao Instituto Oceanográfico da Universidade de São Paulo, como parte dos requisitos para a obtenção do título de Mestre em Ciências na área de Oceanografia Física.

Orientador:

Prof. Dr. Paulo Simionatto Polito

São Paulo 


\section{UNIVERSIDADE DE SÃO PAULO \\ INSTITUTO OCEANOGRÁFICO}

\section{Avaliação da composição modal dinâmica do interior geostrófico dos oceanos}

\section{Lucas Cardoso Laurindo}

Dissertação apresentada ao Instituto Oceanográfico da Universidade de São Paulo, como parte dos requisitos para a obtenção do título de Mestre em Ciências na área de Oceanografia Física.

Julgada em ___ I__

$\operatorname{Prof}($ a.). $\operatorname{Dr}($ a.).

Conceito

$\operatorname{Prof(a.).~Dr(a.).}$

Conceito

$\operatorname{Prof(a.).} \operatorname{Dr}($ a.).

Conceito 


\section{Sumário}

Resumo ix

$\begin{array}{ll}\text { Abstract } & \mathbf{x} \\ & \end{array}$

1 Introdução 1

2 Hipóteses e Objetivos 9

3 Métodos $\quad 11$

3.1 Dados . . . . . . . . . . . . . . . . . . . . . . . 11

3.1 .1 Anomalia da altura da superfície livre . . . . . . . . . . . . . . 11

3.1.2 Temperatura da superfície do mar . . . . . . . . . . . . 12

3.1 .3 Perfis in situ de temperatura . . . . . . . . . . . . . . . . . . . 13

3.1.4 Dados climatológicos . . . . . . . . . . . . . . . . . . . . . 14

3.2 Processamento preliminar . . . . . . . . . . . . . . 15

3.2.1 Dados de satélite . . . . . . . . . . . . . . . . 15

3.2 .2 Perfis verticais $\ldots \ldots \ldots \ldots \ldots$

3.3 Construção de perfis sintéticos de temperatura . . . . . . . . . . . . . . . 19

3.3 .1 Formulação inicial . . . . . . . . . . . . . . . . . . . . . 19

3.3 .2 Falhas observadas . . . . . . . . . . . . . . . 21

3.3.3 Adaptação do método . . . . . . . . . . . . . . 23

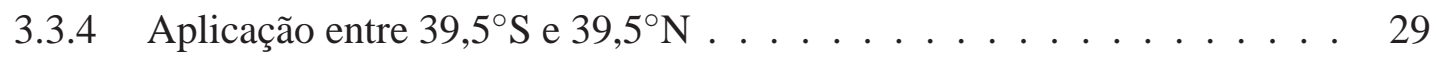

3.3.5 Avaliação do desempenho dos perfis sintéticos . . . . . . . . . . . 32

3.4 Cálculo da velocidade geostrófica $\ldots \ldots \ldots$

3.4 .1 Método dinâmico . . . . . . . . . . . . . . . . . 35

3.4 .2 Velocidades de referência $\ldots \ldots \ldots$

3.4 .3 Aplicação . . . . . . . . . . . . . . . . . . 37

3.5 Cálculo dos modos dinâmicos e raios de deformação . . . . . . . . . . . 38

3.5 .1 Fundamentos . . . . . . . . . . . . . . . 38

3.5 .2 Aplicação . . . . . . . . . . . . . . . . . . 41

3.6 Estimativa da importância relativa dos modos dinâmicos . . . . . . . . . . . . 42 
3.6.1 Circulação geostrófica total . . . . . . . . . . . . . . . . . 42

3.6.2 Anomalias em relação ao fluxo médio . . . . . . . . . . . . . . 43

3.6.3 Modos baroclínicos significativos nos oceanos . . . . . . . . . . 44

3.7 Limitações metodológicas . . . . . . . . . . . . . . . . . . . 45

3.7.1 Limites observacionais dos perfis sintéticos . . . . . . . . . . . 45

3.7.2 Importância da salinidade . . . . . . . . . . . . . . 48

3.7.3 Aproximação quase-geostrófica . . . . . . . . . . . . . . . . . . . 49

4 Resultados e Discussão $\quad 53$

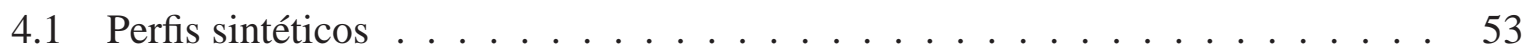

4.2 Raios de deformação . . . . . . . . . . . . . . . . . . . . . . 59

$4.2 .1 \quad$ Padrões médios . . . . . . . . . . . . . . . . . . . . . . . . 59

4.2 .2 Variabilidade temporal . . . . . . . . . . . . . . . 70

4.2.3 Influência de efeitos não-lineares . . . . . . . . . . . . . . . 81

4.3 Importância relativa dos modos dinâmicos . . . . . . . . . . . . . . . . 82

4.3.1 Identificação da origem e remoção do ruído observado em $\vartheta_{i}$ e $\vartheta_{i}^{\prime} \quad \ldots \quad$. 82

4.3.2 Circulação geostrófica total . . . . . . . . . . . . . . . . . . . 87

4.3.3 Anomalias em relação ao fluxo médio . . . . . . . . . . . . . . . . . 104

$\begin{array}{lll}5 & \text { Sumário e Conclusões } & 124\end{array}$

$\begin{array}{ll}\text { Referências } & 134\end{array}$ 


\section{Lista de Figuras}

1 Formas funcionais dos dois primeiros modos EOF da anomalia vertical da temperatura para duas posições no oceano Atlântico: $34,5^{\circ} \mathrm{W} / 29,5^{\circ} \mathrm{S}$ (esquerda) e $4,5^{\circ} \mathrm{N} / 38,5^{\circ} \mathrm{W}$ (direita) . . . . . . . . . . . . . . . . 22

2 Mapa da soma dos valores superficias das formas funcionais normalizadas dos dois primeiros modos EOF . . . . . . . . . . . . . . . . . . 24

3 Painéis superiores: representação esquemática da construção de retas de regressão teóricas da anomalia da altura $\eta$ vs. profundidade da termoclina. Painel inferior: mapa do coeficiente de correlação $R^{2}$ entre pontos de origem e suas respectivas retas de regressão . . . . . . . . . . . . . . . . . 2

4 Perfil hiperbólico construído a partir da Equação (10), exemplo emblemático da forma funcional utilizada para extrapolar para cima a camada de mistura de perfis sintéticos calculados a partir do método adaptado . . . . . . . . . . 28

$5 \quad$ Número de perfis in situ selecionados em caixas de $2^{\circ} \times 2^{\circ}$ ao redor dos pontos da grade de $1^{\circ} \times 1^{\circ}$ climatológica $\ldots \ldots \ldots . \ldots \ldots$

6 Ajuste da organização espacial dos perfis sintéticos e climatológicos para a aplicação do método dinâmico (painel superior), e para a decomposição modal

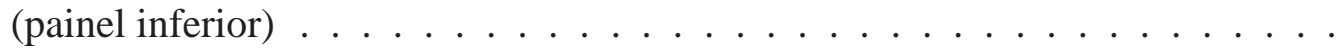

7 Mapa da percentagem da variância da anomalia vertical de temperatura explicada por seus dois primeiros modos estatísticos . . . . . . . . . . . .

8 Comportamento meridional dos números de Rossby $R o$ e planetário $\hat{\beta}$ entre $39^{\circ} \mathrm{S}$ e $39^{\circ} \mathrm{N}$, considerando o cenário com perfis de densidade organizados sobre uma grade espacial com resolução de $1^{\circ} \times 1^{\circ} \ldots \ldots \ldots$. . . . . . . . .

9 Seções zonais-verticais de temperatura sintética no oceano Índico, centradas em $29,5^{\circ} \mathrm{S}$ e abrangendo o período de 03/01 a 01/07/2008, com uma seção à cada 20 dias . . . . . . . . . . . . . . . . . . 54

10 Mapas do erro médio quadrático normalizado $(\varepsilon)$ calculados entre perfis mensais climatológicos de temperatura e perfis in situ ( $\varepsilon_{c i}$, painel superior), e entre perfis sintéticos e in situ $\left(\varepsilon_{s i}\right.$, painel inferior $) \ldots \ldots \ldots$. . . . . . . . . . 55 
11 Diferença entre $\varepsilon_{c i}$ e $\varepsilon_{i s}$. Valores positivos marcam pontos de grade onde os perfis in situ em média assemelham-se mais aos perfis sintéticos do que à climatologia mensal . . . . . . . . . . . . . . . . . 57

12 Mapa do primeiro raio de deformação interno médio, calculado a partir de perfis sintéticos de temperatura e perfis climatológicos mensais de salinidade . . . . . 61

13 Similar à Figura 12 para o segundo raio de deformação interno . . . . . . . . . 62

14 Similar à Figura 12 para o terceiro raio de deformação interno . . . . . . . . . 63

15 Média zonal dos cinco primeiros raios de deformação internos $R_{i}$ (esquerda) e das respectivas velocidades de fase de ondas de gravidade internas $c_{i}$ associadas

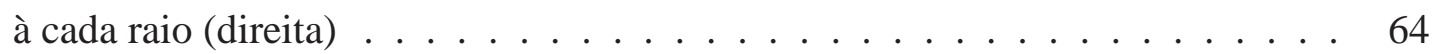

16 Mapa da velocidade de fase para ondas de gravidade internas do primeiro modo

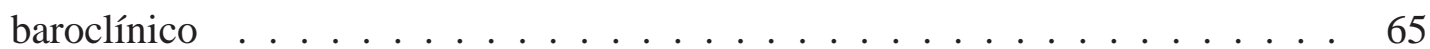

17 Similar à Figura 16 para ondas do segundo modo baroclínico . . . . . . . . . 66

18 Similar à Figura 16 para ondas do terceiro modo baroclínico . . . . . . . . . . 67

19 Diagrama de dispersão dos valores de $R_{1}$ calculados em Chelton et al. 1998 vs. os obtidos neste estudo. São considerados apenas dados referentes à latitudes superiores à $5^{\circ} \ldots \ldots \ldots \ldots$. . . . . . . . . . . . . . . . . . 69

20 Mapas das diferenças percentuais dos primeiros três raios de deformação baroclínicos em relação à média de longo termo, referentes ao dia 07/09/2004 . . 72

21 Mapa dos desvios-padrão das diferenças percentuais para o primeiro raio de deformação interno . . . . . . . . . . . . . . . . . . . . . 74

22 Similar à Figura 21 para o segundo raio interno . . . . . . . . . . . . . . 75

23 Similar à Figura 21 para o terceiro raio interno . . . . . . . . . . . . 76

24 Gráfico da evolução temporal da componente $v$ da velocidade geostrófica (curva azul) e dos resultados obtidos para $\vartheta_{1}$ (curva vermelha), para as coordenadas $30^{\circ} \mathrm{N} / 60^{\circ} \mathrm{W}$, no oceano Atlântico . . . . . . . . . . . . . . . 86

25 Médias globais de $\vartheta_{i}^{\prime}(\%)$ para as componentes $u$ e $v$ da velocidade geostrófica, considerando o modo barotrópico e os cinco primeiros modos baroclínicos . . . 89

26 Similar à Figura 25 para o primeiro modo baroclínico . . . . . . . . . . . . . 90

27 Similar à Figura 25 para o segundo modo baroclínico . . . . . . . . . . . . 91

28 Similar à Figura 25 para o terceiro modo baroclínico . . . . . . . . . . . . . . 92 
29 Mapas do desvio-padrão de $\vartheta_{0}$ para a componente $u$ (painel superior) e $v$ (painel inferior) da velocidade geostrófica . . . . . . . . . . . . . . . 100

30 Similar à Figura 29 para o primeiro modo baroclínico . . . . . . . . . . . . 101

31 Similar à Figura 29 para o segundo modo baroclínico . . . . . . . . . . . . . . 102

32 Similar à Figura 29 para o terceiro modo baroclínico . . . . . . . . . . . 103

33 Mapas médios da percentagem da estrutura vertical da anomalia da velocidade geostrófica que é explicada pelo modo barotrópico $\left(\vartheta_{0}^{\prime}\right)$ para a componente $u$ (painel superior) e $v$ (painel inferior) . . . . . . . . . . . . . . 106

34 Similar à Figura 33 para o primeiro modo baroclínico . . . . . . . . . . . . 107

35 Similar à Figura 33 para o segundo modo baroclínico . . . . . . . . . . . . 108

36 Similar à Figura 33 para o terceiro modo baroclínico . . . . . . . . . . . . . . 109

37 Mapas do desvio-padrão de $\vartheta_{0}^{\prime}$ para a componente $u$ (painel superior) e $v$ (painel inferior) da velocidade geostrófica . . . . . . . . . . . . . . . 116

38 Similar à Figura 37 para o primeiro modo baroclínico . . . . . . . . . . . . 117

39 Similar à Figura 37 para o segundo modo baroclínico . . . . . . . . . . . . . 118

40 Similar à Figura 37 para o terceiro modo baroclínico . . . . . . . . . . . . . 119 


\section{Lista de Tabelas}

1 Lista das profundidades padrão dos dados do WOA05 . . . . . . . . . . . 15

2 Exemplo ilustrativo da soma ponderada entre um perfil in situ extrapolado até 1500 m e o perfil climatológico anual correspondente entre 1010 e 1490 m de

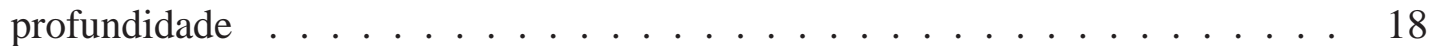

3 Média e desvio-padrão dos valores de $\vartheta_{i}(\%)$ calculados para as componentes $u$ e $v$ da velocidade geostrófica em todos os pontos $(x, y, t)$ da grade utilizada, considerando o modo barotrópico e os cinco primeiros modos baroclínicos . . . 88

4 Similar à Tabela 3 , mas considerando $\vartheta_{i}^{\prime}(\%) \ldots \ldots$. . . . . . . . . 105 


\section{Agradecimentos}

Foram uns anos intensos, mas quer saber? Valeram cada minuto. Meus agradecimentos sinceros à:

- Ao Paulo e à Olga, casal ondas-planetárias-e-calor-armazenado, por me ensinarem o que significa fazer ciência;

- Ao pessoal da turma do mestrado, Leandro, Wandrey, Ju, Márcio, Franzé, Fabíola e Hebe. Diz aí, a matéria do Belmirão foi emocionante, não foi não?

- Ao professor Ilson, pela amizade e por botar fé neste mineiro aqui;

- À todo o pessoal da pós, aos colegas de laboratório, aos amigos da turma II e de todo o IO... Churrasco na 69 pós-defesa!

- Aos meus pais, à quem eu devo tudo, tudo e um pouco mais;

- Minhas irmãs queridas, Clara e Wanda, e claro, aos respectivos maridões Emílio e Márcio!

- Ao COC. Galera, esta continua sendo a melhor idéia que já tivemos;

- Ao pessoal do RPG. Que atire a primeira pedra quem ganhar a iniciativa;

- À Estação 69 de ontem, hoje e sempre. Vocês são meus irmãos aqui nessas paragens distantes;

- Ao Aldo, Fernando, Maria Cecília, Marina e Eduardo, pela compreensão, permitindo que me concentrasse na conclusão do mestrado nos momentos mais críticos;

- À Aline, que não deve nem suspeitar disso, mas deu uma força gigante nesse finalzinho do trabalho!

- E finalmente à Coordenação de Aperfeiçoamento de Pessoal de Nível Superior - CAPES, pelo suporte financeiro ao longo de 24 meses.

Este trabalho é dedicado aos meus sobrinhos, Mateus e Francisco! Dois cabras arretados! 


\section{Resumo}

Este trabalho avalia a importância relativa dos modos dinâmicos na composição da estrutura vertical do fluxo geostrófico e de suas anomalias em relação à média, com o objetivo de fornecer uma descrição das formas de estratificação predominantes na coluna de água e de identificar prováveis regiões de ocorrência de ondas de Rossby planetárias (OR) dos diversos modos dinâmicos. Raios de deformação internos são estimados para avaliar a possibilidade de interações não-lineares entre OR e as alterações da estratificação local forçadas por sua própria passagem. A análise proposta baseia-se em dados de densidade estimados a partir de perfis verticais de salinidade climatológicos aliados a perfis sintéticos de temperatura. Estes últimos são extrapolados verticalmente a partir de dados orbitais da temperatura da superfície do mar (TSM) e da anomalia da altura da superfície livre ( $\eta$ ), segundo um método de reconstrução estatística desenvolvido para este estudo. O primeiro modo baroclínico é dominante tanto no fluxo total quanto em suas anomalias, respondendo em média por 30\% da estrutura vertical de velocidade, sendo que este valor descresce aproximadamente por uma razão de três em modos superiores. O segundo modo é significativo ou mesmo dominante em algumas regiões, particularmente em latitudes próximas ao equador. O terceiro é evidente em algumas áreas localizadas, mas não assume papéis importantes em escala de bacia. O modo 0 responde por frações de 6 a 9\%, mas é provável que estes resultados sejam subestimados pela metodologia aplicada. Anomalias verticais relacionadas ao primeiro modo coincidem com regiões onde OR longas do primeiro modo tem maior expressão, enquanto o segundo modo parece ser um marcador de OR curtas e ondas de instabilidade tropical. Fenômenos transientes associados ao terceiro modo são observados em áreas restritas dos três oceanos. A magnitude das variações dos raios internos em resposta à fenômenos transientes em algumas regiões implicam em variações significativas na velocidade de fase teórica de OR longas lineares, um indício de que efeitos não-lineares podem ser importantes. Por fim, amplificações da importância do modo barotrópico sobre feições topográficas significativas sugere a existência de mecanismos de transferência de energia entre modos dinâmicos induzidas pela interação com a batimetria.

Descritores: altímetro, TSM, Argo, XBT, perfis sintéticos de temperatura, modos dinâmicos, raios de deformação de Rossby, ondas de Rossby planetárias, interações não-lineares. 


\begin{abstract}
This study evaluates the relative importance of the dynamical modes in the composition of the geostrophic flow and of its anomalies from the long-term average, respectively seeking to determine the dominant vertical stratification structures of the water column and to identify regions where planetary Rossby waves (RW) of different dynamical modes may most likely occur. The baroclinic Rossby radii of deformation are estimated to evaluate the possibility of nonlinear interactions between RW and changes of the local stratification forced by the wave's passing. This analysis is based on density data estimated from climatological salinity profiles and synthetic temperature profiles. The latter are vertically extrapolated for sea surface temperature (SST) and sea surface height anomaly $(\eta)$ satellite data, using a statistical reconstruction method developed in this study. The first baroclinic mode dominates both the total geostrophic flow and its anomalies, accounting for $30 \%$ of the velocity's vertical structure on average, where this value decreases approximately by a factor of 3 in subsequent baroclinic orders. The second mode is significant or even dominant in some areas, particularly near the equator. The third mode is evident in some localized regions, but can be ignored at basin-scales. The barotropic mode accounts for 6 to $9 \%$ fractions on average, however these values are probably underestimated by the used methods. Vertical anomalies related to the first baroclinic mode coincide with regions where long RWs answers for a significant fraction of local variance, while the second mode highlights zones where short RWs and tropical instability waves are reported. Transient phenomena related with the third mode are observed in comparatively small areas on all three oceans. The magnitude of the baroclinic radii's variations in response of the transient variability results in significant changes of the theorethical phase speed for long linear RWs, an evidence that nonlinear effects may be important. Lastly, the greater significance of the barotropic mode over proeminent bottom features suggests the existence of energy transfer mechanisms between dynamical modes triggered by the interaction with the bathymetry.
\end{abstract}

Keywords: altimeter, SST, Argo, XBT, synthetic temperature profiles, dynamical modes, Rossby radius of deformation, planetary Rossby waves, nonlinear interactions. 


\section{Introdução}

A extensão horizontal dos oceanos sobre a superfície do planeta é três ordens de grandeza maior que a sua profundidade. Em vista da grande diferença entre as escalas envolvidas, é razoável supor que a maior parte da energia associada aos movimentos oceânicos esteja contida em suas componentes horizontais (Gill 1982). De fato, as velocidades horizontais em geral são de quatro a cinco ordens de grandeza maiores que as verticais, resultado da grande anisotropia associada ao equilíbrio hidrostático e à rotação do planeta (Abarbanel e Young 1987).

Portanto, é possível considerar que os movimentos oceânicos de meso a larga escala são essencialmente horizontais. Esta aproximação permite representar sua estrutura de velocidade de maneira simplificada, decompondo-a em componentes horizontais e verticais através da técnica de separação de variáveis. Especificamente, assumindo uma representação plana de uma região da superfície esférica do planeta e coordenadas cartesianas, o campo quadridimensional das componentes zonal e meridional da velocidade horizontal podem ser representados como a soma de uma série infinita de funções ortogonais ou modos normais com estruturas verticais fixas, cada uma multiplicada por funções amplitude dependentes do tempo e do espaço horizontal (LeBlond e Mysak 1978).

Segundo a formulação de Silveira et al. 2000, modos normais para a estrutura vertical de velocidade podem ser obtidos através da resolução de um problema de autovalor e autovetor, definido a partir da aplicação da separação de variáveis à equação da conservação da vorticidade derivada para um oceano linear, quase-geostrófico e continuamente estratificado. Os modos normais, conhecidos como modos dinâmicos por serem obtidos através das equações do movimento, são os autovetores do problema e seu cálculo é baseado no perfil vertical de densidade local. Podem ser interpretados portanto como sendo componentes baroclínicas do campo de velocidade geostrófica, onde o modo 1 é o primeiro modo baroclínico, o modo 2 é o segundo modo baroclínico, etc. O primeiro modo cruza o zero uma vez ao longo da coluna de água, o segundo duas vezes e assim por diante, representando diferentes formas de cisalhamento vertical. Assume-se também a existência de um modo 0 ou barotrópico com magnitude unitária em todas as profundidades. Os autovalores associados à cada modo baroclínico são inversamente proporcionais aos raios de deformação de Rossby internos ou baroclínicos correspondentes e portanto contém a dependência com a estratificação. Por outro lado, o raio externo ou barotrópico varia 
simplesmente em função da latitude e da profundidade locais.

Raios de deformação são parâmetros dinâmicos que determinam as escalas horizontais necessárias para a ocorrência de fenômenos oceânicos regidos pela teoria quase-geostrófica. O raio externo pode ser interpretado como a distância sobre a qual a tendência da gravidade de aplainar a superfície livre é balanceada pela tendência da aceleração de Coriolis de deformá-la, constituindo portanto uma escala pertinente a fenômenos barotrópicos. Os raios internos levam ainda em conta a estratificação vertical de densidade, representando neste caso a distância onde o balanço entre as acelerações do empuxo e de Coriolis estabiliza a inclinação das superfícies isopicnais, e portanto escalam as dimensões de movimentos que dependem da existência de gradientes laterais de densidade, como vórtices de mesoescala e ondas de Rossby baroclínicas (Emery et al. 1984; Pedlosky 1986).

Em suma, as formas funcionais de cada modo dinâmico, seus raios de deformação associados e as respectivas amplitudes que os modos assumem ao compor perfis verticais das componentes $u$ e $v$ da velocidade geostrófica são parâmetros que dependem da estratificação interna dos oceanos. Em conjunto, são capazes de descrever o comportamento dinâmico de regiões oceânicas ao longo das três dimensões espaciais e do tempo assumindo que a aproximação quase-geostrófica seja válida. São comumente utilizados para ajustar modelos de camadas a sistemas de correntes regionais, facilitando a determinação e o estudo dos processos dinâmicos dominantes (Flierl 1978). No contexto das teorias lineares clássica (Rossby 1938) e extendida (Killworth e Blundell 2004) da propagação de ondas de Rossby livres, as equações de onda deste fenômeno podem ser derivadas para cada um dos modos dinâmicos. Fisicamente, isto significa que a passagem de uma onda de Rossby planetária provoca anomalias verticais de velocidade compatíveis com a forma funcional de seu modo correspondente. Ou seja, ondas de Rossby barotrópicas causam anomalias na velocidade horizontal verticalmente uniformes, ondas de Rossby do primeiro modo baroclínico geram anomalias com estrutura vertical correspondente ao primeiro modo baroclínico, e assim por diante (Cipollini et al. 2004). Como os modos são ortogonais entre si, ondas de diferentes modos podem coexistir. Adicionalmente, os raios de deformação são diretamente proporcionais às velocidades de fase de ondas de gravidade, consequentemente também figurando nas expressões para velocidade de fase e de grupo de ondas de Rossby planetárias (Chelton et al. 1998).

A aquisição de dados para o estudo das estruturas verticais de densidade e velocidade dos 
oceanos sempre foi limitada pelo alto custo das missões oceanográficas. Isto faz com que levantamentos observacionais dos padrões de circulação geostrófica e de fenômenos regidos pela teoria quase-geostrófica em geral sejam relegados à estudos regionais e/ou baseados em conjuntos amostrais quase-sinóticos, que correspondem à aproximações das condições oceânicas instantâneas. Séries temporais contínuas são ainda mais raras, em geral se restringindo às poucas regiões que contam com fundeios oceanográficos. Sistemas de amostragem in situ menos dispendiosos, como o lançamento de XBTs por navios de oportunidade, a utilização de bóias de deriva, e mais recentemente, de sistemas de observação autônomos como gliders e flutuadores Argo, foram concebidos como alternativas aos cruzeiros. Estes sistemas são capazes de cobrir vastas porções oceânicas e de fornecer grande quantidade de medições, porém seus dados nem sempre estão disponíveis e em geral pecam pela falta de sinopticidade e/ou cobertura espacial irregular.

Sensores orbitais provaram ser instrumentos valiosos para a oceanografia pois comparativamente possuem excelentes periodicidade e cobertura espacial. Porém, no contexto apresentado possuem utilidade limitada uma vez que a maioria dos parâmetros medidos, como temperatura e salinidade de superfície (TSM e SSM, respectivamente) e a tensão de cisalhamento dos ventos, refletem processos com expressão essencialmente superficial. As observações altimétricas são uma importante exceção, uma vez que os dados da anomalia da altura da superfície livre ( $\eta$ ) refletem flutuações do calor integrado verticalmente e portanto remetem à variações das estruturas internas de temperatura e densidade (Chambers et al. 1997). Os dados de $\eta$ não podem, por si só, fornecer informações à respeito da estrutura modal do fluxo geostrófico médio dos oceanos, pois tal análise requer dados médios da estrutura vertical de velocidade geostrófica. Em contrapartida, diversos estudos relacionam as anomalias observadas à estrutura modal dinâmica de fenômenos transientes, como ondas de Rossby planetárias (Chelton e Schlax 1996; Stammer 1997; Polito e Liu 2003; Maharaj et al. 2007).

Stammer 1997 relata que as dimensões dos padrões resultantes da autocorrelação em lag zero de mapas de $\eta$ altimétrico são proporcionais ao primeiro raio de deformação interno, apresentando isto como evidência de que os sinais em $\eta$ refletem predominantemente fenômenos ligados ao primeiro modo baroclínico. Observações globais da velocidade de propagação de ondas de Rossby através de dados altimétricos sugerem que ondas do primeiro modo dominam o espectro de energia dos sinais propagantes para oeste (Chelton e Schlax 1996; Polito e Liu 
2003). Por fim, Maharaj et al. 2007 faz uso da transformada de Fourier bidimensional sobre dados de $\eta$ para avaliar a contribuição de ondas de Rossby de diferentes modos baroclínicos ao espectro energético no Pacífico sul. Maharaj et al. 2007 mostra uma clara dominância do primeiro modo baroclínico ao longo da bacia, destacando ainda que o segundo modo possui importância significativa em larga escala e que o terceiro pode assumir magnitudes não desprezíveis em escalas regionais.

Porém, especula-se que os altímetros sejam pouco sensíveis a sinais baroclínicos de ordens superiores ao primeiro, deficiência que pode ser decorrente da maneira como o oceano responde à formas de variabilidade com estruturas baroclínicas de modos superiores ao primeiro (Cipollini et al. 1997; Challenor et al. 2004). Em uma primeira aproximação, um oceano dominado pelo primeiro modo pode ser simplificado a um modelo de 2 camadas, pelo segundo modo a um de 3 camadas, etc. Considerando a passagem de ondas planetárias do primeiro modo em um modelo de duas camadas, a interface entre as camadas representa a base da termoclina, fazendo com que a oscilação na interface induzida pela passagem da onda necessariamente cause variações do calor integrado na coluna de água, produzindo um sinal propagante em $\eta$ que pode ser reconhecido em dados altimétricos (Polito e Sato 2003). Para ondas de maiores modos em modelos com mais camadas, a oscilação da interface entre camadas mais profundas podem compensar o deslocamento da termoclina em termos de calor armazenado, não gerando portanto sinais significativos em $\eta$.

Evidências observacionais em séries temporais de temperatura vertical de fundeios e em dados orbitais de TSM, cor do oceano e mesmo de $\eta$ sugerem a existência de ondas com modos maiores que o primeiro em uma faixa latitudinal razoavelmente extensa, entre $4^{\circ} \mathrm{N}$ (Laurindo et al. 2010) e $10^{\circ} \mathrm{N}$ (Polito e Sato 2003; Brandt et al. 2002), até cerca de $35^{\circ} \mathrm{N}$ (Cipollini et al. 1997; Challenor et al. 2004). Adicionalmente, o trabalho de Lapeyre 2009 realiza uma decomposição em modos verticais sobre dados de um modelo numérico que resolve a dinâmica de mesoescala, utilizando os conceitos da teoria da vorticidade potencial quase-geostrófica, incluindo ainda na análise um modo com vorticidade potencial zero não ortogonal aos modos dinâmicos, cuja expressão é confinada à superfície. Lapeyre 2009 justifica esta inclusão argumentando que a decomposição em modos dinâmicos não é completa uma vez que não contempla a existência de anomalias superficiais de empuxo em mesoescala, sendo portanto necessário acrescentar o modo não-ortogonal para obedecer a condição de contorno de superfície. O tra- 
balho relata que o modo superficial responde por uma fração da variância observada em $\eta$ equivalente ao primeiro modo baroclínico, com os modos internos de maior ordem respondendo por porções sucessivamente menores, e conclui que estes resultados "enfatizam a necessidade de uma nova interpretação dos dados de satélite da altura da superfície livre dos oceanos". Estas evidências sugerem portanto que frações potencialmente significativas da energia propagante nos oceanos podem ser simplesmente invisíveis aos altímetros orbitais, estando contidas em fenômenos transientes de meso a larga escalas com estruturas baroclínicas referentes à modos dinâmicos superiores ao primeiro.

No caso dos raios de deformação baroclínicos, Emery et al. 1984 apresenta mapas médios climatológicos do primeiro raio interno para os oceanos Pacífico norte e Atlântico norte na resolução de $5^{\circ} \times 5^{\circ}$. O trabalho de Houry et al. 1987 se concentra nas regiões oceânicas contidas entre os limites $70^{\circ} \mathrm{S}$ e $30^{\circ} \mathrm{N}$ e $70^{\circ} \mathrm{W}$ e $70^{\circ} \mathrm{E}$, que abrangem o Atlântico tropical, Atlântico sul e a porção oeste do oceano Índico, apresentando mapas do primeiro e segundo raios internos na mesma resolução espacial. Picaut e Sombardier 1993 publicou os mapas médios climatológico das velocidades de propagação de ondas de gravidade dos primeiros cinco modos baroclínicos, parâmetro diretamente proporcional aos raios internos, na maior resolução de $1^{\circ} \times 1^{\circ}$ entre as latitudes $30^{\circ} \mathrm{S}$ e $30^{\circ} \mathrm{N}$ no oceano Pacífico. Por fim, Chelton et al. 1998 apresenta o primeiro mapa global do primeiro raio de deformação baroclínico de $1^{\circ} \times 1^{\circ}$, calculado a partir de dados climatológicos provenientes do World Ocean Atlas 1994 (WOA94) (Levitus e Boyer 1994). Deve-se lembrar que o surgimento do sistema Argo em 1998 aumentou significativamente a quantidade de dados in situ de temperatura e salinidade do oceano global disponíveis, o que possivelmente resultou em um aprimoramento dos bancos de dados climatológicos da série World Ocean Atlas desde a sua versão de 1994.

Uma importante premissa sobre a qual a decomposição modal da velocidade geostrófica e o cálculo dos raios de deformação baroclínicos são baseados é de que a variabilidade temporal da estratificação pode ser desprezada. De fato, tal aproximação viabiliza a obtenção de uma forma linear da equação de conservação da vorticidade potencial. Chelton et al. 1998 investiga a sua validade através do cálculo da variação do primeiro raio de deformação em relação aos raios médios em escala sazonal, através de dados da climatologia mensal do WOA94, e de intrasazonal a interanual através do conjunto histórico de dados hidrográficos de densidade para o Atlântico norte compilado por Lozier et al. 1994. As diferenças observadas em geral 
eram inferiores a $1 \%$ em escala sazonal em qualquer ponto do oceano global, mostrando que este aspecto da linearidade é válido na escala de variabilidade considerada. Porém, o trabalho anterior de Laurindo et al. 2010 mostra, através de dados in situ, que a passagem de ondas de Rossby intrasazonais em latitudes inferiores à $10^{\circ}$ pode provocar anomalias subsuperficiais de temperatura (densidade) de até $9^{\circ} \mathrm{C}\left(1,2 \mathrm{~kg} \cdot \mathrm{m}^{-3}\right)$, com dezenas a centenas de metros de extensão vertical. Apesar de a aproximação quase-geostrófica ser mais adequada à latitudes médias, os raios de deformação calculados a partir de perfis in situ obtidos em fases opostas das ondas amostradas apresentavam diferenças de quase 10\% em relação aos raios médios climatológicos. Segundo a teoria linear de ondas livres, a relação de dispersão de ondas de Rossby planetárias é resolvida em função dos raios de deformação, sendo que a diferença observada implicaria em variações percentuais da velocidade de fase de até $21 \%$, assumindo um caso extremo onde o quadrado do inverso do número de onda (que é funcional do comprimento de onda) é duas ordens de grandeza menor que o quadrado do raio de deformação (aproximação para ondas de Rossby longas). Esta é uma evidência de que a alteração da estrutura vertical de densidade forçada pela própria passagem destas ondas pode exercer uma influência não-linear significativa sobre suas características de propagação.

Assim, uma série de questões relevantes a respeito do comportamento do interior geostrófico dos oceanos ainda permanecem em aberto. Não foram encontrados na literatura mapas globais da composição modal dinâmica nem dos raios de deformação baroclínicos de ordens superiores ao primeiro. Não se sabe ao certo a observabilidade dos diferentes modos de propagação de ondas de Rossby planetárias frente aos diversos tipos de sensores orbitais, e consequentemente não se conhece a contribuição de cada um ao espectro da energia propagante nos oceanos. Um efeito não-linear possivelmente significativo sobre a propagação de ondas de Rossby, decorrente da interação da onda em si com a evolução da estrutura baroclínica em resposta à sua própria passagem, ainda não foi avaliado.

Outra questão pendente é a possível existência de mecanismos de transferência de energia entre diferentes modos dinâmicos. Barnier 1988 simula numericamente a propagação de ondas de Rossby baroclínicas através de uma cadeia meso-oceânica meridional submersa, onde a interação da onda baroclínica com o obstáculo gera ondas de Rossby topográficas barotrópicas, sugerindo que este fenômeno pode ser responsável pelo aumento da amplitude de ondas planetárias ao cruzar as cadeias meso-oceânicas. Ainda neste contexto, Fu 2007 apresenta ev- 
idências da interação entre ondas de Rossby barotrópicas e vórtices de meso-escala na região da confluência Brasil-Malvinas. É possível que mecanismos de transferência de energia semelhantes também se apliquem à modos baroclínicos de ordem mais alta, mas até o momento nenhum trabalho avaliou esta hipótese.

Responder à tais questões constitui um desafio observacional e numérico em oceanografia. Como afirmado anteriormente, a obtenção de dados in situ das estruturas de densidade e velocidade do interior geostrófico em escalas sinótica, de bacia, e em séries temporais contínuas não é possível com as plataformas de observação disponíveis atualmente. Neste contexto, a capacidade de se inferir com boa precisão a estrutura termohalina de feições oceânicas a partir de uma amostragem reduzida ou através da extrapolação vertical de dados de satélites é desejável e vem sendo aprimorada ao longo de diversos trabalhos. Estes esforços dirigem-se particularmente à busca de formas mais eficientes de assimilação de dados para modelos numéricos operacionais. As abordagens mais comuns incluem o desenvolvimento de modelos de feição pelo ajuste de curvas paramétricas (Gangopadhyay et al. 1997; Chu et al. 1999), a inversão de campos de vorticidade potencial estimados através de dados altimétricos (Haines 1991) e a reconstrução da estrutura vertical utilizando modos EOF (De Mey e Robinson 1987; Carnes et al. 1990; Agarwal et al. 2007).

Este trabalho procura estimar a importância relativa do modo barotópico e dos três primeiros modos dinâmicos baroclínicos na composição de perfis verticais das componentes $u$ e $v$ da velocidade geostrófica e de suas respectivas anomalias em relação ao fluxo médio nos oceanos entre $39^{\circ} \mathrm{S}$ e $39^{\circ} \mathrm{N}$ mais profundos que $1000 \mathrm{~m}$ em função da latitude, da longitude e do tempo, calculando ainda os três primeiros raios de deformação baroclínicos ao longo destes mesmos eixos. Especificamente, procura-se identificar quais regiões oceânicas possuem maior probabilidade de ocorrência de ondas de Rossby planetárias com modos de propagação superiores ao primeiro modo baroclínico, e as regiões onde efeitos não-lineares são significativos. A análise proposta baseia-se em dados sintéticos da estrutura interna de temperatura extrapolados verticalmente a partir de dados orbitais de TSM e $\eta$, segundo um método de reconstrução estatística inspirado nos trabalhos de Carnes et al. 1990 e Agarwal et al. 2007, desenvolvido especificamente para este estudo.

A seção 2 explicita as hipóteses e os objetivos deste trabalho. A seção 3 descreve os conjuntos de dados utilizados, seu processamento preliminar, e apresenta a metodologia desenvolvida 
para a construção de perfis verticais de temperatura sintéticos. Inclui ainda todo o processamento envolvido no cálculo dos modos dinâmicos, raios de deformação e do campo quadridimensional da velocidade geostrófica, por fim descrevendo a forma como a importância relativa de cada modo dinâmico ao longo dos oceanos foi estimada. A seção 4 apresenta e discute os resultados, e a seção 5 sumariza este estudo e traz suas conclusões. 


\section{Hipóteses e Objetivos}

Este trabalho estima a importância relativa do modo barotrópico e dos três primeiros modos baroclínicos na composição de perfis verticais das componentes $u$ e $v$ da velocidade geostrófica e de suas respectivas anomalias em relação á média de longo termo, calculando ainda os três primeiros raios de deformação baroclínicos. A análise proposta abrange as regiões oceânicas mais profundas que $1000 \mathrm{~m}$ contidas entre as latitudes $39,5^{\circ} \mathrm{S}$ e $39,5^{\circ} \mathrm{N}$.

As hipóteses principais são:

- O primeiro modo domina tanto o campo médio de velocidade geostrófica quanto a estrutura vertical de fenômenos transientes, com regiões onde o segundo modo é significativo, seguido em menor grau pelo terceiro modo;

- No contexto da equação da conservação da vorticidade potencial em um oceano linear e continuamente estratificado, a dependência temporal da densidade pode ser desprezada em larga escala, porém pode torna-se significativa sob a ação de fenômenos transientes intensos.

Os objetivos específicos são:

- Desenvolver um método para construção de perfis sintéticos de temperatura à partir de (a) dados climatológicos do WOA05, (b) perfis verticais in situ de temperatura obtidos por perfiladores Argo e XBT, (c) dados de TSM obtidos pelo imageador de microondas TRMM Microwave Imager (TMI) do satélite Tropical Rainfall Measuring Mission (TRMM), e (d) de calor armazenado inferido a partir de dados altimétricos dos satélites TOPEX/Poseidon e Jason-1 (T/P e J-1, respectivamente). Validar os perfis sintéticos através de perfis in situ de temperatura;

- Gerar mapas médios dos três primeiros raios de deformação baroclínicos;

- Avaliar a variação percentual em relação à média dos três primeiros raios de deformação baroclínicos ao longo do tempo, com o intuito de checar a hipótese da aproximação linear dos oceanos em larga escala;

- Gerar mapas da importância relativa do modo barotrópico e dos três primeiros modos baroclínicos nos perfis sintéticos das componentes $u$ e $v$ da velocidade geostrófica; 
- Gerar mapas da importância relativa do modo barotrópico e dos três primeiros modos baroclínicos nos perfis da anomalia das componentes $u$ e $v$ da velocidade geostrófica em relação aos respectivos perfis médios de longo termo, buscando identificar regiões do oceano com maior probabilidade de ocorrência de ondas planetárias de modos superiores ao primeiro modo baroclínico. 


\section{Métodos}

\subsection{Dados}

\subsubsection{Anomalia da altura da superfície livre}

Os dados de anomalia da altura da superfície livre ( $\eta$ ) são provenientes dos satélites TOPEX/ Poseidon (T/P) e Jason-1 (J-1), e foram adquiridos junto ao Physical Oceanography Distributed Active Archive Center do Jet Propulsion Laboratory (JPL/PO.DAAC, podaac . jpl . nasa . gov), instituição ligada à agência espacial norte-americana National Aeronautics and Space Administration (NASA). Os dados são medidos através de altímetros de precisão à bordo dos satélites. Resumidamente, estes instrumentos operam através da emissão de pulsos de radar para a superfície do planeta, estimando a altitude relativa do instrumento à partir da medição do tempo de retorno dos pulsos, que viajam na velocidade da luz. Os pulsos são emitidos na frequência de 13,9 GHz, faixa do microondas, à qual as nuvens e a precipitação superficial são quase $100 \%$ transparentes. As medições dos altímetros são submetidas à uma série de correções para descontar efeitos atmosféricos que influenciam na velocidade de propagação dos pulsos e na distância efetiva entre a antena que emite os pulsos de radar e a superfície que os reflete, que incluem:

- Flutuações na densidade de elétrons livres na ionosfera;

- O viés introduzido pela diferença de refletividade eletromagnética entre a metade superior e a metade inferior das ondas de gravidade;

- Variações do vapor d'água integrado na troposfera;

- Incrementos na elevação provocados por marés oceânicas, sólidas e polares;

- Incrementos provocados por efeitos de barômetro invertido.

A altura da superfície do mar é calculada em relação à uma superfície teórica com potencial gravitacional constante, o geóide, cuja distância em relação aos altímetros é conhecida. A forma funcional do geóide é calculada através de modelos numéricos que ajustam uma superfície definida por harmônicos esféricos às medidas gravimétricas, implicando que sua performance é limitada pela precisão destes modelos. De fato, a superfície obtida não possui resolução suficiente para, por exemplo, fazer com que os dados altimétricos representem realisticamente as correntes de contorno oeste. Neste contexto, o cálculo de $\eta$ através da diferença de cada 
medida da altura da superfície do mar em relação à média local de longo termo permite a remoção simultânea tanto das correntes médias quanto dos erros do geóide (Chelton e Schlax 1996; Cipollini et al. 2004; Polito e Liu 2003).

O satélite T/P foi lançado em agosto de 1992 e manteve-se em operação até outubro de 2005. Seu substituto, o J-1, foi lançado em dezembro de 2001 e permanece ativo até hoje. Com o intuito de manter a continuidade da série temporal de dados altimétricos mesmo após a desativação do T/P, o J-1 foi posicionado em uma órbita coincidente com a do primeiro satélite, sendo que ambos possuem as mesmas características amostrais: varredura da superfície do planeta entre as latitudes $66,03^{\circ} \mathrm{S}$ e $66,03^{\circ} \mathrm{N}$, periodicidade de aproximadamente $10(9,9157)$ dias, separação equatorial entre ground tracks consecutivos de $315 \mathrm{~km}$ na direção zonal e altímetros capazes de medir a altura da superfície do mar no Nadir com acurácia de $2 \mathrm{~cm}$. Foram obtidos dois conjuntos de dados distintos correspondendo à medições individuais de cada satélite, onde os dados já foram submetidos à todas as correções-padrão (Benada 1997) e encontram-se interpolados ao longo da trajetória dos feixes dos altímetros sobre a superfície do planeta. Considerando medições de ambos os satélites, a série de dados altimétricos adquirida abrange o período que vai de janeiro de 1993 à abril de 2008.

\subsubsection{Temperatura da superfície do mar}

Os dados de temperatura da superfície do mar (TSM) são provenientes do radiômetro de microondas TRMM Microwave Imager (TMI) à bordo do satélite Tropical Rainfall Measuring Mission (TRMM). Estes dados foram obtidos junto à empresa Remote Sensing Systems (www.remss.com), e seu processamento e distribuição são financiados pelo projeto Earth Science MEaSUREs DISCOVER da NASA.

Segundo a lei de Planck, toda a matéria com temperatura superior ao zero absoluto emite radiação eletromagnética. Um objeto ideal capaz de absorver toda a radiação eletromagnética incidente, chamado de corpo negro, reemitiria radiação em um espectro contínuo característico que dependeria exclusivamente de sua temperatura. O espectro eletromagnético emitido pela Terra, assim como por todo objeto celeste conhecido, pode ser aproximado ao emitido por um corpo negro na mesma temperatura. A expressão de Stefan-Boltzmann relaciona a potência irradiada com a temperatura, explicitando que quanto mais quente um corpo, maior é a potência 
emitida por ele. A potência é irradiada em todas as direções e em várias frequências, sendo que a equação de Planck estima a fração que é emitida em bandas específicas do espectro. Para diferentes temperaturas, o pico de emissão ocorre em diferentes frequências, sendo que as curvas de emissividade não se interceptam. Isto implica que, quanto maior a temperatura, maior a emissão ao longo de todo o espectro eletromagnético. Resumidamente, radiômetros orbitais são sensores passivos que medem a potência emitida por determinadas áreas do planeta em faixas específicas do espectro eletromagnético. A determinação de parâmetros geofísicos como o vapor de água integrado na troposfera, a magnitude dos ventos, a presença de gelo e a própria TSM é possível devido à existência de uma forte correlação entre estes parâmetros e a potência recebida nas bandas espectrais observadas. Radiômetros que operam na faixa do microondas, como o TMI, possuem a vantagem de que nuvens e a precipitação são essencialmente transparentes à esta banda de frequências. Porém, a potência emitida pelo planeta na faixa do microondas é significativamente menor do que na banda do visível ou do infravermelho, fazendo com que a resolução espacial de radiômetros de microondas seja em geral inferior à de sensores que operam em faixas espectrais mais próximas do pico de emissividade do planeta.

Os dados de TSM adquiridos se referem ao período entre dezembro de 1997 e janeiro de 2009, e estão organizados na forma de mapas diários contendo medições correspondentes aos segmentos ascendentes e descendentes das passagens orbitais do TRMM. Os dados possuem resolução espacial de $0,25^{\circ} \times 0,25^{\circ}$ e abrangem a região do globo contida entre as latitudes $40^{\circ} \mathrm{S}$ e $40^{\circ} \mathrm{N}$, sendo que o TMI é capaz de realizar uma amostragem completa de TSM nesta faixa à cada três dias. A resolução espacial é muito inferior à de sensores orbitais infravermelhos $(1,4$ ou 9 km). Porém, a capacidade de obtenção de dados mesmo em condições de tempo encoberto é desejável, e sua resolução, embora limitada, é suficiente para os propósitos deste estudo.

\subsubsection{Perfis in situ de temperatura}

Perfis in situ de temperatura são provenientes de perfiladores autônomos Argo e perfiladores XBT (sigla em inglês para Expendable Bathytermograph). Estes perfis foram obtidos junto ao Coriolis Data Center (www. coriolis.eu.org), um dos centros mundiais de processamento e distribuição de dados do projeto Argo.

O projeto Argo é uma rede com cerca de 3000 flutuadores autônomos capazes de perfilagem 
vertical de temperatura e salinidade espalhados por todos os oceanos livres de gelo do planeta. Existem diferentes modelos de flutuadores mas todos seguem o mesmo princípio básico de operação: cada flutuador Argo passa a maior parte de sua vida útil derivando em equilíbrio neutro à 1000 ou $2000 \mathrm{~m}$ de profundidade. A cada 10 dias ele inicia um processo de emersão, medindo temperatura e salinidade ao longo da subida. Uma vez na superfície, os dados coletados são enviados para estações de recepção em terra. Terminada a transmissão, o flutuador afunda até atingir a sua profundidade de cruzeiro e lá permanece, derivando lentamente até a próxima emersão.

O XBT é um perfilador de temperatura descartável que pode ser lançado de um navio em movimento. Consiste basicamente em um termistor protegido por um casco com forma hidrodinâmica, equilibrado por um peso na extremidade que vence a água. Como não contam com um sensor de pressão, a profundidade nos perfis é calculada em função da razão de descida da sonda através de uma equação de queda. Um fio de cobre liga o XBT à uma unidade de lançamento, que por sua vez é ligada à uma unidade de processamento/armazenamento de dados. Uma vez lançado, carretéis se desenrolam simultaneamente no interior do casco do XBT e em seu estojo na unidade de lançamento, permitindo a descida da sonda em queda livre independentemente dos movimentos do navio ou das condições de mar. Uma vez alcançado o comprimento máximo do fio, ele se rompe e o XBT é perdido. Profundidades máximas de operação e velocidades de navegação ideais para o lançamento dependem do modelo de XBT, variando respectivamente entre 200 e 1830 m e entre 6 e 30 nós. As facilidades operacionais fazem com que XBTs sejam rotineiramente lançados ao redor do mundo por navios de oportunidade, como cargueiros e navios de cruzeiro.

Para este trabalho, foram adquiridos todos os perfis Argo e XBT disponibilizados pelo Coriolis Data Center medidos entre $40^{\circ} \mathrm{N}$ e $40^{\circ} \mathrm{S}$ até janeiro de 2010 . Este conjunto conta com cerca de 390.000 perfis de temperatura Argo e 250.000 perfis XBT, não submetidos à qualquer controle de qualidade prévio pelo distribuidor.

\subsubsection{Dados climatológicos}

Os perfis climatológicos de temperatura e salinidade utilizados aqui foram obtidos do World Ocean Atlas 2005 (WOA05) (Antonov et al. 2006; Locarnini et al. 2006), e são disponibiliza- 
dos gratuitamente pelo National Oceanographic Data Center (NODC, www.nodc.noaa.gov), um dos centros de dados ambientais operado pela agência norte-americana National Oceanic and Atmospheric Administration (NOAA). A climatologia do WOA05 baseia-se em dados hidrográficos coletados desde o início do século 20 até o ano de 2005, interpolados segundo a metodologia proposta por Levitus e Boyer (1994). Contém perfis climatológicos mensais e anuais de temperatura e salinidade extendendo-se respectivamente até os 1500 e $5500 \mathrm{~m}$ de profundidade, interpolados até estes limites nas profundidades padrão mostradas na Tabela 1, e organizados sobre uma grade global com resolução espacial de $1^{\circ} \times 1^{\circ}$. Informações estatísticas da coleção de dados in situ sobre os quais a climatologia foi construída, como média, variância e desvio-padrão, são também fornecidas e encontram-se organizadas de maneira idêntica aos perfis climatológicos anuais.

Tabela 1: Profundidades padrão $(m)$ dos dados do WOA05;

\begin{tabular}{l|l|l|l|l}
\hline 0 & 125 & 600 & 1300 & 3500 \\
10 & 150 & 700 & 1400 & 4000 \\
20 & 200 & 800 & 1500 & 4500 \\
30 & 250 & 900 & 1750 & 5000 \\
50 & 300 & 1000 & 2000 & 5500 \\
75 & 400 & 1100 & 2500 & \\
100 & 500 & 1200 & 3000 & \\
\hline
\end{tabular}

\subsection{Processamento preliminar}

\subsubsection{Dados de satélite}

O método utilizado mais adiante na construção de perfis sintéticos de temperatura irá requerer que os dados altimétricos e de TSM se refiram aos mesmos pontos no tempo e no espaço, sendo que a grade espacial destes conjuntos deve ser também coincidente com a dos dados climatológicos. Portanto, o pré-processamento dos dados de satélite consistiu em padronizar suas grades e em ajustá-las à resolução horizontal dos dados do WOA05. 
Dados de cada ciclo completo dos satélites T/P e J-1 foram interpolados segundo um esquema de mínima curvatura (Smith e Wessel 1990) para uma grade regular com resolução espacial de $1^{\circ} \times 1^{\circ}$ coincidente com a dos dados climatológicos, formando uma série temporal de mapas de $\eta$ com resolução de 9,9157 dias. Utilizando o mesmo método de interpolação, dados de TSM medidos a menos de 4,5 dias das datas de cada mapa altimétrico foram combinados em mapas únicos, também organizados sobre a grade espacial do WOA05. Selecionando-se a interseção das coberturas espaciais e séries temporais de cada conjunto de dados, o conjunto de mapas resultante abrange a região do globo contida entre as latitudes $39,5^{\circ} \mathrm{S}$ e $39,5^{\circ} \mathrm{N}$ e se refere ao período entre 24 de dezembro de 1997 e 28 de abril de 2008, resultando em um total de 378 mapas de cada parâmetro.

A precisão dos modelos globais de maré oceânica se degrada em regiões mais rasas que $1000 \mathrm{~m}$ devido à amplificação de efeitos regionais induzidos pela batimetria e pelos contornos continentais. Como estes modelos são utilizados para descontar o efeito das marés sobre as medições de altímetro, esta falha se traduz nos dados na forma de uma diminuição da precisão das medições altimétricas a partir da isóbata de $1000 \mathrm{~m}$. Por essa razão, regiões nos mapas de $\eta$ e TSM com profundidades inferiores a este limite foram mascaradas juntamente com os continentes. Pequenas ilhas e montes submarinos rasos foram ignorados nesta operação.

\subsubsection{Perfis verticais}

A metodologia proposta por este estudo requer perfis verticais com uma mesma resolução vertical e que se estendam da superfície até o fundo do oceano. Porém, uma análise qualitativa dos perfis in situ obtidos mostra que a organização vertical das medidas de temperatura varia de perfil a perfil, assim como a profundidade máxima amostrada. Falhas como erros sistemáticos de medição, inversões de temperatura inverossímeis por implicarem em colunas de água dinamicamente instáveis, ruído amostral e spikes (valores isolados a mais de 3 desvios-padrão da média local) são também evidentes no conjunto. O processamento do conjunto de perfis in situ envolveu portanto a padronização de suas resoluções verticais, o controle de qualidade para remover perfis considerados inadequados/errôneos, o tratamento para remover spikes e reduzir o ruído, e por fim a extrapolação até o fundo utilizando perfis climatológicos.

Foram preliminarmente removidos do conjunto perfis considerados curtos no contexto deste 
estudo, com menos de 750 m de coluna de água perfilados, e perfis contendo erros grosseiros em seus registros associados de pressão, como a presença de valores repetidos ou decrescentes em direção ao fundo. Especificamente para os dados Argo, o Coriolis Data Center fornece uma lista dos flutuadores onde foram detectadas falhas sistemáticas de medição, sendo que todos os perfis obtidos por flutuadores nestas condições não foram utilizados. Todos os perfis verticais, Argo, XBT e climatológicos, foram então padronizados a um incremento vertical $\Delta z=10 \mathrm{~m}$ por interpolação linear. A utilização de médias em caixa é inadequada para esta operação, pois a separação entre medidas na vertical é irregular e em geral superior à $5 \mathrm{~m}$. Nesta primeira etapa do tratamento, perfis Argo e XBT foram truncados aos $1000 \mathrm{~m}$ de profundidade e suavizados utilizando um filtro de média móvel do tipo hamming, com 5 pontos.

O controle de qualidade realizado aqui consistiu em separar subconjuntos de perfis a cada caixa de $1^{\circ} \times 1^{\circ}$ centradas nos pontos de grade da malha climatológica, e em compará-los com os perfis climatológicos anuais correspondentes e seus respectivos desvios-padrão. Foram excluídos perfis in situ com mais de 30 valores (ou seja, mais de 30\% do perfil) que se afastassem além de dois desvios-padrão da média climatológica. Nos perfis restantes, spikes foram localizados através do perfil da primeira derivada vertical da temperatura, onde aparecem na forma de mudanças bruscas de sinal, e então apagados. As lacunas remanescentes foram preenchidas através de um esquema de interpolação bicúbica por splines cúbicos, método que ajusta segmentos de parábola entre os pontos a serem interpolados de modo a manter a continuidade da função final.

Diversos perfis obtidos por XBTs mostram inversões significativas de temperatura, isto é, temperaturas crescentes em direção ao fundo, nos primeiros $200 \mathrm{~m}$ da coluna de água. Inversões deste tipo não são observadas na climatologia e nem são comuns em perfis Argo, mas são relativamente frequentes em perfis XBT de latitudes entre $30^{\circ}$ e $40^{\circ}$. Especula-se que esta falha esteja associada à um efeito de inércia térmica sobre os termistores dos XBTs, uma vez que não é incomum a atmosfera estar vários graus mais fria que o oceano nestas latitudes, sendo que o lançamento destes perfiladores não inclui uma pausa nos primeiros metros para o sensor entrar em equilíbrio com a temperatura da água. Inversões térmicas próximo à superfície em perfis que sobreviveram aos critérios de exclusão anteriores foram localizadas automaticamente através da primeira derivada vertical, e então apagadas. Em perfis que ainda contassem com mais de 750 m de coluna de água perfiladas mesmo após esta operação, as regiões sem dados 
Tabela 2: Exemplo ilustrativo da soma ponderada entre um perfil in situ extrapolado até 1500 m (In situ extr.) e o perfil climatológico anual correspondente (Clim. anual) entre 1010 e 1490 $m$ de profundidade. Esta operação tem como objetivo fazer o perfil in situ tender suavemente à climatologia anual;

\begin{tabular}{|c|c|c|c|c|c|c|c|c|c|}
\hline Prof. (m) & In situ extr. & & Pesos & & Clim. Anual & & Pesos & & Transição \\
\hline-1000 & - & & - & & - & & - & & - \\
\hline-1010 & 8,144 & & 0,98 & & 5,037 & & 0,02 & & 8,082 \\
\hline-1020 & 8,043 & & 0,96 & & 4,970 & & 0,04 & & 7,920 \\
\hline-1030 & 7,942 & & 0,94 & & 4,902 & & 0,06 & & 7,760 \\
\hline-1040 & 7,841 & & 0,92 & & 4,835 & & 0,08 & & 7,601 \\
\hline$\vdots$ & $\vdots$ & $x$ & $\vdots$ & + & $\vdots$ & $x$ & $\vdots$ & $=$ & $\vdots$ \\
\hline-1460 & 3,598 & & 0,08 & & 3,268 & & 0,92 & & 3,294 \\
\hline-1470 & 3,497 & & 0,06 & & 3,249 & & 0,94 & & 3,264 \\
\hline-1480 & 3,396 & & 0,04 & & 3,231 & & 0,96 & & 3,237 \\
\hline-1490 & 3,295 & & 0,02 & & 3,212 & & 0,98 & & 3,214 \\
\hline-1500 & - & & - & & - & & - & & - \\
\hline
\end{tabular}

foram extrapoladas para cima por interpolação bicúbica, assumindo-se: 1) uma temperatura de superfície igual à média climatológica do mês correspondente; e 2) que o valor mais raso não excluído tenha uma temperatura menor que a temperatura superficial da climatologia mensal.

Ao final destas operações, o conjunto de perfis in situ contava com cerca de 273.000 perfis Argo e 127.000 perfis XBT, que foram então extrapolados verticalmente para baixo através dos perfis climatológicos mais próximos de suas posições. Inicialmente, os perfis são interpolados bicubicamente até as temperaturas climatológicas dos meses correspondentes aos 1500 $\mathrm{m}$ de profundidade, o limite da climatologia mensal do WOA05. Abaixo deste limite assumese que os todos os perfis são idênticos ao perfil climatológico anual. Para unir perfis in situ e climatológicos de modo suave, evitando "degraus", foi feita uma soma ponderada de seus valores entre 1010 e $1490 \mathrm{~m}$, da maneira esquematizada na Tabela 2. Como o limite inferior dos dados climatológicos em geral não coincide com a profundidade local real, o dado mais 
profundo dos perfis extrapolados foi repetido de dez em dez metros até o fundo. Os dados batimétricos nos quais esta operação se baseou são provenientes do ETOPO1 (Amante e Eakins 2009). Especificamente, a profundidade considerada em cada ponto de grade corresponde à média das profundidades do ETOPO1 selecionadas em uma área de $1^{\circ} \times 1^{\circ}$ ao redor do ponto considerado.

\subsection{Construção de perfis sintéticos de temperatura}

\subsubsection{Formulação inicial}

O método para a construção de perfis sintéticos de temperatura proposto aqui foi inspirado nos trabalhos de Carnes et al. 1990 e Agarwal et al. 2007, e baseia-se na associação de modos EOF da anomalia vertical da temperatura à dados de $\eta$ e TSM obtidos por satélites. Foi especificamente desenvolvido para operar com dados do WOA05, fazendo com que os perfis sintéticos sejam obtidos sobre a grade espacial de $1^{\circ} \times 1^{\circ}$ climatológica, sendo também limitados à latitudes entre $39,5^{\circ} \mathrm{S}$ e $39,5^{\circ} \mathrm{N}$ devido à cobertura espacial dos dados de TSM e às regiões mais profundas que $1000 \mathrm{~m}$ devido ao efeito da maré nas medições altimétricas. A formulação proposta é detalhadamente descrita a seguir.

Os perfis de temperatura são tratados aqui como funções que dependem apenas da coordenada vertical, $T=T(z)$. Considerando um conjunto contendo $N$ perfis in situ de temperatura $T_{i}(z)$, onde $i=1,2,3, \ldots, N$, obtidos em uma região arbitrária do oceano com $2^{\circ} \times 2^{\circ}$ de área centrada em um ponto da grade horizontal do WOA05. O $i$-ésimo perfil $T_{i}(z)$ do conjunto pode ser representado na forma da soma do perfil médio climatológico $\bar{T}(z)$ da região a uma anomalia vertical de temperatura $\Delta T_{i}(z)$ correspondente, ou seja:

$$
T_{i}(z)=\bar{T}(z)+\Delta T_{i}(z)
$$

O conjunto das anomalias $\Delta T_{i}(z)$ é então submetido à uma análise EOF, técnica que estatisticamente particiona a variância de um conjunto de perfis em uma série de modos normais, chamados de modos estatísticos ou modos EOF. Cada $\Delta T_{i}(z)$ pode ser representado como a soma de uma série de modos EOF multiplicados por amplitudes correspondentes, da seguinte forma:

$$
\Delta T_{i}(z)=\sum_{k=1}^{M} \tau_{i k} F e_{k}(z)
$$


onde $F e_{k}(z)$ são modos EOF de ordem $k$, para $k=1,2,3, \ldots, M$, e $\tau_{i k}$ são suas amplitudes. Simulações de Monte Carlo comparadas com análises EOF preliminares de dados Argo e XBT mostraram que em geral apenas os dois primeiros modos EOF são estatisticamente significantes ao nível dos $95 \%$ de confiança, sendo que os dois combinados respondem em média por $83 \%$ da variância observada. Isto significa que $\Delta T_{i}(z)$ pode ser razoavelmente bem representado utilizando-se apenas $k \leq 2$, permitindo reescrever a Equação (2) como:

$$
\Delta T_{i}(z)=\tau_{i 1} F e_{1}(z)+\tau_{i 2} F e_{2}(z)
$$

Se o conjunto de perfis utilizado no cálculo dos modos estatísticos constituir uma amostra representativa da variabilidade local, então é possível considerar que os modos estatísticos $F e_{1}$ e $\mathrm{Fe}_{2}$ são válidos para qualquer perfil da região. A Equação (3) pode então ser generalizada para perfis referentes à qualquer tempo $t$.

$$
\Delta T_{t}(z)=\tau_{t 1} F e_{1}(z)+\tau_{t 2} F e_{2}(z)
$$

Ao contrário da Equação (3), onde $\tau_{i 1}$ e $\tau_{i 2}$ são valores conhecidos, em (4) as amplitudes $\tau_{t 1}$ e $\tau_{t 2}$ são variáveis da equação. A obtenção de perfis sintéticos proposta neste trabalho baseia-se no cálculo de $\tau_{t 1}$ e $\tau_{t 2}$ através da resolução de um sistema de duas equações, definidas à partir da utilização de dados de TSM e $\eta$ referentes à um mesmo tempo $t$ como condições de contorno da Equação (4).

A primeira equação do sistema é definida a partir de dados de TSM.

$$
\Delta T_{s t}=\tau_{t 1} F e_{1}(z=0)+\tau_{t 2} F e_{2}(z=0)
$$

onde $\Delta T_{s t}$ é a diferença entre a temperatura média climatológica na superfície, $\bar{T}(z=0)$, e a temperatura medida via satélite no instante $t$.

A seguir, assume-se por hipótese que os sinais em $\eta$ são resultantes da expansão térmica causada por variações do calor armazenado integrado na coluna de água, tornando possível relacionar $\eta_{t}$ com a anomalia vertical da temperatura $\Delta T_{t}(z)$. Isso é feito através da equação da dilatação térmica, aplicando-a então à Equação (4):

$$
\eta_{t}=\int_{-H}^{0} \alpha(z) \Delta T_{t}(z) d z=\tau_{t 1} \int_{-H}^{0} \alpha(z) F e_{1}(z) d z+\tau_{t 2} \int_{-H}^{0} \alpha(z) F e_{2}(z) d z
$$

onde $H$ é a profundidade local e $\alpha(z)$ é o perfil vertical do coeficiente de expansão térmica da coluna de água. $\alpha(z)$ é estimado à partir dos perfis climatológicos mensais de temperatura e 
salinidade da região, extrapolados verticalmente até o limite da climatologia anual e deste ponto até a profundidade local que consta no ETOPO1 de maneira idêntica à descrita para perfis Argo e XBT. Por simplicidade, fazendo:

$$
G_{k}=\int_{-H}^{0} \alpha(z) F e_{k}(z) d z
$$

a Equação (6) se torna:

$$
\eta_{t}=\tau_{t 1} G_{1}+\tau_{t 2} G_{2}
$$

As Equações (5) e (7) possuem duas variáveis, $\tau_{t 1}$ e $\tau_{t 2}$, constituindo um sistema linear quadrado. Este sistema pode ser representado na forma da equação matricial $A X=B$, onde:

$$
A=\left|\begin{array}{cc}
F e_{1}(0) & F e_{2}(0) \\
G_{1} & G_{2}
\end{array}\right|, \quad X=\left|\begin{array}{c}
\tau_{t 1} \\
\tau_{t 2}
\end{array}\right|, \quad B=\left|\begin{array}{c}
\Delta T_{s t} \\
\eta_{t}
\end{array}\right|
$$

e, assumindo que a matriz $A$ é não singular e que o sistema apresentado é consistente, as soluções para as amplitudes contidas na matriz $X$ podem ser encontradas através de:

$$
X=A^{-1} B
$$

onde $A^{-1}$ é a matriz inversa de $A$. As amplitudes encontradas são aplicadas em (4) e o $\Delta T(z)$ resultante é somado ao perfis médio climatológico $\bar{T}(z)$ conforme a Equação (1), obtendo-se assim os perfis sintéticos desejados.

\subsubsection{Falhas observadas}

Testes preliminares mostram que a formulação inicial é capaz de gerar perfis sintéticos consistentes em cerca de $78 \%$ dos pontos de grade, se considerados os mesmos critérios de exclusão aplicados aos perfis in situ originais. Como poderia ser esperado, perfis evidentemente espúrios são gerados em regiões com carência de dados in situ, em geral com menos de 10 perfis, ou onde a forma do perfil climatológico de temperatura difere significamente da observada para a coleção de perfis Argo e XBT obtida nos arredores. Este último tipo de falha foi mais comumente observada junto aos contornos continentais e em regiões de ocorrência de frentes oceânicas, e especula-se que seja condicionada pela presença de gradientes horizontais intensos em uma uma escala inferior às dimensões da janela de procura de perfis in situ $\left(2^{\circ} \times 2^{\circ}\right)$, e/ou 


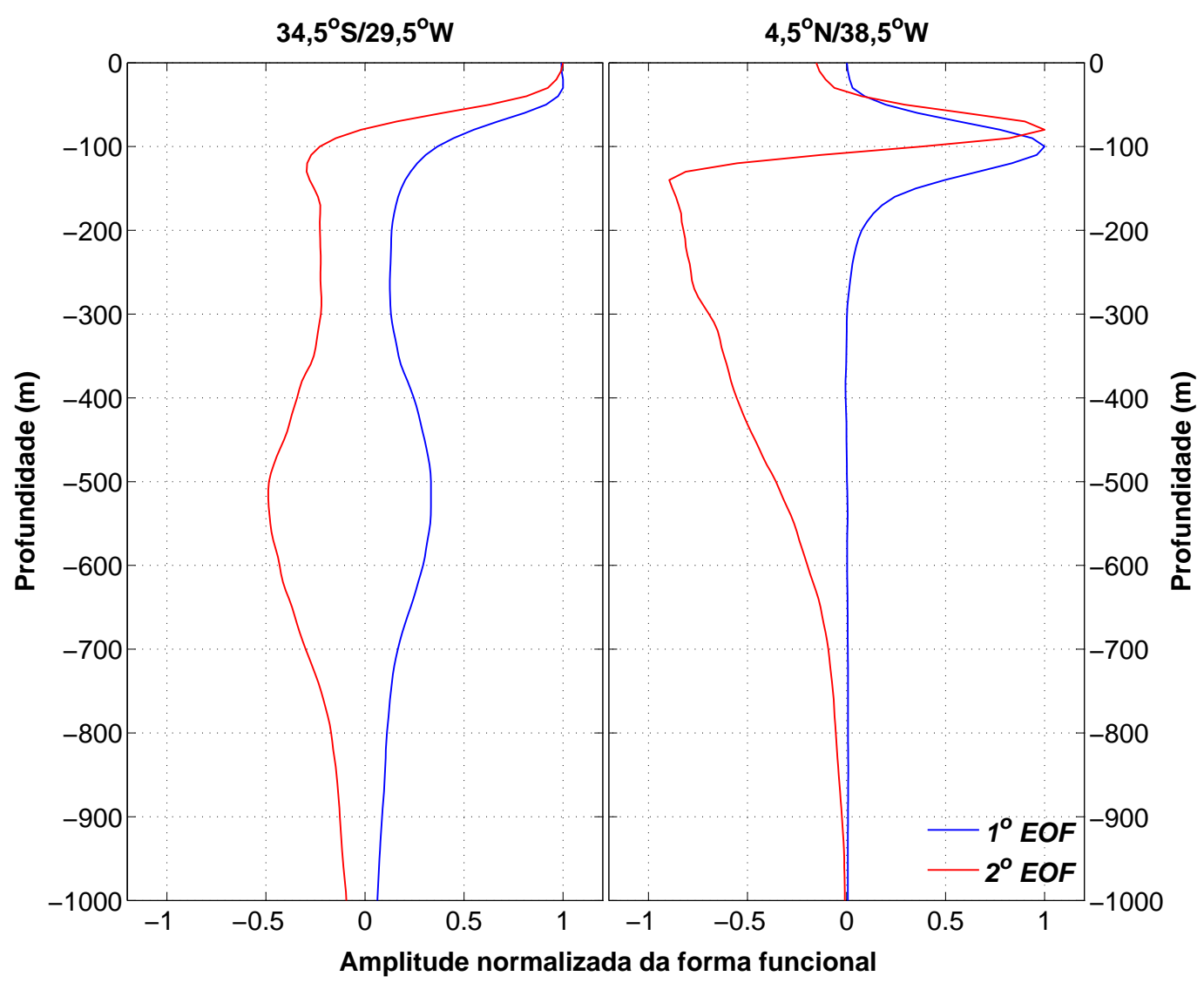

Figura 1: Formas funcionais dos dois primeiros modos EOF da anomalia vertical da temperatura para duas posições no oceano Atlântico: $34,5^{\circ} \mathrm{S} / 29,5^{\circ} \mathrm{W}$ (esquerda) e $4,5^{\circ} \mathrm{N} / 38,5^{\circ} \mathrm{W}$ (direita). A formulação inicial para a construção de perfis sintéticos opera adequadamente na primeira e falha na segunda.

por variações da posição de frentes oceânicas induzida pela ação de fenômenos de larga escala, como ondas planetárias, meandros, vórtices, e do próprio ciclo sazonal.

Porém, estima-se que mais de $90 \%$ dos erros sistemáticos em pontos de grade sejam causados por valores superficiais próximos de zero em um ou ambos modos estatísticos. A natureza desta falha pode ser melhor compreendida através da Equação (5): se $F e_{1}(z=0)$ e $F e_{2}(z=0)$ são próximos de zero, as amplitudes $\tau_{t 1}$ e $\tau_{t 2}$ precisam assumir valores relativamente elevados para obedecerem à condição de contorno de superfície imposta por $\Delta T_{s t}$, assumindo que esta seja não-nula (isto é, que a TSM medida pelo satélite seja diferente da média anual climatológica). Em termos da análise EOF, isto significa que a variabilidade da temperatura na superfície simplesmente não pode ser apropriadamente representada utilizando apenas os dois primeiros modos estatísticos. De fato, reconstruções de perfis in situ com modos EOF em regiões onde 
esta falha é observada mostram a necessidade de às vezes 4,5 ou até mais modos para compor adequadamente a temperatura de superfície.

A Figura 1 mostra a estrutura vertical dos dois primeiros modos estatísticos calculados para as posições $34.5^{\circ} \mathrm{W}, 29.5^{\circ} \mathrm{S}$ e $4.5^{\circ} \mathrm{N}, 38.5^{\circ} \mathrm{W}$, no oceano Atlântico, sendo que o método descrito funciona adequadamente na primeira posição e falha na segunda. A Figura 2 mostra um mapa horizontal com a soma dos valores superficiais absolutos dos dois primeiros modos EOF, normalizados pelos valores máximos de suas respectivas formas funcionais. O que se busca com esta figura é uma indicação da origem das baixas amplitudes superficiais dos dois primeiros modos EOF, se é geofísica, metodológica, ou mero acaso estatístico. Nela nota-se que as regiões em azul escuro (com valores $\leq 0,5$ ) em geral coincidem com posições onde são observadas falhas do método básico, sendo que a presença de padrões contínuos sugere que as características observadas refletem a ação de forçantes geofísicas, não sendo portanto meramente aleatórias.

Assim, especula-se que os baixos valores superficiais dos modos EOF sejam decorrentes de variações de temperatura mais intensas e/ou de maior frequência ao nível da termoclina do que na camada de mistura, característica que é emblematicamente contraposta nas posições representadas na Figura 1 . Em $34,5^{\circ} \mathrm{S}$, os dados de TSM mostram diferenças sazonais de temperatura superfical de até $10^{\circ} \mathrm{C}$, com um desvio-padrão em relação à média de aproximadamente $2,5^{\circ} \mathrm{C}$. Em $4,5^{\circ} \mathrm{N}$ a diferença é de apenas $3^{\circ} \mathrm{C}$ com um desvio padrão de $0,5^{\circ} \mathrm{C}$. Em contrapartida, uma porção significativa do espectro de energia em $4,5^{\circ} \mathrm{N}$ está contida na faixa dos 50 dias, banda de variabilidade que nesta latitude é dominada por ondas de Rossby curtas (Polito e Sato 2003). Estas ondas não possuem uma assinatura térmica superficial distinta, mas são capazes de forçar anomalias superiores à $9^{\circ} \mathrm{C}$ em profundidades compatíveis com as da termoclina climatológica (Laurindo et al. 2010).

\subsubsection{Adaptação do método}

A formulação inicial foi adaptada buscando solucionar as falhas causadas pelos baixos valores superficiais nos dois primeiros modos EOF. A nova formulação baseia-se no fato de que os valores nas funções EOF aumentam rapidamente com a profundidade, e de que em baixas latitudes tipicamente é observada uma camada de mistura durante todo o ano. A premissa a ser testada é de que perfis sintéticos coerentes poderiam ser obtidos atribuindo a condição de 


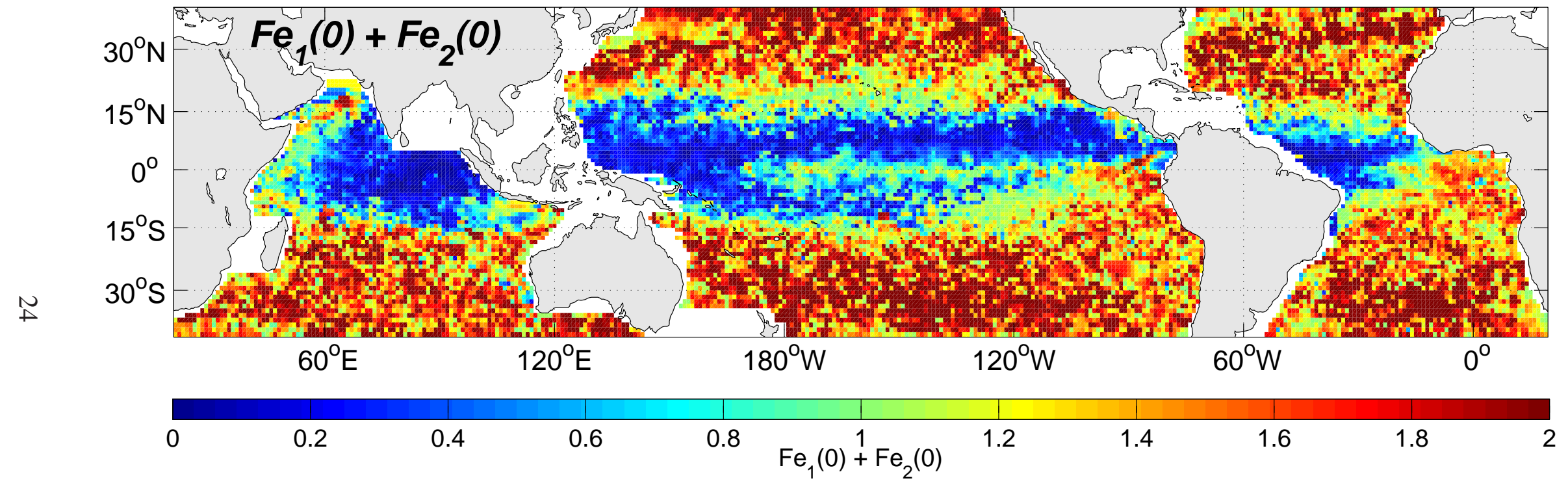

Figura 2: Soma dos valores superficias das formas funcionais normalizadas dos dois primeiros modos EOF. A presença de padrões contínuos sugere que estas características são causadas por forçantes geosfísicas e não meramente aleatórias. 
contorno definida pela TSM à menor profundidade em que ambas as funções EOF possuem valores significativos.

Os testes iniciais deste conceito foram feitos utilizando apenas perfis in situ, selecionados em janelas de $2^{\circ} \times 2^{\circ}$ centradas em pontos da grade do WOA05 e referentes à regiões do oceano onde a falha é observada. Os valores de $\eta$ referentes a cada perfil foram calculados a partir da equação da expansão térmica, enquanto os valores de TSM correspondem simplesmente às suas medições mais rasas de temperatura. Perfis sintéticos foram calculados de maneira similar à descrita para a formulação inicial, mas atribuindo a condição de contorno da TSM a níveis cada vez mais profundos. Observou-se que os perfis sintéticos obtidos tendem a coincidir com os originais quando a temperatura da condição de contorno é similar à temperatura do perfil in situ reconstruído com apenas dois modos EOF na mesma profundidade. Os testes mostraram ainda que este cálculo é particularmente sensível, fazendo com que diferenças inferiores à $0,5^{\circ} \mathrm{C} \mathrm{em}$ geral impliquem na obtenção de perfis sintéticos fisicamente incoerentes. A nova metodologia para construção de perfis sintéticos foi desenvolvida com base nestes resultados, sendo descrita a seguir.

A condição de contorno definida através dos dados de TSM é atribuída a profundidades sucessivamente inferiores a partir do nível onde as duas primeiras funções EOF são simultaneamente maiores que um desvio-padrão de seus respectivos valores médios. Trata-se de um critério arbitrário, desenvolvido para determinar qual a menor profundidade onde ambos os modos estatísticos possuem valores significativos. Perfis sintéticos são calculados deste nível até 100 m (10 profundidades) abaixo. Em cada profundidade assume-se uma oscilação ao redor da medida de temperatura do satélite de $3^{\circ} \mathrm{C}$, um grau positivo e dois negativos, sendo que perfis sintéticos são calculados a incrementos de $0,2^{\circ} \mathrm{C}$. A grande margem de incerteza assumida, de $100 \mathrm{~m}$ e $3^{\circ} \mathrm{C}$, foi estabelecida para garantir que a solução ideal, isto é, a melhor representação possível do perfil de temperatura com 2 modos estatísticos para os dados de TSM e $\eta$ considerados, seja interceptada pela condição de contorno. Para eliminar perfis espúrios gerados durante o processo, alguns critérios foram estabelecidos. São eles:

a) semelhança com a climatologia: critério similar ao controle de qualidade aplicado aos perfis in situ de temperatura. São excluídos perfis sintéticos que apresentem mais de 30 valores nos primeiros 1000 m além de 2 desvios-padrão da média climatológica local; 
b) inversão de densidade: os perfis sintéticos não podem conter inversões significativas de temperatura, isto é, temperaturas crescentes em direção ao fundo. Como a densidade do oceano superior nas latitudes consideradas é governada essencialmente pela temperatura, inversões ao longo da vertical implicariam em colunas de água dinamicamente instáveis. O critério proposto baseia-se portanto na análise da primeira derivada do perfis sintéticos obtidos, sendo excluídos aqueles cuja derivada apresente valores positivos excedendo um desvio padrão da média dos valores obtidos em $\partial T(z) / \partial z$;

c) profundidade da termoclina: uma temperatura típica da base da termoclina é estimada no ponto de maior gradiente no perfil climatológico de temperatura. Em seguida, uma regressão linear simples é realizada entre as profundidades onde este valor de temperatura é observado em cada perfil in situ obtido e o $\eta$ teórico calculado para cada perfil através da equação da expansão térmica, fornecendo uma reta teórica de $\eta$ vs. profundidade da isoterma obtida. Este processo é esquematizado na Figura 3, que inclui ainda um mapa do coeficiente de correlação $\left(R^{2}\right)$ entre as retas teóricas e os pares $\eta$ vs. profundidade da isoterma de cada ponto de grade. Note que este critério não pode ser aplicado a todos os pontos da grade, uma vez que existem regiões do oceano onde a temperatura superficial nos meses mais frios é menor que a temperatura da base da termoclina no perfil climatológico anual, característica geralmente decorrente da formação de uma termoclina sazonal no decorrer do ano. $R^{2}$ varia de 0 a 1 onde 1 é o melhor ajuste possível dos pontos à reta, sendo que valor médio dos pontos utilizados é de 0,76, indicando uma relação robusta na maior parte da região considerada. Para a exclusão de perfis espúrios, são considerados válidos aqueles cuja temperatura típica se encontra à menos de $30 \mathrm{~m}$ da profundidade estimada através da reta teórica.

O perfil sintético final é obtido simplesmente através da média dos perfis que sobreviveram aos critérios de exclusão. Porém, o próprio método obriga sua temperatura de superfície a não coincidir com a medida de TSM obtida via satélite. Como próximo passo, portanto, a porção superior do perfil deve ser apagada e sua camada de mistura realisticamente extrapolada para cima de modo a coincidir com a temperatura observada na superfície. Para tanto, assume-se que a forma funcional da camada de mistura $T_{c m}(z)$ pode ser aproximada à de uma tangente hiperbólica, de acordo com a seguinte expressão (adaptada de Sato e Rossby 2000):

$$
T_{c m}(z)=\left[\mathrm{TSM}-T_{\text {sint }}\left(z=z_{B}\right)\right] \times \tanh \left[\frac{\left(z_{B}-z\right)}{z_{B}}\right]+T_{\text {sint }}\left(z=z_{B}\right)
$$




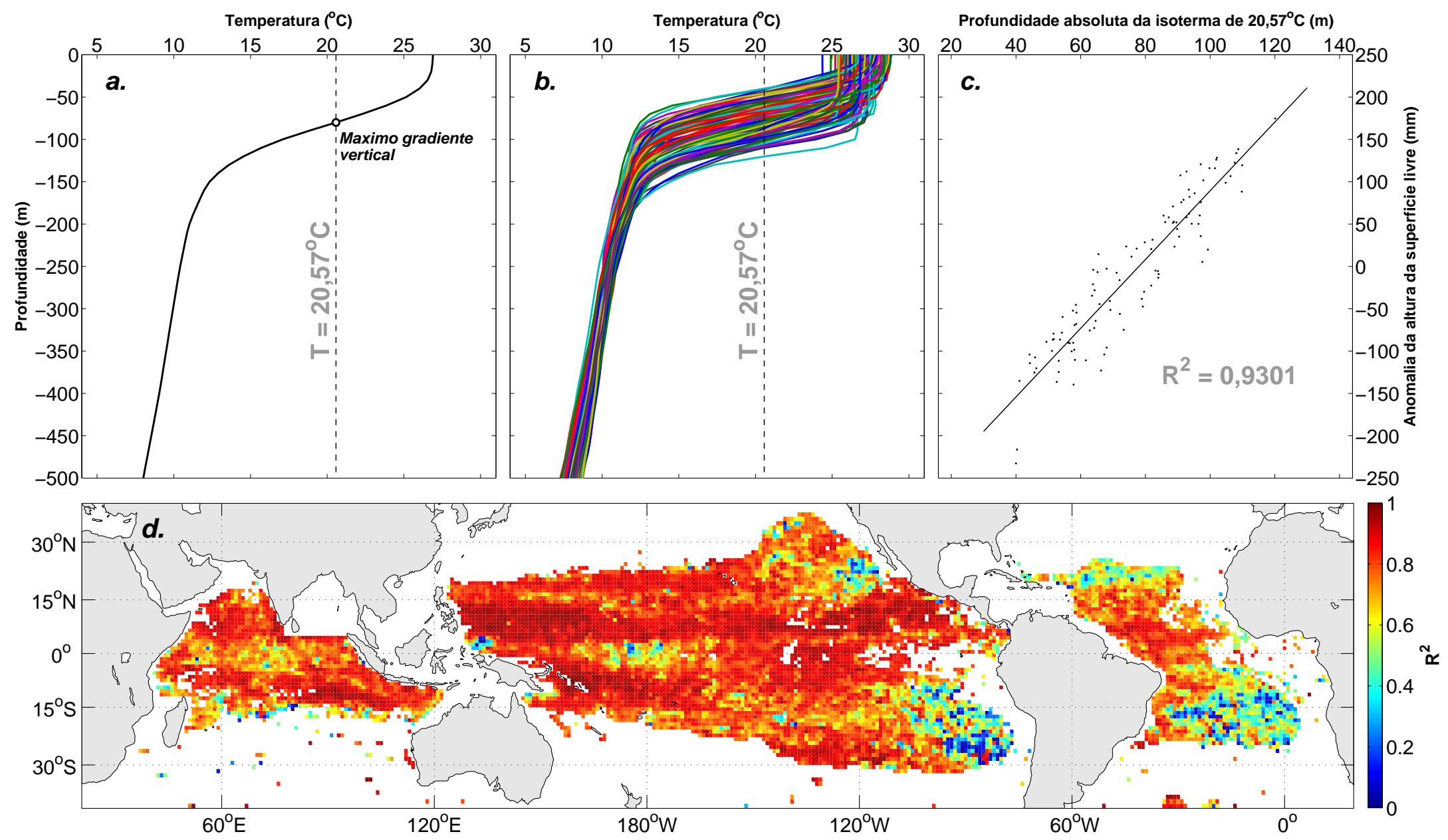

Figura 3: Construção de reta teórica da anomalia da altura $\eta$ vs. profundidade da termoclina em 10,5 N/150,5 $5^{\circ}$ : a) inicialmente, uma temperatura típica da base da termoclina é determinada no ponto de gradiente máximo do perfil climatológico; b) as profundidades desta isoterma são determinadas na coleção de perfis in situ local; c) uma regressão linear dos valores de $\eta$ vs. profundidades da isoterma é realizada. Aqui, $R^{2}$ é o coeficiente de correlação entre os pontos de origem e a reta de regressão. d) mapa de $R^{2}$, evidenciando a existência de uma relação robusta na maioria dos pontos de grade considerados. 


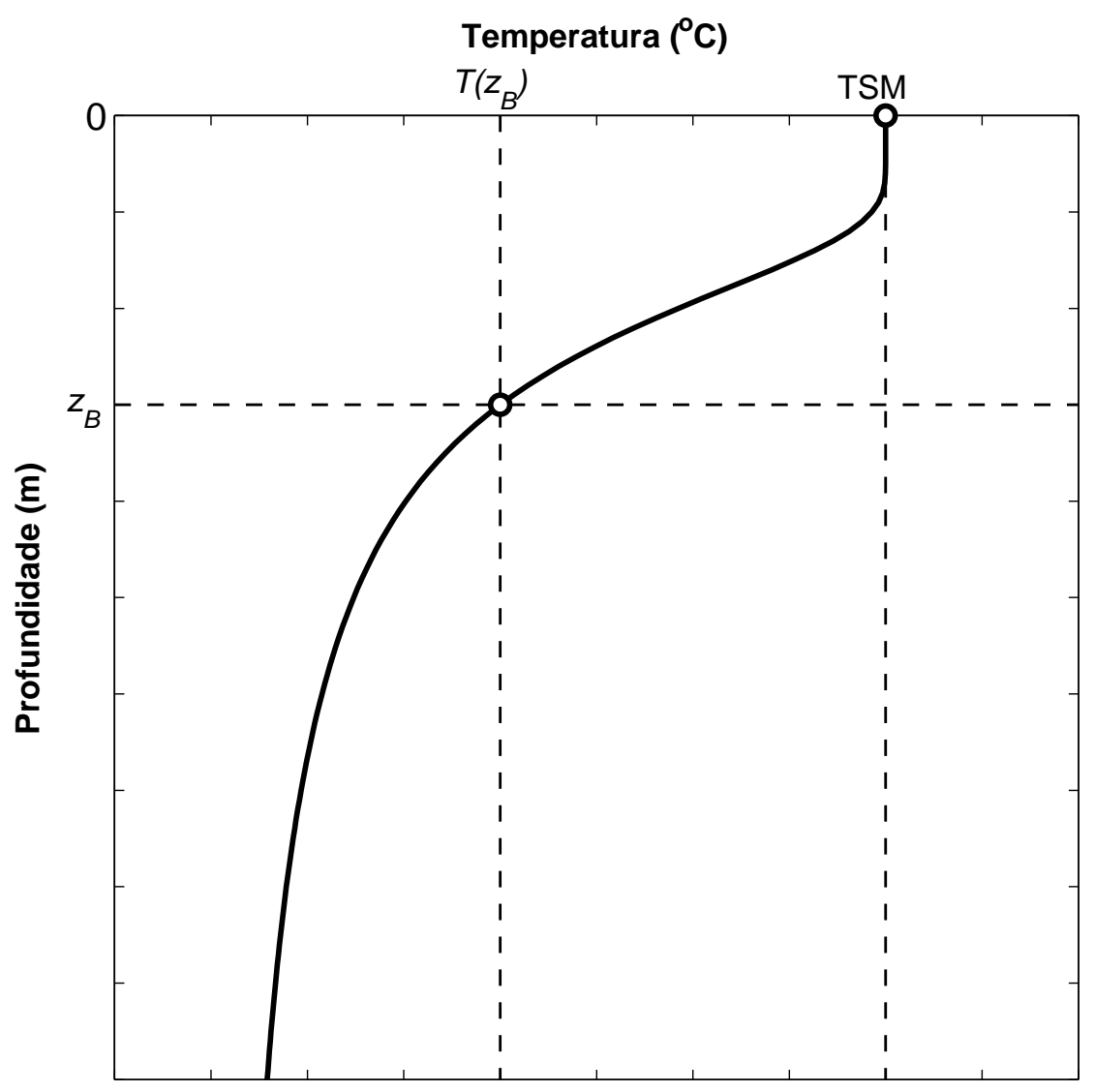

Figura 4: Perfil hiperbólico construído a partir da Equação (10). A porção acima da profundidade $z_{b}$ exemplifica a forma funcional usada para extrapolar para cima a camada de mistura de perfis sintéticos de temperatura calculados a partir do método adaptado.

onde $T_{\text {sint }}$ é o perfil sintético correspondente e $z_{B}$ é o ponto de inflexão da tangente hiperbólica. Um perfil hiperbólico construído por esta expressão é exemplificado na Figura 4, sendo que aqui só serão considerados valores desta função referentes ao intervalo $(z=0)$ entre a superfície e o nível $z_{B}$. Nos perfis sintéticos, $z_{B}$ é a profundidade de corte acima da qual os dados serão substituídos pela tangente hiperbólica da Equação (10). Este nível é encontrado através da análise do perfil da primeira derivada vertical, definido como sendo o ponto mais raso a possuir as seguintes características: 1) possuir temperatura menor que a temperatura de superfície; 2) estar inserido em um intervalo do perfil onde as temperaturas são decrescentes em direção ao fundo; e 3) o valor absoluto da derivada vertical deve ser maior que um desvio-padrão da média. Este último critério arbitrário foi estabelecido para selecionar um ponto intermediário entre a camada de mistura (derivada próxima de zero) e a base da termoclina (derivada com máximo valor absoluto), ao mesmo tempo em que ignora possíveis inversões de temperatura próximas à 
superfície, decorrentes da utilização de apenas os dois primeiros modos estatísticos para compor perfis verticais.

Para a extrapolação em si, inicialmente os níveis mais rasos que $z_{B}$ são apagados dos perfis sintéticos e as lacunas remanescentes são intepoladas bicubicamente até a temperatura de superfície medida pelo satélite. O segmento interpolado é então unido à uma função tangente hiperbólica, construída utilizando valores de TSM, $z_{B}$ e $T_{\text {sint }}\left(z=z_{B}\right)$ correspondentes, através de uma soma ponderada similar à esquematizada na Tabela 1. Nesta operação, maiores pesos são atribuídos à função tangente hiperbólica conforme a profundidade diminui. Porém, foi observado que os valores superficiais das funções tangente hiperbólica construídas em geral não coincidem as medições de TSM. Por esta razão, um perfil vertical com temperaturas constantes e iguais à medida de TSM, se extendendo da superfície até o nível $z_{B}$, foi unido à camada de mistura através de uma soma ponderada, desta vez atribuindo maiores pesos à este segmento de reta conforme a profundidade diminui.

\subsubsection{Aplicação entre $39,5^{\circ} \mathrm{S}$ e $39,5^{\circ} \mathrm{N}$}

Perfis sintéticos de temperatura foram calculados na grade espacial climatológica de $1^{\circ} \times$ $1^{\circ}$ entre as latitudes $39,5^{\circ} \mathrm{S}$ e $39,5^{\circ} \mathrm{N}$ a partir dos mapas processados de TSM e $\eta$. Como mencionado anteriormente, os dois primeiros modos EOF em cada ponto de grade são calculados a partir de conjuntos de perfis in situ selecionados em janelas de $2^{\circ} \times 2^{\circ}$, centradas em cada ponto. A Figura 5 mostra um mapa horizontal com o número de perfis Argo e XBT selecionados deste modo. Testes foram realizados para se determinar empiricamente qual seria o número mínimo de perfis para que o método tenha uma chance razoável de funcionar. Consequentemente, conjuntos com menos de 12 perfis in situ não foram utilizados, sendo que os modos EOF nestes pontos de grade foram calculados a partir das séries de perfis climatológicos mensais correspondentes.

Como critério geral, o método adaptado foi aplicado em vez do método básico em pontos de grade onde o valor superficial de ambos os modos estatísticos é inferior à um desvio-padrão da média de cada modo, assumindo que a variação induzida pela termoclina sazonal permita a sua utilização no ponto de grade considerado. O método adaptado foi também aplicado preferencialmente em bandas latitudinais inteiras onde o método básico mostrou-se ineficaz na maioria 


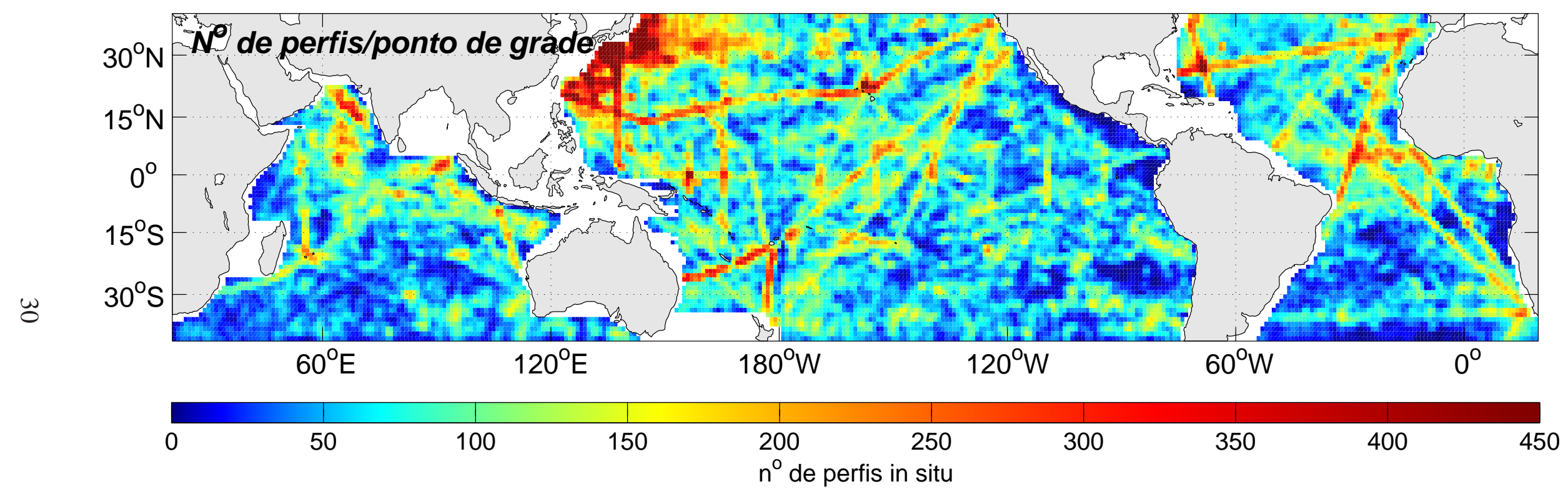

Figura 5: Número de perfis in situ selecionados em caixas de $2^{\circ} \times 2^{\circ}$ ao redor dos pontos da grade de $1^{\circ} \times 1^{\circ}$ climatológica. Note que a escala de cores segue uma progressão logarítmica. 
dos pontos de grade da referida latitude. Isto foi feito para forçar a utilização do método adaptado em pontos de grade onde a falha é observada mas que escapam ao critério geral. A definição destas latitudes foi guiada pela observação da Figura 2, mostrando regiões do oceano onde os modos possuem baixos valores superficiais. Foram escolhidas as áreas compreendidas entre as latitudes entre $6,5^{\circ} \mathrm{S}$ e $12,5^{\circ} \mathrm{N}$ no oceano Atlântico, $10,5^{\circ} \mathrm{S}$ e $20,5^{\circ} \mathrm{N}$ no Índico, e entre $15,5^{\circ} \mathrm{S}$ e $17,5^{\circ} \mathrm{N}$ no Pacífico. Por fim, todos os perfis sintéticos gerados pelo método básico foram comparados com a climatologia local e avaliados quanto à sua forma funcional. Perfis com mais de 30 valores além de 2 desvios-padrão da média anual climatológica e/ou cujo perfil vertical de sua primeira derivada $\partial T(z) / \partial z$ possui valores positivos excedendo um desvio-padrão do valor médio de $\partial T(z) / \partial z$ foram, quando possível, recalculados utilizando a metodologia adaptada, caso contrário simplesmente desprezados.

Os perfis sintéticos de temperatura resultantes foram organizados em séries temporais de seções zonais-verticais, $T_{\text {sint }}(x, z, t)$, para cada latitude de cada um dos três oceanos. Em uma etapa posterior deste trabalho, estes dados sintéticos são utilizados no cálculo de perfis verticais das componentes $u$ e $v$ da velocidade geostrófica através do método dinâmico, que envolve o cálculo de derivadas ao longo dos eixos horizontais. Procurando minimizar a influência de descontinuidades e de ruído horizontal sobre os cálculos, as seções sintéticas de temperatura foram submetidas a um pós-processamento que consistiu na interpolação de lacunas onde o método adaptado não foi capaz de gerar perfis adequados, e na suavização ao longo dos eixos zonal e temporal.

A interpolação foi feita para cada seção zonal-vertical da série temporal, $T_{\operatorname{sint}}(x, z)$, através de um esquema de curvatura contínua em tensão (Smith e Wessel 1990). Este método de interpolação é similar ao esquema por mínimas curvaturas utilizado na construção dos mapas horizontais de $\eta$ e TSM, com a diferença de incorporar um parâmetro que permite ajustar a tensão dos dados interpolados. Os dados interpolados por mínimas curvaturas assemelham-se à uma superfície que se flexiona para passar através dos dados originais, como uma tenda de circo armada frouxamente sobre seus apoios. A inclusão do fator de tensão permite controlar a flexão da superfície interpolada ao redor dos dados originais, uma operação análoga à simplesmente esticar a tenda. A curvatura em tensão foi adotada com o objetivo de minimizar falhas comumente observadas nas seções interpoladas por mínimas curvaturas, como gradientes laterais obviamente espúrios e oscilações sem significado físico. No algoritmo de Smith e Wessel 
1990 a tensão é ajustada por um parâmetro que varia de 0 a 1, sendo que um valor de 0,75 foi utilizado aqui por minimizar a criação de artefatos da interpolação ao mesmo tempo que produz campos laterais visualmente mais suaves.

As seções foram suavizadas em cada profundidade ao longo dos eixos temporal e zonal, nesta ordem, utilizando um filtro de média móvel do tipo hamming com 5 pontos em ambos os eixos. Trata-se de um filtro passa-baixa, isto é, desenhado para remover o ruído de alta frequência. Idealmente, a dimensão da janela de filtragem não deve exceder o número de pontos correspondentes à metade do comprimento de onda e período típicos do fenômeno de maior frequência que seja significativo no espectro de energia, para evitar a eliminação de componentes importantes da variabilidade. Isto torna-se um problema em latitudes inferiores à $10^{\circ}$ devido ao surgimento de ondas de larga escala com períodos inferiores à 50 dias, como ondas de Rossby curtas e ondas de instabilidade tropical, altamente energéticas em algumas regiões (Polito e Sato 2003; Laurindo et al. 2010). Para verificar se este processo é capaz de preservar as componentes principais da variabilidade em baixas latitudes, gráficos da potência espectral de séries temporais da temperatura em profundidades compatíveis com a termoclina foram comparados com suas contrapartes suavizadas. Observou-se que os picos principais com períodos mais longos que a frequência de amostragem (que é de aproximadamente 20 dias) em geral são preservados nas séries filtradas, validando o método de suavização aplicado aqui. A ordem de aplicação dos filtros, primeiro ao longo do eixo temporal e depois ao longo do zonal, foi definida para garantir que os gradientes zonais não sejam alterados por uma filtragem posterior ao longo do eixo temporal, o que poderia introduzir ruído no cálculo das velocidades geostróficas.

\subsubsection{Avaliação do desempenho dos perfis sintéticos}

A construção de perfis sintéticos de temperatura tem como objetivo estimar a variabilidade vertical dos oceanos a partir de dados de satélite. Como a única forma de variablidade presente na climatologia do WOA05 é o ciclo sazonal médio, espera-se que os perfis in situ sejam mais semelhantes aos perfis sintéticos do que à climatologia mensal. Assim, a validação dos perfis sintéticos foi realizada em cada área de $1^{\circ} \times 1^{\circ}$ centrada nos pontos da grade climatológica. Ela consistiu no cálculo da raiz do erro médio quadrático normalizado $(\varepsilon)$ até a profundidade de $1000 \mathrm{~m}$ entre perfis sintéticos e perfis in situ medidos a menos de 4,5 dias das datas referentes 
aos perfis sintéticos, e entre os perfis in situ e perfis climatológicos dos meses correspondentes. O valor de $\varepsilon$ é obtido através da seguinte expressão:

$$
\varepsilon=\sqrt{\frac{\left\langle\left[T(z)-T_{i}(z)\right]^{2}\right\rangle}{\left\langle[T(z)]^{2}\right\rangle}} \times 100
$$

onde $T(z)$ é o perfil sintético ou climatológico mensal e $T_{i}(z)$ é o perfil in situ correspondente. A multiplicação por 100 é feita simplesmente para apresentar $\varepsilon$ em forma percentual, sendo que valores mais próximos de 0 implicam em perfis mais semelhantes aos seus correspondentes in situ. Em cada ponto de grade foi calculada uma média simples dos valores de $\varepsilon$ obtidos para cada comparação, e os resultados foram organizados na forma de mapas horizontais. O método de construção foi considerado efetivo em regiões onde a comparação perfis sintéticos vs. in situ resulta em valores de $\varepsilon$ inferiores aos da comparação climatologia mensal vs. perfis in situ.

Porém, como os modos EOF representam a variabilidade do conjunto de perfis in situ do qual eles se originam, espera-se que os perfis sintéticos obtidos sejam mais próximos dos reais quando os valores de TSM e $\eta$ são semelhantes aos de perfis pertencentes ao conjunto original. Em outras palavras, utilizar os mesmos perfis in situ usados no cálculo dos modos EOF na validação pode potencialmente levar à uma superestimação da performance do método de construção de perfis sintéticos. A solução ideal seria utilizar um conjunto de dados in situ inteiramente distinto para a validação, porém a quantidade e distribuição espacial de perfis requerida impossibilita a aquisição de tal conjunto, simplesmente porque todos os perfis adequados que puderam ser adquiridos já foram utilizados no cálculo dos modos EOF.

Optou-se portanto por um meio-termo: a validação dos perfis sintéticos foi realizada através de sua comparação com quase 268.000 perfis Argo e XBT referentes ao período entre dezembro de 1997 e abril de 2008 que também foram utilizados na obtenção dos modos EOF aplicados em sua construção, somados à cerca de 196.000 perfis in situ independentes. 45,9\% destes são perfis Argo e XBT que não foram utilizados na construção dos perfis sintéticos por possuírem menos de 750 m perfilados. Os perfis restantes são provenientes do World Ocean Database 2009 (WOD09), e correspondem à medições de perfiladores do tipo Conductivity, Temperature and Depth (CTD) $(34,2 \%)$, termômetros de reversão montados em garrafas de coleta hidrográfica $(15,8 \%)$ e batitermógrafos $(4,1 \%)$. Estes perfis adicionais foram submetidos ao mesmo controle de qualidade aplicado sobre o conjunto de dados in situ original, com a diferença de que não 
foram submetidos à uma extrapolação vertical e de que foram admitidos perfis mais curtos que $750 \mathrm{~m}$.

O WOD09 é a versão mais atual do conjunto de dados sobre os quais as climatologias da série World Ocean Atlas são construídas, sendo também disponibilizado gratuitamente pelo NODC em www. nodc . noaa. gov. Uma breve descrição dos instrumentos utilizados na medição dos dados do WOD09 adquiridos para esta etapa do trabalho é feita a seguir.

CTDs são intrumentos utilizados para medição contínua de condutividade, temperatura e profundidade de águas oceânicas, onde a salinidade é calculada em função da condutividade, temperatura e da pressão hidrostática medidas. Os perfis medidos por estes instrumentos são de longe os de melhor qualidade dentre os obtidos para este trabalho, apresentando as maiores resoluções verticais, maiores profundidades amostradas e menores erros associados. CTDs são lançados a partir de navios de pesquisa dotados de guinchos hidrográficos, sendo que muitos modelos requerem ainda a utilização de cabos eletromecânicos que permitam a sua comunicação em tempo real com unidades de armazenamento/processamento de dados à bordo.

Batitermógrafos são sondas reutilizáveis semelhantes à pequenos torpedos que carregam sensores de temperatura e pressão, e que podem ser lançados de navios em movimento através de guinchos hidrográficos. Os primeiros modelos datam da década de 40 e eram mecânicos, fazendo registro dos dados medidos em tambores móveis internos. Modelos posteriores evoluíram para sistemas eletrônicos com registro em fita magnética e eventualmente em sistemas de memória interna, porém caíram em desuso com o desenvolvimento de XBTs e CTDs.

Por fim, termômetros de reversão são intrumentos para a medição discreta da temperatura da coluna de água, geralmente montados em estojos próprios acoplados à garrafas de coleta hidrográfica, descidos até pontos pré-determinados na coluna de água através de guinchos hidrográficos. Os modelos tradicionais consistem em um bulbo de mercúrio convencional ligado à coluna de leitura através de um arranjo de canais capilares. Ao inverter a posição do bulbo em relação ao eixo vertical, os capilares estrangulam o fluxo de mercúrio, registrando a temperatura no momento da reversão para leitura em um momento posterior. Modelos mais recentes são eletrônicos, onde a reversão do termômetro desloca o mercúrio presente em uma cavidade interna abrindo o circuito do sensor de temperatura, congelando a última medição para leitura posterior. 


\subsection{Cálculo da velocidade geostrófica}

\subsubsection{Método dinâmico}

O método dinâmico ou geostrófico desenvolvido por Sandström e Helland-Hansen 1903 permite inferir a velocidade de correntes geostróficas perpendicular a um eixo ligando dois perfis de densidade contíguos com base nos gradientes horizontais de densidade observados. Segundo a formulação mostrada no trabalho clássico, uma expressão para o cálculo da velocidade geostrófica entre dois perfis verticais de densidade em um instante $t$ qualquer pode ser derivada a partir da equação do vento térmico, dada por:

$$
\frac{\partial V(z)}{\partial z}=-\frac{g}{\rho_{0} f_{0}} \frac{\partial \rho(n, z)}{\partial n}
$$

onde $V(z)$ é o perfil vertical da velocidade geostrófica normal ao eixo horizontal que liga os perfis, $\rho_{0}$ é a densidade média da coluna de água, $f_{0}$ é o valor médio do parâmetro de Coriolis na região e $n$ é um versor horizontal paralelo ao eixo que liga os perfis de densidade. Integrando verticalmente a Equação (12) de um nível de referência $z_{0}$ a um nível $z^{\prime}$ qualquer, obtemos:

$$
V\left(z^{\prime}\right)-V\left(z_{0}\right)=-\frac{g}{\rho_{0} f_{0}} \int_{z_{0}}^{z^{\prime}} \frac{\partial \rho(n, z)}{\partial n} d z
$$

aqui, $z_{0}$ é um nível de referência onde a velocidade é conhecida ou então onde simplesmente assume-se velocidade zero, sendo chamado neste caso de nível de movimento nulo.

Em coordenadas isobáricas, a Equação (13) se torna:

$$
V\left(p^{\prime}\right)-V\left(p_{0}\right)=-\frac{1}{f_{0}} \frac{\partial}{\partial n} \int_{p_{0}}^{p^{\prime}} \theta(n, p) d p
$$

onde $\theta$ é o volume específico, igual ao inverso da densidade $\left(\rho^{-1}\right)$. Escrevendo $\theta$ em termos da soma de uma componente média à uma perturbação, temos:

$$
\theta(n, p, t)=\bar{\theta}(p)+\delta_{\theta}(n, p)
$$

onde $\delta_{\theta}(n, p)$ é a anomalia do volume específico. Integrando (15) verticalmente de $p_{0}$ a $p^{\prime}$, definimos o geopotencial $\Phi$ :

$$
\Phi=\int_{p_{0}}^{p^{\prime}} \theta(n, p) d p=\bar{\Phi}(p)+\Delta \Phi(n, p)
$$


onde $\bar{\Phi}(p)$ é o geopotencial padrão e $\Delta \Phi(n, p)$ é a anomalia do geopotencial. Aplicando (16) em (14) e generalizando para qualquer nível isobárico $p$, obtemos enfim a expressão para o cálculo da velocidade geostrófica entre os perfis considerados:

$$
V(p)=-\frac{1}{f_{0}} \frac{\partial[\Delta \Phi(n, p)]}{\partial n}+V\left(p_{0}\right)
$$

\subsubsection{Velocidades de referência}

Como mostra a Equação (17), é necessário estabelecer níveis isobáricos de referência com velocidades conhecidas para a utilização do método dinâmico. Na ausência de medições diretas de velocidade, estes níveis em geral são definidos com base no conhecimento prévio da dinâmica local, normalmente atribuindo velocidade zero à profundidades onde são observadas inversões de fluxo ou que estão associadas à fracos gradientes de pressão baroclínicos. Porém, esta abordagem não é prática no contexto deste trabalho, uma vez que a diversidade de cenários dinâmicos existente entre $39,5^{\circ} \mathrm{S}$ e $39,5^{\circ} \mathrm{N}$ é simplesmente grande demais para o estabelecimento de um critério geral para a escolha do nível de referência.

Assim, optou-se por utilizar dados médios de velocidade de correntes provenientes do modelo numérico oceânico Global Ocean Data Assimilation System (GODAS) referentes a profundidades de até $3000 \mathrm{~m}$ para referenciar perfis de velocidade geostrófica. Esta escolha foi baseada nas seguintes premissas:

1) o GODAS é um modelo de assimilação, isto é, que continuamente incorpora medições reais dos oceanos para a redefinição de suas condições iniciais. Na ausência de medições diretas, dados de modelos númericos baseados em medições reais constituem a melhor representação disponível dos padrões de circulação;

2) os perfis sintéticos de temperatura obtidos são idênticos ao perfil climatológico anual em profundidades maiores que $1500 \mathrm{~m}$ para qualquer tempo $t$, fazendo com que as velocidades geostróficas calculadas aqui sejam também constantes abaixo deste nível. A possibilidade de utilizar velocidades médias como referência para o método dinâmico elimina o efeito de possíveis discrepâncias entre dados sintéticos e modelados decorrentes da variabilidade representada por cada conjunto;

3) as velocidades de correntes em profundidades abaixo dos 1000 m são uma ordem de grandeza 
menores que as velocidades superficiais, implicando em menores margens de erro decorrentes da utilização de velocidades modeladas como referência para o método dinâmico.

Os dados do GODAS são gratuitamente disponibilizados pelo Climate Prediction Center (CPC, www.cpc.noaa.gov), uma divisão do National Weather Service da agência norteamericana NOAA. O modelo foi desenvolvido para prover condições iniciais oceânicas para o modelo climático global Climate Forecast System (CFS) do National Centers for Environmental Prediction (NCEP), e assimila perfis sintéticos de salinidade e perfis in situ de temperatura provenientes de perfiladores Argo, XBT e de fundeios das redes TAO/TRITON e PIRATA (Saha et al. 2006). Os dados obtidos para este estudo são das componentes $u$ e $v$ da velocidade total (geostrófica e ageostrófica) e correspondem à simulações feitas para o período entre janeiro de 1980 e abril de 2010. Estão organizados sobre um grade quase global abrangendo as latitudes entre $75^{\circ} \mathrm{S}$ e $65^{\circ} \mathrm{N}$, com resolução espacial de $1^{\circ} \times 1^{\circ}$ refinada para $1 / 3^{\circ} \times 1 / 3^{\circ} \mathrm{em}$ latitudes menores que $10^{\circ}$. Os dados apresentam 40 níveis verticais, com resolução de $10 \mathrm{~m}$ nos primeiros $200 \mathrm{~m}$. Particulamente para este estudo, foram selecionados dados de velocidade com resolução temporal mensal. O processamento e a aplicação dos dados de velocidade do GODAS são descritos no tópico a seguir, juntamente com a metodologia envolvida no cálculo das velocidades geostróficas.

\subsubsection{Aplicação}

Aqui, as componentes $u$ e $v$ da velocidade geostrófica são calculadas através da aplicação do método dinâmico sobre perfis sintéticos de temperatura e perfis climatológicos mensais de salinidade, referenciadas utilizando dados da velocidade total média provenientes do modelo numérico GODAS. As etapas envolvidas nesta operação são descritas abaixo:

Preliminarmente, os perfis climatológicos mensais de salinidade foram atribuídos ao dia 15 do mês correspondente e ajustados à grade temporal dos perfis sintéticos por interpolação linear. Isto foi feito para prevenir possíveis descontinuidades nas velocidades calculadas induzidas por variações bruscas de salinidade. A seguir, a organização espacial dos perfis sintéticos e climatológicos foi ajustada para garantir que as componentes $u$ e $v$ obtidas se refiram às mesmas posições no espaço, uma vez que o método dinâmico calcula a velocidade geostrófica perpendicular ao eixo ligando perfis contíguos de densidade. Foram calculados perfis médios a partir 
de pares de perfis de temperatura sintéticos consecutivos ao longo dos eixos $x$ e $y$ e referentes à um mesmo instante $t$, que foram atribuídos à posição média dos segmentos ligando os dois perfis originais. O mesmo foi feito com os perfis da climatologia mensal de salinidade interpolados ao longo do tempo. Perfis médios de temperatura e salinidade referentes ao mesmo ponto no espaço e no tempo foram então combinados em perfis de densidade. O método dinâmico foi por fim aplicado a pares de perfis de densidade consecutivos ao longo dos eixos $x$ e $y$ em um mesmo instante $t$ para obter as componentes $v$ e $u$ da velocidade geostrófica, respectivamente, ainda não referenciadas. A resolução de $1^{\circ} \times 1^{\circ} \times \sim 10$ dias dos dados de origem é conservada aqui, porém a nova grade sobre a qual as velocidades são calculadas é deslocada em $0,5^{\circ}$ ao longo dos eixos horizontais em relação à grade original. $\mathrm{O}$ ajuste da grade climatológica para a aplicação do método dinâmico é esquematizado no painel superior da Figura 6.

Para adequar os dados do GODAS ao referenciamento das velocidades obtidas pelo método dinâmico, inicialmente foram calculadas médias dos perfis de $u$ e $v$ da velocidade absoluta do modelo em cada ponto de sua grade horizontal. Cada perfil médio foi interpolado linearmente para um incremento vertical de $10 \mathrm{~m}$, e em seguida mapas horizontais referentes à cada profundidade foram interpolados por mínimas curvaturas numa grade coincidente com a das velocidades geostróficas. Para evitar o fluxo de correntes ageostróficas forçadas pelo atrito com o fundo oceânico, os níveis de referência foram fixados a $200 \mathrm{~m}$ do fundo até a profundidade máxima de $3.000 \mathrm{~m}$. O referenciamento em si foi realizado simplesmente somando as velocidades nos níveis de referência em cada ponto de grade aos perfis de velocidade geostrófica obtidos, em conformidade com a Equação (17).

\subsection{Cálculo dos modos dinâmicos e raios de deformação}

\subsubsection{Fundamentos}

A obtenção dos modos dinâmicos e raios de deformação de Rossby é feita com base no formalismo apresentado por Silveira et al. 2000. Segundo LeBlond e Mysak 1978, uma maneira de se lidar com problemas em fluidos geofísicos é utilizar o método de separação de variáveis sobre a equação do movimento para obter expressões independentes para a estrutura vertical e para a dependência horizontal e temporal. No caso específico das componentes $u$ e $v$ da velocidade geostrófica, elas são decompostas em uma série infinita de funções ortogonais para 


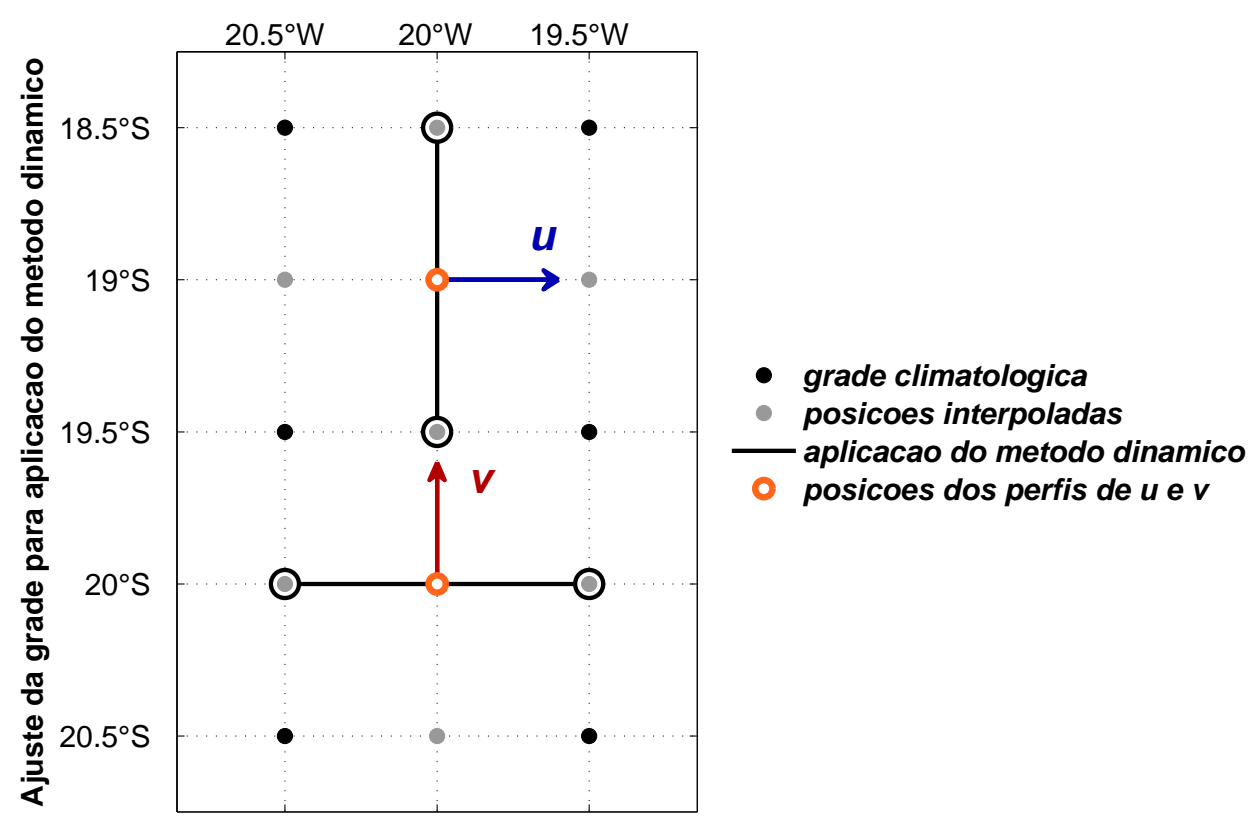

- grade climatologica

selecao de perfis adjacentes

- posicao dos perfis medios

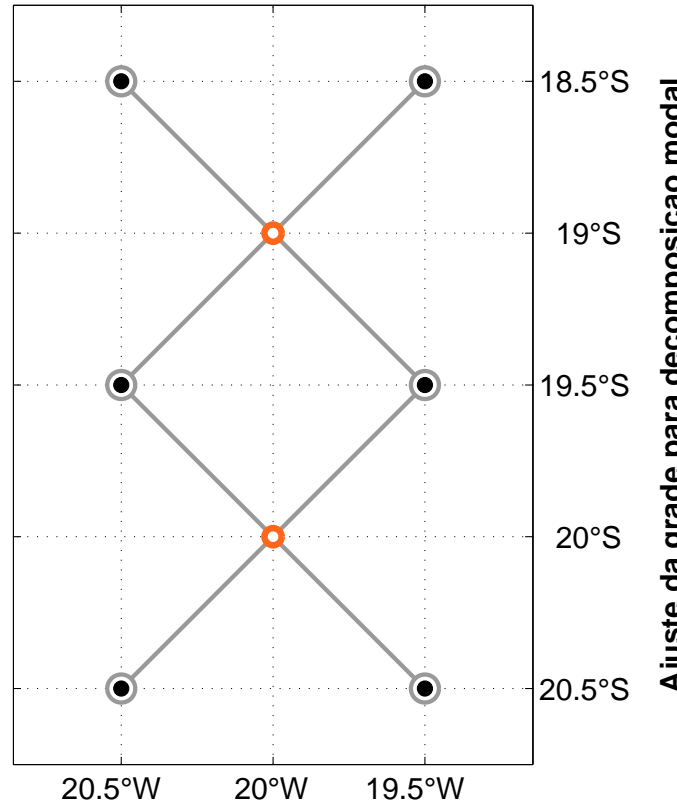

Figura 6: Ajuste da organização espacial dos perfis sintéticos e climatológicos para a aplicação do método dinâmico (painel superior), e para a decomposição modal (painel inferior). Painel superior: os perfis de u $e \mathrm{v}$ geostróficos são calculados para as posições marcadas pelos pontos laranjas através do método dinâmico a partir do par de perfis de densidade imediatamente ao norte e ao sul (a leste e a oeste) de suas posições. Painel inferior: os perfis médios de densidade referentes às posições marcadas pelos pontos laranjas são obtidos simplesmente através da média simples dos quatro perfis adjacentes referentes a um mesmo instante t. 
a estrutura vertical, onde cada uma delas é multiplicada por funções amplitude dependentes do tempo e dos eixos horizontais, da seguinte forma:

$$
\left.\begin{array}{l}
u(x, y, z, t)=\sum_{i=1}^{\infty} \mathcal{U}_{i}(x, y, t) F_{i}(z) \\
v(x, y, z, t)=\sum_{i=1}^{\infty} \mathcal{V}_{i}(x, y, t) F_{i}(z)
\end{array}\right\}
$$

onde as estruturas verticais $F_{i}$ são as $i$-ésimas funções ortogonais bases ou modos dinâmicos, e as estruturas horizontais $\mathcal{U}_{i}$ e $\mathcal{V}_{i}$ são respectivamente as $i$-ésimas amplitudes modais das componentes zonal e meridional da velocidade. Analogamente, a separação em estruras verticais e horizontais da função de corrente geostrófica $\psi$ assume a seguinte forma:

$$
\psi(x, y, z, t)=\sum_{i=1}^{\infty} \Psi_{i}(x, y, t) F_{i}(z)
$$

A decomposição de $\psi$ mostrada em (19) é aplicada na equação da conservação da vorticidade linearizada, derivada assumindo um oceano continuamente estratificado, invíscido e hidrostático. São obtidas então equações do tipo Sturm-Liouville para a evolução da amplitude e para a estrutura vertical. Os modos dinâmicos $F_{i}$ podem ser obtidos através da resolução da equação que descreve a estrutura vertical, tomando como condições de contorno uma tampa rígida na superfície e fundo plano:

$$
\left.\begin{array}{c}
\frac{\partial}{\partial z} \frac{f^{2}}{N^{2}(z)} \frac{\partial F_{i}(z)}{\partial z}+\lambda_{i} F_{i}(z)=0, \\
\text { onde } \quad \frac{\partial F_{i}}{\partial z}=0 \quad \text { em } \quad z=0,-H
\end{array}\right\}
$$

onde $\lambda_{i}$ são autovalores, $N$ é a frequência de estratificação ou frequência de Brunt-Väisälä $\left(N^{2}(z)=-g / \rho_{0} \times \partial \rho(z) / \partial z\right) ; f$ é o parâmetro de Coriolis sob a aproximação do plano $\beta$, onde $f=f_{0}+\beta y$, sendo que $f_{0}$ é o valor de Coriolis na latitude central do plano local e $\beta$ a sua variação meridional $(\partial f / \partial y)$; e $H$ é a profundidade local. Existe um número infinito de soluções para $F_{i}$, uma para cada $i=1,2,3, \ldots, \infty$, sendo que cada solução está associada a um autovalor $\lambda_{i}$ real e discreto. Nesta formulação, cada $\lambda_{i}$ equivale ao inverso do quadrado do raio de deformação interno correspondente $\left(\lambda_{i}=R_{i}^{-2}\right)$. Os raios de deformação internos são dados ainda pela relação $R_{i}=c_{i} / f$, onde $c_{i}$ é a velocidade de propagação de ondas de gravidade internas do $i$-ésimo modo baroclínico em um fluido continuamente estratificado. 
Isto significa que os únicos parâmetros necessários para calcular os modos dinâmicos e raios de deformação internos são o parâmetro de Coriolis e o perfil vertical de $N^{2}(z)$ locais, este último inferido a partir do perfil vertical de densidade, que por sua vez pode ser calculado a partir de perfis verticais de temperatura e salinidade da região. $O$ modo barotrópico $F_{0}$ é dado simplesmente por uma função com valor unitário ao longo de toda a coluna de água, isto é, $F_{0}(z)=1$

\subsubsection{Aplicação}

Para permitir a obtenção de $F_{i}$ e $R_{i}$ sobre a mesma grade das velocidades geostróficas, foi necessário preliminarmente reorganizar a grade espacial dos perfis sintéticos e climatológicos envolvidos. Isto foi feito simplesmente através de uma média simples dos quatro perfis adjacentes à cada ponto da nova grade espacial, conforme esquematizado no painel inferior da Figura 6. O problema apresentado em (20) é resolvido em cada ponto no tempo e no espaço horizontal através de um esquema numérico iterativo que utiliza como dados de entrada perfis verticais locais e instantâneos de $N$, por sua vez calculados através de perfis sintéticos de temperatura e perfis climatológicos mensais de salinidade, e suavizados utilizando um filtro passa-baixa do tipo hamming, de cinco pontos. Também aqui os perfis climatológicos mensais de salinidade foram preliminarmente interpolados numa resolução temporal coincidente com a dos perfis sintéticos, com o objetivo de evitar sinais espúrios induzidos por variações bruscas de salinidade.

Como mencionado anteriormente, o problema de autovalores apresentado em (20) é derivado assumindo que a variação temporal da estratificação pode ser desprezada, aproximação que os trabalhos de Emery et al. 1984 e Chelton et al. 1998 mostram ser válida em escalas sazonais. Porém, Laurindo et al. 2010 mostra que ondas de Rossby intrasazonais são capazes de forçar anomalias subsuperfciais de temperatura e densidade superiores à $9^{\circ} \mathrm{C}$ e $1,3 \mathrm{~kg} \cdot \mathrm{m}^{-3}$, onde cálculos preliminares realizados para este estudo indicam que estas anomalisa podem implicar em variações dos raios internos superiores à $10 \%$ em relação aos raios médios locais. Um dos objetivos do presente estudo é avaliar a variação dos raios de deformação em relação à média anual em um oceano sob a ação de fenômenos transientes, e portanto os raios de deformação baroclínicos são analisados em termos de sua variabilidade temporal, sendo calculados a partir 
dos dados sintéticos em cada instante $t$.

Porém, assumindo que de fato existam formas variabilidade da estratificação interna dos oceanos que não possam ser desprezadas nas relações do movimento baroclínicas, é possível que as formas funcionais dos modos internos também variem significativamente ao longo do tempo. Como será descrito no tópico a seguir, a composição modal do interior geostrófico dos oceanos é estimada através da comparação da forma funcional dos modos com perfis verticais de velocidade. Como a velocidade geostrófica obviamente também varia no tempo, os resultados obtidos desta operação incluiriam portanto duas dependências temporais, uma associada à evolução temporal da distribuição espacial do campo de densidade (velocidades geostróficas) e outra associada à evolução da estratificação (modos dinâmicos), cuja interação e efeitos sobre os resultados seriam de difícil interpretação. Assim, este trabalho assume que os modos dinâmicos são invariáveis no tempo, em concordância com a premissa de não depedência temporal da estratificação, sendo portanto calculados a partir da climatologia anual de densidade do WOA05.

\subsection{Estimativa da importância relativa dos modos dinâmicos}

\subsubsection{Circulação geostrófica total}

A importância que cada modo dinâmico assume ao compor perfis verticais das componentes $u$ e $v$ da velocidade geostrófica foi estimada em termos da raiz do erro médio quadrático normalizado $(\varepsilon)$ calculada entre os perfis de velocidade e os perfis de cada modo dinâmico $F_{i}$ multiplicados pelos valores de amplitude referentes ao ponto $(x, y)$ e no instante $t$ considerados. Este cálculo é realizado através de uma forma adaptada da Equação (11), então utilizada na validação dos perfis sintéticos de temperatura, expressa aqui por:

$$
\vartheta_{i}=\left\{1-\sqrt{\frac{\left\langle\left[(u, v)-\left(\mathcal{U}_{i}, \mathcal{V}_{i}\right) F_{i}\right]^{2}\right\rangle}{\left\langle(u, v)^{2}\right\rangle}}\right\} \times 100
$$

Nesta formulação, $\varepsilon$ propriamente dito é apenas o termo da raiz quadrada, cujo resultado varia de 0 a 1 . Valores iguais à 0 significam que a forma funcional de $u, v$ é idêntica à de $\left(\mathcal{U}_{i}, \mathcal{V}_{i}\right) F_{i}$, enquanto 1 implica em estruturas verticais ortogonais entre si. Buscando tornar a análise dos resultados mais intuitiva, a subtração de 1 por $\varepsilon$ foi realizada para fazer com que 
valores maiores se traduzam em maiores semelhanças, e a multiplicação por 100 simplesmente para apresentar resultados em forma percentual. A quantidade $\vartheta_{i}$ obtida é interpretada como sendo a percentagem da estrutura vertical que é explicada por cada modo dinâmico. Esta formulação foi inspirada pelo trabalho de Silveira et al. 2000, onde uma expressão semelhante é utilizada para verificar os modos mais importantes na composição da estrutura dinâmica da retroflexão da corrente norte do Brasil.

Para esta análise são considerados os 5 primeiros modos baroclínicos e mais o modo 0 ou barotrópico. As amplitudes $\mathcal{U}_{i}, \mathcal{V}_{i}$ para as ordens de 0 a 5 para cada perfil de $u$ e $v$ geostróficos foram estimadas ajustando por mínimos quadrados a estrutura vertical de cada modo dinâmico sobre o perfil de velocidade correspondente. Especificamente, em um primeiro momento foram consideradas as matrizes:

$$
A=\left|\begin{array}{lllll}
F_{0}(z) & F_{1}(z) & \ldots & F_{4}(z) & F_{5}(z)
\end{array}\right|, \quad X=\left|\begin{array}{c}
{\left[\mathcal{U}_{0}, \mathcal{V}_{0}\right]} \\
{\left[\mathcal{U}_{1}, \mathcal{V}_{1}\right]} \\
\vdots \\
{\left[\mathcal{U}_{4}, \mathcal{V}_{4}\right]} \\
{\left[\mathcal{U}_{5}, \mathcal{V}_{5}\right]}
\end{array}\right|, \quad B=|[u(z), v(z)]|
$$

onde as soluções para as amplitudes $\mathcal{U}_{i}$ e $\mathcal{V}_{i}$ contidas na matriz $X$ foram encontradas através da seguinte formulação:

$$
X=\left(A_{t} \times A\right)^{-1} \times\left(A_{t} \times B\right)
$$

onde $A_{t}$ é a matriz transposta de $A$.

Assim, através dos perfis sintéticos de $u$ e $v$, dos modos dinâmicos e suas respectivas amplitudes para as ordens baroclínicas de 0 à $5, \vartheta_{i}$ foi calculado sobre a grade espacial e temporal sobre a qual os dados de velocidade geostrófica encontram-se ajustados.

\subsubsection{Anomalias em relação ao fluxo médio}

Espera-se que a passagem de ondas de Rossby planetárias provoque anomalias verticais de velocidade compatíveis com a forma funcional de seu modo dinâmico correspondente. Isto significa que ondas de Rossby barotrópicas provocam anomalias de velocidade uniformes ao longo da coluna de água, ondas do primeiro modo baroclínico geram anomalias verticais com forma correspondente ao primeiro modo baroclínico, e assim por diante (Cipollini et al. 2004). 
Observações globais da ondas de Rossby em dados altimétricos sugere que ondas do primeiro modo dominam o espectro da energia propagante para oeste nos oceanos (Chelton e Schlax 1996; Polito e Liu 2003). É portanto possível que parte significativa das anomalias de velocidade geostrófica em relação ao campo geostrófico médio dos oceanos também sejam provocadas por sua passagem. Adicionalmente, como é possível que os altímetros sejam pouco sensíveis à ondas planetárias de ordens baroclínicas maiores que 1, a estrutura vertical de anomalias de velocidade podem fornecer indícios da ação destes fenômenos.

Buscando determinar regiões mais prováveis da ocorrência de ondas de Rossby pertencentes à diferentes modos dinâmicos, uma análise idêntica à descrita no tópico anterior para os perfis verticais componentes $u$ e $v$ da velocidade geostrófica foi aplicada sobre os perfis verticais de suas anomalias em relação às respectivas médias de longo termo. Especificamente, tratando os campos de velocidade geostrófica totais $u, v(x, y, z, t)$ em termos da soma de um campo médio $\bar{u}, \bar{v}(x, y, z)$ à anomalias de velocidade $u^{\prime}, v^{\prime}(x, y, z, t)$, temos:

$$
\left.\begin{array}{l}
u(x, y, z, t)=\bar{u}(x, y, z)+u^{\prime}(x, y, z, t) \\
v(x, y, z, t)=\bar{v}(x, y, z)+v^{\prime}(x, y, z, t)
\end{array}\right\}
$$

Para cada ponto $(x, y)$ da grade horizontal e instante $t$ considerados, a percentagem da estrutura vertical das anomalias de velocidade $u^{\prime}$ e $v^{\prime}$ explicada por cada modo dinâmico $\left(\vartheta_{i}^{\prime}\right)$ é dada pela seguinte expressão:

$$
\vartheta_{i}^{\prime}=\left\{1-\sqrt{\frac{\left\langle\left[\left(u^{\prime}, v^{\prime}\right)-\left(\mathcal{U}_{i}^{\prime}, \mathcal{V}_{i}^{\prime}\right) F_{i}\right]^{2}\right\rangle}{\left\langle\left(u^{\prime}, v^{\prime}\right)^{2}\right\rangle}}\right\} \times 100
$$

Aqui, $\mathcal{U}_{i}^{\prime}, \mathcal{V}_{i}^{\prime}$ são as amplitudes que os modos dinâmicos $F_{i}$ assumem ao compor perfis verticais de $u^{\prime}$ e $v^{\prime}$, calculadas através do ajuste linear de $F_{i}$ à $u^{\prime}$ e $v^{\prime}$ por mínimos quadrados através de uma formulação idêntica à apresentada nas Equações (22) e (23) para a velocidade geostrófica total.

\subsubsection{Modos baroclínicos significativos nos oceanos}

Como mencionado anteriormente, diversos trabalhos sugerem que a maior parte da variabilidade dos oceanos está contida em um número relativamente pequeno de modos dinâmicos. Observações globais da velocidade de propagação de ondas de Rossby através de dados altimétricos sugerem que ondas do primeiro modo baroclínico são dominantes nos oceanos (Chelton e 
Schlax 1996; Cipollini et al. 1997; Polito e Liu 2003; Challenor et al. 2004). O estudo numérico de Dewar e Morris 2000 relata que um modelo quase-geostrófico de três camadas (isto é, que aproxima oceano dominado pelo modo barotrópico e os dois primeiros baroclínicos) já é capaz de representar os mecanismos básicos de ajuste oceânico à perturbações de larga escala. Por fim, Maharaj et al. 2007 apresenta evidências de que a fração da variância em $\eta$ atribuída à ondas de Rossby apreende ondas apenas dos três primeiros modos internos, onde a contribuição do quarto modo é desprezível. Não espera-se portanto que modos baroclínicos de ordem superior ao terceiro exerçam papéis importantes na composição do campo médio geostrófico e nem na dinâmica de ondas de Rossby planetárias.

Adicionalmente, como será discutido em maiores detalhes no próximo tópico, especula-se que a variância máxima que os perfis sintéticos são capazes de representar seja limitada pela fração representada pelos modos EOF utilizados em sua construção, pelos erros intrínsecos ao método e pela própria natureza indireta do método de construção proposto. Uma premissa portanto é de que formas de cisalhamento vertical cada vez mais complexas seriam piores representadas nos perfis sintéticos, aumentando os erros associados à esta análise conforme a ordem dos modos baroclínicos aumenta. Assim, apesar de o modo barotrópico e mais cinco modos dinâmicos baroclínicos serem ajustados aos perfis de velocidade geostrófica, este estudo concentra-se na interpretação dos parâmetros ligados ao modo barotrópico e aos três primeiros baroclínicos.

\subsection{Limitações metodológicas}

\subsubsection{Limites observacionais dos perfis sintéticos}

Desconsiderando as falhas intrínsecas ao método proposto, os limites observacionais dos perfis sintéticos se referem ao seu alcance vertical e à fração máxima da variância vertical que são potencialmente capazes de recuperar. Cada um destes limites é discutido a seguir.

Os perfis sintéticos são calculados da superfície até o fundo. Porém, como os perfis in situ foram truncados à $1000 \mathrm{~m}$ de profundidade, toda a variabilidade nos perfis sintéticos com significado físico está presente apenas até este nível. De fato, a variabilidade observada entre 1000 e 1500 m provém de trechos extrapolados nos perfis in situ, sendo que em níveis mais profundos os perfis sintéticos são rigorosamente idênticos à climatologia anual em qualquer instante $t$. Esta característica pode potencialmente limitar a análise da importância de cada modo dinâmico 
em perfis das componentes $u$ e $v$ da velocidade geostrófica. Porém, este problema é inevitável, pois decorre da carência de dados globais em maiores profundidades.

A maior parte da variabilidade nos oceanos está contida em sua porção mais superficial, da camada de mistura até níveis picnoclínicos. Porém, dados climatológicos mostram que a picnoclina pode extender-se até abaixo dos $1000 \mathrm{~m}$ em algumas regiões, sendo que formas de variabilidade ligadas à modos baroclínicos de ordem superior ao primeiro podem potencialmente ter expressão em níveis abaixo desta interface. Laurindo et al. 2010 apresenta evidências da passagem de ondas de Rossby do segundo modo baroclíco em dados de temperatura obtidos por uma bóia ATLAS da rede PIRATA em $4^{\circ} \mathrm{N} / 38^{\circ} \mathrm{W}$. No caso, o segundo modo é caracterizado por anomalias de até $9^{\circ} \mathrm{C}$ centradas em $120 \mathrm{~m}$, profundidade da termoclina climatológica local, ocorrendo em oposição de fase com anomalias de cerca de $2^{\circ} \mathrm{C}$ abaixo dos $200 \mathrm{~m}$, que aparentemente se extendem até abaixo do último sensor de temperatura da bóia ATLAS à 500 m. Apesar de este evento ter sido observado acima dos $1000 \mathrm{~m}$, ele mostra que flutuações de temperatura significativas forçadas pela passagem de ondas de larga escala podem ocorrer em níveis mais profundos que a termoclina. Adicionalmente, formas funcionais do segundo e terceiro modos baroclínicos em diversas regiões do oceano mostram suas primeiras inversões de sinal em profundidades próximas ou superiores à $1.000 \mathrm{~m}$. Estas evidências sugerem que parte da energia associada a modos baroclínicos maiores que o primeiro pode estar contida em profundidades superiores à $1000 \mathrm{~m}$, e portanto simplesmente além do limite de observação dos perfis sintéticos. No contexto da análise proposta, isto pode causar uma subestimação da importância relativa de modos baroclínicos superiores ao primeiro.

É razoável esperar que os perfis sintéticos sejam capazes de recuperar no máximo a fração da variância que é explicada pelos dois primeiros modos EOF da anomalia vertical da temperatura. A Figura 7 mostra o mapa horizontal da percentagem da variância da anomalia vertical de temperatura explicada pelos dois primeiros modos estatísticos. De maneira geral, a distribuição da variância forma padrões contínuos que são essencialmente diferentes da distribuição dos perfis in situ originais (Figura 5), sugerindo que trata-se de uma característica de origem geofísica e não meramente fruto da distribuição heterogênea de dados. A percentagem da variância explicada pelos dois primeiros modos combinados varia de 58 a 98\% na área considerada, com um valor médio de $83 \%$. Assumindo que o método de construção de perfis sintéticos opere adequadamente, espera-se que quanto maior a fração da variância explicada maior será 


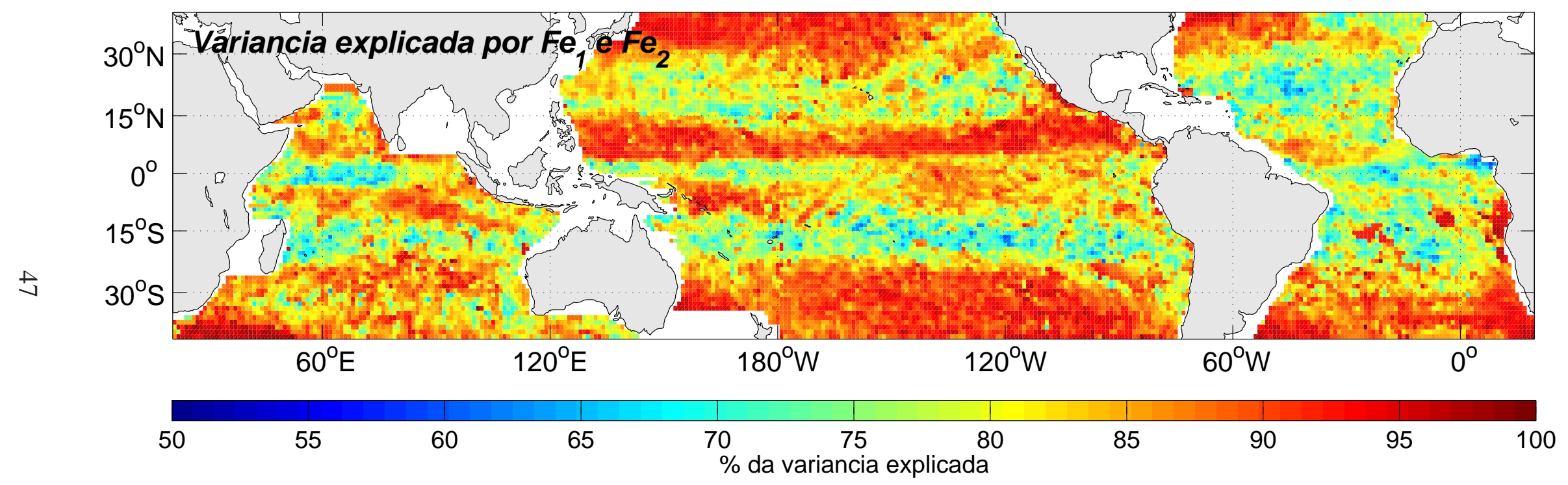

Figura 7: Mapa da percentagem da variância da anomalia vertical de temperatura explicada por seus dois primeiros modos estatísticos. 
a riqueza espectral contida nos dados sintéticos calculados. Em outras palavras, espera-se que perfis sintéticos obtidos em pontos de grade onde os dois primeiros modos EOF explicam uma baixa fração da variância representem apenas as componentes mais energéticas da variabilidade, como o ciclo sazonal e o El Niño. Em pontos de grade onde estes modos apreendem quase a totalidade da variância, os perfis sintéticos poderiam representar formas de variabilidade menos energéticas e com maior frequência, como ondas intrasazonais.

\subsubsection{Importância da salinidade}

Este trabalho assume que a contribuição da variabilidade da salinidade (halostérica) sobre a estrutura vertical de densidade, e consequentemente sobre a anomalia da altura da superfície livre, é secundária em relação à variabilidade da temperatura (termoestérica), e faz uso de dados climatológicos de salinidade para estimar os perfis verticais do coeficiente de expansão térmica $\alpha$ e de densidade $\rho$. Porém, os estudos de Sato et al. 2000 e Sato e Polito 2008 mostram que a componente halostérica exerce uma influência não desprezível em algumas regiões do oceano, constituindo portanto uma fonte potencial de erros para a análise desenvolvida aqui.

Sato et al. 2000 avalia a importância da salinidade sobre as estimativas da anomalia do calor armazenado realizadas através de dados de $\eta$ obtidos pelos satélites T/P e J-1. Naquele trabalho, a anomalia do calor armazenado calculada através dos dados de altímetro é comparado com o estimado através de dados in situ, provenientes de três conjuntos de dados, sendo dois de bóias fundeadas (HOT e Hydrostation S) e um de uma série trimestral de cruzeiros (CalCoFi). Todos os dados provém de latitudes médias dos oceano Pacífico e Atlântico, em três casos: sem correção halina, corrigidos pela salinidade climatológica anual e por fim pela salinidade in situ. A correção halina baseada na climatologia mostrou performance equivalente ou inferior aos dados onde nenhuma correção foi aplicada, sendo que utilização da salinidade in situ resulta em uma melhora significativa do $\eta$ estimado in situ com o medido através dos altímetros.

O trabalho posterior de Sato e Polito 2008 analisa a influência de efeitos halostéricos em tendências interanuais do calor armazenado no oceano Atlântico. Um de seus resultados mostra que a componente halostérica pode exercer uma influência não desprezível ou mesmo dominante na determinação do calor armazenado em algumas regiões do oceano, particularmente no mar de Labrador (portanto fora da área de estudo considerada aqui), e em alguns pontos isolados 
do Atlântico sul e Atlântico tropical. Foi chamada atenção para a bóia PIRATA de $15^{\circ} \mathrm{N} / 38^{\circ} \mathrm{W}$, onde foi observada uma baixa correlação entre o calor armazenado calculado através de dados in situ e o estimado através de dados altimétricos. Especulou-se que tal característica estaria ligada à variabilidade da salinidade induzida pela descarga de água doce do rio Amazonas.

Assim, este trabalho assume uma postura conservadora ao utilizar dados climatológicos de salinidade no cálculo de $\alpha$ e $\rho$, ao invés de simplesmente desconsiderar os efeitos da contração halina conforme apontam os resultados de Sato et al. 2000. Porém, buscando minimizar possíveis erros decorrentes desta aproximação, dados climatológicos mensais foram aplicados em todas as operações onde a salinidade se fez necessária. Foi feita exceção ao cálculo dos modos dinâmicos, onde a climatologia anual foi utilizada uma vez que suas formas funcionais por definição não são dependentes do tempo. A extensão e o efeito de possíveis erros decorrentes da exclusão da componente halostérica não puderam ser quantificados, mas espera-se que sua ocorrência esteja ligada à regiões oceânicas com formas de variabilidade de salinidade mais intensas e de maior frequência, particularmente próximo à foz de grandes rios e na região tropical, nesta última devido à maior intensidade da evaporação e precipitação. Efeitos halostéricos possivelmente também constituiriam uma importante fonte de erros na aplicação da metodologia proposta em mares glaciais, regiões influenciadas pelo derretimento de geleiras e de formação de água de fundo.

\subsubsection{Aproximação quase-geostrófica}

As formulações para o método dinâmico e para a decomposição da estrutura vertical de velocidade em modos dinâmicos foram derivadas a partir das equações do movimento linearizadas, assumindo um oceano quase-geostrófico continuamente estratificado. Logo, estas técnicas são capazes de descrever realisticamente os padrões de circulação somente se utilizadas em regiões oceânicas que puderem ser descritas sob estas aproximações. Aqui, a utilização de perfis sintéticos de temperatura já implicam em uma estratificação vertical da densidade. Resta portanto analisar este conjunto de dados sob a perspectiva da quase-geostrofia, que é definida por um conjunto de três aproximações (Flierl 1978; Silveira et al. 2000):

a) aproximação geostrófica: um fluxo é considerado geostrófico quando o balanço dominante na equação do movimento é entre a aceleração de Coriolis e a aceleração do gradiente 
de pressão. Para tanto, deve ser possível descrever a pressão em qualquer profundidade em termos apenas da massa de água acima de cada nível, ou seja $\partial p / \partial z=\rho g$, por aproximação hidrostática. Adicionalmente, os termos ageostróficos da equação do movimento, isto é, referentes à advecção, inércia e viscosidade, devem ser duas ordens de grandeza menores que os termos do balanço geostrófico para que possam ser desconsiderados na formulação. Se fará uso dos números adimensionais $R o, E_{v}$ e $E_{h}$, respectivamente chamados de número de Rossby e números de Ekman vertical e horizontal, que caracterizam a razão entre a força de Coriolis e as forças advectivas/inerciais $(R o)$ e friccionais $\left(E_{v, h}\right)$, e são dados por $R o=U /\left(f_{0} L\right)$, $E_{v}=A_{v} /\left(f_{0} H^{2}\right)$ e $E_{h}=A_{h} /\left(f_{0} L^{2}\right)$. Aqui, $f_{0}$ é o parâmetro de Coriolis, que varia em função do seno da latitude (dado por $2 \Omega \sin \theta$, onde $\Omega$ é velocidade angular do planeta e $\theta$ é a latitude), $U$ são as velocidades horizontais típicas, $L$ e $H$ são respectivamente as dimensões horizontal e vertical do domínio e $A_{v, h}$ representa os coeficientes de atrito dinâmico para os eixos vertical e horizontais. Para que a aproximação geostrófica seja válida, $R o, E_{v}$ e $E_{h}$ devem possuir ordens de grandeza inferiores à $10^{-2}$;

b) aproximação do plano $\beta$ de latitudes médias: o plano $\beta$ consiste em uma representação localmente plana da superfície curva do planeta, onde o parâmetro de Coriolis varia linearmente ao longo da dimensão meridional a partir de uma latitude central. O número adimensional $\hat{\beta}$, chamado de número planetário, relaciona a variação máxima do parâmetro de Coriolis ao longo do eixo meridional do domínio com o seu valor $f_{0}$ na sua latitude central do plano. Matematicamente, $\hat{\beta}=\beta L /\left|f_{0}\right|$, onde $\beta=\partial f / \partial y$ e $L$ é dimensão meridional do domínio. A aproximação do plano $\beta$ é considerada válida quando o número planetário assume valores com ordens de grandeza inferiores à $10^{-2}$. Esta condição faz com que o movimento geostrófico seja aproximadamente não-divergente;

c) aproximação das espessuras: a razão de aspecto $\delta$ entre a dimensão vertical $H$ e as horizontais $L(\delta=H / L)$ deve ter ordem de grandeza inferior à $10^{-2}$. No caso barotrópico, $H$ é a profundidade local e no baroclínico é a profundidade da base da picnoclina. Esta aproximação impõe que o oceano deve assemelhar-se à uma lâmina fina de fluido, implicando em velocidades verticais de duas a três ordens de grandeza menores que as horizontais e conduzindo à aproximação hidrostática requerida para a aproximação geostrófica.

Aqui, o método dinâmico e a decomposição modal foram aplicados a perfis de densidade 


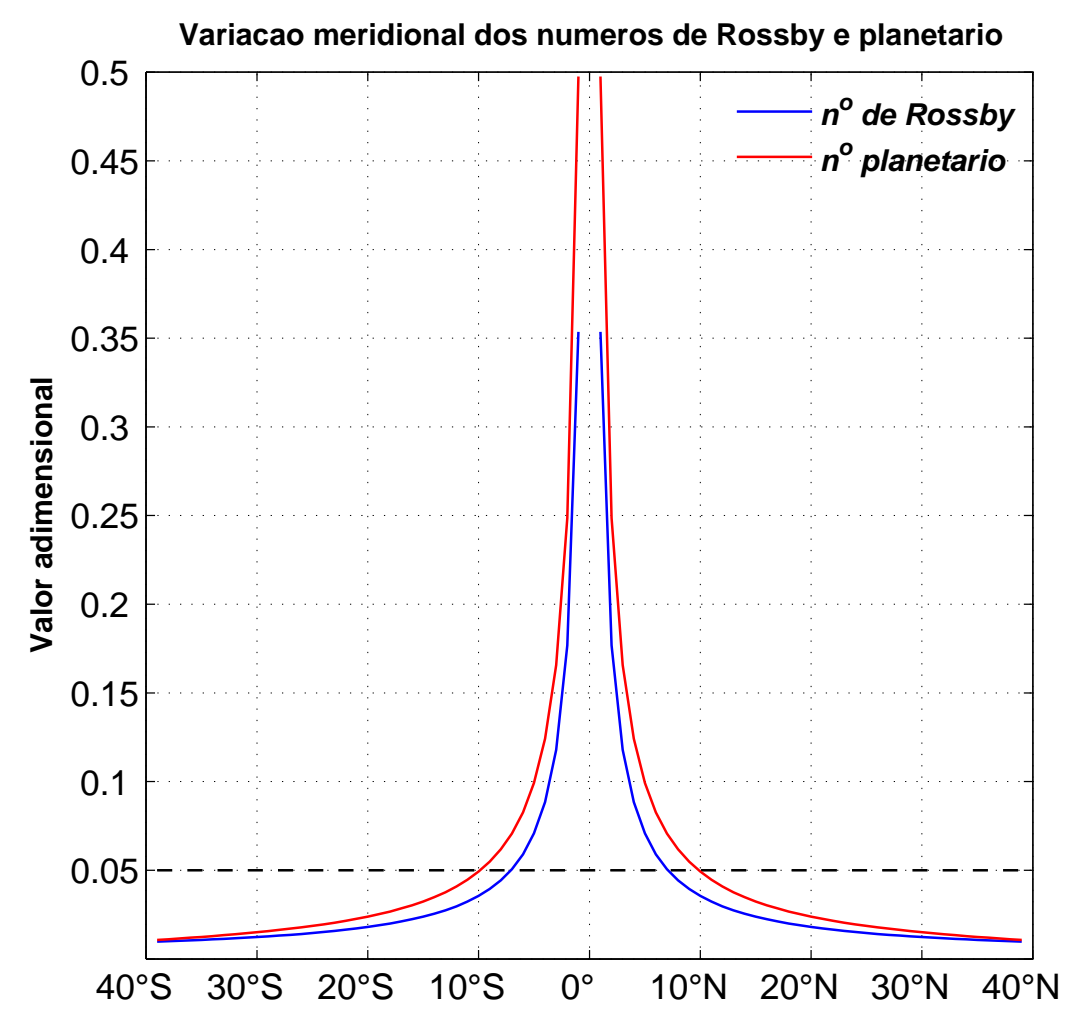

Figura 8: Comportamento meridional dos números de Rossby Ro (linha azul) e planetário $\hat{\beta}$ (linha vermelha) entre $39^{\circ} \mathrm{S}$ e $39^{\circ} \mathrm{N}$, considerando o cenário com perfis de densidade organizados sobre uma grade espacial com resolução de $1^{\circ} \times 1^{\circ}$. A linha tracejada marca o valor máximo com ordem de grandeza ideal $\left(10^{-2}\right)$ para a aplicação da aproximação quase-geostrófica; ajustados sobre uma grade com resolução horizontal de $1^{\circ} \times 1^{\circ}$. Para avaliar a representabilidade da aproximação quase-geostrófica neste cenário, a ordem de grandeza dos números $R o$, $E_{v}, E_{h}, \hat{\beta}$ e $\delta$ foi estimada com base em escalas de $U, H, A_{v}$ e $A_{h}$ típicas de meso-escala, respectivamente $10^{-1} \mathrm{~m} . \mathrm{s}^{-1}, 10^{3} \mathrm{~m}, 10^{-1} \mathrm{~m}^{2} . \mathrm{s}^{-1}$ e $10 \mathrm{~m}^{2} . \mathrm{s}^{-1}$. Para $L$, foi considerada a distância entre pontos de grade consecutivos ao longo do eixo meridional, igual a $111.120 \mathrm{~m}$. Especificamente no cálculo de $\hat{\beta}$, os planos $\beta$ assumidos vão meridionalmente de um ponto de grade a outro, fazendo com que as bordas do plano encontrem-se a $0,5^{\circ}$ de distância da latitude central, e neste caso $L$ tem portanto dimensão igual a $55.560 \mathrm{~m}$. Os valores de $f_{0}$ utilizados referem-se à latitude central de cada plano $\beta$.

$\delta$ e $E_{h}$ possuem ordens de grandeza iguais ou inferiores a $10^{-2}$ ao longo de toda a região considerada. Como mostra a Figura 8 , Ro e $\hat{\beta}$ possuem ordem $10^{-2}$ dos limites exteriores da área de estudo até aproximadamente $10^{\circ}$ de latitudes em ambos os hemisférios, subindo em 
uma ordem de grandeza deste ponto até o equador. $E_{v}$ é insignificante considerando a coluna de água como um todo $\left(\mathrm{O}\left[\leq 10^{-4}\right]\right)$, porém assume ordens de grandeza significativas junto aos contornos superior e inferior devido à tensão do cisalhamento do vento na superfície e ao atrito com o fundo. As faixas de profundidades onde $E_{v}$ tem $\mathrm{O}(1)$ são chamadas de camadas limite ou de Ekman $\left(H_{e}\right)$, e podem ser estimadas através da relação $H_{e}=\sqrt{A_{v} /\left|f_{0}\right|}$. Devido à relação inversa com $f_{0}, H_{e}$ tende a aumentar em direção ao equador, apresentando espessuras da ordem de $10^{1} \mathrm{~m}$ entre $39^{\circ}$ e $15^{\circ}$ e de $10^{2} \mathrm{~m}$ entre $14^{\circ}$ e $1^{\circ}$, considerando um $A_{v}$ de $10^{-1} \mathrm{~m}^{2} \cdot \mathrm{s}^{-1}$.

Isto significa que termos referentes à inércia e à advecção crescem em ordem de grandeza em relação à aceleração de Coriolis em latitudes inferiores à aproximadamente $10^{\circ}$, e que o transporte de momento induzido pela tensão de cisalhamento do vento ou transporte de Ekman pode responder por uma parcela significativa da circulação superficial. De fato, medições diretas na região tropical mostram que o transporte de Ekman meridional alcança a casa das dezenas de Sverdrups nos três oceanos $\left(1 \mathrm{~Sv}=10^{6} \mathrm{~m}^{3} \cdot \mathrm{s}^{-1}\right)$, exercendo portanto um importante papel no balanço de massa superficial e sendo possivelmente dominante no fluxo meridional de calor em baixas latitudes (Chereskin e Roemmich 1991; Wijffels et al. 1994; Chereskin e Roemmich 1997).

Em outras palavras, é importante ter-se em mente que a análise realizada aqui advém da teoria quase-geostrófica e que portanto refere-se apenas à componente geostrófica da circulação, uma vez que parte significativa da variabilidade pode potencialmente estar contida em suas componentes ageostróficas. Isto é particularmente verdadeiro em latitudes inferiores à $10^{\circ}$, como mostra a análise dos números adimensionais. Nas imediações do equador o parâmetro de Coriolis tende a zero, fazendo o método dinâmico e a decomposição modal falharem. Operações preliminares mostram que resultados obviamente espúrios para raios de deformação e modos dinâmicos são obtidos em latitudes inferiores à $3^{\circ}$, decorrentes do rápido decréscimo de $f$. Esta faixa de latitudes ao redor do equador foi portanto desconsiderada nas análises subsequentes. 


\section{Resultados e Discussão}

\subsection{Perfis sintéticos}

A Figura 9 mostra seções zonais-temporais de temperatura sintética no oceano Índico referentes à latitude de $25,5^{\circ} \mathrm{S}$ calculadas para o período de janeiro a julho de 2008 , onde as isotermas de $13,15,18$ e $20^{\circ} \mathrm{C}$ são destacadas. Os painéis são mostrados de $20 \mathrm{em} 20$ dias, e constituem um exemplo emblemático das características presentes em toda a área de estudo. Os perfis obtidos são fisicamente consistentes, apresentando profundidades razoáveis para a termoclina e, desconsiderada a salinidade, implicam em colunas de água dinamicamente estáveis. É observada ainda a presença de padrões contínuos no espaço e no tempo apesar de o cálculo ser realizado independentemente em cada ponto de grade e em cada instante $t$. O ciclo sazonal é evidente, particularmente na metade leste da bacia, se manifestando tanto na variação da temperatura da camada superior como na profundidade média das isotermas de 18 e $20^{\circ} \mathrm{C}$. Sinais propagantes para oeste são também prontamente observados na forma de oscilações verticais das isotermas, característica presente na maioria das seções oceânicas calculadas. Isto mostra que os perfis sintéticos obtidos são capazes de representar formas de variabilidade interna da temperatura dos oceanos em uma ampla faixa espectral, um pré-requisito ao desenvolvimento da análise proposta aqui.

A Figura 10 contém mapas do erro médio quadrático normalizado $(\varepsilon)$ calculados entre perfis mensais climatológicos de temperatura e perfis in situ ( $\varepsilon_{c i}$, mapa superior) e entre perfis sintéticos e in situ ( $\varepsilon_{s i}$, mapa inferior). Os mapas são muito semelhantes entre si, mostrando que os perfis sintéticos em média são mais próximos à climatologia mensal do que aos perfis in situ. Chama-se a atenção para o fato de que dados climatológicos mensais são utilizados no cálculo dos perfis sintéticos simplesmente para estimar o perfil vertical do coeficiente de expansão térmica $\alpha(z)$, o que não é considerado um condicionante significativo para a semelhança dos dados sintéticos aos dados mensais do WOA05. Isto é antes interpretado como evidência de que os perfis sintéticos são mais eficazes na reconstrução dos fenômenos oceânicos predominantes no espectro de energia, característica atribuída à perda de resolução espectral decorrente do uso de apenas dois modos estatísticos na reconstrução da estrutura vertical de temperatura e da própria natureza indireta do método. 


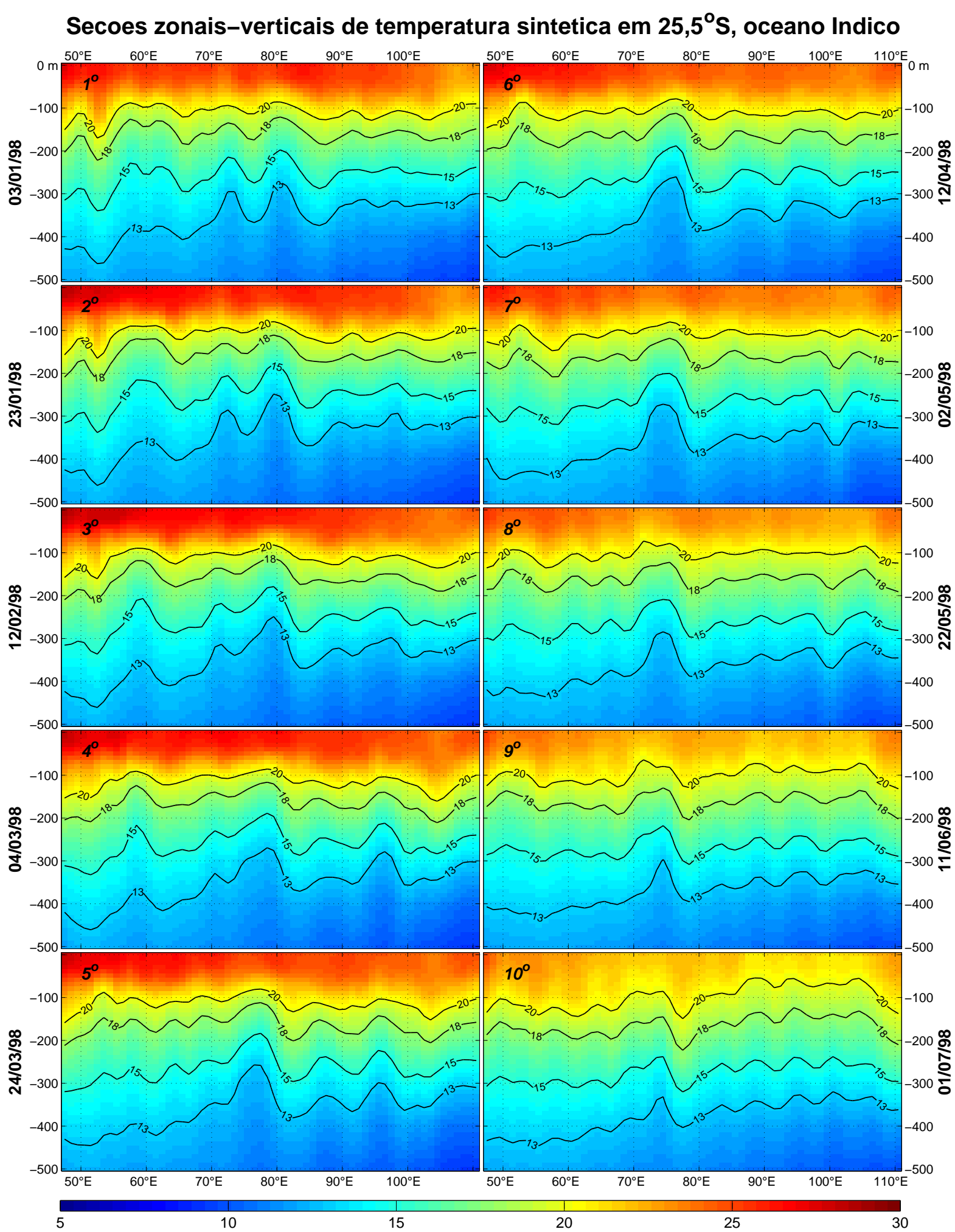

Figura 9: Seções zonais-verticais de temperatura sintética no oceano Índico, centradas em $25,5^{\circ} \mathrm{S}$ e abrangendo o período de 03/01 a 01/07/2008, com uma seção à cada 20 dias. Os painéis são numerados do primeiro ao décimo para facilitar a identificação de sua ordem no tempo. As isotermas de 13,15, 18 e $20^{\circ} \mathrm{C}$ são destacadas, evidenciando que os perfis sintéticos calculados são espacialmente consistentes e incluem formas de variabilidade subsuperficial em uma ampla faixa espectral. 

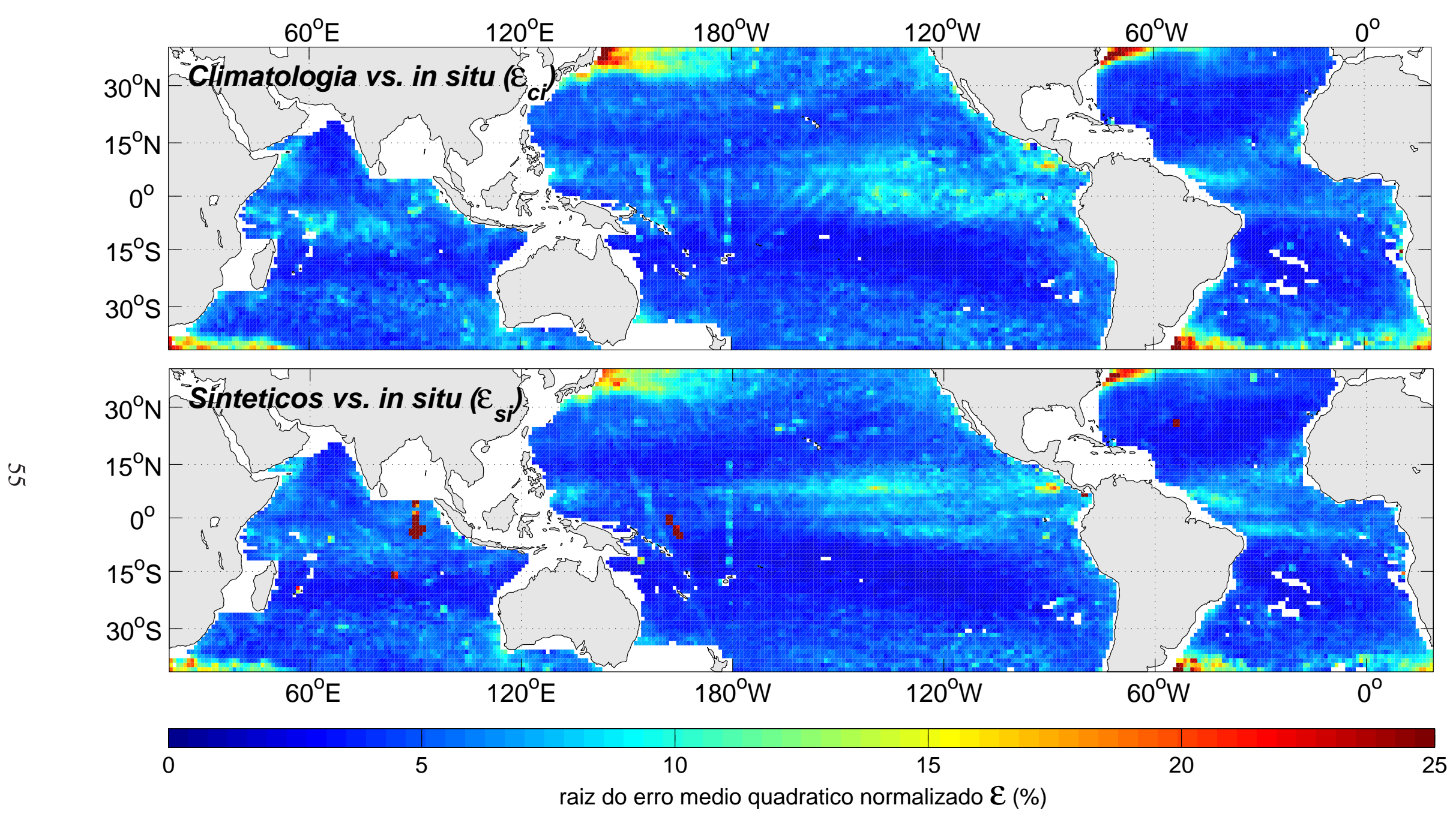

Figura 10: Mapas do erro médio quadrático normalizado $(\varepsilon)$ calculados entre perfis mensais climatológicos de temperatura e perfis in situ $\left(\varepsilon_{c i}\right.$, painel superior), e entre perfis sintéticos e in situ $\left(\varepsilon_{s i}\right.$, painel inferior). 
Os menores erros observados $(\varepsilon<5 \%)$ são observados aproximadamente entre as latitudes de $10^{\circ}$ e $30^{\circ}$ em ambos os hemisférios dos três oceanos, estando portanto associados ao interior dos giros subtropicais e aos limites exteriores do sistema de correntes e contra-correntes zonais da circulação tropical. Nestas regiões, a variabilidade de larga escala do oceano superior é dominada por componentes de baixa frequência, como ondas de Rossby planetárias longas e o próprio ciclo sazonal (Polito e Liu 2003), explicando a semelhança de perfis in situ e sintéticos à climatologia mensal. Em latitudes inferiores à cerca de $10^{\circ}$ os valores de $\varepsilon$ elevam-se para entre 10 e $15 \%$ nos três oceanos, feição que é particularmente evidente no Pacífico equatorial de aproximadamente $170^{\circ} \mathrm{W}$ até a costa oeste americana. Estes padrões são provavelmente decorrentes da maior representatividade de fenômenos transientes no espectro de energia que logicamente não são contemplados pela climatologia mensal, como ondas de Rossby intrasazonais, ondas de Kelvin e de instabilidade tropical, a passagem de vórtices de mesoescala e o meandramento das correntes zonais que compõe a circulação tropical (Polito e Liu 2003). No Pacífico equatorial, os valores de $\varepsilon$ são possivelmente amplificados pelos fenômenos altamente energéticos do El Niño e La Niña também por estes implicarem em perfis de temperatura significativamente diferentes dos climatológicos.

Os maiores valores $(\varepsilon>15 \%)$ são observados em posições compatíveis com as de sistemas dinâmicos associados à frentes oceânicas, a saber: confluência das correntes Kuroshio-Oyashio, região onde a corrente do Golfo se afasta da costa, confluência Brasil-Malvinas, corrente das Agulhas e a porção oeste da corrente sul do oceano Índico (Tomczak e Godfrey 2005). A presença de gradientes laterais intensos em uma escala inferior às dimensões da janela de procura de perfis in situ ao redor de cada ponto de grade, associada a variações da posição destas frentes induzidas pela ação de fenômenos como ondas planetárias, meandros, vórtices e o próprio ciclo sazonal, pode fazer com que perfis in situ de temperatura significativamente diferentes da climatologia local e dos perfis sintéticos sejam selecionados. Estas características em conjunto podem induzir erros no cálculo dos perfis sintéticos e explicar o aumento dos valores de $\varepsilon$ observados na comparação dos perfis calculados/climatológicos à perfis in situ regionais. Estas também são as possível causas para os valores de $\varepsilon$ de cerca de $10 \%$ observados próximos aos limites norte e sul do oceano Pacífico e à sudoeste da Austrália, no oceano Índico. Adicionalmente, a climatologia suaviza os gradientes laterais de densidade associados à correntes oceânicas intensas, o que pode também ser um condicionante aos erros observados nestas regiões. 


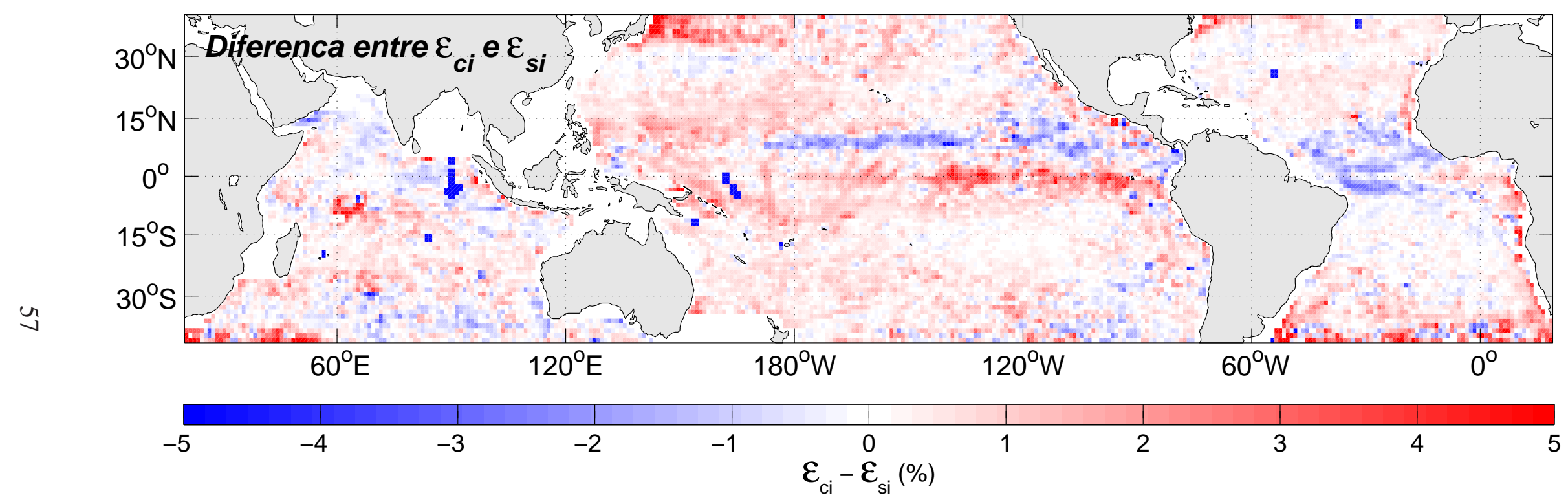

Figura 11: Diferença entre $\varepsilon_{c i}$ e $\varepsilon_{s i}$. Valores positivos marcam pontos de grade onde os perfis in situ em média assemelham-se mais aos perfis sintéticos do que à climatologia mensal. 
A Figura 11 mostra a diferença entre os mapas apresentados na Figura 10, $\varepsilon_{c i}-\varepsilon_{s i}$. Como a única forma de variabilidade presente na climatologia mensal do WOA05 é um ciclo sazonal médio, espera-se que os perfis in situ em média assemelhem-se mais aos dados sintéticos do que à climatologia mensal. $\mathrm{O}$ método de construção de perfis sintéticos é considerado efetivo portanto em regiões onde a diferença $\varepsilon_{c i}-\varepsilon_{s i}$ resulta em valores positivos, o que ocorre em cerca de $70 \%$ dos pontos de grade considerados. Com exceção do oceano Índico, as menores diferenças são observadas entre as latitudes $10^{\circ}$ e $35^{\circ}$ de ambos os hemisférios, como mencionado anteriormente, devido à predominância do ciclo sazonal sobre o espectro energético nestas regiões. As maiores diferenças positivas estão associadas à sistemas ligados à frentes oceânicas e ao Pacífico equatorial. Frações significativas da variabilidade nestas áreas estão contidas em fenômenos transientes, o que portanto reforça a conclusão de que os perfis sintéticos são capazes de recuperar formas da variabilidade interna em uma ampla banda espectral. Por fim, em diversas regiões do mapa é possível ver feições retilíneas com valores positivos coincidentes com linhas com alta densidade de perfis de XBT's lançados por navios de oportunidade (vide Figura 5), mostrando que a acuidade dos perfis sintéticos é também função do número de perfis in situ disponível para o seu cálculo.

Feições onde os dados in situ são proeminentemente mais semelhantes à climatologia do que aos perfis sintéticos são observadas no Atlântico tropical entre aproximadamente as latitudes $5^{\circ} \mathrm{S}$ e $14^{\circ} \mathrm{N}$ e no Pacífico entre $5^{\circ} \mathrm{N}$ e $10^{\circ} \mathrm{N}$. Os padrões contínuos e extensos sugerem a existência de uma condicionante geofísica para a queda de performance do método de construção de perfis sintéticos, mas a sua natureza não foi identificada. Porém, estes padrões são observados aproximadamente em regiões dominadas pela migração sazonal da zona de convergência intertropical (ZCIT), ao longo da qual a precipitação é intensa ao longo de todo o ano. Especula-se portanto que talvez estas falhas estejam ligadas à efeitos halostéricos intensos nas primeiras centenas de metros da coluna de água, onde encontra-se a maior fração do calor armazenado, o que introduziria erros significativos na estimativa do perfil vertical do coeficiente de expansão térmica da coluna de água. Como o método de construção de perfis sintéticos adaptado elimina perfis considerados espúrios, as série temporais de perfis sintéticos resultantes podem não ser capazes de representar apropriadamente componentes importantes da variabilidade, como a própria variação vertical do ciclo sazonal. Esta também pode a causa dos erros observados a sudoeste do continente Asiático, entre aproximadamente $10^{\circ} \mathrm{S}$ e $20^{\circ} \mathrm{N}$, 
também sob a infuência da migração sazonal da ZCIT. Esta hipótese porém não é baseada em nenhuma evidência observacional, e deve ser testada para aprimoramentos futuros da metodologia proposta aqui. Por fim, especula-se que a maioria das diferenças negativas observadas ao sul da latitude de $10^{\circ} \mathrm{S}$ nos três oceanos sejam decorrentes simplesmente da baixa densidade de perfis in situ.

\subsection{Raios de deformação}

\subsubsection{Padrões médios}

A chamada aproximação de WKB é uma técnica desenvolvida para encontrar soluções aproximadas de equações diferenciais parciais lineares com coeficientes variáveis. Chelton et al. 1998 aplicarm este método sobre um problema conceitualmente idêntico ao apresentado na Equação (20), procurando estimar uma solução aproximada $\left(R_{i}^{\mathrm{WKB}}\right)$ para o $i$-ésimo raio de deformação interno $\left(R_{i}\right)$. A equação utilizada possui a seguinte forma:

$$
R_{i} \approx R_{i}^{\mathrm{WKB}}=\frac{1}{|f| \pi i} \int_{-H}^{0} N(z) d z
$$

onde os termos da equação são definidos como na seção 3.5. Em Chelton et al. 1998, os valores do primeiro raio de deformação baroclínico obtidos pelo método WKB eram em média 6,5\% maiores do que os calculados pela iteração numérica. Esta acurácia é insuficiente para, por exemplo, estimar a velocidade de fase de ondas planetárias ou avaliar a variabilidade temporal dos raios de deformação. Porém, esta formulação é muito útil na interpretação física dos valores de $R_{i}$ calculados numericamente, mostrando que a distribuição geográfica deste parâmetro possui as seguintes características (Chelton et al. 1998):

a) os raios internos tendem a crescer em direção ao equador, dominados por uma dependência inversa com $|f|$;

b) para uma mesma latitude e estratificação vertical, os raios de deformação de sucessivas ordens sucessivamente mais altas decrescem na razão inversa de sua ordem $i$;

c) para uma mesma latitude, $R_{i}$ é diretamente proporcional à integral vertical de $N(z)$. Como em geral as feições topográficas nos oceanos não se elevam até níveis picnoclínicos, a influência da topografia geralmente é restrita à porções da coluna de água onde $N(z)$ é baixo e aproxi- 
madamente constante, resultando em uma dependência aproximadamente linear de $R_{i}$ com a profundidade $H$.

Mapas dos primeiros três raios de deformação baroclínicos são apresentados nas Figuras 12 à 14. A forte dependência inversa com $f$ inferida através da Equação (26) é claramente visível no aumento dos raios calculados em direção ao equador e na orientação predominantemente zonal dos contornos. O painel esquerdo da Figura 15 apresenta o gráfico da tendência meridional das médias zonais dos 5 primeiros raios de deformação baroclínicos, colocando em evidência a intensa dependência latitudinal dos raios de deformação, a simetria dos valores entre os hemisférios e a razão inversa de suas magnitude com o número do modo $i$. Com exceção de latitudes inferiores à $5^{\circ}$, os valores médios do segundo raio interno equivalem a aproximadamente metade dos observados para o primeiro interno, os do terceiro equivalem à um terço do primeiro interno, e assim por diante. Os valores calculados para o primeiro raio baroclínico atingem um máximo de aproximadamente $350 \mathrm{~km}$ aos $3^{\circ}$ de latitude, decrescendo rapidamente a $200 \mathrm{~km} \mathrm{em} 5^{\circ}$, a $100 \mathrm{~km}$ aos $10^{\circ}$ e por fim apresentando valores mínimos de aproximadamente $30 \mathrm{~km}$ em $39^{\circ}$. O segundo e terceiro raios internos atingem os valores máximos de aproximadamente 210 e $135 \mathrm{~km}$ na região equatorial, apresentando em maiores latitudes cerca da metade e um terço dos valores observados para o primeiro raio interno, respectivamente.

São observadas deflexões dos contornos ao cruzar feições topográficas submersas, que são destacadas nos mapas através dos contornos da isóbata de $3500 \mathrm{~m}$. Como inferido pela solução de $R_{i}$ por WKB, estas feições são provocadas pela redução do $N(z)$ integrado ao longo da coluna de água. O efeito topográfico é amortecido em latitudes próximas ao equador em decorrência do aumento da importância dos efeitos da rotação em virtude do rápido incremento do efeito $\beta$ em direção ao equador.

Os efeitos da estratificação vertical de densidade dos oceanos podem ser observados através da deflexão em direção aos pólos dos contornos em regiões onde a termoclina permanente é mais profunda e logo a estratificação vertical é mais forte, por exemplo junto à porção oeste dos giros subtropicais dos oceanos Atlântico e Pacífico. Porém, os padrões observados são sutilmente diferentes nos mapas de cada ordem baroclínica. Para exemplificar, a deflexão dos contornos em direção ao norte no noroeste do Pacífico observada no mapa do primeiro raio interno não possui paralelo nos demais mapas. No mapa do segundo raio, as deflexões associadas 


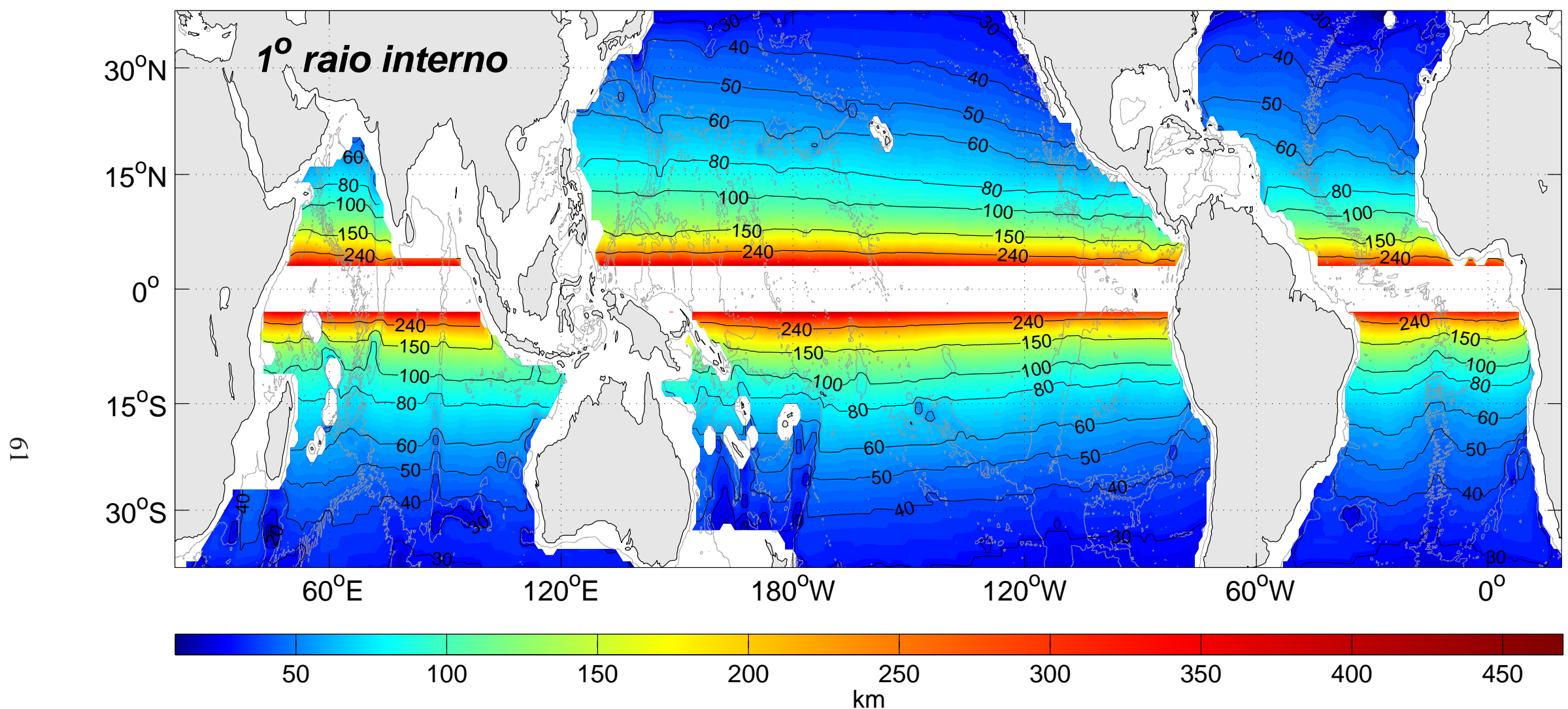

Figura 12: Mapa médio do primeiro raio de deformação interno calculado a partir de perfis sintéticos de temperatura e perfis climatológicos mensais de salinidade. A isóbata de $3500 \mathrm{~m}$ é destacada aqui na forma de contornos cinzas. Note que a escala de cores segue uma progressão logarítmica. 


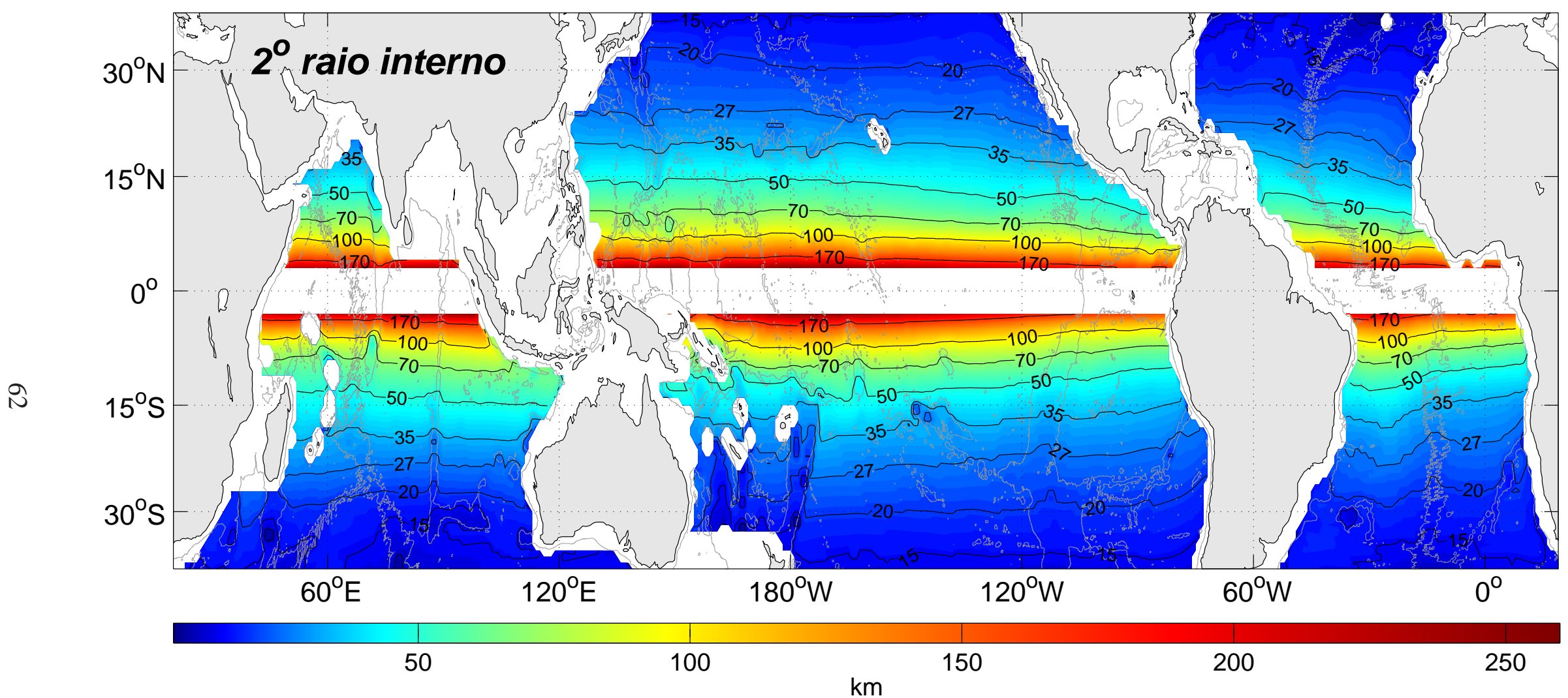

Figura 13: Similar à Figura 12, mas considerando o segundo raio de deformação interno. 


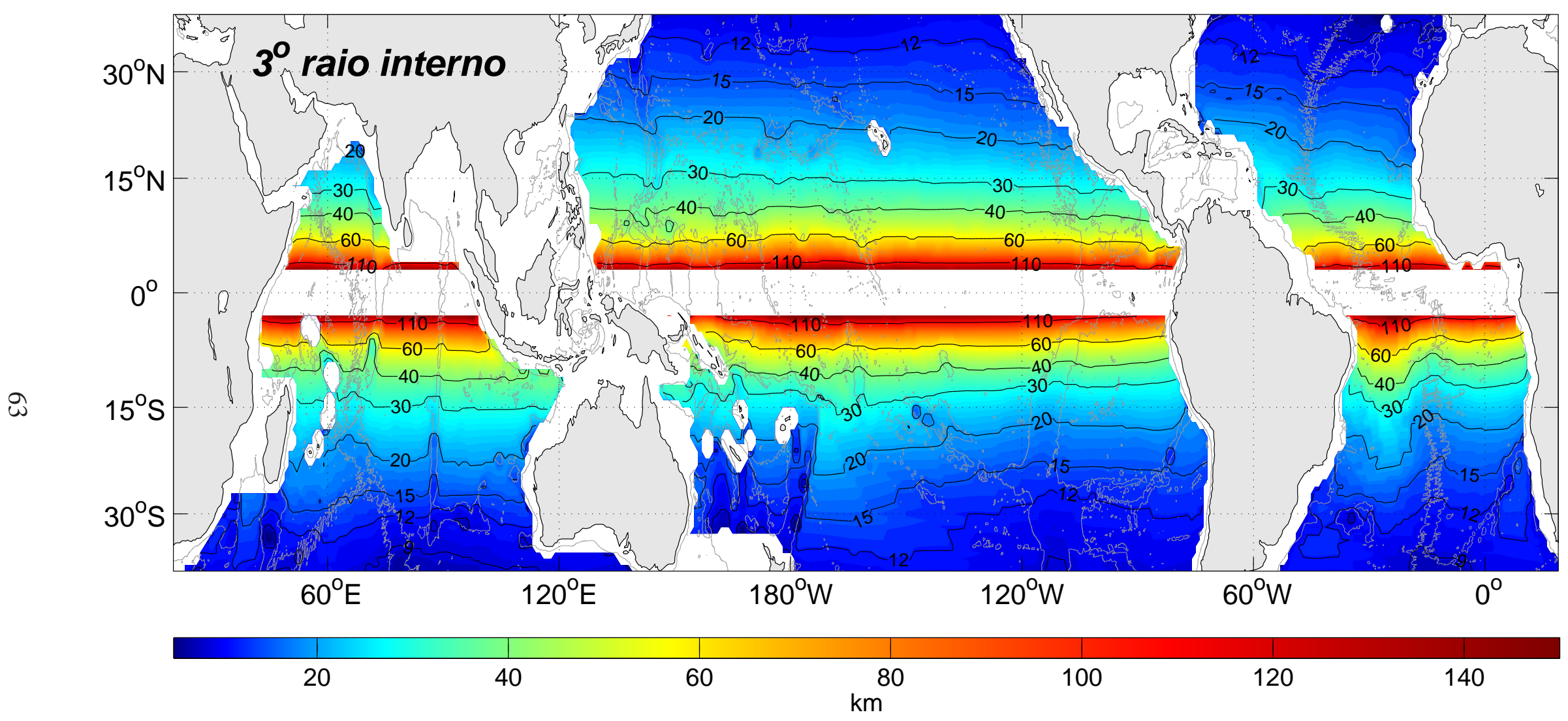

Figura 14: Similar à Figura 12, mas considerando o terceiro raio de deformação interno. 


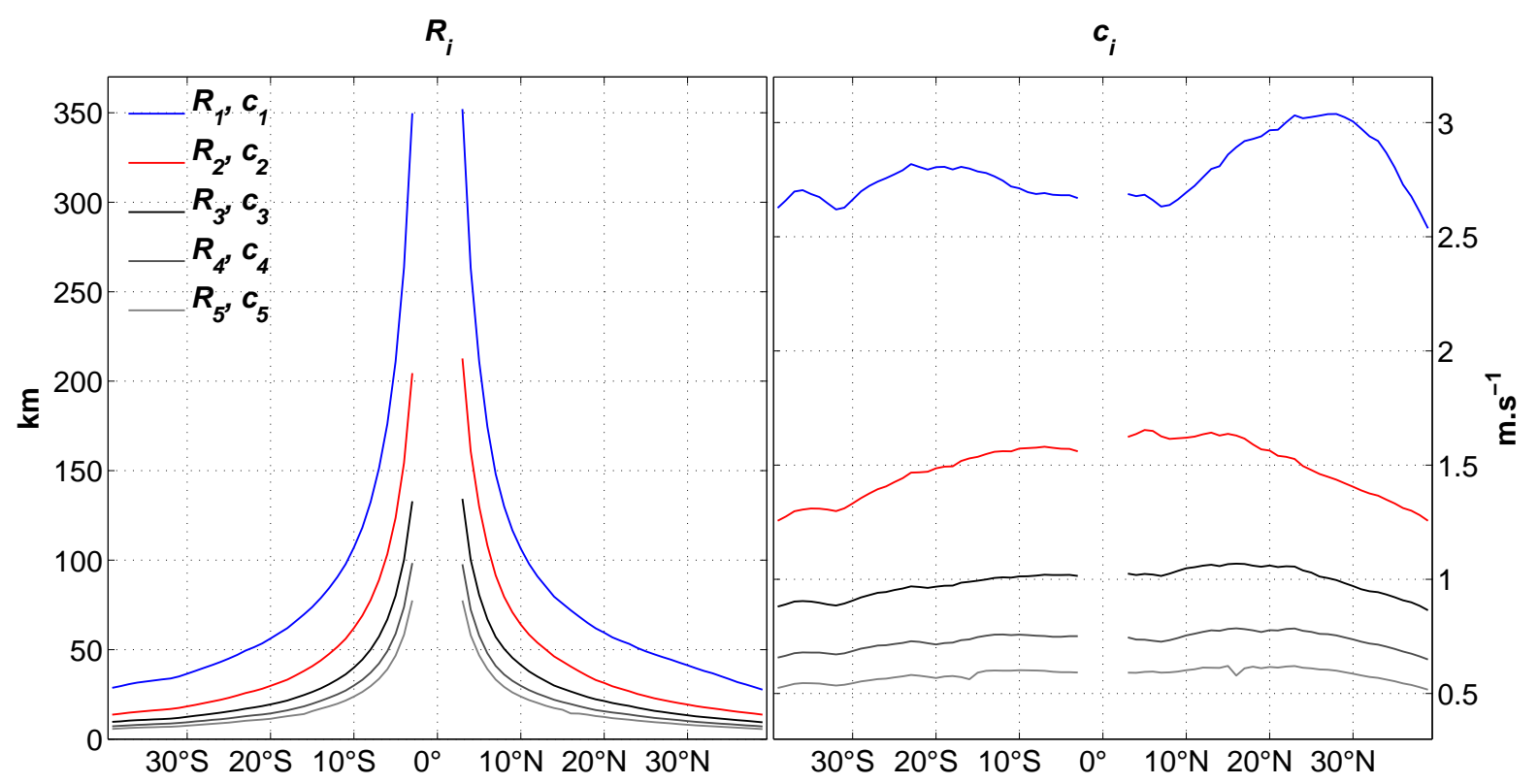

Figura 15: Média zonal dos cinco primeiros raios de deformação internos $R_{i}$ (esquerda) $e$ das respectivas velocidades de fase de ondas de gravidade internas $c_{i}$ associadas à cada raio (direita).

à batimetria aparentemente são mais suaves do que as observadas nos demais raios internos. Por fim, os dados referentes ao terceiro raio interno mostram um forte deflexão dos contornos junto à borda oeste do Atlântico sul, ausente nos modos de menor ordem. Buscando avaliar os efeitos da estratificação e da topografia independentemente da influência de Coriolis, foram construídos mapas da velocidade de fase de ondas de gravidade internas dos três primeiros modos baroclínicos, apresentados nas Figuras 16 à 18 .

A influência da topografia de fundo é evidente nos mapas de $c_{i}$. Os contornos de velocidades de fase tendem a ser paralelos aos contornos batimétricos, claramente delineando feições como cordilheiras oceânicas, fossas e cadeias de montes submarinos. Como características gerais, maiores velocidades ocorrem na porção oeste dos oceanos Atlântico e Pacífico, e menores junto à suas bordas oeste e próximo aos limites meridionais da área do globo abrangida por este estudo. Esta característica é prevista pela Equação (26), que aponta para maiores valores de $c_{i}$, onde a integral vertical de $N(z)$ é maior em decorrência de uma picnoclina mais extensa, relação que é menos evidente no oceano Índico devido à combinação da estratificação vertical com a complexa topografia de fundo desta bacia. Porém, como mencionado para os mapas de $R_{i}$, os padrões observados nos mapas de $c_{i}$ são essencialmente diferentes entre os modos baroclínicos. 


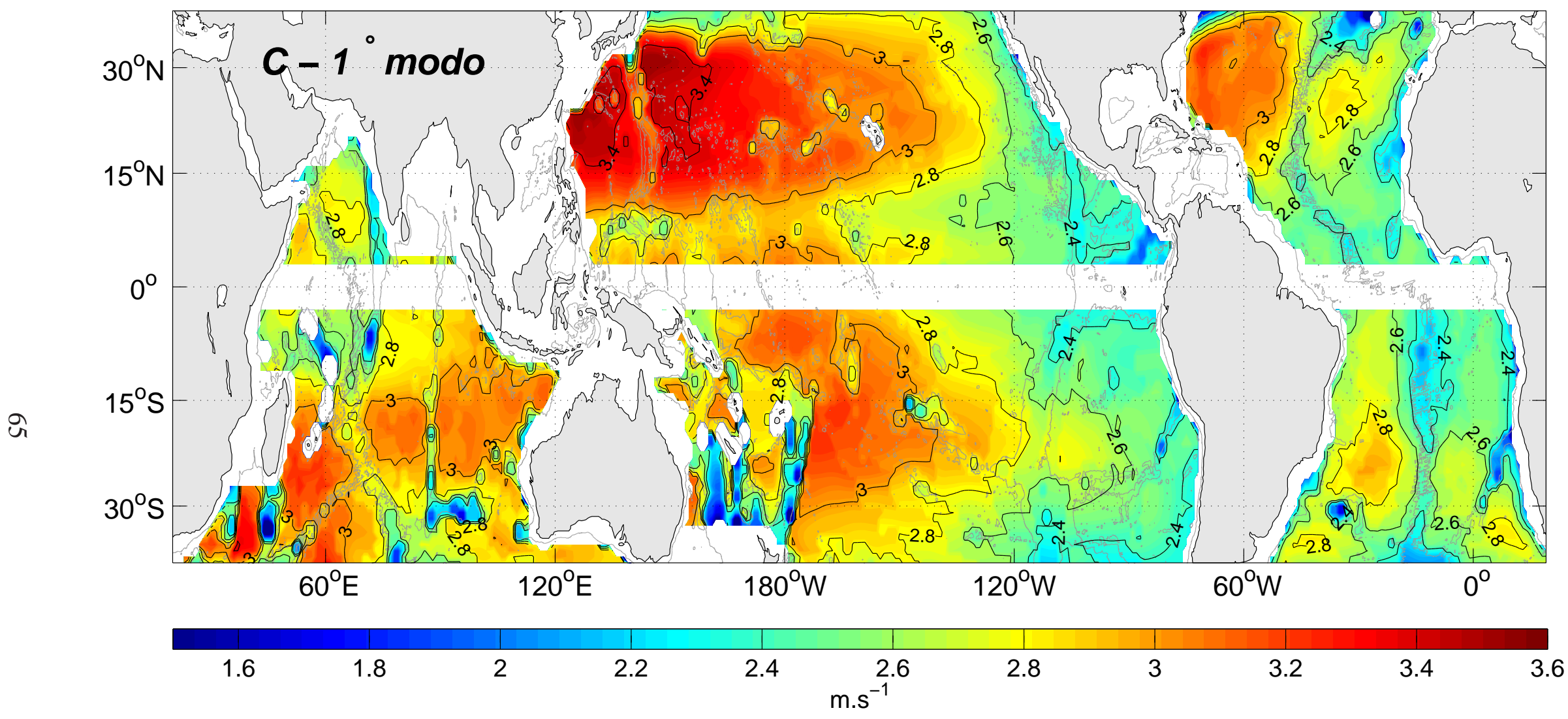

Figura 16: Mapa da velocidade de fase de ondas de gravidade internas do primeiro modo baroclínico. A isóbata de 3500 m é destacada aqui na forma de contornos cinzas. 


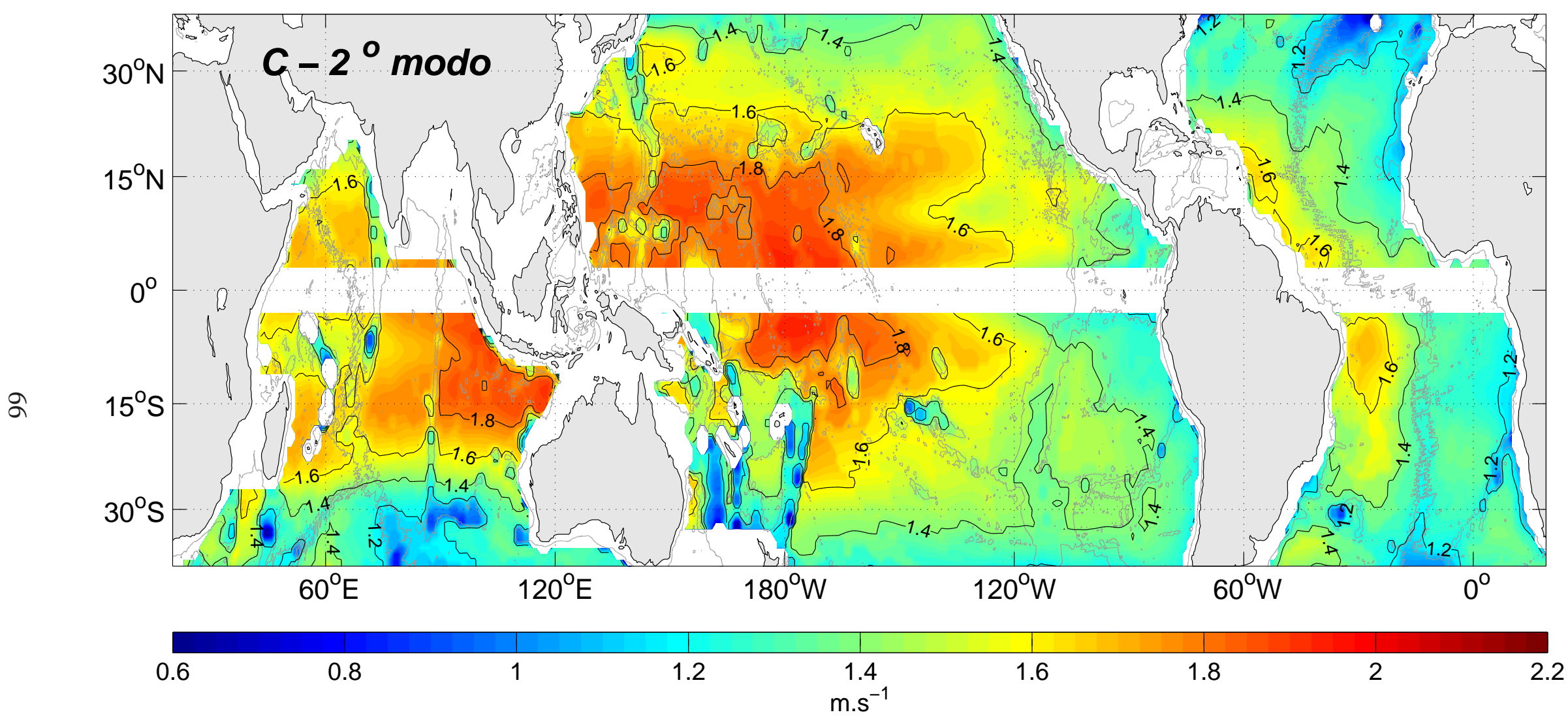

Figura 17: Similar à Figura 16, mas considerando ondas de gravidade internas do segundo modo baroclínico. 


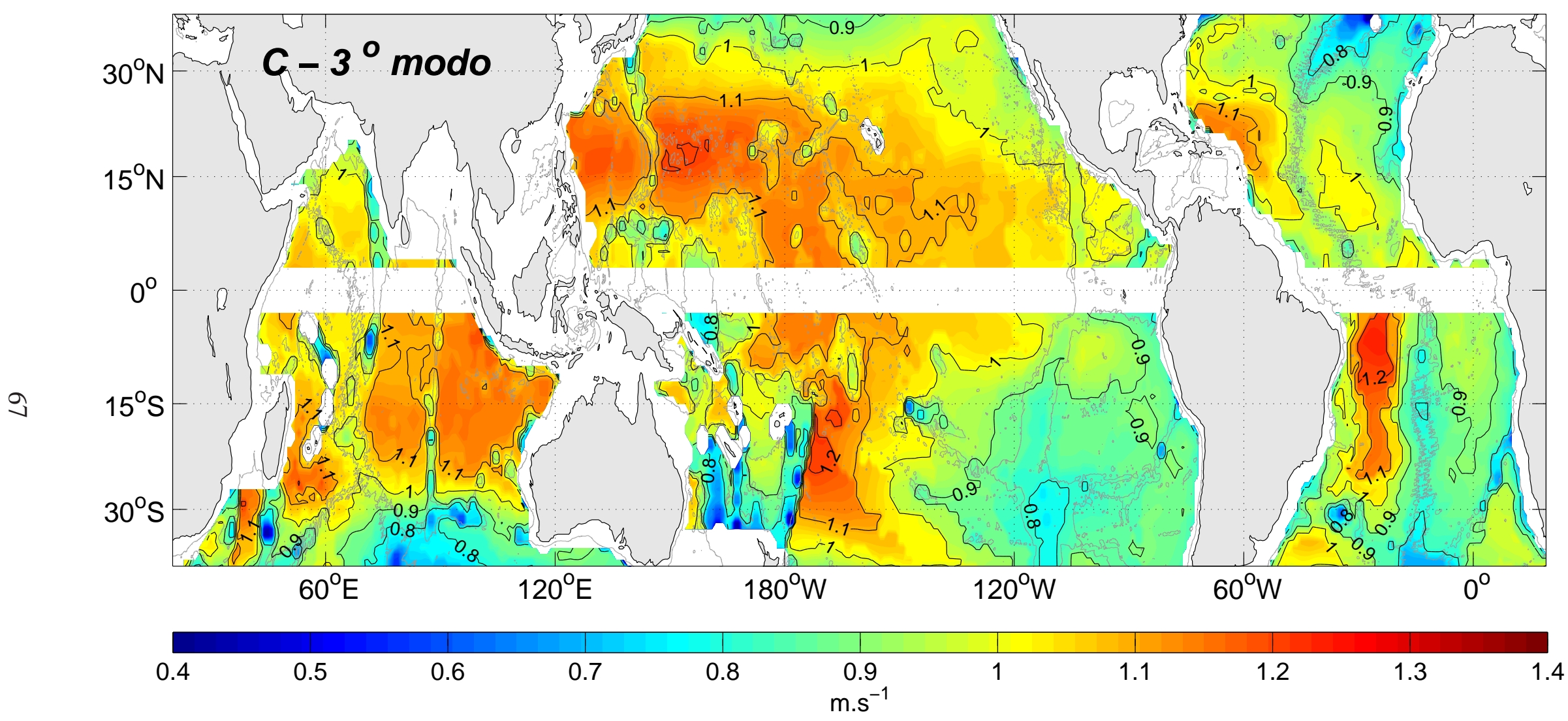

Figura 18: Similar à Figura 16, mas considerando ondas de gravidade internas do terceiro modo baroclínico. 
O painel direito da Figura 15 mostra a média zonal das velocidades de fase para cada um dos modos, evidenciando que a distribuição meridional das velocidades varia significativamente entre eles, particularmente entre o primeiro e os demais. Isto sugere que não existe uma relação linear entre $i$ e a integral vertical de $N(z)$, como sugere a Equação (26).

Especificamente, $c_{1}$ possui uma média global de cerca de $2,8 \mathrm{~m} \cdot \mathrm{s}^{-1}$, mostrando maiores médias zonais aproximadamente entre as latitudes de 10 e $30^{\circ}$ de ambos os hemisférios. Em latitudes correspondentes ao centro dos giros subtropicais no oceano Pacífico, os valores variam zonalmente de $2,4 \mathrm{~m} \cdot \mathrm{s}^{-1}$ na borda leste até cerca de 3,0 a $3,4 \mathrm{~m} \cdot \mathrm{s}^{-1}$ junto ao contorno oeste, respectivamente para os hemisférios norte e sul. Uma assimetria semelhante é observada no Atlântico, porém os contornos neste oceano são marcados pela visível influência da cordilheira Meso-Atlântica. No Índico, velocidades da ordem de 3,0 m.s ${ }^{-1}$ são observadas à sudeste do continente africano e entre as latitudes de $10^{\circ} \mathrm{S}$ e $25^{\circ} \mathrm{S}$, com valores de $2,8 \mathrm{~m} . \mathrm{s}^{-1}$ predominando no restante das zonas mais profundas que $3500 \mathrm{~m}$ da bacia. As velocidades decaem significativamente sobre as diversas feições batimétricas desta bacia.

A média zonal de $c_{2}$ (Figura 15, direita) destaca a tendência de crescimento das velocidades em direção ao equador, um padrão claramente distinto do observado para $c_{1}$. A média global de velocidade para o segundo modo baroclínico é de $1,48 \mathrm{~m} . \mathrm{s}^{-1}$, onde as velocidades crescem meridionalmente de aproximadamente $1,30 \mathrm{~m} \cdot \mathrm{s}^{-1} \mathrm{em} 39^{\circ}$ até $1,9 \mathrm{~m} \cdot \mathrm{s}^{-1} \mathrm{em} 3^{\circ} \mathrm{em}$ ambos os hemisférios. O mapa de $c_{2}$ (Figura 17) evidencia ainda uma clara assimetria leste-oeste da velocidade nos três oceanos. Em latitudes inferiores à $15^{\circ}$, os valores tendem a crescer a partir de $1,40 \mathrm{~m} . \mathrm{s}^{-1}$ junto à borda leste até cerca de $1,70 \mathrm{e} 1,90 \mathrm{~m} \cdot \mathrm{s}^{-1}$ na borda oeste, respectivamente para os oceanos Atlântico e Pacífico. No Índico, os maiores valores $\left(\sim 1,8 \mathrm{~m} . \mathrm{s}^{-1}\right)$ são observados a sudoeste da Indonésia, na borda oeste da bacia, decaindo zonalmente até cerca de 1,5 $\mathrm{m} . \mathrm{s}^{-1}$ junto à costa africana. Notavelmente há um intenso gradiente em direção ao sul neste oceano, fazendo com que as velocidades atinjam valores de $1,2 \mathrm{~m} \cdot \mathrm{s}^{-1} \mathrm{em} 39^{\circ} \mathrm{S}$, feição que não é bem caracterizada no mapa de $c_{1}$. Como citado para o mapa de $R_{2}$, também aqui a batimetria parece exercer uma influência menos marcante do que a observada nos mapas referentes aos demais modos baroclínicos.

O mapa de $c_{3}$ (Figura 18) apresenta uma média global de $0,98 \mathrm{~m} \cdot \mathrm{s}^{-1}$, sendo que a variação de sua média zonal (Figura 15, esquerda) apresenta um padrão intermediário entre os observados para as velocidades de propagação do primeiro e segundo modos baroclínicos. Existe 


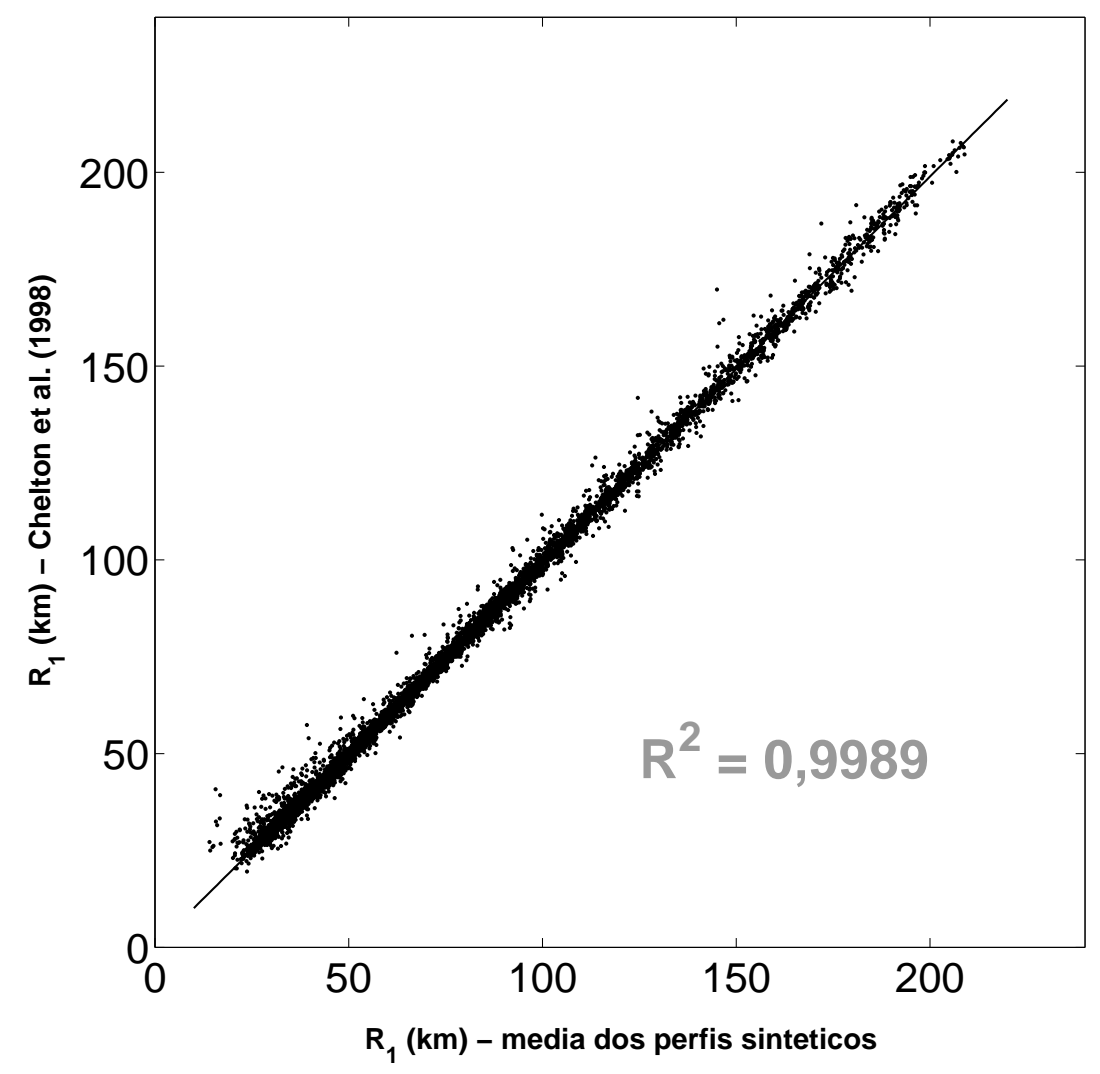

Figura 19: Diagrama de dispersão dos valores de $R_{1}$ calculados em Chelton et al. 1998 vs. os obtidos aqui. Não são incluídos valores obtidos em latitudes inferiores à $6^{\circ}$, uma vez que os raios de deformação nesta faixa equatorial são definidos de maneira diferente em Chelton et al. 1998.

uma tendência geral de aumento das velocidades em direção ao equador, mas os valores máximos parecem se concentrar fora da banda equatorial, aproximadamente entre as latitudes de 5 e $20^{\circ}$. As feições mais proeminentes são as grandes diferenças entre as porções leste e oeste dos oceanos Atlântico e Pacífico, particularmente no hemisfério sul, onde os valores variam de aproximadamente 0,8 junto no contornos leste a até $1,2 \mathrm{~m} \cdot \mathrm{s}^{-1}$ no lado oeste. No Atlântico sul entre $3^{\circ} \mathrm{S}$ e $15^{\circ} \mathrm{S}$, o limite entre as porções leste e oeste da bacia é claramente marcado pela cordilheira Meso-Atlântica. Como mencionado anteriormente, o intenso efeito da estratificação sobre o terceiro modo baroclínico na porção oeste é claramente visível sobre os valores de $R_{3}$ (Figura 14). Por fim, no oceano Índico, em uma região oceânica à aproximadamente sudoeste da Austrália, é observada uma significativa diminuição das velocidades calculadas em direção ao sul, de $1,1 \mathrm{~m} \cdot \mathrm{s}^{-1} \mathrm{em} 25^{\circ} \mathrm{S}$ até cerca de $0,8 \mathrm{~m} \cdot \mathrm{s}^{-1} \mathrm{em} 39^{\circ} \mathrm{S}$. Esta feição é análoga ao forte 
gradiente presente na mesma região do mapa de $c_{2}$ apresentado na Figura 17.

Qualitativamente, os valores calculados para o primeiro e segundo raios de deformação baroclínicos são consistentes com os apresentados em Emery et al. 1984 e em Houry et al. 1987 em termos de magnitude e distribuição espacial. Por sua vez, os valores de $R_{1}$ e $c_{1}$ publicados em Chelton et al. 1998 são disponibilizados gratuitamente via Internet pelos autores em www. coas . oregonstate. edu, possibilitando uma comparação quantitativa com os resultados obtidos aqui. Em média, os valores de $R_{1}$ e $c_{1}$ apresentados aqui são subestimados em cerca de $1,8 \%$ em relação aos obtidos em Chelton et al. 1998. As maiores diferenças são observadas em latitudes inferiores à $5^{\circ}$, uma vez que naquele trabalho assume-se um efeito $\beta$ constante na região, com os raios de deformação sendo definidos de forma diferente. Nas demais latitudes, a utilização de diferentes conjuntos de dados não condiciona as diferenças observadas, uma vez que a média dos perfis sintéticos obtidos aqui é aproximadamente igual à média anual climatológica do WOA05, sendo que a análise de Chelton et al. 1998 baseia-se na versão de 1994 deste mesmo conjunto de dados. Especula-se que as diferenças sejam decorrentes principalmente da maneira como os dados são extrapolados até o fundo e da utilização de metodologias distintas em cada trabalho no cálculo de $N(z)$. A Figura 19 apresenta o diagrama de dispersão dos valores de $R_{1}$ calculados em Chelton et al. 1998 vs. os obtidos aqui, referentes apenas à latitudes superiores à $5^{\circ}$ devido ao fato de Chelton et al. 1998 definir os raios de deformação de uma maneira distinta nesta faixa equatorial. É observada uma relação linear direta e robusta entre os resultados de ambos os estudos.

\subsubsection{Variabilidade temporal}

A variabilidade temporal dos raios de deformação é uma informação relevante no contexto da circulação oceânica de meso a larga escalas. Soluções para ondas de Rossby planetárias variam em função dos raios de deformação e são derivadas assumindo que estes parâmetros não possuem dependência temporal. Em um contexto mais amplo, a própria linearização que conduz à teoria quase-geostrófica em um oceano continuamente estratificado é aplicada assumindo que seu campo de densidade é aproximadamente constante no tempo.

A variação sazonal do primeiro raio de deformação interno foi avaliada em Emery et al. 1984 e Chelton et al. 1998, que relatam diferenças em relação aos valores médios locais da or- 
dem de 1\%. Em Chelton et al. 1998, a baixa variabilidade sazonal foi interpretada em termos da solução WKB aproximada para os raios de deformação internos, apresentada na Equação (26). A influência do ciclo sazonal sobre os valores de $N(z)$ em geral é restrita apenas às primeiras centenas de metros da coluna de água, fazendo com que a variação de seu valor integrado na coluna inteira seja relativamente pequena. Chelton et al. 1998 procura ainda avaliar a variabilidade de $R_{1}$ em escalas intrasazonais e interanuais, comparando raios calculados através de perfis in situ selecionados em caixas de $5 \times 5 \mathrm{~km}$ no Atlântico norte com os valores climatológicos correspondentes. Foram observadas diferenças máximas de aproximadamente 10\%, em geral associadas à corrente do Golfo. Porém, os autores concluíram que a maior parte desta variabilidade provavelmente seria decorrente de variações horizontais da estratificação vertical em uma escala inferior à resolução de $1^{\circ} \times 1^{\circ}$ dos dados climatológicos, fazendo com que formas da estratificação vertical muito distintas entre si fossem comparadas em um mesmo ponto de grade. Interpretou-se portanto que a variabilidade temporal efetiva de $R_{1}$ induzida exclusivamente pela passagem de fenômenos transientes deveria ser também relativamente baixa.

O trabalho de Laurindo et al. 2010 apresenta séries de perfis in situ coincidentes com a passagem de ondas de Rossby intrasazonais no Atlântico tropical, demonstando que a passagem destas ondas é capaz de forçar anomalias de temperatura e densidade em profundidades próximas à termoclina/picnoclina superiores à $9^{\circ} \mathrm{C}$ e $1,2 \mathrm{~kg} \cdot \mathrm{m}^{-3}$, com dezenas a centenas de metros de extensão vertical. Buscando testar as conclusões de Chelton et al. 1998, estas séries de perfis foram avaliadas quanto à variação dos raios de deformação baroclínicos em resposta à passagem destas ondas. Foram observadas variações superiores à $10 \%$ em relação aos raios internos médios climatológicos locais. Estes resultados são evidências de que a ação de fenômenos transientes são capazes de alterar significativamente os raios de deformação baroclínicos em relação às suas médias locais. Particularmente para as ondas observadas, isto implica que efeitos não-lineares possivelmente exercem papéis significativos em sua propagação.

Esta seção avalia a variação temporal dos raios de deformação internos calculados a partir de dados sintéticos. Esta análise é realizada em termos das diferenças percentuais em relação à média local de longo termo (DPs) dos três primeiros raios internos, abordagem que foi adotada em favor da utilização dos valores originais de $R_{i}$ ou mesmo de suas anomalias em relação à média de longo termo devido à grande variação meridional deste parâmetro dinâmico. O cálculo de suas anomalias ou de seus desvios-padrão implicaria em valores com magnitudes significati- 

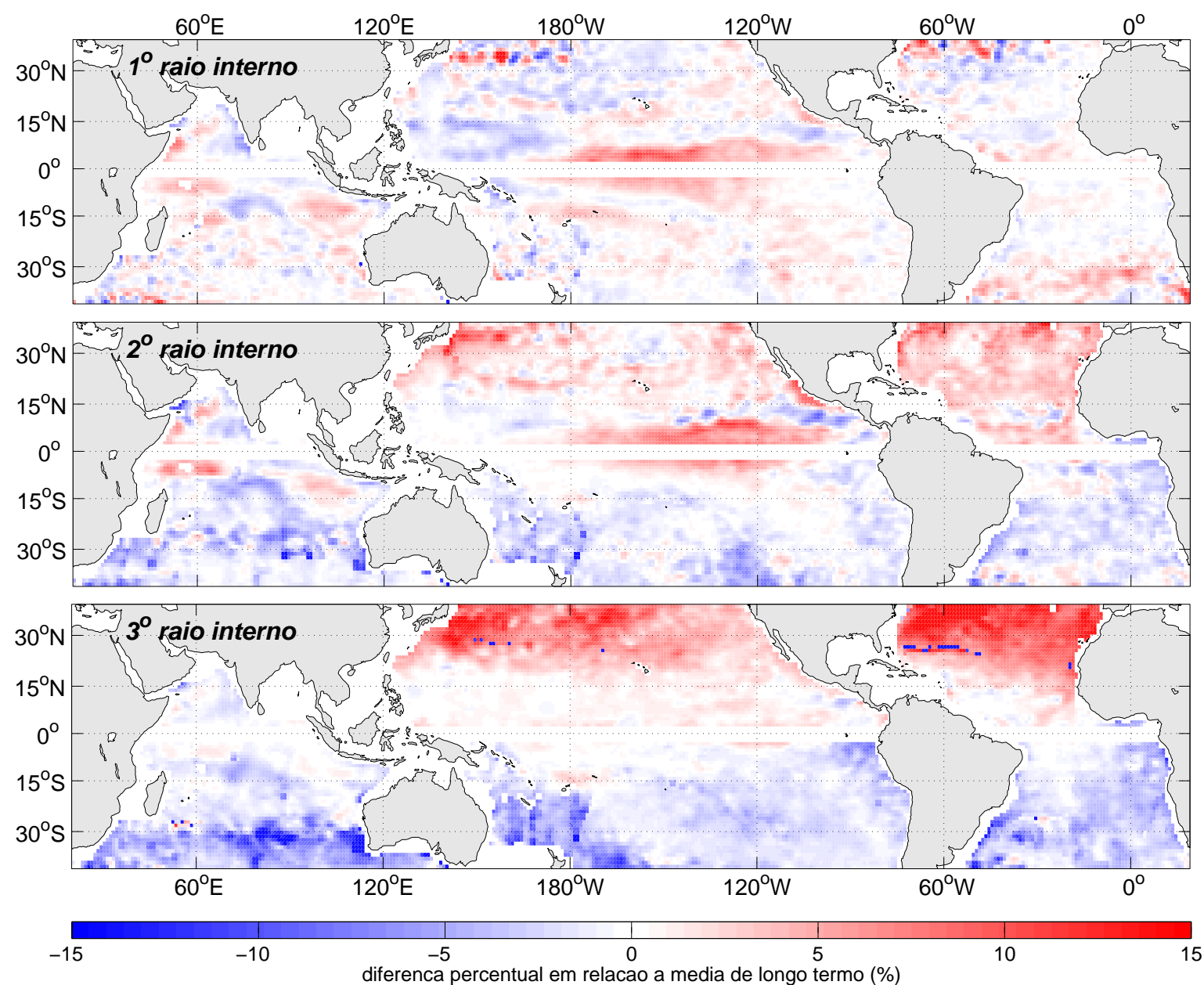

Figura 20: Mapas das diferenças percentuais dos primeiros três raios de deformação baroclínicos em relação à média de longo termo, referentes ao dia 07/09/2004.

vamente diferentes ao longo das latitudes, e que consequentemente não podem ser comparados entre si. Uma alternativa seria descontar os efeitos da rotação através da utilização dos valores de $c_{i}$ associados, porém considerou-se que sua dimensão de $\mathrm{m} \cdot \mathrm{s}^{-1}$ não seria prática para interpretação dos resultados. A utilização de diferenças ou anomalias percentuais foi considerada mais intuitiva neste contexto, além de fornecer resultados equivalentes para $R_{i}$ e $c_{i}$.

A Figura 20 mostra mapas das DPs para os três primeiros raios de deformação internos referentes ao dia 07/09/2004. As feições mostradas em cada um são notavelmente diferentes entre si. Observou-se que as feições presentes na série temporal de mapas da DP do primeiro raio de deformação são qualitativamente muito semelhantes às observadas nos mapas de $\eta$ dos satélite T/P e J-1 correspondentes. Porém, feições propagantes atribuídas à ondas planetárias, 
vórtices e outros fenômenos vão evanescendo conforme a ordem baroclínica $i$ aumenta, e o ciclo sazonal vai se tornando cada vez mais evidente. Este efeito é claramente visível na Figura 20 através da predominância sucessivamente maior de valores positivos no hemisfério norte e negativos no sul nos mapas do segundo e terceiro raios internos, em uma situação referente ao verão boreal.

A semelhança das DPs do primeiro raio interno com os padrões observados em $\eta$ pode ser interpretada em termos da solução WKB para os raios baroclínicos apresentada na Equação (26). A formulação proposta assume que os raios internos variam em função da integral vertical da frequência de estratificação $N(z)$, sendo que uma das premissas deste trabalho é de que os sinais em $\eta$ são causados essencialmente pela variação do calor integrado na coluna de água. Em uma abordagem simplista, isto significa que variações positivas ou negativas do calor armazenado implicariam respectivamente em uma maior ou menor estratificação vertical, o que portanto se traduziria em flutuações tanto em $\eta$ quanto nos raios de deformação baroclínicos. Porém, esta explicação não é válida para ordens baroclínicas maiores que 1 . O fato de o sinal sazonal tornar-se sucessivamente mais claro no segundo e terceiro raios internos sugere que, conforme a ordem baroclínica aumenta, a variação temporal dos raios de deformação passa a ser dominada por fenômenos com expressão cada vez mais superficial, efeito que não é previsto pela Equação (26).

Para avaliar os efeitos de fenômenos transientes sobre os primeiros três raios de deformação baroclínicos, as Figuras 21 a 23 apresentam mapas dos desvios-padrão das diferenças percentuais correspondentes. Chama-se a atenção para o fato de que a escala de cores do mapa referente ao terceiro raio baroclínico abrange valores até $40 \%$ maiores do que os apresentados para os dois primeiros raios internos. Também aqui são observados padrões distintos entre os mapas de cada ordem baroclínica. Características comuns incluem a baixa variabilidade no interior dos giros subtropicais para os três raios e a sua amplificação em regiões compatíveis com sistemas dinâmicos já mencionados anteriormente, a saber: confluência Kuroshio-Oyashio, a região de separação da corrente do Golfo da costa, confluência Brasil-Malvinas, corrente das Agulhas e a porção oeste da corrente sul do oceano Índico. Especula-se que motivos semelhantes aos relatados para o aumento dos erros na geração de perfis sintéticos nestas regiões condicionem também o aumento observado da variabilidade dos raios de deformação. Estes sistemas são associados à frentes oceânicas e estão sujeitos à intensa atividade transiente, que inclui o meandramento de 


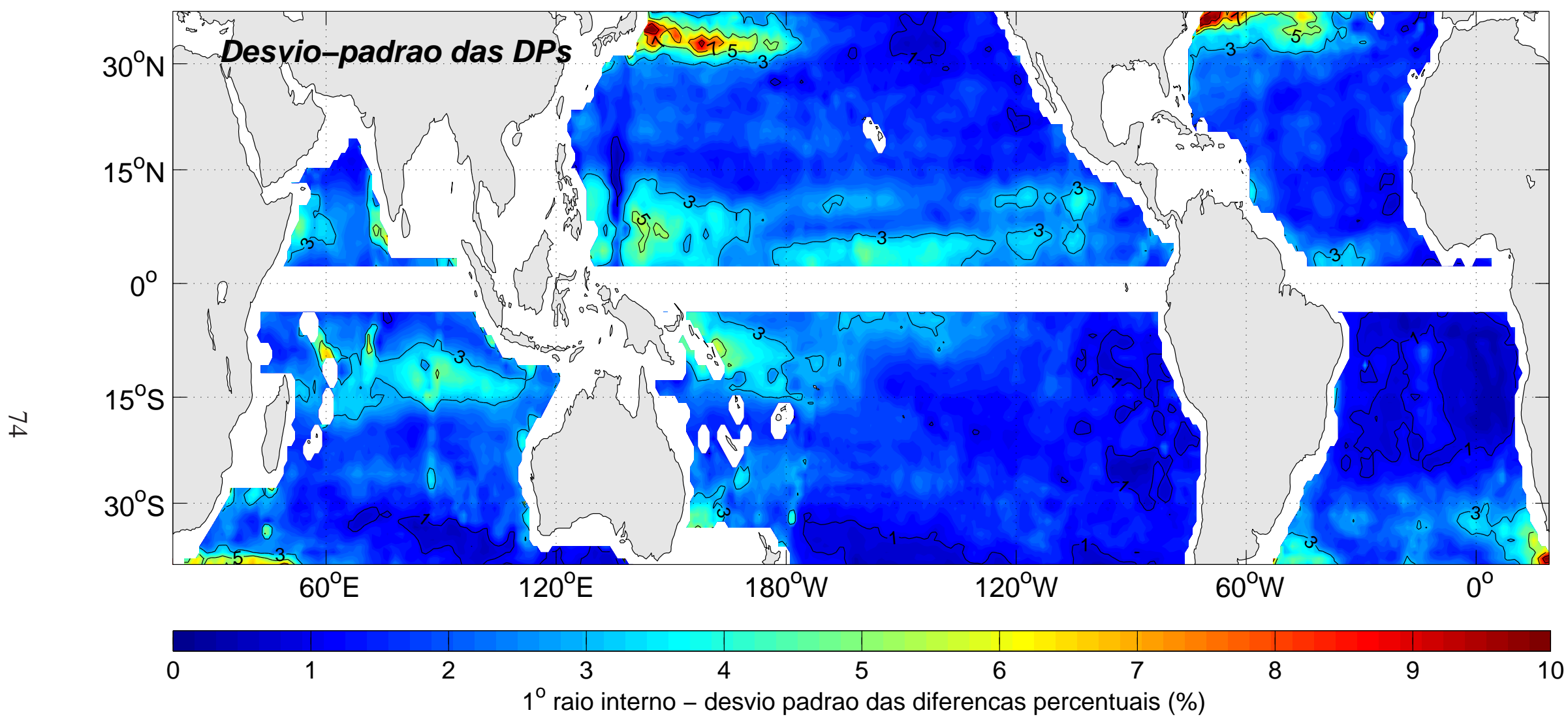

Figura 21: Mapa dos desvios-padrão das diferenças percentuais em relação à média de longo termo para o primeiro raio de deformação baroclínico. 


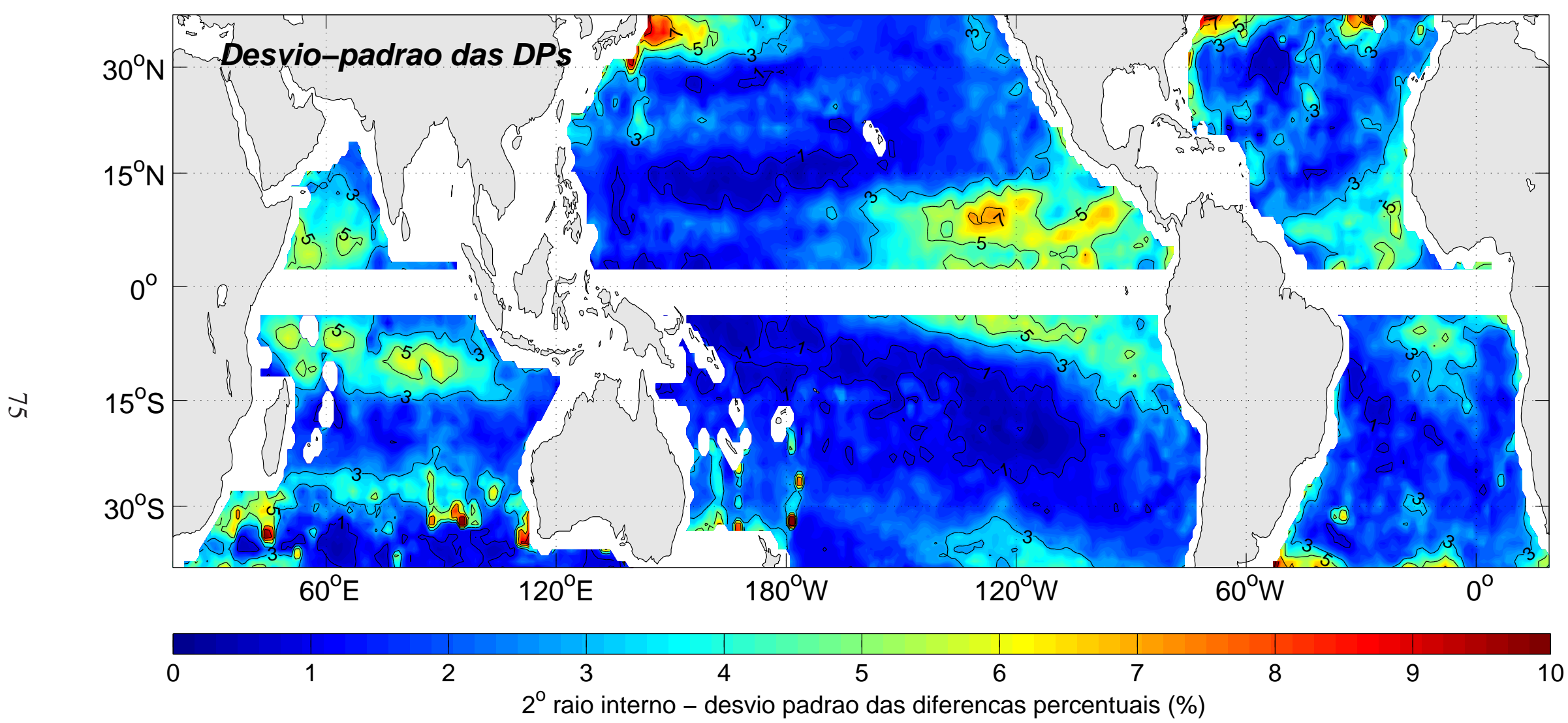

Figura 22: Similar à Figura 21, mas considerando o segundo raio de deformação baroclínico. 


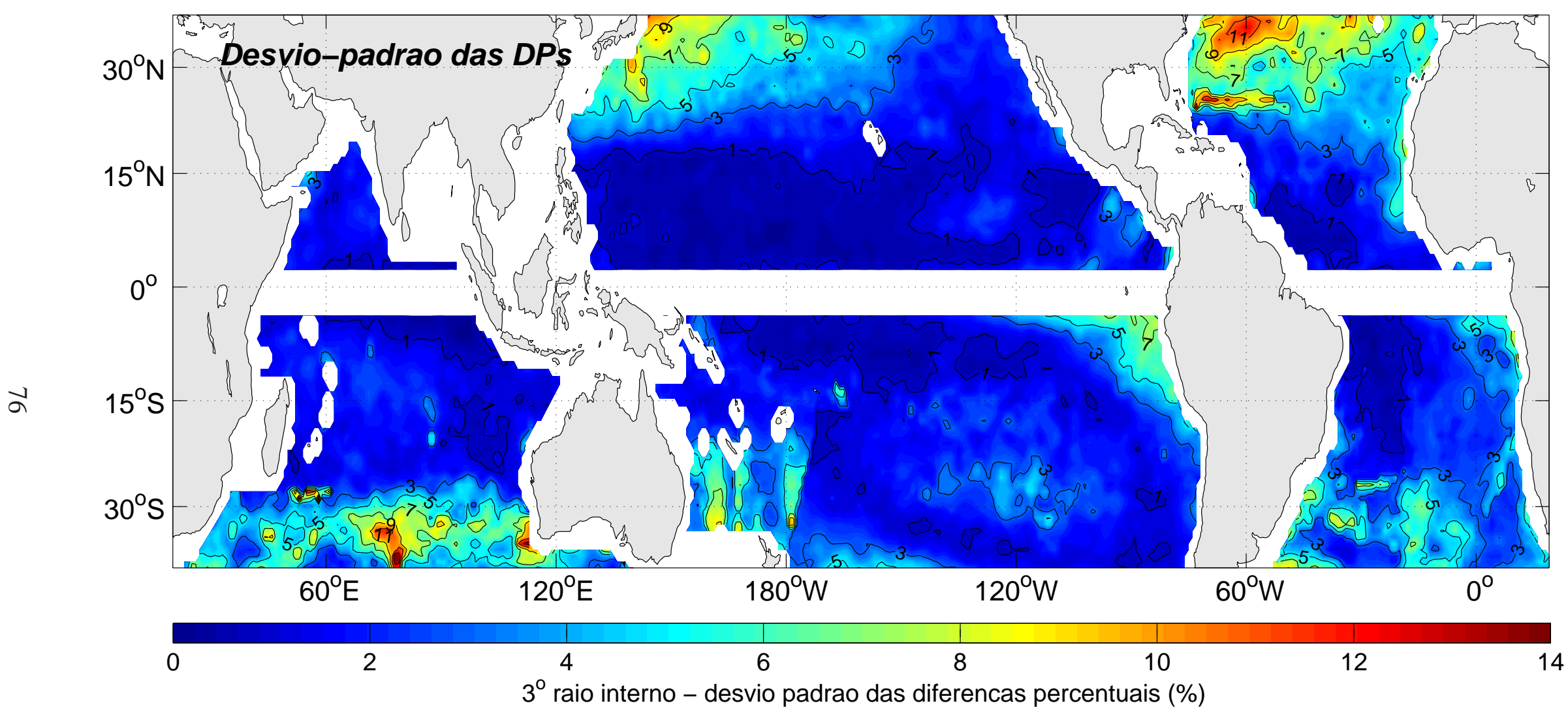

Figura 23: Similar à Figura 21, mas considerando o terceiro raio de deformação baroclínico. 
correntes, a passagem de vórtices de mesoescala, a propagação de ondas de Rossby planetárias de período semianual ou superior e o próprio ciclo sazonal (Polito e Liu 2003). A variação da posição das frentes em resposta à ação de tais fenômenos pode fazer com que formas inteiramente distintas de estratificação vertical ocorram em um mesmo ponto de grade, causando as altas diferenças percentuais observadas nestas regiões. Como mencionado anteriormente, variações do primeiro raio interno em relação à média climatológica de até $10 \%$ associadas à corrente do Golfo observadas em Chelton et al. 1998 foram interpretadas de maneira semelhante.

Quanto às demais feições observadas, os desvios-padrão das anomalias percentuais para o primeiro raio interno (Figura 21) amplificam-se proeminentemente na zona equatorial do Pacífico, e em duas faixas zonais contidas aproximadamente entre as latitudes de $5^{\circ}$ e $15^{\circ} \mathrm{em}$ ambos os hemisférios no oceano Índico. Feições mais discretas são observadas no oceano Atlântico acima do equador ao largo da costa sul-americana, e também ao sul da latitude de $20^{\circ} \mathrm{S}$. No Pacífico, os valores também se amplificam ao largo da costa leste australiana. Cada uma destas feições é descrita brevemente à seguir, com considerações sobre os fenômenos transientes dominantes nas regiões correspondentes.

Ainda na Figura 21 e considerando o Pacífico equatorial, desvios-padrão entre 2 e $4 \%$ são observados em latitudes inferiores à cerca de $5^{\circ}$ desde a borda leste da bacia até as imediações da linha internacional de mudança de data. O sinal é mais intenso no hemisfério norte, sendo que toda a região está sujeita à ação de ondas equatoriais e aos fenômenos altamente energéticos do El Niño e La Niña, estando também sob a influência da migração sazonal da ZCIT. Os padrões observados são particularmente semelhantes aos presentes na Figura 7 do trabalho de Polito e Liu 2003, que mostra a amplitude média da componente propagante para oeste com períodos de aproximadamente 50 dias, atribuídos naquele trabalho à ondas de Rossby intrasazonais. Isto sugere uma influência mais marcada deste fenômeno sobre a variabilidade de $R_{1}$ observada na região. Da linha internacional de data até a borda oeste da bacia, a magnitude dos desviospadrão aumenta para 3 a $5 \%$ e os padrões espalham-se meridionalmente até aproximadamente a latitude de $15^{\circ} \mathrm{em}$ ambos os hemisférios. Mais ao sul, os desvios-padrão de até $4 \%$ observados ao largo da costa leste da Austrália coincidem com a região da retroflexão da corrente LesteAustraliana, feição associada à uma frente subtropical (Tomczak e Godfrey 2005) e submetida à ação de ondas de Rossby de períodos semianual a bianual (Polito e Liu 2003). Assim, a ampli- 
ficação da variabilidade do primeiro raio interno nesta região pode ser estar sendo condicionada pelos mesmo fatores descritos anteriormente para os sistemas associados à frente oceânicas, como a confluência Brasil-Malvinas.

No Índico, considerando ainda a Figura 21, as faixas zonais com desvios-padrão de 3-4\% são observadas em regiões onde parte significativa da energia propagante para oeste é dominada por ondas de Rossby em uma ampla faixa espectral, de trimestral a bianual (Polito e Liu 2003). Adicionalmente, a faixa zonal observada ao sul do equador parece ser coincidente com a região de ocorrência do chamado dipolo do oceano Índico, um fenômeno altamente energético que causa oscilações aperiódicas da TSM de maneira análoga à oscilação El Niño/La Niña no Pacífico.

No oceano Atlântico, ainda na Figura 21, os desvios de 3-4\% observados ao norte do equador podem ser decorrentes da ação de ondas equatoriais, e são consistentes com a grande assimetria energética entre os hemisférios norte e sul relatada em trabalhos anteriores (Polito e Liu 2003; Polito e Sato 2003; Laurindo et al. 2010). Porém, estes resultados devem ser tratados com suspeita, uma vez que há uma redução sensível da performance dos perfis sintéticos na região, como foi descrito na seção 4.1 a partir da interpretação da Figura 11. Por fim, ao sul da latitude de $20^{\circ} \mathrm{S}$ é observado um aumento discreto da variabilidade, com os desvios-padrão de 2 a $3 \%$. O espectro de energia propagante para oeste na região é dominado por ondas de Rossby de frequência semianuais a bianuais e vórtices de meso-escala emitidos pela corrente das Agulhas.

No mapa refente ao segundo raio interno (Figura 22), os desvios padrão das anomalias percentuais formam padrões proeminentes na porção oeste da região tropical dos oceanos Pacífico e Atlântico. As feições são similares entre estes oceanos, sendo meridionalmente mais largas junto aos contornos leste das bacias e afunilando-se em direção ao oeste. Os padrões são assimétricos entre os hemisférios norte e sul, apresentando maiores valores no hemisfério norte. No Pacífico, os valores observados variam na faixa dos 3 a 7\%, contra os 3 a $5 \%$ do Atlântico. A predominância de maiores desvios no lado leste destes oceanos é oposta ao observado para o primeiro raio baroclínico, onde a maior variabilidade ocorre junto ao contorno oeste.

Ainda na Figura 22, no extremo sul do Pacífico é visível uma feição quase diagonal e contínua, com valores de até 3\%, se estendendo desde a costa oeste da América do Sul até as proximidades da fossa de Tonga à leste da Austrália. Nessas latitudes a variabilidade propagante 
para oeste é dominada por ondas de Rossby anuais a semianuais, sendo que a amplificação dos desvios-padrão pode também se dever à proximidade da frente subtropical associada a tais fenômenos transientes. No oceano Atlântico nos extremos norte e sul da região do globo considerada são observados aumentos dos desvios a até 7\%, que por sua localização é possível que sejam condicionados pelo efeito topográfico da cordilheira Meso-Atlântica em conjunto com o sinal sazonal. Aqui, especula-se que a redução da profundidade amplifique a importância do sinal sazonal nas variações da integral vertical de $N(z)$. No Índico tropical, uma feição de variabilidade relativamente alta (desvios-padrão entre 3 e 5\%) é observada em latitudes inferiores à $15^{\circ}$ no lado oeste da bacia, cruzando-a zonalmente entre as latitudes de $15^{\circ} \mathrm{S}$ e $5^{\circ} \mathrm{S}$. Uma segunda faixa zonal com desvios-padrão de cerca de 3\% é observada mais ao sul, centrada aproximadamente em $27^{\circ} \mathrm{S}$. Os desvios em seu interior se amplificam a até $9 \%$ sobre feições topográficas significativas, como a cordilheira de $90^{\circ} \mathrm{E}$ e a cordilheira submarina ao sul de Madagascar.

O mapa referente ao terceiro raio interno (Figura 23) difere significativamente dos anteriores no fato de que a maior parte da variabilidade é observada fora da zona tropical dos oceanos, normalmente próximo aos limites meridionais da área de estudo. Especificamente, amplificações dos desvios-padrão são observadas nas regiões noroeste dos oceanos Pacífico e Atlântico e ao sul dos três oceanos (porém de maneira significativamente menos intensa no Pacífico), sendo atribuídas à grande contribuição do ciclo sazonal sobre a variabilidade do terceiro raio interno observada em sua série de temporal de mapas das DPs. Curiosamente, a influência das feições batimétricas sobre a amplificação dos desvios-padrão parece maior aqui do que sobre os dois primeiros raios internos, o que pode ser interpretado como mais um indício de que a variação dos raios internos se relaciona à faixas distintas da coluna de água em cada ordem baroclínica. Os efeitos da batimetria são particularmente visíveis no mar de Coral a leste da Austrália, na faixa de alta variabilidade ao sul do Índico, e por fim no oceano Atlântico ao sul da latitude de $20^{\circ}$, onde feições como a cordilheira de Walvis, a elevação de Rio Grande e a própria dorsal Meso-Atlântica são bem delineadas pelas isolinhas de desvio-padrão.

As poucas feições significativas observadas próximo ao equador são observadas junto à costa do Peru, no oceano Pacífico, com desvios entre 3 e 7\%, e uma feição similar no oceano Atlântico junto à costa de Angola, com desvios entre 3 e 5\%. Estas feições são coincidentes com a posição de importantes sistemas de ressurgência costeira ao longo dos contornos oeste, respectivamente a ressurgência do Peru e o domo de Angola. A existência de uma relação é 
apenas especulativa, mas conduziu à uma observação mais cuidadosa das anomalias percentuais presentes sobre as posições de sistemas de ressurgência correspondentes no hemisfério norte, particularmente da ressurgência da Califórnia e do domo da Guiné. Na posição do primeiro sistema é observado apenas um aumento discreto dos desvios-padrão para 3\%. No caso do domo da Guiné, são observados desvios de até 5\%, contíguos à uma feição que acompanha a costa africana em direção ao norte, unindo-se aos altos valores observados em latitudes aproximadamente acima de $20^{\circ} \mathrm{N}$. É portanto considerada possível a existência de uma relação entre a presença de zonas de ressurgência e as variações observadas sobre o terceiro raio interno, porém uma avaliação quantitativa foge aos objetivos deste trabalho.

Em um breve sumário dos resultados apresentados nesta seção, as diferenças observadas entre os mapas do primeiro ao terceiro raios de deformação baroclínicos (Figuras 12 a 14) e entre os da velocidade de fase de ondas de gravidade internas (Figuras 16 a 18) sugerem que a relação entre a ordem baroclínica $i$ e a integral vertical de $N(z)$ não pode ser linear como mostra a Equação (26). A observação qualitativa da série temporal de mapas das diferenças ou anomalias percentuais dos raios de deformação em relação à sua média de longo termo (DPs), exemplificados na Figura 20, mostra que o ciclo sazonal torna-se cada vez mais evidente conforme a ordem baroclínica aumenta. Por fim, os mapas dos desvios-padrão das DPs (Figuras 21 a 23) mostram que a variabilidade tem maior expressão em regiões significativamente diferentes entre os mapas dos desvios-padrão das DPs referentes à cada ordem baroclínica, e fornecem ainda um contexto dinâmico aos mapas da variabilidade da altura para diferentes bandas do espectro de ondas planetárias apresentados por Polito e Liu 2003.

Como afirmado anteriormente, a amplificação do ciclo sazonal sugere que os valores de DP se relacionam com faixas da coluna de água cada vez mais rasas conforme a ordem baroclínica aumenta. Especula-se que outros fenômenos além do próprio ciclo sazonal sejam também caracterizados em $i=1$ de maneira suavizada ou mesmo tornados invisíveis, caso seus efeitos sobre a estratificação vertical sejam também negligíveis frente ao valor de $N(z)$ integrado na coluna de água inteira, e portanto considera-se possível que tais fenômenos sejam também destacados em ordens baroclínicas de ordens superiores à 1. De fato, observações de mapas sinóticos das DPs de $R_{2}$ mostram feições que ou aparecem suavizadas ou simplesmente não são contempladas em $R_{1}$, e vice-versa. Esta hipótese é compatível com a significativa diferença na distribuição da variabilidade nos oceanos observada entre os mapas do desvio-padrão das DPs 
dos três primeiros raios baroclínicos.

\subsubsection{Influência de efeitos não-lineares}

Os efeitos da variabilidade dos raios internos observada sobre os fenômenos oceânicos é brevemente discutida em termos da velocidade de fase $c_{p i}$ de ondas de Rossby baroclínicas longas (ORLs). Este fenômeno em particular é utilizado uma vez que a ocorrência de ORLs do primeiro modo baroclínico foi reportada em todas as latitudes abrangidas neste estudo e por compreenderem uma porção significativa da energia propagante para oeste nos oceanos (Chelton e Schlax 1996; Polito e Liu 2003). Segundo a teoria linear de ondas livres, a expressão para a velocidade de fase do ondas de Rossby baroclínicas pode ser escrita da seguinte forma:

$$
c_{p i}=-\frac{\beta}{k^{2}+l^{2}+R_{i}^{-2}}
$$

onde $k$ e $l$ são os números de onda zonal e meridional, definidos como $2 \pi \lambda^{-1}$, onde $\lambda$ é o comprimento de onda no eixo correspondente. Assumindo que a propagação é essencialmente zonal, $l^{2}$ pode ser desprezado. Adicionalmente, a aproximação de ondas longas assume que o quadrado do comprimento de onda zonal é duas ordens de grandeza menor que o quadrado do raio de deformação correspondente, fazendo com que $k^{2}$ possa ser também desprezado na Equação (27):

$$
c_{p i}=-\beta R_{i}^{2}
$$

Os valores médios dos desvios-padrão das anomalias percentuais nos mapas de cada ordem baroclínica, apresentados da primeira à terceira nas Figuras 21 a 23, é de respectivamente 2,06, 2,76 e 2,80\%. Isto implica em variações das velocidades de propagação de 4,2 a 5,7\%, margens consideradas pequenas considerando os desvios-padrão apresentados para medições da velocidade de fase de ORLs realizadas em Polito e Liu 2003. Porém, assumindo que a distribuição das anomalias percentuais contidas ao longo das séries temporais de cada ponto de grade é aproximadamente gaussiana e simétrica, os mapas citados portanto ilustram os valores máximos que estas anomalias percentuais assumem em $68,2 \%$ da série temporal. Da mesma maneira, valores de DPs da ordem de 1 a 2 (2 a 3) vezes os ilustrados ocorrem em 27,2\% (4,2\%) do tempo. Os mapas sinóticos das DPs (exemplificados na Figura 20) mostram que tais variações extremas em geral estão ligadas à variabilidade propagante dos oceanos, particularmente no primeiro e 
segundo raios de deformação internos. Assumindo que tais sinais correspondam à ORLs, a variação dos raios internos induzida por sua própria propagação implicaria em diferenças da velocidade de fase de 8,41 a 11,51\%, assumindo DPs equivalentes a até 2 desvios-padrão, e de 12,74 a 17,51\% assumindo até 3 desvios-padrão. Deve-se lembrar que estas variações da velocidade de fase são estimadas em relação aos desvios-padrão típicos (médios) das DPs dos primeiros três raios internos. Como mostram as Figuras 21 a 23, os desvios-padrão e consequentemente as variações de velocidade de fase podem ser significativamente maiores em regiões específicas do oceano.

Assim, o impacto potencialmente significativo que as variações do raio de deformação teriam sobre a velocidade de fase de ORLs sugerem que uma descrição linear destas ondas pode não ser capaz de descrever apropriadamente a sua propagação, particularmente onde as Figuras 21 a 23 mostram uma variação mais expressiva dos raios em resposta à variabilidade transiente. A variação da estrutura vertical de densidade induzida pela própria passagem de ondas planetárias pode potencialmente interagir de maneira não linear com propriedades como frequência e número de onda. Como ondas planetárias de diferentes comprimentos e frequências (e possivelmente de diferentes modos baroclínicos, como será discutido mais adiante neste trabalho) coexistem nos oceanos, interações não-lineares decorrentes da sobreposição de ondas (efeito conhecido como piggyback) podem também ocorrer e exercer influências não-desprezíveis sobre o seu movimento (Isachsen et al. 2007).

\subsection{Importância relativa dos modos dinâmicos}

\subsubsection{Identificação da origem e remoção do ruído observado em $\vartheta_{i}$ e $\vartheta_{i}^{\prime}$}

Os campos de $\vartheta_{i}(x, y, t)$ e $\vartheta_{i}^{\prime}(x, y, t)$ obtidos mostraram-se relativamente ruidosos ao longo de seus três eixos para todas as ordens baroclínicas consideradas, se comparados com os resultados obtidos para os perfis sintéticos e raios de deformação. Esta seção procura indentificar as causas prováveis para o ruído observado, analisando a consistência dos campos de velocidades geostróficas calculados e sua influência sobre os resultados obtidos para a importância dos modos dinâmicos.

Como descrito anteriormente, $\vartheta_{i}$ e $\vartheta_{i}^{\prime}$ são obtidos a partir da comparação da projeção de modos dinâmicos a perfis verticais das componentes $u$ e $v$ da velocidade geostrófica e de suas 
anomalias em relação à média de longo termo, respectivamente, que se encontram organizados sobre uma grade com resolução de $1^{\circ} \times 1^{\circ} \times \sim 10$ dias. A velocidade em si é calculada a partir da aplicação do método dinâmico sobre um campo de densidades sintético $\rho(x, y, z, t)$, por sua vez estimado indiretamente a partir de dados climatológicos e medições orbitais de $\eta \mathrm{e}$ TSM. O conjunto sintético de densidades é também utilizado no cálculo dos modos dinâmicos mencionados. Como os resultados destas operações são interdependentes para a geração do resultado final, espera-se que as limitações e falhas associadas a cada operação acumulem-se nos campos de $\vartheta_{i}, \vartheta_{i}^{\prime}(x, y, t)$ resultantes.

Especificamente, o campo de densidade $\rho(x, y, z, t)$ é calculado através de dados climatológicos de salinidade, o que o torna propenso à falhas decorrentes da ação de efeitos halostéricos, e através do conjunto de perfis sintéticos de temperatura desenvolvido para este estudo, cujo desempenho pode ser influenciado por uma série de fatores, a saber:

- Os perfis obtidos são capazes de recuperar no máximo a fração da variância vertical que pode ser explicada pelos dois primeiros modos EOF da anomalia vertical da temperatura, cuja média na região do globo considerada é de $83 \%$;

- Toda a variabilidade com significado físico está contida apenas nos primeiros $1000 \mathrm{~m}$ da coluna de água. A variabilidade observada entre 1000 e $1500 \mathrm{~m}$ provém de trechos extrapolados dos perfis in situ, enquanto níveis mais profundos são indênticos à média anual climatológica em qualquer tempo $t$;

- A acurácia depende da qualidade dos dados climatológicos de temperatura e salinidade utilizados no cálculo;

- Sua acurácia depende também da qualidade e da quantidade de perfis in situ disponíveis para o cálculo dos modos EOF utilizados em sua construção;

- O método de construção dos perfis sintéticos depende da estimativa prévia do perfil vertical do coeficiente de expansão térmica da coluna de água, que é calculado através da climatologia mensal de temperatura e salinidade. É portanto possível que efeitos termoestéricos e halostéricos significativos possam induzir falhas nos perfis calculados.

Como mostra a Equação (17), o método dinâmico baseia-se na aplicação de derivadas ao longo dos eixos horizontais do campo de densidade, operação que amplifica gradientes espúrios ou o ruído que porventura estejam presentes em $\rho(x, y, z, t)$. Assim, com o objetivo de avaliar 
possíveis falhas presentes nos campos de valocidade geostrófica obtidos, eles foram submetidos à uma avaliação qualitativa que consistiu na comparação com velocidadas calculadas através de dados climatológicos e na verificação da capacidade do conjunto de representar feições dinâmicas descritas na literatura.

Falhas óbvias como valores excessivamente elevados e/ou estruturas verticais espúrias foram mais comumente observadas próximo aos contornos continentais. Erros persistentes foram também observados no Atlântico tropical norte entre as latitudes de 3 e $10^{\circ} \mathrm{N}$. Como descrito na seção 4.1, uma visível queda de desempenho do método de geração de perfis sintéticos ocorre nesta área, o que possivelmente é um condicionante para as falhas observadas. À parte destes erros, seções zonais-verticais médias das componentes $u$ e $v$ da velocidade geostrófica mostram-se qualitativamente consistentes com suas correspondentes médias anuais climatológicas. A médias locais de longo termo das velocidades em geral apresentam magnitudes típicas de meso e larga escalas $\left(10^{-2}\right.$ a $\left.10^{-1} \mathrm{~m} . \mathrm{s}^{-1}\right)$, sendo que a intensidade e a direção dos fluxos principais observados mostram-se compatíveis com correntes descritas na literatura. De fato, o conjunto é capaz de representar feições como o fluxo na camada superior em direção ao equador no interior dos giros subtropicais, correspondente ao transporte de Sverdrup, e as correntes principais que compõe os giros com exceção das correntes de contorno oeste, por motivos que serão descritos a seguir. Componentes principais da circulação tropical fora do cinturão equatorial também foram identificadas, sendo possível observar-se estruturas ciclônicas em posições compatíveis com os domos da Guiné e de Angola, no Atlântico. Feições qualitativamente coerentes são observadas até mesmo em posições correspondentes à sistemas de correntes bastante complexos, como as confluências Brasil-Malvinas, Kuroshio-Oyashio e a retroflexão da corrente das Agulhas.

Especula-se que a má definição das correntes de contorno oeste sejam principalmente decorrentes do fato de que estes fluxos, que tem uma componente baroclínica expressiva, por vezes ocorrem sobre o talude continental, uma vez que regiões mais rasas que $1000 \mathrm{~m}$ são desconsideradas da análise devido à diminuição da precisão das medições altimétricas a partir desta isóbata. Isso é suportado pelo fato de que os fluxos referentes às correntes do Golfo e Kuroshio tornarem-se gradativamente mais visíveis em latitudes ao norte de aproximadamente $30^{\circ} \mathrm{N}$, próximo à onde estas correntes conhecidamente se afastam da costa em direção ao interior das bacias oceânicas (Campos e Olson 1991). Outro fator condicionante é a redução da precisão dos perfis sintéticos gerados próximo às bordas continentais, falha que se propaga para todas as 
operações subsequentes da análise realizada aqui.

Quanto à variabilidade, as feições mais evidentes observadas em séries temporais de seções zonais-verticais da velocidade geostrófica de ambas as componentes horizontais são faixas alternadas de fluxos com sinais opostos que se propagam para oeste. Como apresentado na seção 4.1, os dados sintéticos de temperatura são capazes de reproduzir formas de variabilidade em uma ampla gama espectral. A variabilidade propagante para oeste em geral se apresenta na forma de oscilações verticais sobre as isotermas/isopicnais, característica prontamente observada na série de seções zonais-verticais apresentadas na Figura 9 referentes à latitude de $25,5^{\circ} \mathrm{S}$ no oceano Índico. A Figura 7 de trabalho de Laurindo et al. 2010 esquematiza a oscilação vertical da termoclina induzida pela passagem de ondas planetárias buscando interpretar anomalias de temperatura e densidade observadas em séries de perfis Argo coincidentes com sinais propagantes observados em dados altimétricos, configuração compatível com os sinais observados aqui. Por geostrofia, anomalias de densidade com esta configuração provocariam inversões de fluxo toda a vez que a primeira derivada da inclinação da isopicnal invertesse o seu sinal. Uma oscilação completa, compreendendo a passagem de um cavado e uma crista, provocaria portanto quatro inversões da velocidade geostrófica. Estas feições são claramente visíveis nas seções sinóticas de velocidade geostrófica obtidas para a maioria das latitudes consideradas.

Erros no cálculo das velocidades geostróficas em escala sinótica são esperados em regiões onde parte significativa da energia propagante está contida em fenômenos que não podem ser apropriadamente resolvidos pela resolução espacial e temporal considerada aqui, uma vez que os padrões subamostrados induziriam à erros na composição dos gradientes horizontais de densidade e consequentemente no cálculo das velocidades geostróficas. Tais fenômenos incluem vórtices de mesoescala, que possuem dimensões típicas da ordem de 10 a $100 \mathrm{~km}$, e ondas de Rossby barotrópicas e de instabilidade tropical, por contarem com períodos inferiores à duas vezes a resolução temporal dos dados sintéticos, que é de aproximadamente 10 dias.

Assim, apesar de compreenderem em si os erros e limitações acumulados de etapas anteriores do trabalho, os campos de velocidade em geral mostram-se suaves no tempo e no espaço e, com exceção das corrententes de contorno oeste, são capazes de representar as feições principais de circulação citadas na literatura relacionada. Adicionalmente, os fluxos representados mostram-se significativamente menores abaixo da termoclina/picnoclina, e não são observados pontos de convergência/divergência que seriam indicativos de compressibilidade ou de vio- 


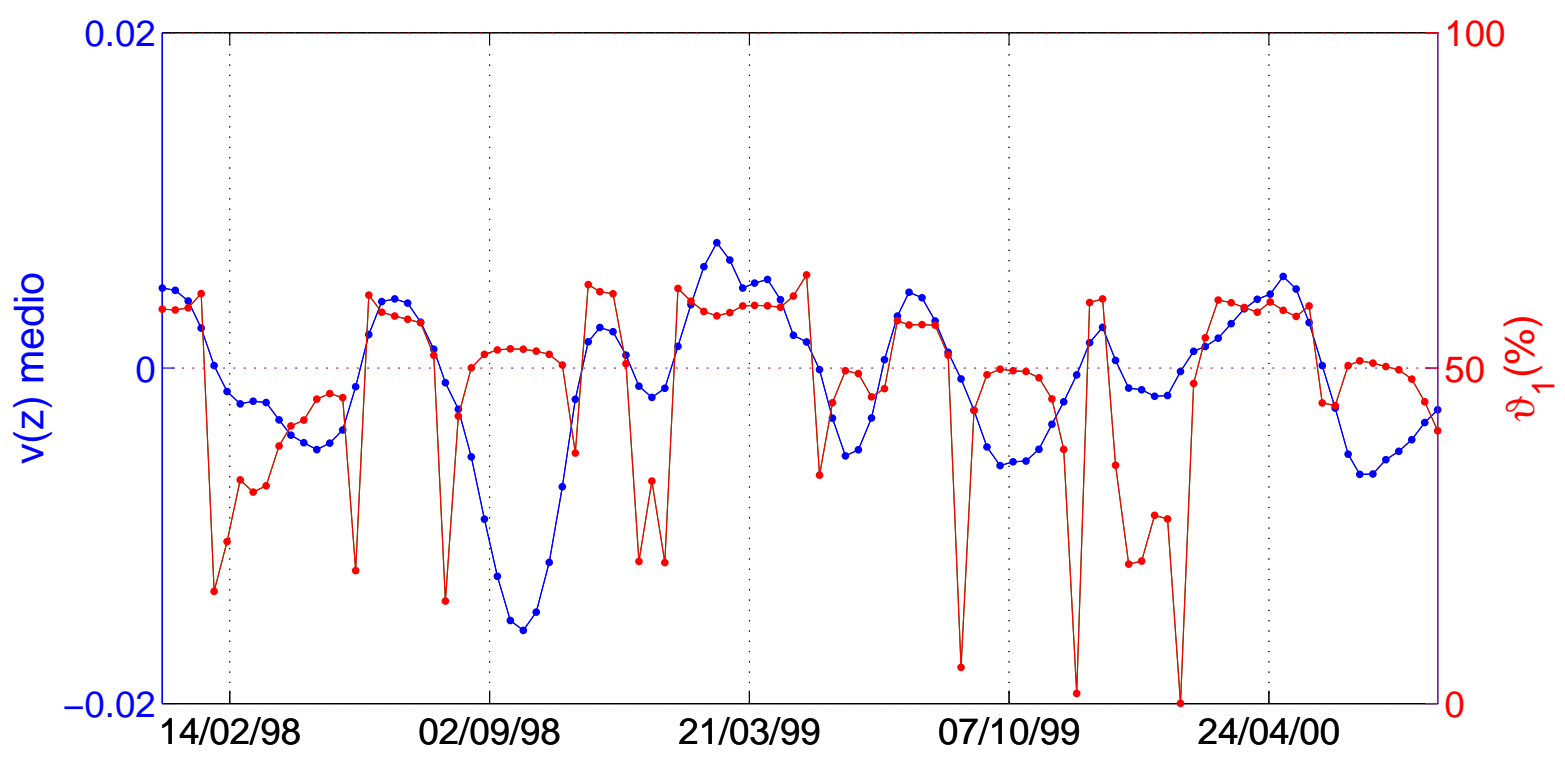

Figura 24: Gráfico da evolução temporal da média vertical da componente $\mathrm{v}$ da velocidade geostrófica (curva azul) e dos resultados obtidos para $\vartheta_{1}$ (curva vermelha), para as coordenadas $30^{\circ} \mathrm{N} / 60^{\circ} \mathrm{W}$, no oceano Atlântico. $\vartheta_{1}$ cai significativamente quando a velocidade média é próxima de zero.

lações da condição de conservação de massa, características que suportam a sua consistência física. Os campos de velocidade geostrófica, portanto, por si só não são capazes de explicar o ruído observado em $\vartheta_{i}$ e $\vartheta_{i}^{\prime}$. Para identificar a origem provável deste erro, o cálculo destes valores percentuais foi testado em pontos $(x, y)$ da grade horizontal espalhados pelo oceano, verificando os resultados obtidos pela operação descrita pela Equação (21) ao longo de cada instante $t$ da série temporal. Um exemplo emblemático dos resultados dos testes realizados é apresentado na Figura 24, que apresenta sobre o mesmo eixo temporal a média vertical da velocidade meridional e os resultados obtidos para $\vartheta_{1}$, referentes ao ponto de grade na posição $30^{\circ} \mathrm{N} / 60^{\circ} \mathrm{W}$ no oceano Atlântico. Verificou-se que o sinal interpretado como ruído corresponde a variações abruptas do valores obtidos para $\vartheta_{i}$ quando a velocidade aproxima-se de zero ao longo de toda a vertical. Isto é observado também para os demais modos dinâmicos considerados, ocorrendo de maneira similar em $\vartheta_{i}^{\prime}$.

Como mostra a Equação (21), cada modo dinâmico é multiplicado por sua amplitude ao ser comparado em termos da raiz do erro médio quadrátrico com o perfil de velocidade correspondente, o que significa que os valores comparados entre si possuem magnitudes semelhantes. 
Quando a velocidade nos primeiros $1000 \mathrm{~m}$ dos perfis verticais tendem à zero (chama-se a atenção para o fato de que é praticamente impossível que todos os valores ao longo da vertical sejam exata e simultâneamente nulos), a estrutura de sua forma funcional apresenta variação randômica e portanto sem significado físico, consequentemente fazendo com que o cálculo de $\vartheta_{i}, \vartheta_{i}^{\prime}$ resulte em valores espúrios. Tais valores foram tratados como spikes ao longo das séries temporais referentes à cada ponto de grade, onde os valores que se afastassem além de dois desvios-padrão das respectivas médias de longo termo foram desconsiderados. Os resultados obtidos para $\vartheta_{i}, \vartheta_{i}^{\prime}$ após esta etapa final do processamento são apresentados e discutidos nos tópicos a seguir.

\subsubsection{Circulação geostrófica total}

Como afirmado anteriormente, $\vartheta_{i}$ é interpretado como sendo a percentagem da estrutura vertical de perfis das componentes $u$ e $v$ da velocidade geostrófica que é explicada pelo $i$-ésimo modo dinâmico. Sua formulação é apresentada na Equação (21), e baseia-se no cálculo da raiz do erro médio quadrático normalizado $(\varepsilon)$ do perfil de velocidade em questão em relação a cada modo dinâmico, estes últimos escalados por um fator obtido através do ajuste por mínimos quadrados do modo ao perfil de velocidade correspondente. $\vartheta_{i}$ propriamente dito é obtido a partir da relação $(1-\varepsilon) \times 100$, redefinição aplicada para apresentar os resultados em um formato mais intuitivo, com dimensão percentual e onde valores maiores implicam em maiores semelhanças entre as estruturas verticais de modos dinâmicos e de perfis de velocidade. Assim, $\vartheta_{i}$ varia de 0 a $100 \%$, onde $0 \%$ indica que a forma funcional do perfil de velocidade é ortogonal à do modo dinâmico correspondente e 100\% implica em estruturas verticais idênticas entre si.

Uma primeira visão da importância de cada modo na composição do interior geostrófico dos oceanos é fornecida pela Tabela 3, que apresenta as médias e os desvios-padrão dos valores de $\vartheta_{i}$ obtidos para o modo barotrópico e os cinco primeiros baroclínicos, calculados a partir das componentes $u$ e $v$ da velocidade geostrófica em todos os pontos $(x, y, t)$ da grade considerada. Os resultados mostram que o primeiro modo baroclínico é dominante nos oceanos, e que a representatividade média dos modos subsequentes decresce aproximadamente por uma razão de três conforme a ordem baroclínica aumenta. O terceiro, quarto e quinto modos baroclínicos respondem em média por frações da ordem de $1 \%$. No caso do terceiro modo, observou-se que 
Tabela 3: Média e desvio-padrão dos valores de $\vartheta_{i}(\%)$ calculados para as componentes $\mathrm{u} e \mathrm{v}$ da velocidade geostrófica em todos os pontos $(\mathrm{x}, \mathrm{y}, \mathrm{t})$ da grade utilizada, considerando o modo barotrópico e os cinco primeiros modos baroclínicos.

\begin{tabular}{c|c|c|c|c|c|c|c}
\cline { 2 - 7 } & \multicolumn{2}{c|}{0} & 1 & 2 & 3 & 4 & 5 \\
\cline { 2 - 7 } & componente $\Downarrow$ & & & & & \\
\hline \multirow{2}{*}{$\left\langle\vartheta_{i}(\%)\right\rangle$} & $u$ & 8,51 & 28,56 & 11,80 & 4,37 & 1,51 & 0,67 \\
\cline { 2 - 8 } & $v$ & 9,86 & 28,92 & 10,36 & 3,37 & 1,43 & 0,68 \\
\hline \multirow{2}{*}{$\sigma^{2}\left[\vartheta_{i}(\%)\right]$} & $u$ & 3,70 & 4,59 & 4,34 & 3,05 & 1,45 & 0,77 \\
\cline { 2 - 8 } & $v$ & 4,07 & 4,64 & 4,27 & 2,54 & 1,31 & 0,68 \\
\hline
\end{tabular}

cerca de $20 \%$ dos valores calculados alcançam a ordem de grandeza dos $10 \%$. Porém, o mesmo não se aplica ao quarto e quinto modos baroclínicos, onde seus valores médios e desvios-padrão de $\vartheta_{i}$ parecem ser simplesmente baixos demais para permitir uma distinção confiável entre sinais geofísicos e o ruído metodológico. Por fim, os resultados mostram que a importância relativa média do segundo modo baroclínico supera a do modo barotrópico, característica inesperada uma vez que pressupõe-se que formas barotrópicas sejam mais comuns nos oceanos por estarem ligadas à gradientes horizontais da altura da superfície livre, enquanto feições dinâmicas relacionadas ao segundo modo baroclínico raramente são citadas na literatura. Especula-se portanto que o fato de a estrutura vertical de velocidade abaixo dos primeiros $1500 \mathrm{~m}$ da coluna de água ser constante no tempo, aliado às inversões da velocidade em relação ao fluxo médio forçadas pela ação de ondas planetárias e outros fenômenos transientes, possam induzir erros na estimativa de $\vartheta_{0}$. Outra possibilidade é de que sinais barotrópicos sejam interpretados como baroclínicos, particularmente em regiões onde as formas funcionais dos modos baroclínicos apresentam suas inversões de sinais mais rasas em níveis próximos ou abaixo dos $1500 \mathrm{~m}$.

As Figuras 25 a 28 apresentam os mapas médios de $\vartheta_{i}$ referentes ao modo barotrópico e aos três primeiros modos baroclínicos, calculados para as componentes $u$ (painéis superiores) e $v$ (painéis inferiores) da velocidade geostrófica. Chama-se a atenção para o fato de que $\vartheta_{i}$ é calculado para cada ponto $(x, y, t)$ da grade considerada, em escala sinótica, e que por isso os mapas médios de $\vartheta_{i}$ não refletem a importância dos modos dinâmicos sobre o fluxo geostrófico mé- 

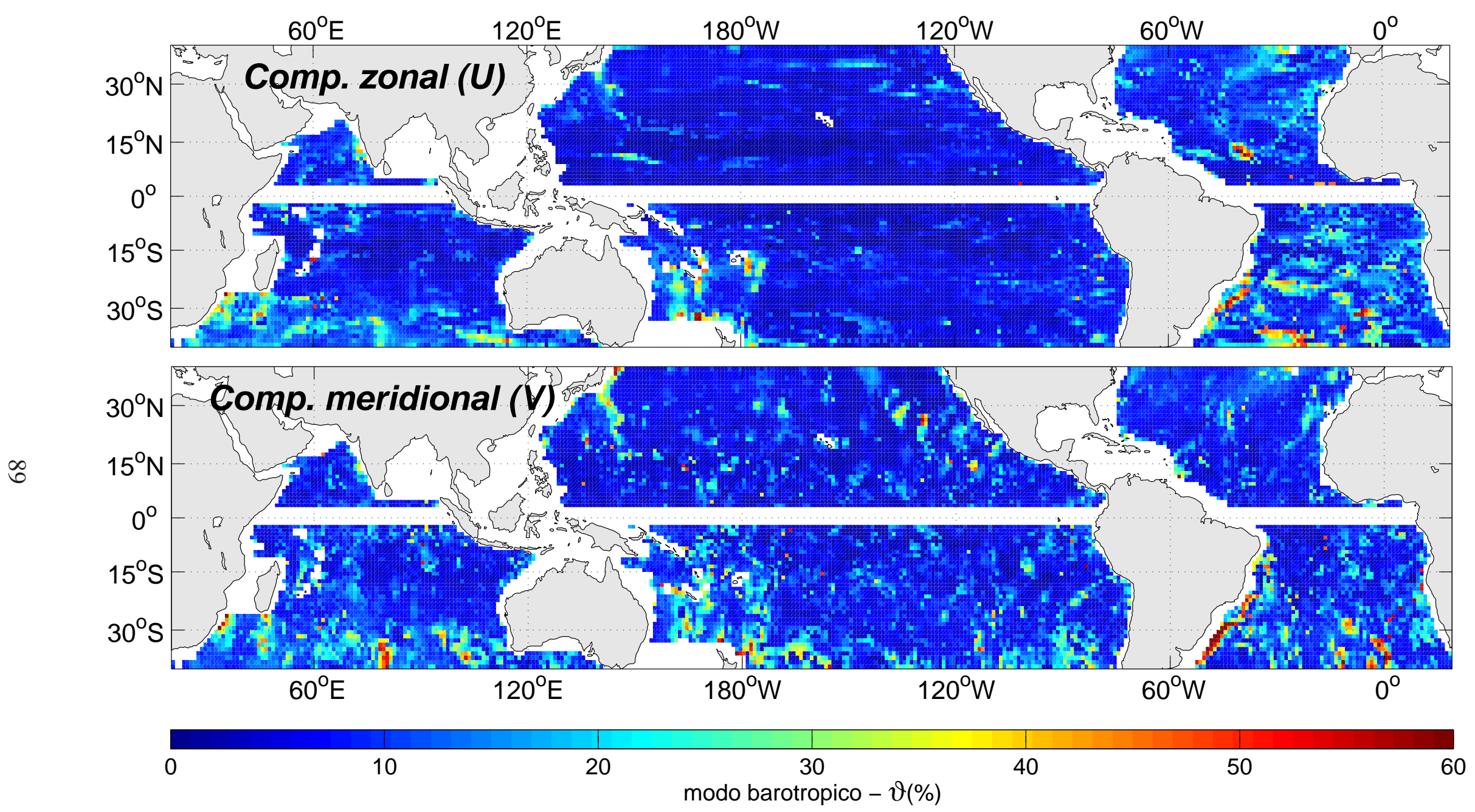

Figura 25: Médias globais de $\vartheta_{i}^{\prime}(\%)$ para as componentes u e v da velocidade geostrófica, considerando o modo barotrópico e os cinco primeiros modos baroclínicos. 


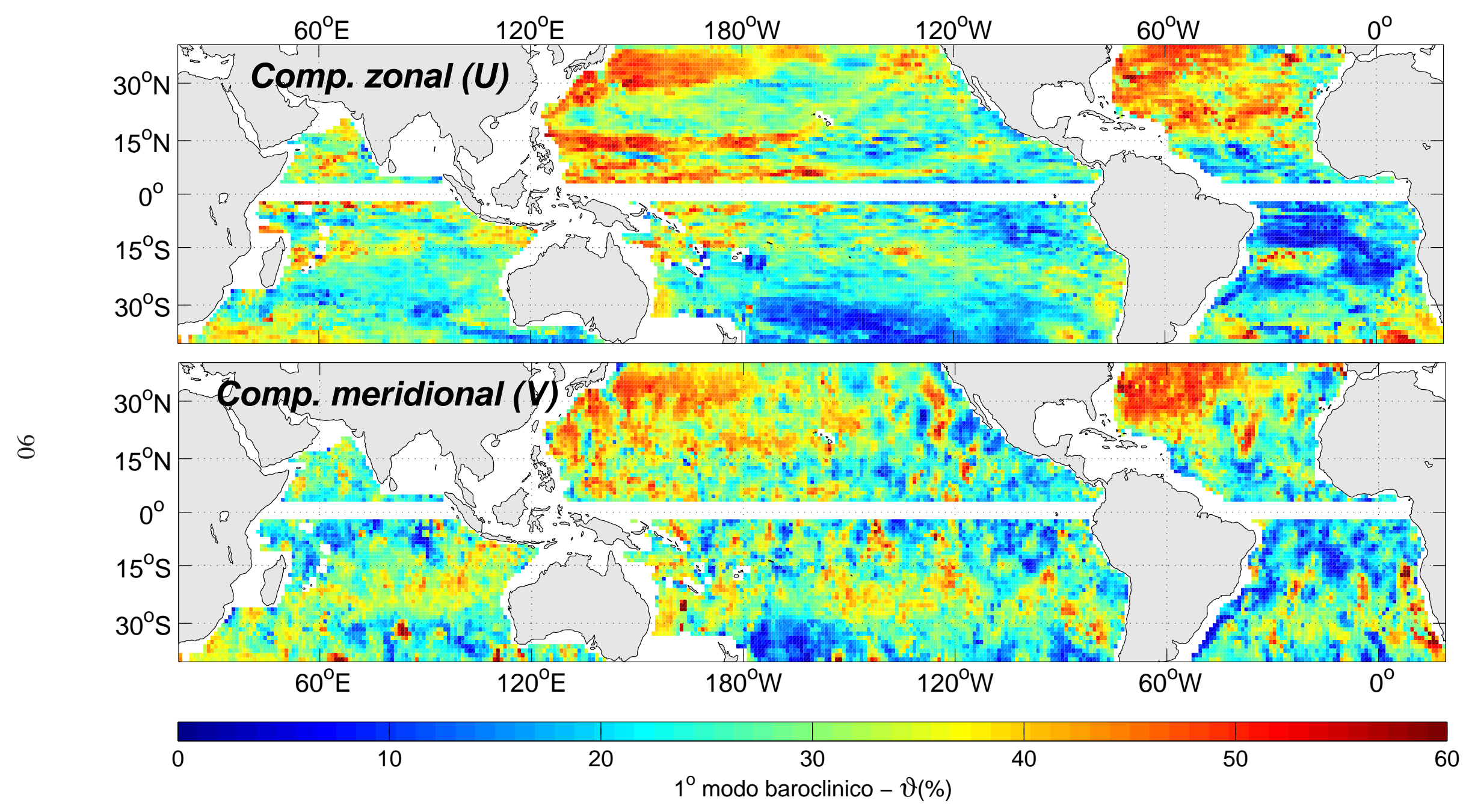

Figura 26: Similar à Figura 25, mas considerando o primeiro modo baroclínico. 


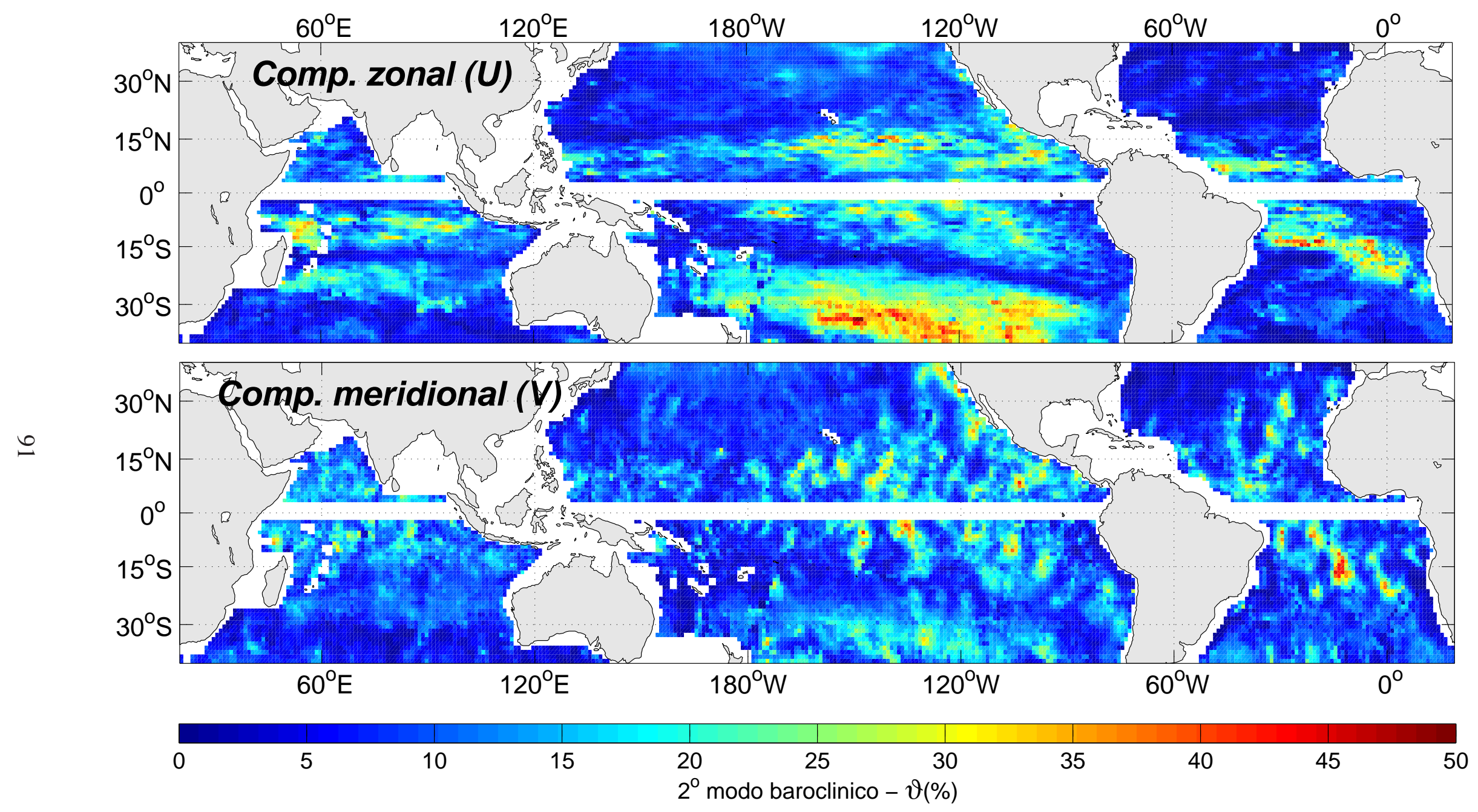

Figura 27: Similar à Figura 25, mas considerando o segundo modo baroclínico. 


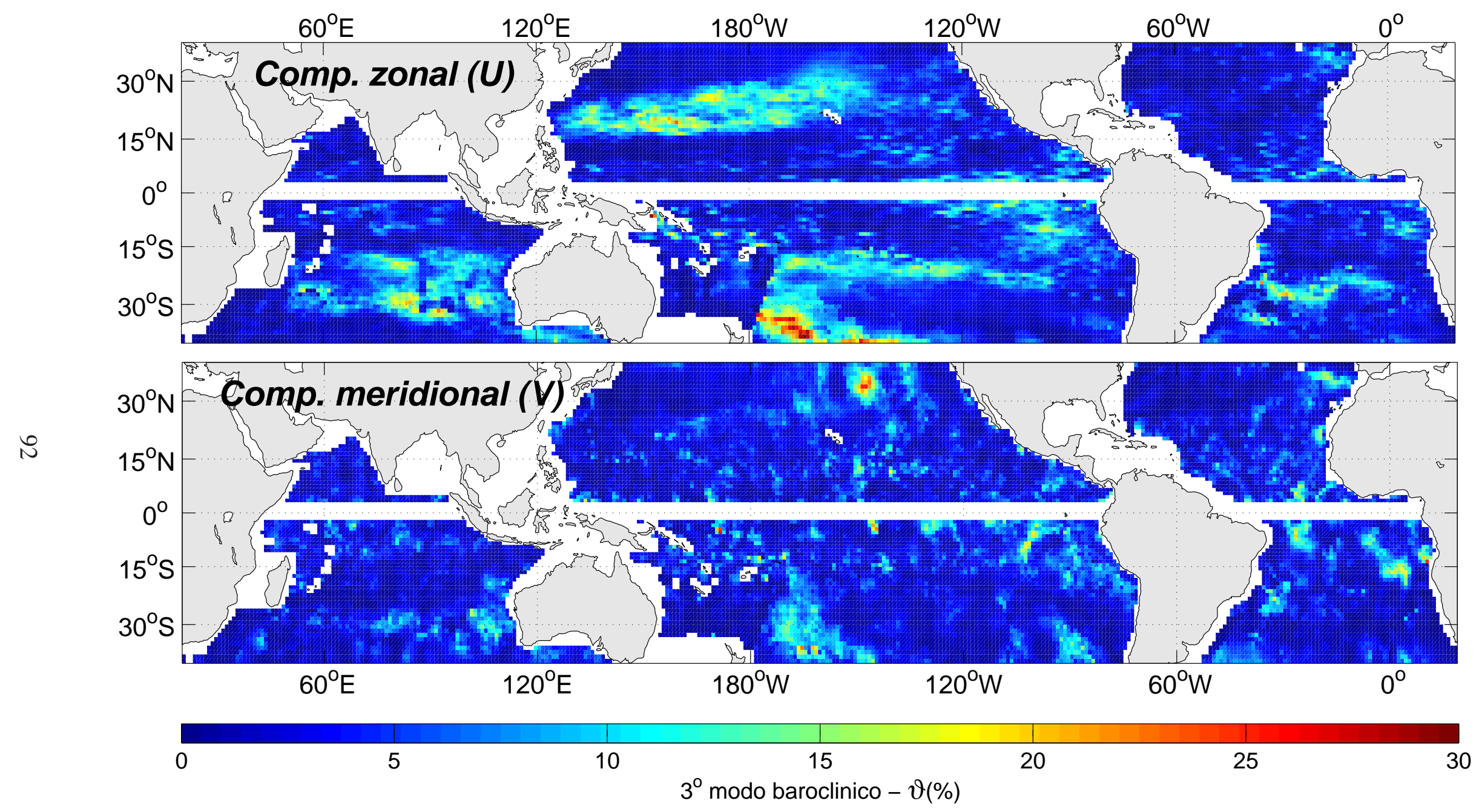

Figura 28: Similar à Figura 25, mas considerando o terceiro modo baroclínico. 
dio uma vez que a composição modal pode variar significativamente sob a ação de fenômenos transientes. Por exemplo, o fluxo médio de um sistema de correntes pode ser dominado pelo primeiro modo baroclínico, mas a contínua passagem de ondas planetárias do segundo modo induziria um aumento dos valores médios de $\vartheta_{2}$. Não só a ação de ondas, mas processos como a instabilização de correntes, o crescimentos de meandros, a emissão de vórtices, etc, não são contempladas no fluxo médio, tornando o cálculo de $\vartheta_{i}$ em escala sinótica uma análise dinamicamente mais relevante do que simplesmente a determinação da composição modal do campo geostrófico médio.

Como características gerais, as Figuras 25 a 28 mostram que as feições representadas por cada componente da velocidade para um mesmo modo dinâmico não são coincidentes entre si, característica atribuída à maneira como $\vartheta_{i}$ é calculado. Como descrito no tópico anterior, o método de determinação de $\vartheta_{i}$ não opera adequadamente quando as velocidades são baixas ao longo dos primeiros $1000 \mathrm{~m}$, em geral por implicarem em estruturas verticais mal resolvidas. Isto faz com que a estrutura modal de correntes com fluxo predominantemente zonal (meridional) sejam melhor representadas em mapas de $\vartheta_{i}$ calculados a partir da componente $u(v)$, explicando a assimetria observada. Adicionalmente, as feições presentes nos mapas são pouco suaves se comparadas aos resultados obtidos para perfis sintéticos e raios de deformação, particularmente para a componente $v$. Sua aparência granulada é atribuída à ação de fenômenos transientes, como ondas equatoriais, ondas de Rossby planetárias, meandros e vórtices de mesoescala (ainda que espacialmente subamostrados). Especula-se que a maior suavidade espacial do $\vartheta_{i}$ calculado sobre a componente $u$ deva-se ao fato de que, desconsideradas as correntes de contorno leste e oeste, os fluxos predominantes no interior das bacias oceânicas são essencialmente zonais, permitindo uma maior precisão no cálculo de $\vartheta_{i}$ ao longo desta componente. Outro possível condicionante seria o fato de a passagem de ondas de Rossby longas causar anomalias de velocidade predominantemente meridionais, destacando a expressão destes fenômenos sobre a componente $v$. É possível que o fluxo médio no interior das bacias também contribua para mascarar as anomalias decorrentes da passagem destas ondas sobre a componente $u$.

Especificamente nos mapas médios referentes ao modo barotrópico (Figura 25), observase que $\vartheta_{0}$ em média assume valores superiores à $20 \%$ sobre feições topográficas submarinas significativas, que incluem a cordilheira Meso-Atlântica, a cadeia submarina de Iozima ao sul 
do Japão, e as complexas topografias de fundo do oceano Índico ao sul da latitude de $30^{\circ} \mathrm{S}$, e do mar de Coral à leste da Austrália. Porém, estes padrões espaciais são pouco distintos e não delineam claramente os contornos batimétricos. Este efeito pode estar ligado à um tendenciamento metodológico, onde a diminuição da profundidade reduz a fração da coluna de água que é constante no tempo, permitindo uma melhor caracterização do modo barotrópico. Outra possibilidade é de que tais feições constituam evidências de uma conversão da energia contida no primeiro modo baroclínico para o modo barotrópico forçada pela topografia, fenômeno previsto pelo trabalho numérico de Barnier 1988. Esta possibilidade é discutida em maiores detalhes na seção 4.3.3, que analisa a estrutura modal das anomalias verticais em relação ao fluxo médio buscando especificamente prováveis regiões de ocorrência de ondas planetárias de diferentes modos dinâmicos.

Os mapas médios de $\vartheta_{0}$ mostram ainda feições junto à costa atlântica da América do Sul aproximadamente ao sul da latitude de $20^{\circ} \mathrm{S}$ com valores superiores à $60 \%$. Nada na literatura indica fluxos tão fortemente barotrópicos próximo à plataforma continental nesta região, pelo contrário. Devido à proximidade com a corrente do Brasil e aos fenômenos transientes associados à ela, como meandros e vórtices, espera-se que a circulação na região seja predominantemente baroclínica. Tratam-se portanto de resultados espúrios, possivelmente induzidos por falhas nos perfis sintéticos que escaparam aos critérios de exclusão estabelecidos. Especula-se que estas falhas sejam condicionadas pela menor eficiência dos dados altimétricos na representação das correntes de contorno oeste, em decorrência da resolução do modelo de geóide utilizado não permitir uma representação apropriada dos gradientes de pressão associados à estes fluxos intensos, aliada à baixa densidade relativa de perfis in situ na região.

A Figura 26 apresenta os mapas médios de $\vartheta_{1}$, que reafirmam a predominância do primeiro modo baroclínico na maior parte da área considerada. De fato, valores de $\vartheta_{1}$ superiores à $20 \%$ são observados em cerca de $82 \%$ dos pontos de grade (fração média das componentes $u$ e $v$ ), contra os $9 \%, 7 \%$ e $4 \%$ para os mapas de $\vartheta_{i}$ referentes aos modos 0,2 e 3, respectivamente. Os mapas construídos a partir de cada componente são visualmente semelhantes entre si, porém cada um carrega feições que não são representadas em seu correspondente e que podem refletir possíveis condicionantes geofísicas, como será descrito a seguir. Feições comuns à ambos os mapas incluem os valores de $\vartheta_{1}$ superiores à $50 \%$ observados nas porções noroeste dos oceanos Pacífico norte e Atlântico norte, associadas à porção oeste dos giros subtropicais e 
que incluem as correntes de Kuroshio e do Golfo, respectivamente. Valores de $\vartheta_{1}$ superiores à $35 \%$ são ainda observados em posições compatíveis com as correntes Leste-Australiana no oceano Pacífico, das Agulhas no oceano Índico, e de Benguela no Atlântico sul. Por fim, ambos os mapas evidenciam também a redução da importância relativa média do primeiro modo ao sul da latitude de $20^{\circ} \mathrm{S}$ no oceano Pacífico, na região equatorial deste mesmo oceano a partir aproximadamente do meridiano de $130^{\circ} \mathrm{W}$ até a costa sul americana, e na zona tropical do oceano Atlântico.

Especificamente para a componente $u$ (Figura 26, painel superior), feições alongadas de valores de $\vartheta_{1}$ coincidem com a posição de correntes zonais ao longo dos oceanos, proeminentemente no oceano Pacífico com as correntes do Pacífico norte e Norte Equatorial, sendo que neste mesmo oceano uma feição próxima ao equador extendendo-se zonalmente de $130^{\circ} \mathrm{W}$ a até $120^{\circ} \mathrm{E}$ pode se referir ao fluxo médio da Contra-Corrente Norte Equatorial. Feições equivalentes são menos distintas no hemisfério sul, mas valores significativos de $\vartheta_{1}$ são observados em posições compatíveis com as correntes Sul Equatorial e a corrente Sul do Oceano Índico, a corrente Sul Equatorial no Pacífico, e por fim as correntes Sul Equatorial e do Atlântico sul no oceano Atlântico. Em relação aos valores de $\vartheta_{1}$ sobre as posições médias das correntes, a importância relativa do primeiro modo baroclínico é comparativamente baixa no centro dos giros subtropicais dos oceanos Índico, Pacífico e no Atlântico sul. A distribuição dos valores de $\vartheta_{1}$ no mapa referente à componente $v$ (Figura 26, painel inferior) possuem um aspecto significativamente mais granulado, sendo que as feições no mapa da componente $u$ anteriormente atribuídas à correntes zonais simplesmente não são observadas. Em contrapartida, os valores de $\vartheta_{1}$ calculado a partir de $v$ se amplificam no interior dos giros subtropicais dos oceanos Índico, Pacífico e Atlântico sul, característica atribuída à ação de fenômenos como ondas planetárias do primeiro modo baroclínico e vórtices.

Mapas médios de $\vartheta_{2}$ são apresentados na Figura 27. Os valores referentes à componente $u$ formam feições significativamente mais suaves do que os obtidos a partir de $v$, sendo que as magnitudes que o $\vartheta_{2}$ médio assume em escala regional podem também diferir significativamente entre as componentes (por exemplo, no Pacífico sul valores superiores à 35\% são observados para a componente $u$, contra apenas $20 \%$ de $v$ ). À parte destas diferenças, amplificações dos valores médio de $\vartheta_{2}$ em geral ocorrem nas mesmas regiões dos mapas, e os padrões de larga escala formados são visualmente semelhantes entre si. As feições mais proeminentes 
são as amplificações dos valores de $\vartheta_{2}$ nas regiões tropicais dos três oceanos e notavelmente no oceano Pacífico ao sul da latitude de $20^{\circ} \mathrm{S}$, aproximadamente.

A presença de valores relativamente altos de $\vartheta_{2}$, superiores até mesmo à $\vartheta_{1}$, em algumas regiões do oceano é intrigante uma vez que inversões significativas do fluxo ao longo da vertical, possíveis assinaturas de modos baroclínicos superiores ao primeiro, não são comumente reportadas pela literatura. Buscando identificar como o segundo modo baroclínico se expressa nas regiões onde $\vartheta_{2}$ se amplifica, seções zonais-verticais das estruturas do primeiro e segundo modos baroclínicos e das componentes da velocidades geostrófica destas regiões foram avaliadas visualmente. Constatou-se que inversões da velocidade ao longo da vertical não são comumente observadas, e que as mudanças de sinal mais rasas nas formas funcionais do primeiro e segundo modos baroclínicos ocorrem em níveis diferentes, em geral mais profundos no primeiro modo. Para exemplificar, no oceano Pacífico em $30^{\circ} \mathrm{S}$, as mudanças de sinal mais rasas do primeiro e segundo modos ocorrem respectivamente entre os 1000 e $1700 \mathrm{~m}$ e entre 300 e $400 \mathrm{~m}$ de profundidade, aproximadamente. Os fluxos predominantes em geral foram observados em níveis acima da mudança de sinal mais rasa do segundo modo, com a velocidade reduzindo-se significativamente abaixo deste limite. Esta estrutura vertical resulta em maiores valores de $\vartheta$ para o segundo modo do que para o primeiro, mesmo sem serem distintamente observadas inversões da velocidade ao longo da vertical. Assim, deve ter-se em mente nesta análise que os perfis de velocidade geostrófica correspondem à uma combinação linear de modos dinâmicos, e que a amplificação dos valores de $\vartheta_{2}$ significa simplesmente que a forma funcional do segundo modo baroclínico apresenta melhor ajuste à estrutura vertical de velocidade geostrófica que os demais modos.

Ainda considerando os mapas médio de $\vartheta_{2}$ apresentados na Figura 27, especificamente no oceano Índico são observadas as maiores diferenças entre as feições representadas por cada componente da velocidade. Para a componente $u$, as amplificações de $\vartheta_{2}$ mais evidentes manifestam-se como duas faixas que cruzam a bacia zonalmente, centradas aproximadamente em $10^{\circ} \mathrm{S}$ e $25^{\circ} \mathrm{S}$, sendo que o formato em "L" da cordilheira de $90^{\circ} \mathrm{E}$ é claramente delineado por valores de $\vartheta_{2}$ de cerca de $20 \%$. Na componente $v$, maiores valores concentram-se próximo ao equador, sendo que a amplificação observada em $u$ na faixa centrada em $25^{\circ} \mathrm{S}$ não é observada. Como discutido para o primeiro modo baroclínico, a ausência deste sinal em $v$ pode se dever às baixas velocidades observadas no interior do giro subtropical para esta componente, 
afetando o cálculo de $\vartheta_{2}$. No oceano Pacífico os valores amplificam-se proeminentemente na zona tropical, aproximadamente a partir da linha internacional de mudança de data até a costa americana. A feição possui o formato semelhante à uma cunha, mais afilada próximo no interior da bacia e aumentando sua extensão meridional em direção ao leste. No Pacífico sul, uma feição aproximadamente diagonal é observada abaixo da latitude de $20^{\circ} \mathrm{S}$, cruzando a bacia zonalmente a partir da costa da América do Sul até a fossa de Tonga, à leste da Austrália. A feição topográfica referente ao arco de choque entre as placas Indo-Australiana e a do Pacífico, à leste da Austrália, é relativamente bem delineada pelos valores de $\vartheta_{2}$. Por fim, no oceano Atlântico os valores de $\vartheta_{2}$ dominam a região tropical, particularmente na porção oeste da bacia. A componente $u$ mostra ainda uma intensificação dos valores do lado leste da cordilheira MesoAtlântica no hemisfério sul, confinada entre as latitudes $10^{\circ} \mathrm{S}$ e $20^{\circ} \mathrm{S}$. Os padrões observados na componente $v$ são particularmente ruidosos, mas observa-se uma amplificação dos valores sobre a cordilheira Meso-Atlântica aproximadamente de $15^{\circ} \mathrm{S}$ até $30^{\circ} \mathrm{N}$.

Ainda na Figura 27, os padrões de $\vartheta_{2}$ observados próximo ao equador são coincidentes com os complexos sistemas de correntes e contra-correntes que compõe a circulação tropical, submetidos à fenômenos como ondas de Rossby com periodicidade intrasazonal à bianual, ondas de Kelvin e de instabilidade tropical (Polito e Liu 2003). Particularmente, o trabalho de Laurindo et al. 2010 observa na latitude de $4^{\circ} \mathrm{N}$ do Atlântico tropical um fenômeno propagante com períodos de cerca de 90 dias, cuja comparação de suas frequências e números de onda com curvas de dispersão teóricas para ondas lineares e a anomalia vertical de temperatura observada em uma série de dados in situ sugerem tratar-se de ondas de Rossby do segundo modo baroclínico. Ondas de Rossby com períodos intrasazonais observadas por Polito e Liu 2003 mostram maiores amplitudes em regiões coincidentes com zonas onde os mapas da Figura 27 indicam uma amplificação dos valores de $\vartheta_{2}$, proeminentemente na porção norte da região tropical dos oceanos Atlântico e Pacífico, e ao sul da linha do equador no oceano Índico. Por último, a amplificação dos valores de $\vartheta_{2}$ observada no oceano Pacífico ao sul da latitude de $20^{\circ} \mathrm{S}$ coincide com o fluxo da corrente do Pacífico Sul, que flui de oeste para leste entre as latitudes de $35^{\circ} \mathrm{S}$ e $30^{\circ} \mathrm{S}$ (Tomczak e Godfrey 2005), e parte do interior do giro subtropical. A variabilidade na região está associada à atividade de meso-escala, como meandros e vórtices, e à ação de ondas de Rossby com periodicidade semestral à bianual (Polito e Liu 2003).

Mapas médios de $\vartheta_{3}$ são apresentados na Figura 28. De todos os modos dinâmicos anali- 
sados, o terceiro baroclínico apresenta os menores valores de $\vartheta$ associados e as maiores diferenças entre as feições observadas entre os mapas deste parâmetro referentes à cada componente da velocidade geostrófica. Como para o segundo modo baroclínico, a observação de seções zonaisverticais da velocidade geostrófica e das estruturas verticais dos modos dinâmicos sugere que a amplificação dos valores de $\vartheta_{3}$ ocorre em regiões onde a mudança de sinal mais rasa nas formas funcionais do terceiro modo baroclínico coincidem com a profundidade acima da qual o fluxo geostrófico superficial é predominante, implicando em melhores ajustes entre este modo e estrutura vertical da velocidade.

Particularmente no mapa referente à componente $u$ (Figura 28, painel superior), a feição mais proeminente são os valores de $\vartheta_{3}$ de até $30 \%$ observados à leste da Austrália, que delineiam as fossas de Tonga e Kermadec observadas na região de encontro das placas do Pacífico e Indo-Australiana. Contíguos à esta feição, valores de até 10\% parecem delinear regiões dominadas pelo fluxo da corrente Sul Equatorial, centrada aproximadamente na latitude de $17^{\circ} \mathrm{S}$. Feições de $\vartheta_{3}$ com valores entre 10 e $20 \%$ são ainda observadas no centro dos giros subtropicais dos oceanos Índico, Pacífico norte e Atlântico sul, sendo que uma elevação dos valores até cerca de $10 \%$ é observada na região equatorial do oceano Pacífico relativamente próximo à costa americana. Curiosamente, o formato em "L" da cordilheira de $90^{\circ} \mathrm{E}$ no oceano Índico é claramente delineado por valores de $\vartheta_{3}$ próximos de zero, em contraste com o que é observado no mapa de $\vartheta_{2}$ médio para a componente $u$ (Figura 27, painel superior), onde valores de $\vartheta_{2}$ de até $20 \%$ também delineam a mesma porção da cordilheira. Esta pode ser uma evidência de interações com a topografia de fundo induzindo transferências de energia entre modos dinâmicos, no caso entre o segundo e terceiro modos baroclínicos.

As feições observadas no mapa referente à componente $v$ (Figura 28, painel inferior) possuem um aspecto significativamente mais granulado e são comparativamente pior resolvidas em relação ao mapa de $u$. Podem ser discernidas amplificações dos valores no sudoeste do Pacífico ao largo das fossas de Tonga e Kermadec, além de valores relativamente elevados no Pacífico equatorial próximo à costa americana e à oeste da Austrália, características também presentes em $u$ e provavelmente condicionadas pelos mesmo fatores. As demais características observadas, como os valores relativamente altos de $\vartheta_{3}$ observados em regiões isoladas do Pacífico norte e do oceano Atântico, não possuem paralelo com padrões observados em $u$ e a princípio parecem ser demasiadamente mal resolvidas para serem relacionadas à feições dinâmicas 
conhecidas.

As Figuras 29 a 32 apresentam os mapas do desvio-padrão em relação à média de $\vartheta_{i}$ para o modo barotrópico e os três primeiros modos baroclínicos, calculados para a componente $u$ (painéis superiores) e $v$ (painéis inferiores) da velocidade geostrófica. Em uma intepretação física, especula-se que as amplificações do desvio-padrão de $\vartheta_{i}$ nos mapas das Figuras 29 a 32 remetam à ação intermitente de fenômenos com estrutura vertical do modo dinâmico correspondente, particularmente de ondas de Rossby planetárias. Como afirmado anteriormente, a passagem destas ondas provoca anomalias de velocidade geostrófica com a forma funcional de seu modo correspondente, isto é, ondas de Rossby barotrópicas forçam anomalias verticalmente homogêneas, ondas do primeiro modo baroclínico com forma correspondente ao primeiro modo baroclínico, etc. Esta interpretação é suportada pelo fato de que é possível discernir sinais propagantes para oeste nos mapas sinóticos de $\vartheta_{i}$ para todos os modos dinâmicos considerados, apesar do ruído associado.

Em uma primeira análise, observa-se que as feições formadas pelos desvios-padrão de $\vartheta_{i}$ associados aos modos barotrópico e ao segundo e terceiro modos baroclínicos (Figuras 29, 31 e 32, respectivamente) são muito semelhantes aos formados por seus valores médios (Figuras 25, 27 e 28), sugerindo que a ocorrência de ondas planetárias do modo barotrópico (levando em conta as limitações envolvidas em sua detecção) e do segundo e terceiro modos baroclínicos é intermitente e limitada à regiões do oceano onde estes modos já respondem por uma maior parcela da circulação geostrófica média.

Especificamente para o primeiro modo baroclínico (Figura 30), os desvios-padrão de $\vartheta_{1}$ formam feições significativamente diferentes das observadas para suas médias de longo termo. Os mapas do desvio-padrão de $\vartheta_{1}$ apreendem os maiores valores dentre os modos dinâmicos, apresentando ainda a distribuição espacial mais homogênea. Ambas as componentes mostram que os desvios-padrão diminuem próximos aos limites norte dos oceano Pacífico e Atlântico, sendo que o mapa referente à componente $u$ mostra ainda reduções dos desvios em posições correspondentes às correntes que constituem os limites norte e sul dos giros subtropicais. As reduções nos valores podem se dever à um mascaramento dos sinais de ondas de Rossby pelo fluxo médio particularmente na componente $u$, e/ou ao fato de que estes fenômenos ocorrem com regularidade, e cujo sinal portanto está mesclado aos padrões médios de $\vartheta_{1}$. Os desviospadrão relativamente altos ao longo de praticamente toda a região do globo considerada é um 


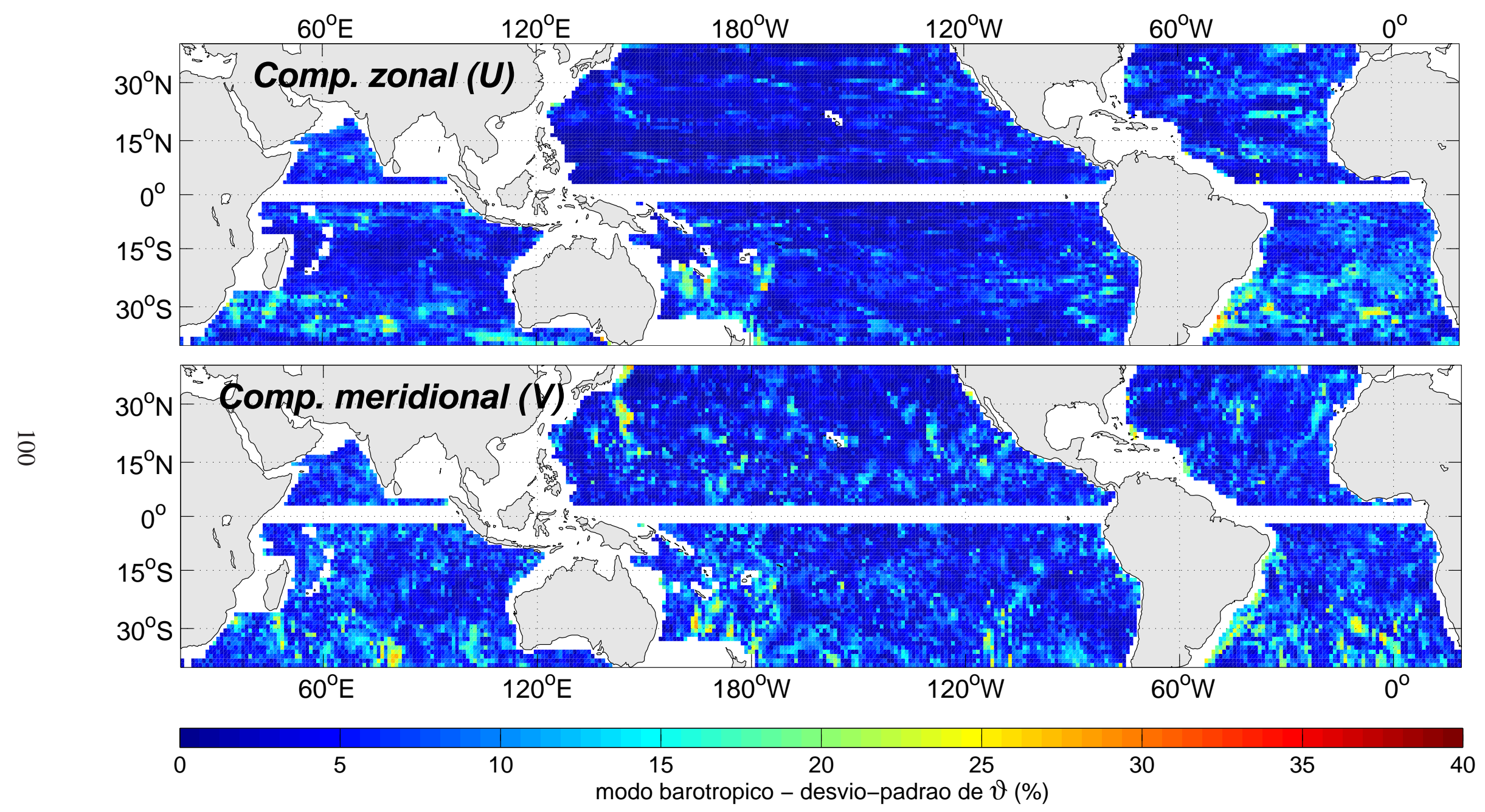

Figura 29: Mapas do desvio-padrão de $\vartheta_{0}$ para a componente u (painel superior) e v (painel inferior) da velocidade geostrófica. 


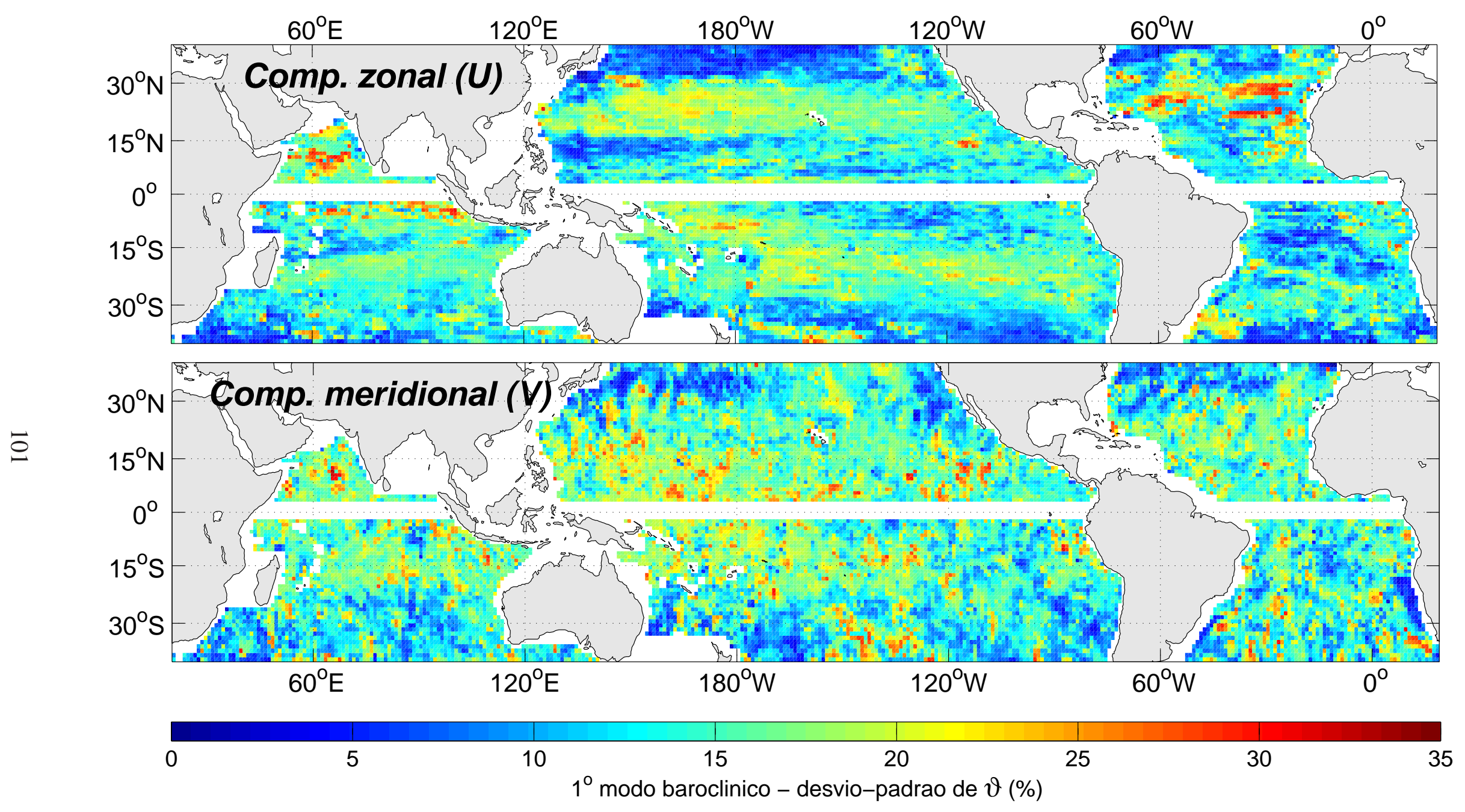

Figura 30: Similar à Figura 29, mas considerando $\vartheta_{1}$. 


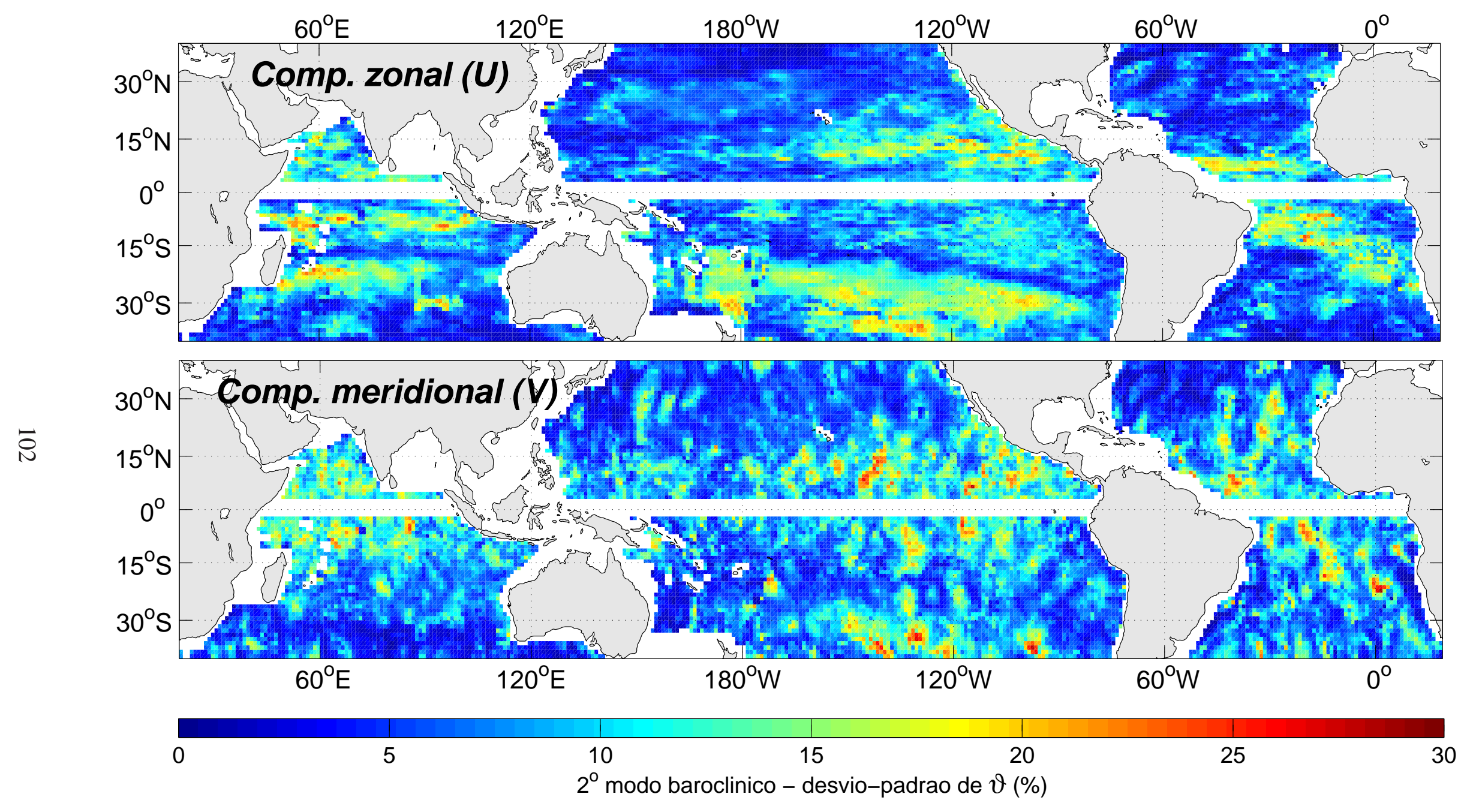

Figura 31: Similar à Figura 29, mas considerando $\vartheta_{2}$. 


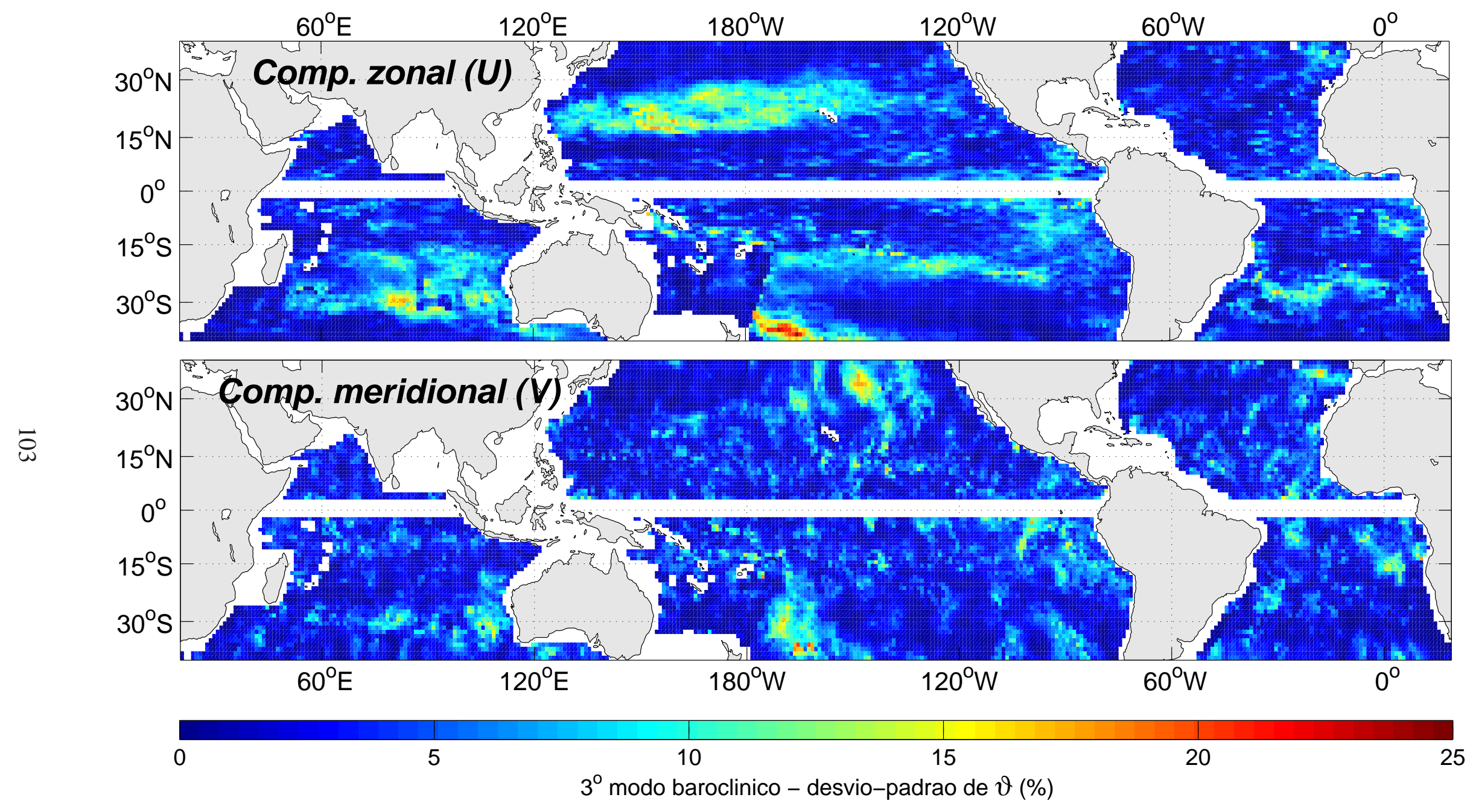

Figura 32: Similar à Figura 29, mas considerando $\vartheta_{3}$. 
indicativo de que fenômenos transientes com estrutura vertical relacionada ao primeiro modo baroclínico são predominantes no oceano. Este resultado é compatível com observações globais de sinais propagantes através de dados altimétricos, que sugerem que ondas de Rossby planetárias do primeiro modo baroclínico dominam o espectro da energia propagante para oeste nos oceanos (Chelton e Schlax 1996; Cipollini et al. 1997; Polito e Liu 2003; Challenor et al. 2004).

\subsubsection{Anomalias em relação ao fluxo médio}

Esta seção apresenta e discute os resultados obtidos para $\vartheta_{i}^{\prime}$, parâmetro interpretado como a fração da estrutura vertical das anomalias em relação à média de longo termo das componentes $u$ e $v$ da velocidade geostrófica que é explicada pelo $i$-ésimo modo dinâmico, cuja formulação é apresentada na Equação 25. Uma das premissas desta análise é de que a passagem de ondas planetárias provoca anomalias verticais de velocidade geostrófica com a forma funcional de seu modo dinâmico correspondente. Assim, enquanto os resultados de $\vartheta_{i}$ fornecem uma visão geral da importância relativa de cada modo dinâmico na composição da estrutura vertical da velocidade geostrófica, $\vartheta_{i}^{\prime}$ estima a composição modal das anomalias em relação ao fluxo médio especificamente com o objetivo de mapear possíveis regiões de ocorrência de ondas planetárias de diferentes modos dinâmicos.

A Tabela 4 apresenta as médias e os desvios-padrão dos valores de $\vartheta_{i}^{\prime}$ obtidos para o modo barotrópico e os cinco primeiros modos baroclínicos, calculados em todos os pontos $(x, y, t)$ da grade considerada. Os resultados são próximos aos obtidos para $\vartheta_{i}$, mostrados na Tabela 3, com as maiores diferenças sendo observadas na redução de cerca de 2 e $3 \%$ nos valores médios de $\vartheta_{0}$ para respectivamente as componentes $u$ e $v$ e de cerca de $2 \%$ em seus desvios-padrão, e no aumento de aproximadamente $5 \%$ nas médias de $\vartheta_{1}$. Também aqui o primeiro modo baroclínico mostra-se dominante, com os valores médios de $\vartheta_{i}$ decrescendo aproximadamente por uma razão de três conforme a ordem baroclínica aumenta, sendo que as médias e os desviospadrão de $\vartheta_{i}$ associados ao terceiro e quarto modos parecem implicar em valores baixos demais para serem capazes de refletir características de relevância geofísica. A representatividade do modo 0 é intermediária entre a observada para o segundo e terceiro modos. Como discutido na seção anterior, o fato de o modo barotrópico responder por uma fração da estrutura vertical de 
Tabela 4: Média e desvio-padrão dos valores de $\vartheta_{i}^{\prime}(\%)$ calculados para as componentes $\mathrm{u} e \mathrm{v}$ da velocidade geostrófica em todos os pontos $(\mathrm{x}, \mathrm{y}, \mathrm{t})$ da grade utilizada, considerando o modo barotrópico e os cinco primeiros modos baroclínicos.

\begin{tabular}{|c|c|c|c|c|c|c|c|}
\hline & $\mathrm{n}^{\circ}$ do modo $\Rightarrow$ & \multirow{2}{*}{0} & \multirow{2}{*}{1} & \multirow{2}{*}{2} & \multirow{2}{*}{3} & \multirow{2}{*}{4} & \multirow{2}{*}{5} \\
\hline & componente $\Downarrow$ & & & & & & \\
\hline \multirow{2}{*}{$\left\langle\vartheta_{i}^{\prime}(\%)\right\rangle$} & $u$ & 6,67 & 33,25 & 10,77 & 3,36 & 1,48 & 0,65 \\
\hline & $v$ & 6,53 & 33,08 & 10,85 & 3,27 & 1,40 & 0,62 \\
\hline \multirow{2}{*}{$\sigma^{2}\left[\vartheta_{i}^{\prime}(\%)\right]$} & $u$ & 1,95 & 4,29 & 3,81 & 2,05 & 1,38 & 0,74 \\
\hline & $v$ & 1,79 & 4,23 & 3,84 & 1,95 & 1,26 & 0,64 \\
\hline
\end{tabular}

velocidade inferior à do segundo modo baroclínico é uma característica inesperada. Considerase provável que os resultados de $\vartheta_{0}^{\prime}$ sejam subestimados na análise realizada aqui pelo fato de as estruturas de velocidade abaixo dos $1500 \mathrm{~m}$ serem incapazes de emular respostas barotrópicas.

As Figuras 33 a 36 mostram os mapas médios de $\vartheta_{i}^{\prime}$ referentes ao modo barotrópico e aos três primeiros modos baroclínicos, calculados a partir das anomalias das componentes $u$ (painéis superiores) e $v$ (painéis inferiores) da velocidade geostrófica em relação às respectivas médias de longo termo. Em contraste com os resultados de $\vartheta_{i}$ apresentados na seção anterior, os mapas de $\vartheta_{i}^{\prime}$ para todos os modos dinâmicos considerados mostram feições comparativamente suaves e bem resolvidas, característica atribuída à eliminação de possíveis erros decorrentes da presença de valores não nulos e constantes abaixo dos $1500 \mathrm{~m}$ e à interferência do fluxo médio. Adicionalmente, os mapas de $\vartheta_{i}^{\prime}$ de cada componente da velocidade referentes a um mesmo modo dinâmico apresentam feições surpreendentemente semelhantes entre si, o que à princípio parece contradizer a premissa de que a passagem de ondas de Rossby força anomalias de velocidade significativamente mais intensas ao longo do eixo meridional do que do zonal. Porém, é preciso ter-se em mente que $\vartheta_{i}^{\prime}$ não é proporcional à intensidade do fenômeno, mas sim ao grau de semelhança das formas funcionais das anomalias em relação aos modos dinâmicos. A similaridade das feições obtidas a partir de cada componente é antes interpretada como um indicativo de que, subtraído o fluxo médio, as anomalias verticais de velocidade forçadas pela passagem de ondas de Rossby assumem estruturas verticais bem definidas ao longo de ambos os eixos 

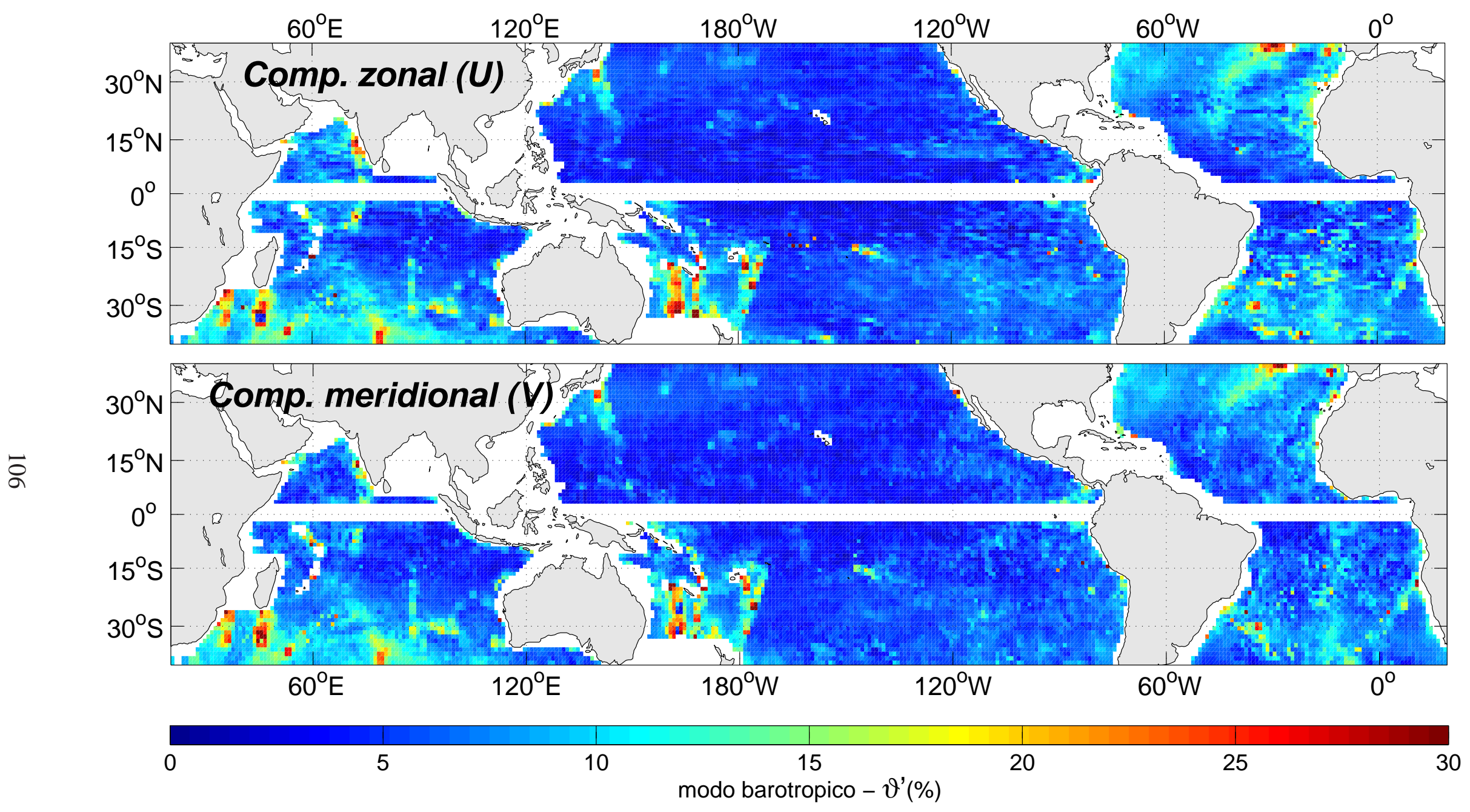

Figura 33: Mapas médios da percentagem da estrutura vertical da anomalia da velocidade geostrófica que é explicada pelo modo barotrópico $\left(\vartheta_{0}^{\prime}\right)$ para a componente $\mathrm{u}($ painel superior) e $\mathrm{v}$ (painel inferior). 


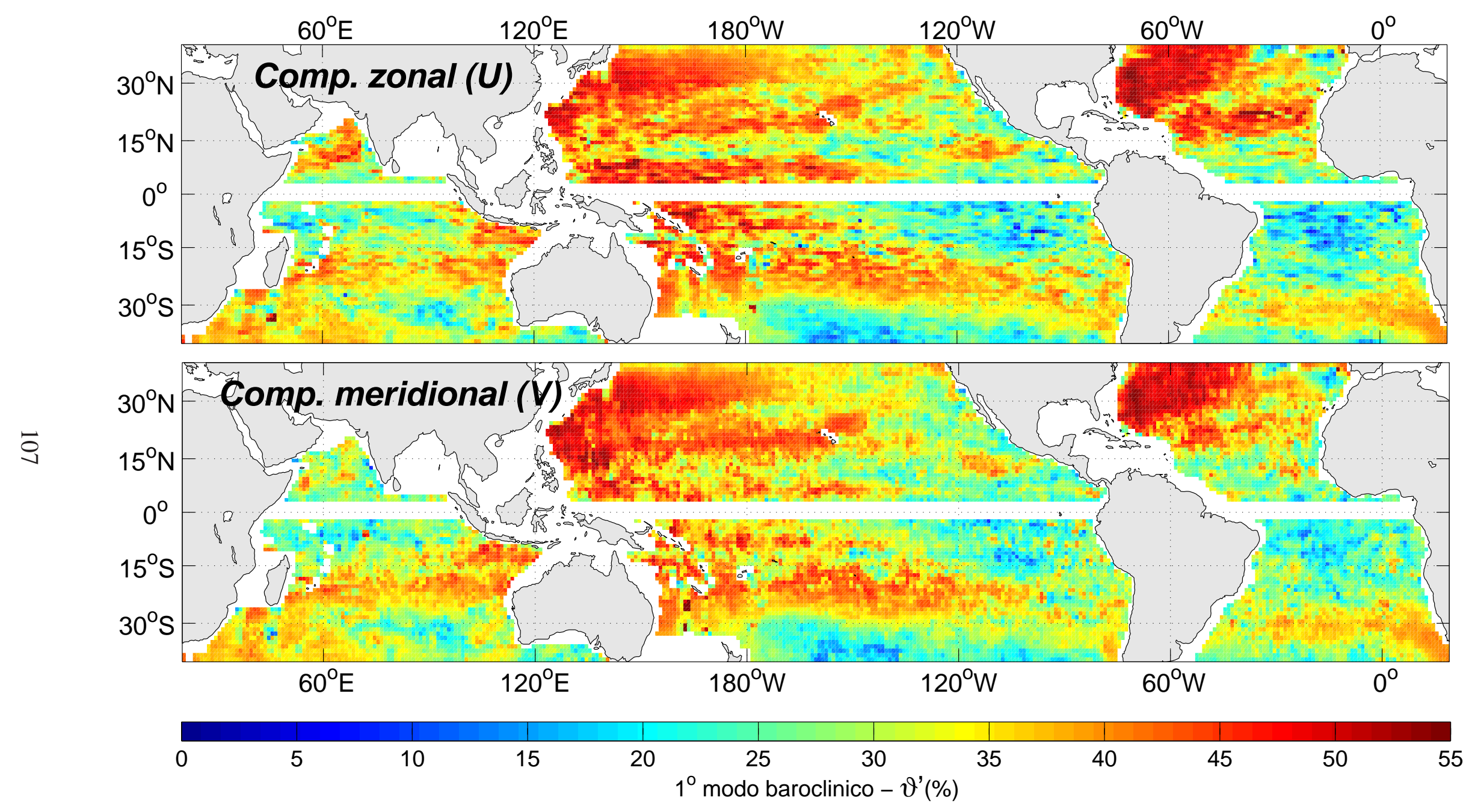

Figura 34: Similar à Figura 33, mas considerando o primeiro modo baroclínico. 


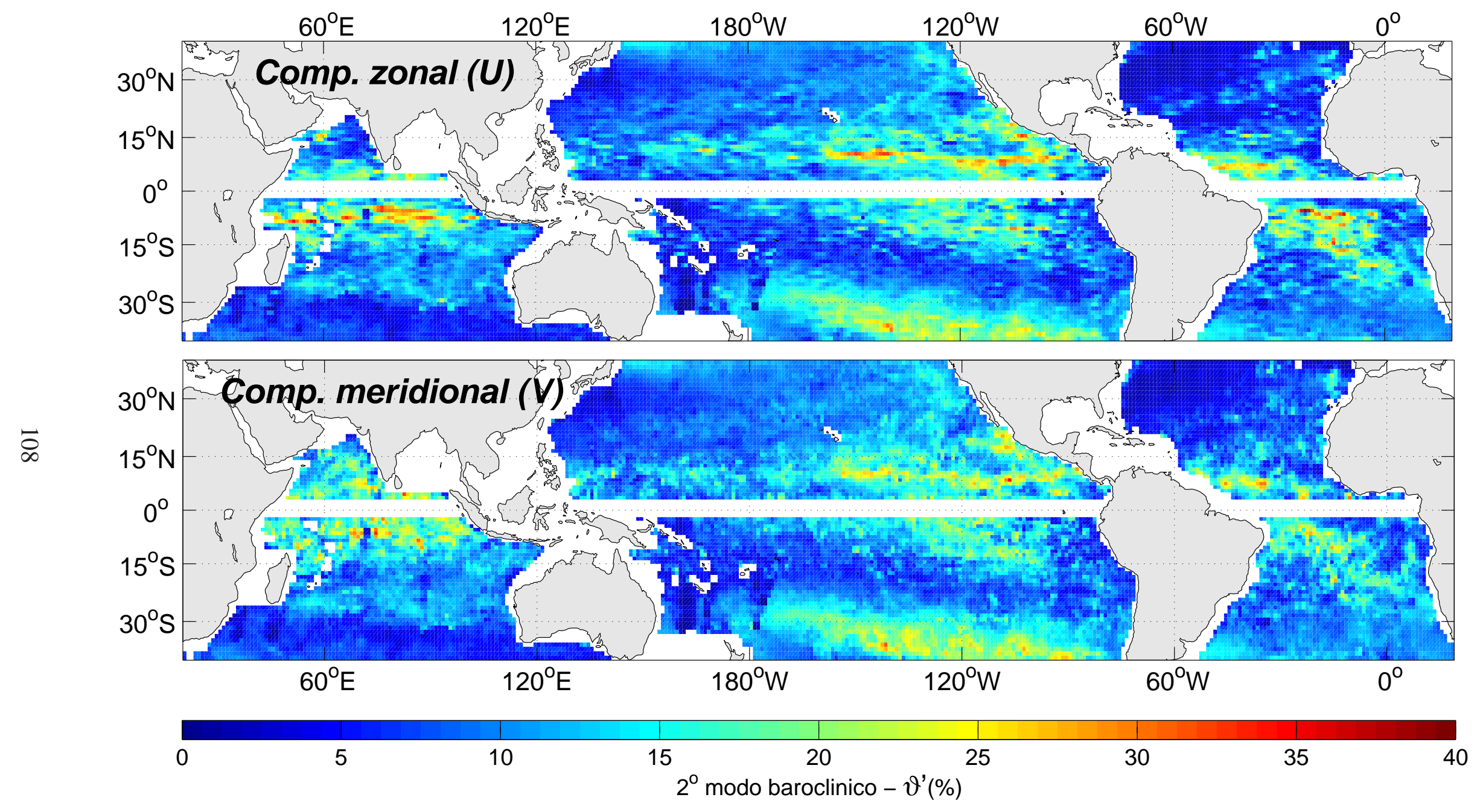

Figura 35: Similar à Figura 33, mas considerando o segundo modo baroclínico. 


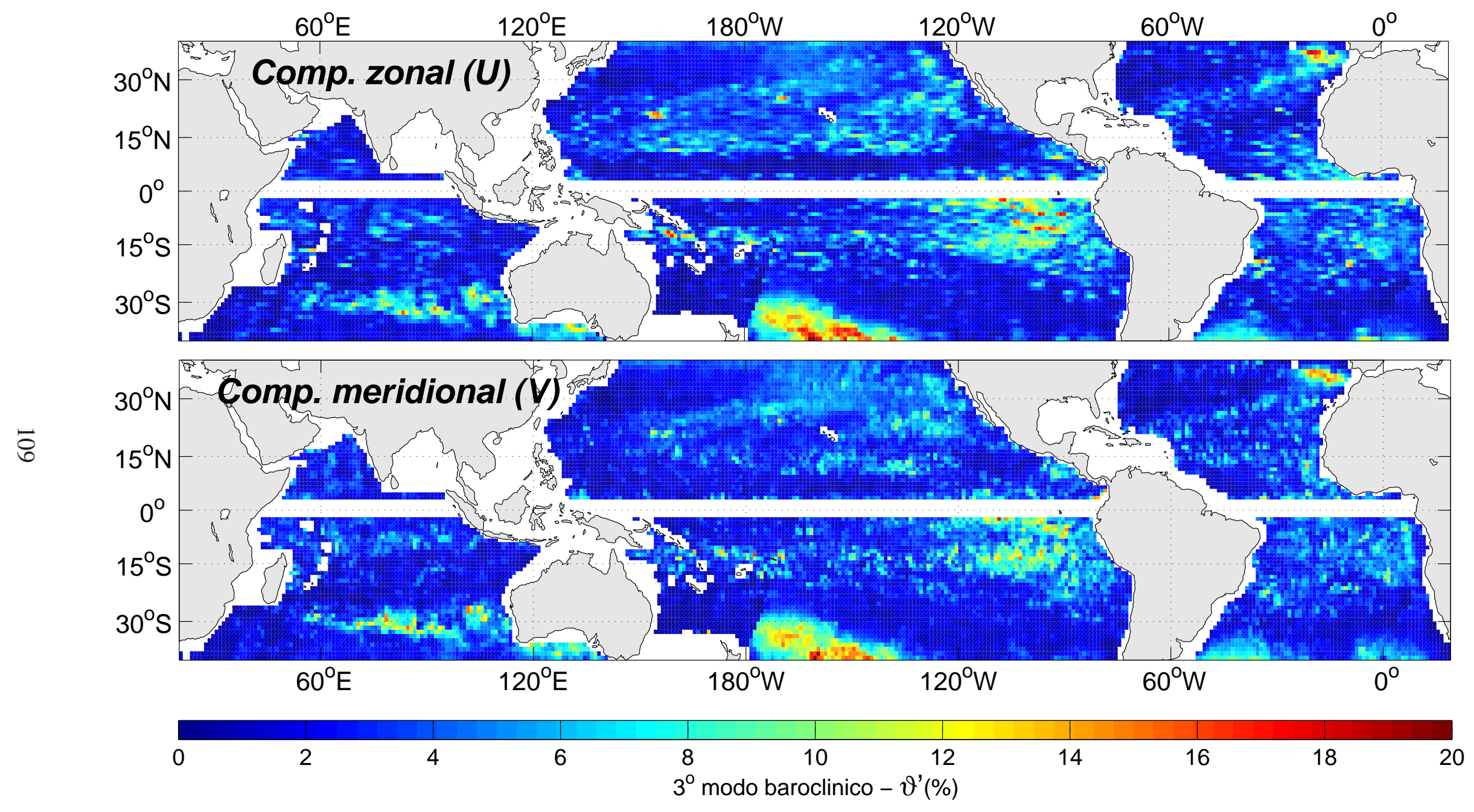

Figura 36: Similar à Figura 33, mas considerando o terceiro modo baroclínico. 
horizontais independentemente de sua magnitude, permitindo um funcionamento adequado do método de determinação de $\vartheta_{i}^{\prime}$ em ambas as componentes.

A Figura 33 apresenta os mapas médios de $\vartheta_{i}^{\prime}$ referentes ao modo barotrópico. A influência da batimetria é evidente, com valores de $\vartheta_{0}^{\prime}$ superiores à $10 \%$ claramente delineando diversas feições topográficas proeminentes do fundo marinho. Teoriza-se duas origens possíveis para este efeito, uma metodológica e outra geofísica. A origem metodológica baseia-se no fato de que a redução da profundidade poderia simplesmente permitir uma melhor caracterização da componente barotrópica da circulação, uma vez que a fração da estrutura vertical de velocidade que é constante no tempo é reduzida. A interpretação geofísica baseia-se no trabalho numérico de Barnier 1988, que simula a propagação de ondas de Rossby não-lineares do primeiro modo baroclínico através de uma cordilheira meridional submersa. Segundo Barnier 1988, a cordilheira bloqueia ondas do primeiro modo provenientes da porção leste da bacia, que ao interagir com a topografia transferem energia para um movimento barotrópico confinado à crista do obstáculo, cuja energia é retransferida para ondas planetárias do primeiro modo baroclínico sobre a face oeste da cordilheira. É possível que a amplificação dos valores de $\vartheta_{0}$ observada sobre feições topográficas de fundo sejam a assinatura do sinal barotrópico decorrente deste tipo de interação entre modos dinâmicos, mas devido às incertezas sobre a capacidade do conjunto sintético de velocidades geostróficas de representar o modo 0, esta hipótese precisa ser testada em trabalhos futuros. Uma característica dos mapas de $\vartheta_{0}^{\prime}$ que talvez suporte esta interpretação é a ausência de valores distintos de $\vartheta_{0}^{\prime}$ sobre algumas feições topográficas significativas, particularmente a cordilheira de $90^{\circ} \mathrm{E}$ no oceano Índico ao norte de aproximadamente $15^{\circ} \mathrm{S}$, e a cordilheira Meso-Atlântica desde a latitude de $15^{\circ} \mathrm{N}$ até as imediações do equador. Como será descrito em breve, as anomalias verticais de velocidade nestas regiões são dominadas pelo segundo modo baroclínico. Se estruturas verticais de velocidade correspondentes ao segundo modo interagirem com a batimetria de forma diferente que o primeiro modo, isto poderia explicar a ausência de valores significativos de $\vartheta_{0}^{\prime}$ delineando as feições topográficas mencionadas.

Os mapas médios de $\vartheta_{1}^{\prime}$ são apresentados na Figura 34, e evidenciam a dominância do primeiro modo baroclínico na estrutura vertical das anomalias de velocidade geostrófica nas zonas oceânicas consideradas. Os padrões espaciais formados pelos valores médios de $\vartheta_{1}^{\prime}$ são semelhantes aos observados na Figura 7 do trabalho de Polito e Liu 2003, que apresenta a raiz 
da média dos quadrados (root mean squared - RMS) das amplitudes superficiais de sinais altimétricos atribuídos à ondas de Rossby do primeiro modo baroclínico pertencentes à diferentes bandas espectrais. A observação destas ondas em Polito e Liu 2003 baseia-se na decomposição de diagramas zonais-temporais do $\eta$ altimétrico em componentes não-propagantes e propagantes em diferentes faixas de frequência através de filtros de resposta infinita, e a semelhança dos padrões espaciais do RMS dos sinais superficiais destas ondas com as feições observadas nos mapas da Figura 34 suporta a premissa de que $\vartheta_{i}^{\prime}$ reflete em grande parte a ação de ondas planetárias, neste caso pertencentes ao primeiro modo baroclínico.

Assim, analisados sob a luz dos resultados apresentados em Polito e Liu 2003, os mapas de $\vartheta_{1}^{\prime}$ da Figura 34 mostram valores superiores à 35\% na porção noroeste dos oceanos Pacífico norte e Atlântico norte, dominando toda a porção oeste dos giros subtropicais e projetando-se em direção ao leste ao longo de posições compatíveis com as correntes Norte-Equatoriais de ambos os oceanos. A variabilidade transiente nestas regiões é dominadas por ondas de Rossby com periodicidades variando de semestral à bianual. Posições compatíveis com as correntes Sul-Equatoriais dos giros subtropicais mostram também valores amplificados de $\vartheta_{1}^{\prime}$, onde as menores latitudes permitem a existência também de ondas de Rossby com periodicidade trimestral. Uma clara assimetria entre as porções leste e oeste dos giros subtropicais do hemisfério norte é observada, com menores valores de $\vartheta_{1}^{\prime}$ no oeste. No Pacífico equatorial em latitudes inferiores à $5^{\circ}$, valores amplificados de $\vartheta_{1}^{\prime}$ são observados na porção oeste da bacia. Polito e Liu 2003 não destaca as maiores contribuições ao espectro energético na região, mas parece estar contida proeminentemente em ondas de Rossby de frequências intrasazonais à bianuais e ondas de Kelvin. Os valores são comparativamente baixos na porção leste do Pacífico equatorial e na mesma faixa latitudinal nos oceanos Atlântico e Índico devido ao aumento da representatividade do segundo modo baroclínico nestas áreas, como será descrito em breve. No hemisfério sul, valores ampliados de $\vartheta_{1}^{\prime}$ parecem destacar processos transientes associados à correntes de contorno leste e oeste, sendo que as principais feições observados são faixas zonais cruzando as bacias oceânicas. Nos oceanos Índico e Pacífico, tais faixas ocupam latitudes coincidentes com as posições de suas correntes Sul-Equatoriais e parte significativa do interior dos giros, enquanto no Atlântico os maiores valores observados aparentemente ocupam o centro do giro subtropical. Para todos os casos, a variabilidade propagante na região é dominada por ondas de Rossby com periodicidade de trimestral à bianual. Nos oceanos Índico e Atlântico, amplifi- 
cações dos valores de $\vartheta_{1}^{\prime}$ a até $40 \%$ são coincidentes com a posição das correntes das Agulhas de do Sul do Índico, cujo espectro propagante inclui ondas com períodos de semestral à bianual, sendo que a maior fração da energia está contida em ondas anuais.

Chama-se a atenção para o fato de que vórtices de meso-escala podem responder por frações significativas da variabilidade ao longo de todo o oceano, e são também capazes de induzir variações expressivas sobre a estrutura termohalina vertical. A resolução espacial de $1^{\circ} \times 1^{\circ} \operatorname{dos}$ dados sintéticos não é capaz de resolver apropriadamente as escalas típicas da ordem de 10 à 100 km destes fenômenos, sendo que ainda um problema em aberto uma distinção apropriada entre ondas de Rossby e vórtices, uma vez que a expressão superficial destes fenômenos é semelhante e que vórtices, ao perturbar o campo de vorticidade potencial, podem induzir a geração de mecanismos de propagação semelhantes ao de ondas planetárias. Porém, mesmo com estas limitações, feições proeminentes nos mapas médios de $\vartheta_{1}^{\prime}$ (Figura 34) também parecem marcar regiões onde corredores de vórtices foram reportados, o que pode significar que o conjunto é capaz de representar variações da estrutura baroclínica em resposta à sua passagem mesmo não resolvendo adequadamente a sua estrutura espacial. Tais feições incluem a emissão de vórtices e anéis da retroflexão da corrente das Agulhas para o interior do Atlântico sul (Penven et al. 2001), e a formação de corredores de vórtices induzidos pelo efeito topográfico de ilhas oceânicas, como Cabo Verde (Sangrà et al. 2009) e as ilhas do Havaí (Calil et al. 2008).

Por fim, ainda na Figura 34, efeitos topográficos não parecem exercer influência importante sobre a distribuição dos valores de $\vartheta_{1}^{\prime}$, porém diminuições podem ser observadas em posições compatíveis com a cordilheira Meso-Atlântica no Atlântico norte, sobre a cadeia de Iozima ao sul do Japão, e sobre as complexas feições batimétricas sob o mar de Coral à leste da Austrália. Tais reduções podem corresponder à transferência de energia entre o primeiro modo baroclínico e o modo barotrópico sobre feições de fundo significativa, como teorizado a partir da observação dos mapas médios de $\vartheta_{0}^{\prime}$ apresentados na Figura 33.

Mapas médios de $\vartheta_{2}^{\prime}$ são apresentados na Figura 35. As feições observadas aqui são semelhantes às descritas para os mapas médios e do desvio-padrão de $\vartheta_{2}$ (Figuras 27 e 31, respectivamente), mas como nos demais modos, são melhor resolvidas e os resultados obtidos a partir de cada componente são muito semelhantes entre si. Em uma breve descrição, as feições mais proeminentes são observadas nas regiões tropicais dos três oceanos, sendo que também observados valores significativos de $\vartheta_{2}^{\prime}$ no sul do oceano Pacífico. As feições observadas próximo 
ao equador podem refletir a influência de fenômenos como ondas de Rossby, Kelvin e de instabilidade tropical. Particularmente no oceano Índico, a região imediatamente ao sul do Equador onde valores superiores à 25\% são observados é dominada pelo fenômeno do dipolo do oceano Índico e uma fração significativa da energia propagante para oeste está contida em ondas de Rossby planetárias bianuais (Polito e Liu 2003; Gnanaseelan et al. 2008). No Pacífico e Atlântico, valores desta magnitude destacam regiões onde ondas de Rossby intrasazonais (períodos entre 50 e 90 dias) e ondas de instabilidade tropical apresentam maior expressão (Polito e Sato 2003; Polito e Liu 2003; Laurindo et al. 2010). Adicionalmente, valores elevados também são observados no sul do Pacífico aproximadamente ao sul da laitude de $20^{\circ} \mathrm{S}$, se estendendo desde a fossa de Tonga à leste da Austrália até a costa da América do Sul. A espectro de ondas de Rossby na região segundo observações altimétricas apreende ondas com periodicidade de semestral à bianual (Polito e Liu 2003). Por fim, a batimetria não parece exercer efeitos significativos, mas algumas feições de fundo são delineadas por variações relativamente pequenas dos valores médios de $\vartheta_{2}^{\prime}$, particularmente a cordilheira de $90^{\circ} \mathrm{E}$ e outras feições notáveis do oceano Índico e a batimetria de fundo do mar de Coral à leste da Austrália.

São raras as observações de ondas planetárias referentes ao segundo modo baroclínico nos oceanos. Particularmente, o trabalho de Brandt et al. 2002 relata que ondas anuais do primeiro e segundo modos são responsáveis por intensas flutuações sazonais entre $6^{\circ} \mathrm{N}$ e $10^{\circ} \mathrm{N}$ no Mar da Arábia. Sua análise utiliza como base observacional dados altimétricos e séries temporais de dados hidrográficos, e os resultados obtidos são consistentes com a ampliação dos valores médios de $\vartheta_{1}^{\prime}$ (Figura 34) e $\vartheta_{2}^{\prime}$ (Figura 35) observados na região. Especificamente no Atântico tropical, o trabalho de Laurindo et al. 2010 observa sinais propagantes com períodos de cerca de 90 dias entre $3,5^{\circ} \mathrm{N}$ e $5,5^{\circ} \mathrm{N}$ cujos valores de frequência e número de onda sugeriam modos baroclínicos superiores ao primeiro. A análise de uma série temporal de dados de temperatura da bóia ATLAS da rede PIRATA posicionada em $4^{\circ} \mathrm{N} / 38^{\circ} \mathrm{W}$ coincidente com a ocorrência destes sinais mostraram anomalias térmicas de cerca de $2^{\circ} \mathrm{C}$ ocorrendo oposição de fase com anomalias de até $9^{\circ} \mathrm{C}$ em níveis compatíveis com a termoclina climatológica, configuração compatível com a estrutura vertical do segundo modo baroclínico na região. Teorizou-se que os sinais observados correspondiam portanto à ondas de Rossby do segundo modo baroclínico, resultado compatível com os altos valores médios de $\vartheta_{2}^{\prime}$ observados no Atlântico (Figura 35). Por fim, Maharaj et al. 2007 faz uso da transformada de Fourier bidimensional sobre dados de 
$\eta$ para avaliar a contribuição de ondas de Rossby de diferentes modos baroclínicos ao espectro energético do Pacífico sul. O trabalho mostra que ondas do primeiro modo dominam o espectro energético, seguidas pelo segundo e terceiro modos, resultado consistente com a importância relativa de cada modo descrita pela Tabela 4. Porém, os mapas da variância explicada por ondas de cada modo apresentados por Maharaj et al. 2007 mostram padrões substancialmente diferentes dos observados aqui nos mapas de $\vartheta_{i}^{\prime}$ mostrados aqui, característica que pode se dever à uma possível insensibilidade dos altímetros à modos baroclínicos superiores ao primeiro.

A Figura 36 apresenta os mapas médios de $\vartheta_{3}^{\prime}$ calculados para ambas as componentes da velocidade geostrófica. As principais feições incluem a amplificação dos valores para até $20 \%$ no sudoeste do Pacífico à leste da Austrália, valores entre 8 e $18 \%$ na região equatorial do Pacífico sul próximo à costa sul americana, uma faixa com valores de até $16 \%$ estendendose aproximadamente sobre a latitude de $30^{\circ} \mathrm{S}$ no oceano Índico, e por fim valores de até $20 \%$ observados na porção leste do oceano Atlântico aproximadamente sobre a latitude de $35^{\circ} \mathrm{N}$, ao largo do estreito de Gibraltar. Ondas de Rossby do terceiro modo baroclínico são ainda mais raramente reportadas na literatura do que ondas do segundo modo, sendo que sua existência normalmente é inferida através análises espectrais (Cipollini et al. 1997; Maharaj et al. 2007). Não foram encontrados exemplos de observações diretas de sua passagem, sendo que os baixos valores de $\vartheta_{3}^{\prime}$ sugerem que anomalias verticais dominadas pelo terceiro modo baroclínico (ou seja, ondas de Rossby efetivamente referentes à este modo dinâmico) de fato são raras nos oceanos. Especificamente, especula-se que a feição observada no sudoeste do Pacífico deva-se ao aumento gradual da profundidade no sentido leste-oeste, em direção às fossas de Tonga e Kermadec. O aumento da profundidade faz com que as formas funcionais do primeiro, segundo e terceiro modos baroclínicos apresentem suas primeiras inversões em níveis mais profundos, enquanto a profundidade acima da qual os fluxos dominantes em superfície prdominam (no caso, da corrente do Pacífico Sul e dos fenômenos transientes que ocorrem na região) não muda significativamente, fazendo com que o terceiro modo baroclínico apresentasse um melhor ajuste às anomalias verticais locais de velocidade. Fluxos mais rasos nas porções oeste das bacias do Pacífico e Atlântico podem também implicar em melhores ajustes dos perfis de velocidade ao terceiro modo baroclínico, implicando nas amplificações dos valores médios de $\vartheta_{3}^{\prime}$ observadas nestas regiões. Particularmente, os altos valores observados na porção nordeste do oceano Atlântico podem estar associados ao corredor de vórtices em níveis de termoclina emitidos 
a partir do estreito de Gibraltar (McDowell e Rossby 1978; Bower et al. 1995). Curiosamente, o trabalho de Cipollini et al. 1997 avalia o espectro energético de diagramas zonais-temporais de dados altimétricos e dados de TSM para a latitude de $34^{\circ} \mathrm{N}$ no oceano Atlântico, reportando três velocidades distintas que especula corresponderem à ondas de Rossby dos três primeiros modos baroclínicos. Por fim, as razões possíveis para o aumento dos valores de $\vartheta_{3}^{\prime}$ discutidas até o momento parecem não se aplicar à faixa zonal observada no oceano Índico, uma vez que uma análise qualitativa não revelou mudanças significativas na estrutura dos modos dinâmicos e nem do fluxo que possam justificar tal aumento. Porém, observa-se que a o contorno zonal da cordilheira de $90^{\circ} \mathrm{E}$ é delineado por baixos valores, enquanto os mapas de $\vartheta_{2}^{\prime}$ acusam um ligeiro aumento sobre esta feição. Isto pode também ser evidência de um mecanismo de transferência de energia entre modos baroclínicos, no caso entre o segundo e terceiro modos, análogo ao descrito por Barnier 1988 entre o modo barotrópico e o primeiro baroclínico.

As Figuras 37 a 40 apresentam os mapas dos desvios-padrão de $\vartheta_{i}^{\prime}$ para o modo barotrópico e os três primeiros modos baroclínicos, calculados a partir das anomalias em relação à média de longo termo das componentes $u$ (painéis superiores) e $v$ (painéis inferiores) da velocidade geostrófica. O significado físico dos desvios-padrão de $\vartheta_{i}^{\prime}$ não é de fácil interpretação, uma vez que este parâmetro já lida com anomalias. A explicação mais direta é de que os desviospadrão de $\vartheta_{i}^{\prime}$ estejam ligados à intermitência de fenômenos com anomalias verticais dominadas pelos modos correspondentes. Por exemplo, altos valores médios de $\vartheta_{1}^{\prime}$ (Figura 34) são observados na porção noroeste do oceano Atlântico, com baixos desvios-padrão associados (Figura 38). Assim, especula-se que a região esteja continuamente sob a ação de fenômenos ligados ao primeiro modo, o que implicaria em variações pequenas dos valores de $\vartheta_{1}^{\prime}$ ao longo do tempo e consequentemente em baixos desvios-padrão. Adicionalmente, a coexistência de ondas planetárias de diferentes modos dinâmicos pode amplificar os desvios-padrão, uma vez que a presença de anomalias com formas referentes à diferentes modos dinâmicos implicaria em maiores variações dos valores de $\vartheta_{1}^{\prime}$ calculados.

Teoriza-se que mudanças da estrutura interna de densidade induzida pela passagem de ondas planetárias possam forçar modificações da distribuição da variância entre os modos, constituindo portanto uma forma de interação não-linear. Da mesma forma, ondas planetárias sobrepostas entre si e/ou com fenômenos de larga escala altamente energéticos, como o El Niño, poderiam também interagir de maneira não-linear, também induzindo alterações da energia 


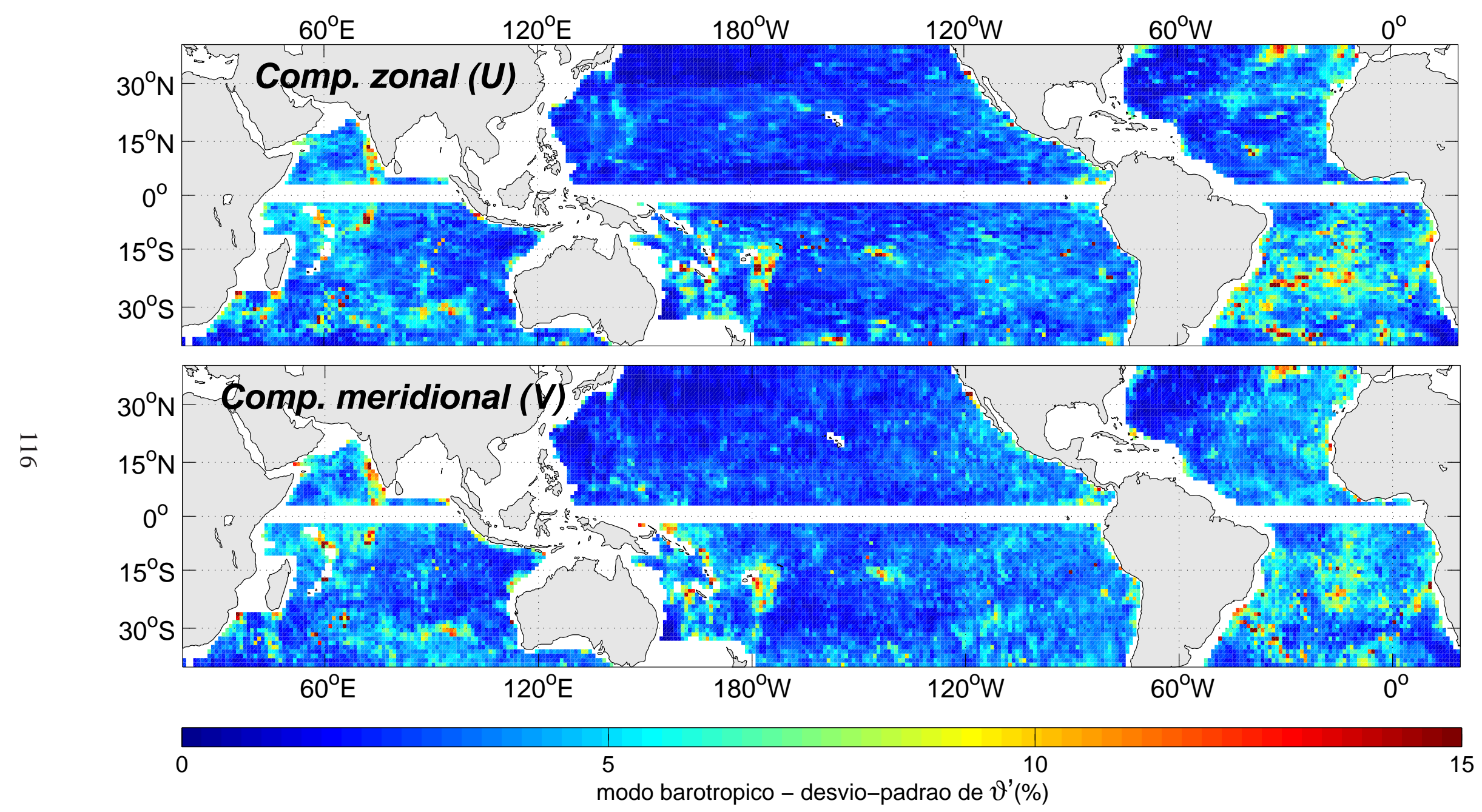

Figura 37: Mapas do desvio-padrão de $\vartheta_{0}^{\prime}$ para a componente $\mathrm{u}$ (painel superior) e $\mathrm{v}$ (painel inferior) da velocidade geostrófica. 

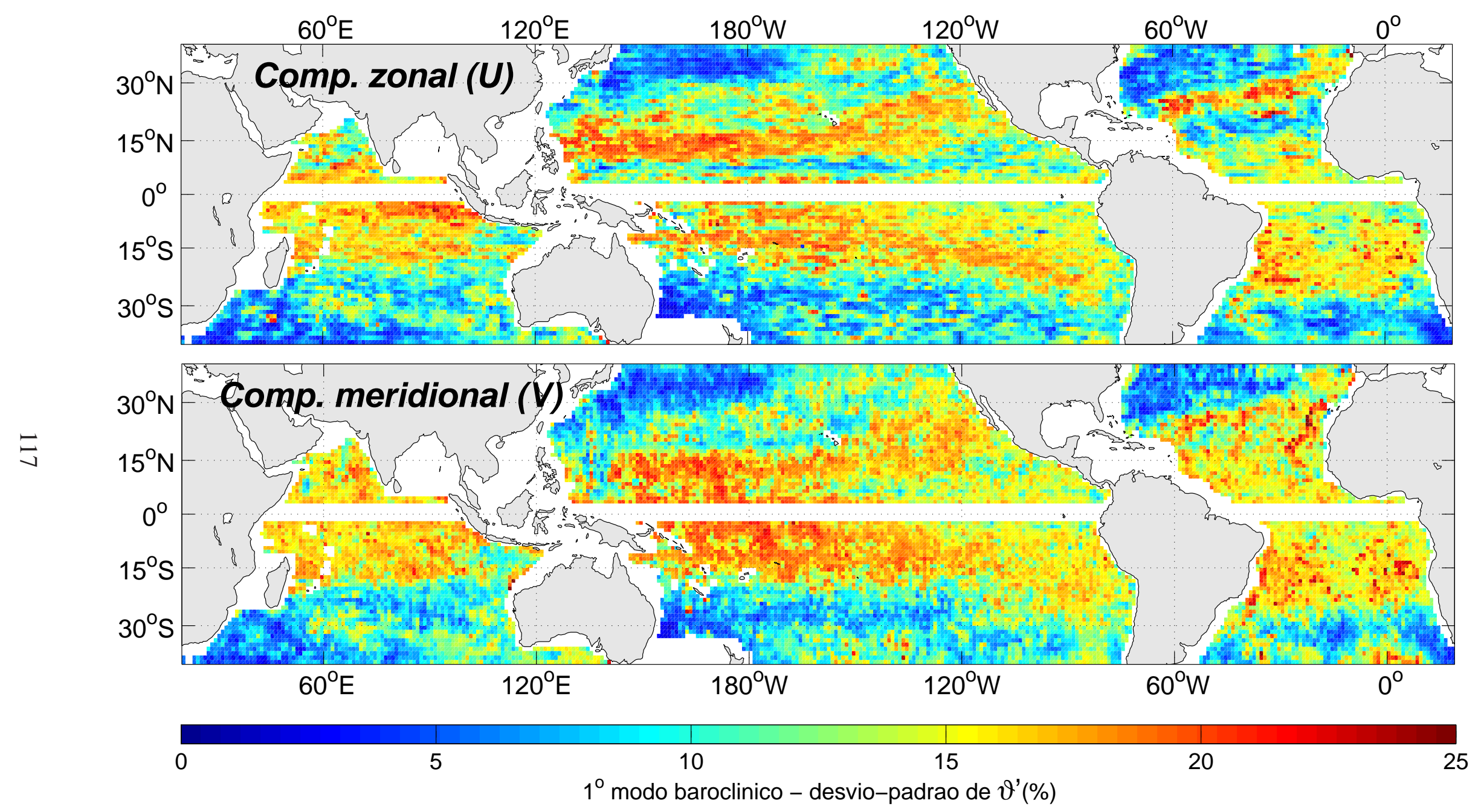

Figura 38: Similar à Figura 37, mas considerando $\vartheta_{1}^{\prime}$. 

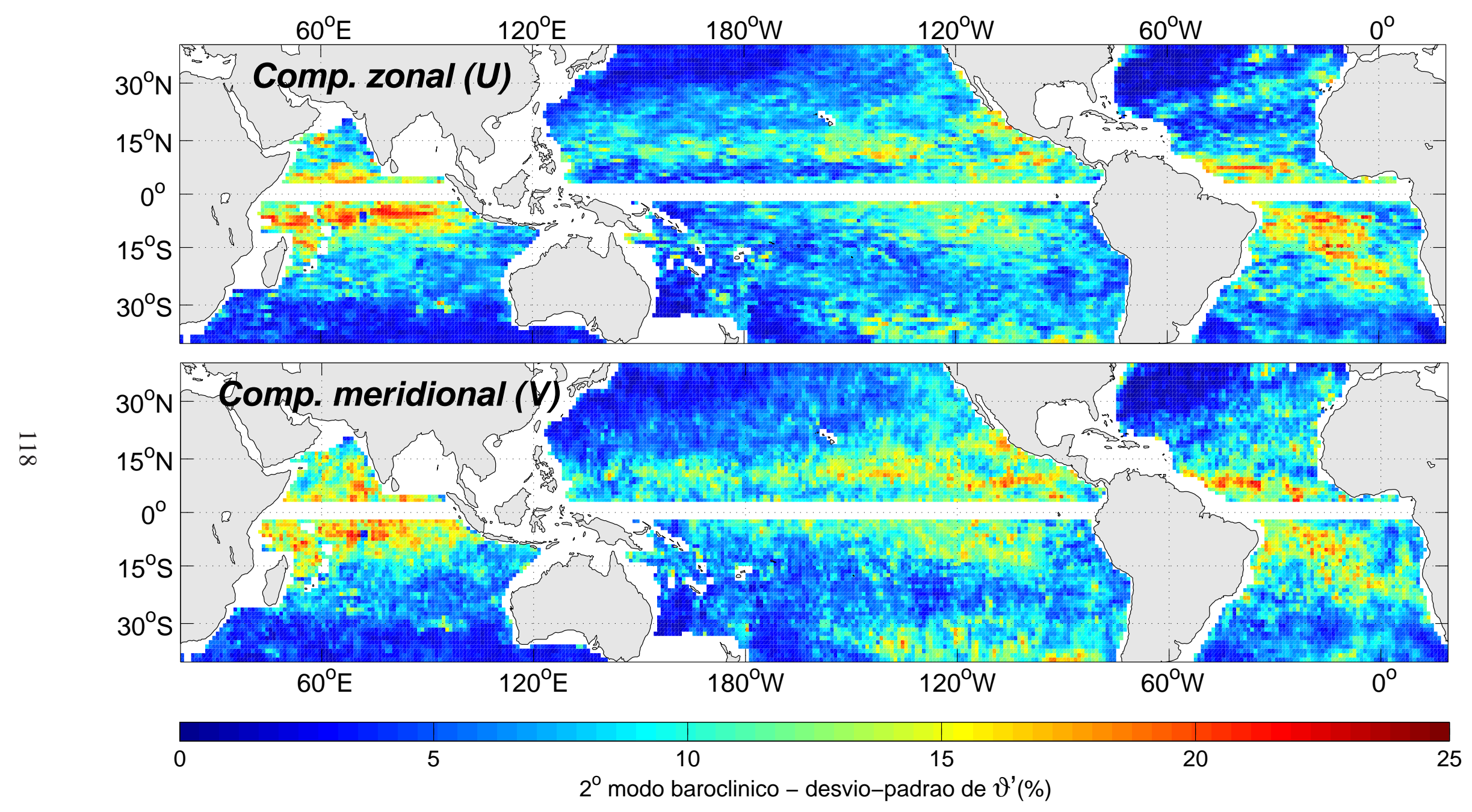

Figura 39: Similar à Figura 37, mas considerando $\vartheta_{2}^{\prime}$. 


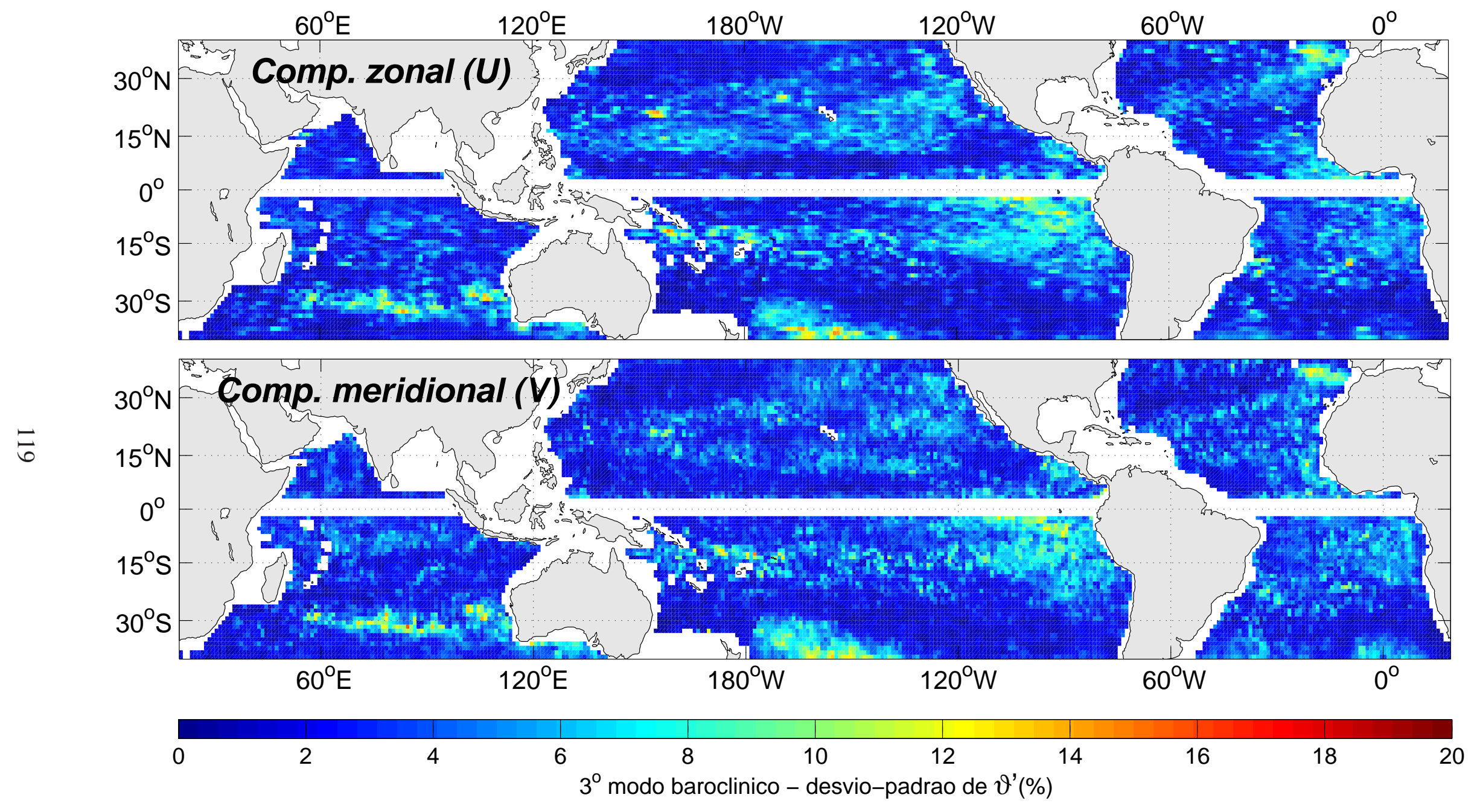

Figura 40: Similar à Figura 37, mas considerando $\vartheta_{3}^{\prime}$. 
contida em cada modo dinâmico. Por exemplo, o aprofundamento da picnoclina decorrente do El Niño no Pacífico equatorial oeste poderia forçar mudanças na estrutura modal de fenômenos como ondas de instabilidade tropical e ondas de Rossby curtas. Especula-se portanto que maiores desvios-padrão destaquem também regiões onde possíveis interações não-lineares deste tipo ocorram, simplesmente por implicarem em anomalias verticais dominadas por diferentes modos dinâmicos coexistindo em uma mesma área.

Como também observado nos mapas do desvio-padrão de $\vartheta_{i}$, as feições formadas pelos desvios-padrão de $\vartheta_{i}^{\prime}$ para o modo barotrópico e o segundo e terceiro modos baroclínicos (Figuras 37, 39 e 40, respectivamente) são muito semelhantes às observadas nos mapas médios (Figuras 33, 35 e 36). Este é um indicativo de que possíveis ondas de Rossby barotrópicas (novamente aqui, deve levar-se em conta as limitações envolvidas em sua observação) e dos segundo e terceiro modos baroclínicos são fenômenos intensos e intermitentes, cuja ocorrência é condicionada por características geofísicas específicas às zonas oceânicas onde estas feições são observadas. No caso do modo barotrópico, os desvios-padrão possuem magnitudes comparativamente baixas em comparação com os demais modos, sendo que sua amplificação sobre obstáculos batimétricos é compatível com a hipótese de transferência de energia entre o modo 0 e o primeiro modo baroclínico através do mecanismo descrito por Barnier 1988. Para o segundo e terceiro modos baroclínicos, como afirmado anteriormente, seções zonais-verticais de suas formas funcionais cruzando feições significativas de seus valores médios e do desviopadrão de $\vartheta_{i}$ e $\vartheta_{i}^{\prime}$ mostram que a profundidade da primeira inversão de sinal ao longo de suas formas funcionais permite melhores ajustes aos fluxos predominantes na coluna de água em relação ao primeiro modo, cuja inversão nestes casos em geral ocorre em níveis significativamente mais profundos. Talvez esta característica faça com que ondas de modos superiores ao primeiro sejam respostas energeticamente viáveis do oceano a perturbações de larga escala no campo de vorticidade potencial, o que explicaria o fato de sua maior expressão nestas regiões. Esta hipótese precisa ser testada em trabalhos futuros, sendo que as características dos sinais propagantes identificados aqui como prováveis ondas planetárias de modos diferentes do primeiro (especificamente, seus números de onda e freqüências associadas) devem ser avaliadas sobre curvas de dispersão teóricas para confirmar a sua natureza dinâmica e os modos baroclínicos que são efetivamente refletidos por sua propagação.

Particularmente para o primeiro modo baroclínico, os mapas dos desvios-padrão de $\vartheta_{1}^{\prime}$ 
(Figura 38) mostram feições significativamente diferentes das formadas por seus valores médios (Figura 34). É observada uma clara diferença na magnitude dos valores associados ao interior dos giros subtropicais e em regiões mais próximas ao equador nos três oceanos. Como descrito anteriormente, em um primeiro momento especula-se que os menores desvios-padrão nos giros subtropicais sejam um indicativo de que ondas planetárias do primeiro modo ocorram continuamente na região, implicando em baixas variações dos valores de $\vartheta_{1}^{\prime}$ e consequentemente em baixos desvios-padrão. Os maiores desvios em latitudes mais baixas indicariam (a) uma maior intermitência dos processos transientes, em decorrência da expansão do espectro de ondas planetárias para faixas de maior frequência ou mesmo da mudança de um regime de ondas de latitudes médias para um regime equatorial, e/ou (b) a coexistência de anomalias referentes ao primeiro modo com outros modos dinâmicos, uma vez que a importância relativa do segundo modo baroclínico cresce junto ao equador. Por fim, os baixos desvios-padrão observados no interior dos giros subtropicais pode ainda significar que as ondas observadas ali podem ser melhor descritas pela teoria linear do que ocorrem na faixa tropical. A relevância deste possível aspecto da não-linearidade na propagação de ondas planetárias baroclínicas deve ser investigada mais a fundo em trabalhos futuros.

Por fim, observa-se que as feições presentes nos mapas médios e do desvio-padrão de $\vartheta_{2}^{\prime}$ (Figura 35 e 39) são semelhantes às apresentadas pelo mapa do desvio-padrão das diferenças percentuais (DPs) do segundo raio de deformação interno (Figura 22). Mapas de ambos os parâmetros apresentam valores significativos nas regiões equatoriais dos três oceanos. Particularmente na porção oeste do Pacífico equatorial, todos os mapas mostram valores significativos ocupando uma faixa meridionalmente mais extensa junto à costa americana e que tornando-se mais estreita em direção ao interior da bacia, sendo que maiores valores são observados aproximadamente sobre a latitude de $10^{\circ} \mathrm{N}$. Ainda no oceano Pacífico, os mapas mostram valores ampliados ao sul da latitude de $30^{\circ} \mathrm{S}$, em uma feição alongada que se estende desde a costa da América do Sul até as fossas de Tonga e Kermadec, à leste da Austrália. A ampliação dos valores junto à confluência de Kuroshio-Oyashio e na região de separação da corrente do Golfo da costa observadas no mapa das DPs em relação ao segundo raio interno não possui paralelo nos valores médios e do desvio-padrão de $\vartheta_{2}$. Porém, como discutido na seção 4.2.2, os altos valores das DPs associados a estes sistemas dinâmicos deve-se à presença de frentes oceânicas em conjunto com a ação de fenômenos transientes, fazendo com que raios de deformação calcu- 
lados para diferentes formas de estratificação vertical sejam comparadas entre si resultando em diferenças significativas em relação às médias locais. A correspondência entre feições formadas pelas DPs dos raios internos e as formadas pelas médias e desvios-padrão de $\vartheta_{i}^{\prime}$ é menos evidente para o terceiro modo baroclínico, mas padrões comuns entre o mapa dos desvios-padrão das DPs para o terceiro raio interno (Figura 23) e os mapas médios e dos desvios-padrão de $\vartheta_{3}^{\prime}$ ainda podem ser distinguidas. Estas feições incluem os maiores valores observados no sudoeste do Pacífico ao largo das fossas de Tonga e Kermadec (embora a amplificação das DPs seja apenas sutil nesta região), neste mesmo oceano junto à costa americana ao sul da linha do equador, e por fim no oceano Índico aproximadamente sobre a latitude de $25^{\circ} \mathrm{S}$. Para o primeiro modo baroclínico, observa-se que os padrões formados por valores elevados da média e desvio-padrão de $\vartheta_{1}^{\prime}$ (Figuras 34 e 38) são muito mais extensos que os observados para as DPs do primeiro raio interno (Figura 21). Porém, valores elevados das DPs do primeiro raio interno em geral coincidem com altos valores médios e/ou do desvio-padrão de $\vartheta_{1}^{\prime}$.

O fato de as variações mais expressivas dos raios internos coincidirem com regiões onde é observada a maior atividade de possíveis sinais de ondas planetárias em ordens baroclínicas correspondentes, particularmente para o segundo modo, é evidência de uma interligação dos mecanismos físicos condicionando cada parâmetro. Uma implicação direta seria que ondas planetárias de modos baroclínicos superiores ao primeiro forçariam variações dos raios proporcionalmente maiores que ondas do primeiro modo, e estando portanto mais propensas à ação de efeitos não-lineares decorrentes da interação entre sua propagação e a alteração da estratificação interna forçada por sua própria passagem.

Outra implicação recai sobre a observabilidade dos diferentes modos internos pelos altímetros. Como discutido na seção 4.2.2, mapas sinóticos das anomalias percentuais do primeiro raio interno em relação às médias locais de longo termo mostram feições muito semelhantes às observadas em mapas do $\eta$ altimétrico, sendo que em ordens baroclínicas superiores o sinal sazonal vai se tornando cada vez mais evidente. Teorizou-se que as variações dos raios se referissem à faixas cada vez mais rasas da coluna de água conforme $i$ aumenta, explicando a melhor definição do sinal sazonal, implicando também que fenômenos cuja expressão em níveis mais rasos também poderiam ser melhor representados em $i>1$. De fato, uma análise qualitativa mostra que além do sinal sazonal, os mapas referentes ao segundo raio interno também destacavam feições suavizadas ou mesmo inexistentes nas DPs do primeiro raio interno. Os re- 
sultados obtidos nesta seção sugerem que as feições destacadas pelas DPs do segundo e terceiro raios de fato correspondem à formas de variabilidade com estruturas verticais ligadas ao segundo e terceiro modos baroclínicos, evidência que suporta uma insensibilidade dos altímetros orbitais à modos baroclínicos maiores que o primeiro.

Por fim, chama-se a atenção para o fato de que os raios de deformação são calculados individualmente em cada ponto de grade a partir dos dados de densidade locais, enquanto os perfis de velocidade geostrófica são calculados a partir dos gradientes horizontais de densidade, e portanto sua forma funcional depende da organização espacial dos dados. A constatação de que estes parâmetros distintos da dinâmica oceânica podem estar respondendo aos mesmos processos suporta a conclusão de que o conjunto de dados sintéticos desenvolvido aqui constitui uma representação fisicamente consistente da variabilidade dos oceanos acima dos $1000 \mathrm{~m}$ de profundidade. 


\section{Sumário e Conclusões}

Este trabalho avalia a importância relativa dos modos dinâmicos na composição dos perfis verticais das componentes $u$ e $v$ da velocidade geostrófica e de suas anomalias em relação ao fluxo médio, respectivamente com o objetivo de fornecer uma descrição das formas de estratificação predominantes na coluna de água e de identificar prováveis regiões de ocorrência de ondas de Rossby planetárias dos diversos modos dinâmicos. Os três primeiros raios de deformação internos são calculados com o objetivo de fornecer um contexto dinâmico às distribuições modais observadas e avaliar a possibilidade da ocorrência de efeitos não-lineares, neste caso caracterizados pela interação de ondas planetárias com alterações da estrutura vertical de densidade induzidas por sua própria passagem. As hipóteses a serem testadas dizem que (1) dentre os modos baroclínicos, o primeiro modo é dominante tanto no fluxo geostrófico total quanto em suas anomalias, com regiões onde o segundo modo mostra-se significativo, seguido em menor grau pelo terceiro; e (2) no contexto da equação da conservação da vorticidade potencial em um oceano linear e continuamente estratificado, a dependência temporal da densidade pode ser desprezada em larga escala, porém pode tornar-se significativa em resposta à ação de fenômenos transientes intensos, como ondas de Rossby.

A análise proposta abrange as regiões oceânicas entre $39^{\circ} \mathrm{S}$ e $39^{\circ} \mathrm{N}$ mais profundas que $1000 \mathrm{~m}$, e baseia-se em dados sintéticos da estrutura interna de temperatura dos oceanos aliados a dados climatológicos de salinidade do World Ocean Atlas 2005 (WOA05). O conjunto de dados sintéticos é obtido a partir de dados orbitais de temperatura da superfície do mar (TSM) medidos pelo radiômetro de microondas TRMM Microwave Imager (TMI) do satélite Tropical Rainfall Measuring Mission (TRMM) e da anomalia da altura da superfície livre ( $\eta$ ) obtidos pelos satélites altimétricos TOPEX/Poseidon e Jason-1 (T/P e J-1, respectivamente), extrapolados verticalmente segundo um método de reconstrução estatística inspirado nos trabalhos de Carnes et al. 1990 e Agarwal et al. 2007, desenvolvido especificamente para este estudo. O conjunto de dados in situ de temperatura que formam a base estatística do método apreende mais de 640.000 perfis verticais obtidos por flutuadores Argo e perfiladores XBT distribuídos desigualmente na região oceânica considerada, como mostra a Figura 5.

Especificamente, perfis sintéticos de temperatura são calculados na grade horizontal de $1^{\circ}$ $\times 1^{\circ}$ dos dados climatológicos e na resolução temporal de aproximadamente 10 dias referente 
ao ciclo amostral dos satélites T/P e J-1. Estes perfis são combinados a dados climatológicos mensais de salinidade para gerar perfis sintéticos de densidade, utilizados no cálculo das componentes $u$ e $v$ da velocidade geostrófica através do método dinâmico (Sandström e HellandHansen 1903) e na obtenção dos modos dinâmicos baroclínicos $F_{i}$ e raios de deformação internos $R_{i}$ (Silveira et al. 2000). A importância de cada modo em perfis verticais das componentes $u$ e $v$ e em suas anomalias é respectivamente avaliada em termos dos parâmetros $\vartheta_{i}$ e $\vartheta_{i}^{\prime}$, que quantificam a fração da estrutura vertical que é explicada pelo $i$-ésimo modo dinâmico.

Como discutido na seção 3.7.1, os perfis sintéticos de temperatura obtidos possuem limites observacionais relacionados ao seu alcance vertical e à fração da variância que são capazes de recuperar. A quase totalidade da variabilidade com significado físico está contida apenas nos primeiros $1000 \mathrm{~m}$ da coluna de água, uma vez que os perfis it situ utilizados na obtenção dos modos EOF utilizados na construção do conjunto sintético são truncados nesta profundidade. De 1000 a 1500 m toda a variabilidade representada provém de trechos extrapolados dos perfis in situ, e em níveis mais profundos o conjunto de dados sintéticos é idêntico à climatologia anual do WOA05 em qualquer instante $t$. Adicionalmente, espera-se que os perfis sintéticos sejam capazes de recuperar no máximo a fração da variância que é explicada pelos dois primeiros modos EOF utilizados em sua construção. A Figura 7 mostra o mapa da variância explicada por estes dois modos combinados, sendo que o valor médio global é de cerca de $83 \%$.

Apesar destas limitações, a seção 4.1 mostra que os perfis sintéticos gerados são capazes de representar realisticamente a base da termoclina, e suas estruturas por si só não violam a condição de estabilidade dinâmica da coluna de água. Apesar do seu cálculo ser efetuado individualmente em cada ponto de grade e em cada instante $t$, feições suaves no tempo e no espaço são formadas. Formas de variabilidade interna em diversas frequências são prontamente identificadas em seções zonais-temporais de temperatura, de variações de temperatura nas primeiras centenas de metros da coluna de água, em resposta ao ciclo sazonal, à oscilações verticais propagantes para oeste nas isotermas, que podem corresponder à assinaturas de ondas de Rossby ou outros tipos de onda de larga escala, ou mesmo à sinais subamostrados de fenômenos de meso-escala como vórtices e meandros.

O método de construção de perfis sintéticos de temperatura foi considerado efetivo em regiões onde perfis in situ de temperatura em média assemelham-se mais aos perfis sintéticos do que aos perfis climatológicos mensais, o que ocorre em cerca de $70 \%$ dos pontos de grade 
considerados (Figura 11). Os dados in situ são notoriamente mais semelhantes aos sintéticos em regiões de alta variabilidade transiente, como as confluências Kuroshio-Oyashio e BrasilMalvinas, corrente do Golfo ao norte de $35^{\circ} \mathrm{N}$, corrente das Agulhas, e na região equatorial do oceano Pacífico, suportando a afirmação de que os dados sintéticos são capazes de representar realisticamente formas da variabilidade interna dos oceanos em em uma ampla faixa espectral. A diferença entre o conjunto sintético e o climatológico se reduz no interior dos giros subtropicais, característica atribuída à grande intensidade do sinal sazonal, que é contemplado nos dados climatológicos, em relação ao sinal dos demais fenômenos transientes. Quedas significativas de desempenho dos dados sintéticos são observadas no Atlântico tropical entre $5^{\circ} \mathrm{S}$ e $15^{\circ} \mathrm{N}$ e no Pacífico em uma faixa zonal centrada aproximadamente em $10^{\circ} \mathrm{N}$. A causa para estas falhas deve ser investigada em futuros aprimoramentos do método, porém especula-se que esteja ligada à efeitos halostéricos significativos, uma vez que ocorrem aproximadamente em regiões dominadas pela Zona de Convergência Intertropical (ZCIT) e logo estão sujeitas à intensos ciclos de evaporação e precipitação. Menos proeminentemente, erros são também observados no sudoeste asiático aproximadamente entre $10^{\circ} \mathrm{S}$ e $20^{\circ} \mathrm{N}$, também sob influência da migração sazonal da ZCIT, o que reforça a hipótese de influência halostérica. Por fim, a maioria das falhas observadas ao sul de $20^{\circ} \mathrm{S}$ nos três oceanos é atribuída simplesmente à baixa densidade de perfis in situ disponíveis para a obtenção dos modos EOF.

A seção 4.2 apresenta os resultados obtidos para os três primeiros raios de deformação de Rossby baroclínicos $R_{i}$ e suas respectivas velocidades de fase de ondas de gravidade internas $c_{i}$. Em um breve resumo da bibliografia relacionada, o trabalho de Emery et al. 1984 apresenta mapas médios de $R_{1}$ para os oceanos Pacífico norte e Atlântico norte na resolução de $5^{\circ} \times 5^{\circ}$. Houry et al. 1987 se concentra no Atlântico tropical, Atlântico sul e a porção oeste do oceano Índico, apresentando mapas de $R_{1}$ e $R_{2}$ na mesma resolução espacial. Picaut e Sombardier 1993 apresenta mapas de $c_{1}$ a $c_{5}$ no na maior resolução de $1^{\circ} \times 1^{\circ}$ para o Pacífico tropical, e por fim Chelton et al. 1998 apresenta os primeiros mapas globais de $R_{1}$ e $c_{1}$ com resolução de $1^{\circ}$ $\times 1^{\circ}$. Os resultados de todos estes trabalhos apresentam feições qualitativamente consistentes com os mapas médios de $R_{i}$ (Figuras 12 a 14) e $c_{i}$ (Figuras 16 a 18) apresentados aqui, tanto em magnitude como distribuição espacial. Adicionalmente, uma comparação quantitativa com os valores médios de $R_{1}$ e $c_{1}$ obtidos em Chelton et al. 1998 mostra que os resultados de ambos os estudos são estatisticamente idênticos entre si. 
Estes resultados foram discutidos em termos da solução de WKB para os raios de deformação baroclínicos derivada em Chelton et al. 1998, apresentada aqui na Equação (26). A variabilidade geográfica de $R_{i}$ é dominada por uma dependência inversa com $f$. Em uma mesma latitude e estratificação vertical, os raios decrescem na razão inversa da ordem baroclínica $i$. Para uma mesma latitude, $R_{i}$ é aproximadamente proporcional à integral vertical da frequência de Brunt-Väisälä $N(z)$, e portanto uma estratificação mais forte implica em maiores raios, enquanto a redução da profundidade sobre feições topográficas implica em menores extensões da coluna de água a ser considerada na integral e portanto em reduções dos valores de $R_{i}$. Os efeitos combinados da estratificação e da topografia são particularmente visíveis nos mapas de $c_{i}$, onde as isolinhas de velocidade de fase claramente delineam diversas feições de fundo proeminentes, e as maiores velocidades nas porções oeste dos oceanos Pacífico e Atlântico são compatíveis com o aprofundamento da picnoclina em direção à oeste nestas bacias. Porém, observa-se que as isolinhas nos mapas médios de $R_{i}$ e $c_{i}$ formam padrões diferentes em cada ordem baroclínica, o que não é compatível com a forma linear da solução WKB.

A variabilidade de $R_{i}$ e $c_{i}$ foi avaliada em termos das diferenças ou anomalias percentuais (DPs) em relação aos valores médios correspondentes. A observação de mapas sinóticos das DPs referentes à cada ordem baroclínica mostra feições em $i=1$ muito semelhantes às formadas pelo $\eta$ altimétrico, sendo que em $i>1$ o ciclo sazonal vai tornando-se progressivamente mais evidente conforme a ordem baroclínica aumenta. Adicionalmente, mapas dos desvios-padrão das séries temporais de DPs (Figuras 21 a 23) evidenciam que a variabilidade expressa-se em regiões significativamente diferentes do globo em cada raio baroclínico. Estes resultados, aliados aos padrões distintos formados pelas isolinhas dos valores médios de $R_{i}$ e $c_{i}$, são indícios de que a a estratificação de densidade se manifesta de forma diferente em cada ordem baroclínica.

Especificamente, a semelhança das feições formadas pelas DPs em $i=1 \mathrm{com}$ os mapas altimétricos sugere uma relação direta da variabilidade de $R_{1}$ com a integral vertical de $N(z)$ como sugerido pela solução WKB, uma vez que $\eta$ está relacionado à variações do campo de densidade integrado na coluna de água. Porém, o aumento do ciclo sazonal em $i>1$ é um indício de que a variabilidade dos raios se relaciona com faixas cada vez mais rasas da coluna de água conforme a ordem baroclínica aumenta. Especula-se que outros fenômenos além do ciclo sazonal também sejam destacados em $i>1$, o que é suportado pelo fato de que avaliações qualitativas de mapas sinóticos das DPs do segundo raio interno revelarem feições que cuja 
expressão é suave ou mesmo inexistente nos mapas referentes à $i=1$.

A magnitude dos desvios-padrão das DPs constituem uma evidência de que variações significativas dos raios internos podem ser induzidas pela ação de fenômenos transientes. Os mapas das Figuras 21 a 23 mostram desvios-padrão entre 1 e 3\%, com regiões isoladas onde os va-lores assumem ordens de grandeza de $10 \%$. Assumindo que os valores nas séries temporais das DPs possuem distribuição gaussiana e simétrica, então DPs iguais ou menores a 1 desvio-padrão são observados em 68,2\% da série temporal, enquanto valores entre 1 e 2 ( 2 e 3) vezes estes desvios ocorreriam em 27,2\% (4,2\%) do tempo. Ondas de Rossby longas (ORLs) são fenômenos que no primeiro modo baroclínico dominam a o espectro da energia propagante para oeste nos oceanos (Chelton e Schlax 1996; Polito e Liu 2003). Sua velocidade de fase segundo a teoria linear de ondas livres é diretamente proporcional ao quadrado do raio de deformação interno correspondente, como evidenciado pela Equação (28). Isto significa que desvios de até $3 \%$ nos mapas podem remeter à variações dos raios internos de até $9 \%$ em casos extremos, implicando em variações da velocidade de propagação de ORLs de até 18,8\%. Como mostram as Figuras 21 a 23, estas diferenças podem ser significativamente maiores em regiões específicas dos oceanos. Isto é uma evidência de que a dependência temporal da estratificação interna não pode ser desprezada na descrição de fenômenos transientes intensos.

No caso específico de ondas de Rossby, especula-se que a propagação da onda interagiria de maneira não-linear com a evolução da estrutura interna de densidade forçada por sua própria passagem, alterando características como número de onda e frequência em relação aos parâmetros previstos pela teoria linear. É ainda possível que ondas planetárias de diferentes frequências sobrepostas umas às outras (piggyback) também interajam não-linearmente entre si via as alterações da estrutura vertical da densidade forçadas por cada uma. A existência e as consequências de tais interações devem ser avaliadas em maiores detalhes em trabalhos posteriores. Uma investigação observacional poderia ser conduzida utilizando abordagens semelhantes às aplicadas em Brandt et al. 2002 e Laurindo et al. 2010, cruzando dados in situ da estrutura termohalina coincidentes com sinais de ondas planetárias identificados em dados de satélites.

Os resultados obtidos para a importância relativa dos modos dinâmicos são apresentados na seção 4.3, sendo as médias e desvios-padrão globais de $\vartheta_{i}$ e $\vartheta_{i}^{\prime}$ respectivamente mostradas nas Tabelas 3 e 4 . Os resultados mostram que o primeiro modo domina tanto a circulação total quanto as anomalias em relação ao fluxo médio, respondendo em média por cerca de $30 \%$ da 
estrutura vertical. Em média, o segundo modo responde por frações de cerca de 10\%, porém pode assumir importância comparável ou mesmo superior à do primeiro modo em algumas regiões dos oceanos, particularmente em latitudes próximas ao equador. O terceiro modo é significativo em regiões isoladas, porém não exerce portanto papéis significativos em escala de bacia, respondendo por frações da estrutura vertical inferiores à 5\% em cerca de $80 \%$ dos oceanos, tanto para $\vartheta_{i}$ quanto $\vartheta_{i}^{\prime}$ e para ambas as componentes da velocidade. O quarto e quinto modos respondem por frações médias de $1 \%$ da estrutura vertical e virtualmente todos os valores de $\vartheta_{i}$ e $\vartheta_{i}^{\prime}$ calculados para estes modos são inferiores à $5 \%$, sendo portanto considerados baixos demais para permitir uma distinção confiável entre sinais geofísicos e ruído metodológico. $\mathrm{O}$ modo barotrópico responde em média por frações de cerca de 6 e $9 \%\left(\vartheta_{i}\right.$ e $\vartheta_{i}^{\prime}$, respectivamente), importância intermediária entre o segundo e terceiro modos baroclínicos. Porém, considera-se provável que a importância do modo barotrópico seja subestimada nesta análise pelo fato de as estruturas verticais da velocidade geostrófica sintética serem constantes no tempo abaixo dos $1500 \mathrm{~m}$.

Apesar de ruidosos, os resultados obtidos para $\vartheta_{i}$ e $\vartheta_{i}^{\prime}$ mostram aspectos chave da dinâmica de larga escala. A predominância do primeiro modo baroclínico observada nos mapas médios de $\vartheta_{1}$ e $\vartheta_{1}^{\prime}$ (Figuras 26 e 34, respectivamente) aliada à grande distribuição espacial das feições observadas nos mapas de seus desvios-padrão (Figuras 30 e 38) são compatíveis com observações globais de sinais propagantes através de dados altimétricos, que apontam para uma dominância de ondas de Rossby planetárias do primeiro modo baroclínico sobre o espectro da energia propagante para oeste nos oceanos (Chelton e Schlax 1996; Polito e Liu 2003; Challenor et al. 2004). Particularmente, as feições observadas nos mapas médios de $\vartheta_{1}^{\prime}$ (Figura 34) são coincidentes com regiões onde ondas de Rossby longas do primeiro modo baroclínico são mais energéticas e respondem por uma fração maior da variância (Polito e Liu 2003).

As feições próximas ao equador observadas nos mapas médios de $\vartheta_{2}$ e $\vartheta_{2}^{\prime}$ (Figuras 27 e 35) parecem marcar regiões associadas à ondas de Rossby intrasazonais e ondas de instabilidade tropical (Polito e Liu 2003). Uma grande amplificação dos valores é observada ao sul do Pacífico, não sendo encontradas referências na literatura a respeito de estruturas associadas ao segundo modo. Maharaj et al. 2007 analisa a fração da variância em dados altimétricos atribuída à ondas planetárias de diferentes modos baroclínicos no Pacífico sul, porém seus resultados para o segundo modo mostram feições que não possuem paralelo com as observadas aqui, mas 
chama-se a atenção ao fato de que é possível que os altímetros sejam pouco sensíveis à modos baroclínicos superiores ao primeiro (Cipollini et al. 1997; Challenor et al. 2004). A análise das formas funcionais dos modos dinâmicos na região e das velocidades calculadas mostra que os fluxos predominantes nas primeiras centenas de metros da coluna de água estendem-se até profundidades compatíveis com a inversão de sinal mais rasa no segundo modo, que ocorre em níveis significativamente mais profundos no primeiro modo. Esta característica faz com que o segundo modo apresente melhores ajustes ao fluxo na região, e é possível que também favoreça a geração de ondas planetárias do segundo modo baroclínico. A análise dos mapas dos desvio-padrão de $\vartheta_{2}$ e $\vartheta_{2}^{\prime}$ (Figuras 31 e 39 ) mostra feições semelhantes às observadas em mapas médios, um indício de que possíveis ondas planetárias do segundo modo são fenômenos intermitentes e dispersivos, uma vez que sua expressão parece ser confinada à regiões específicas dos oceanos. São raras as observações diretas de ondas de segundo modo, e exemplos incluem o trabalho de Laurindo et al. 2010, que relata este fenômeno entre $3,5^{\circ} \mathrm{N}$ e $5,5^{\circ} \mathrm{N}$ no Atlântico tropical, e o de Brandt et al. 2002, mostrando evidências de sua existência no mar da Arábia. Os resultados de ambos os trabalhos são consistentes com as amplificações dos valores médios de $\vartheta_{2}^{\prime}$ observados nestas regiões.

Cipollini et al. 1997 relata três velocidades de fase distintas através da análise espectral de diagramas zonais-temporais de dados altimétricos e de $\operatorname{TSM}$ em $34^{\circ} \mathrm{N}$, atribuindo estes sinais à ondas planetárias dos três primeiros modos baroclínicos. Observou-se que $\vartheta_{3}^{\prime}$ (Figuras $36 \mathrm{e}$ 40) se amplifica ao largo do estreito de Gibraltar próximo a esta latitude, sendo que valores de $\vartheta_{1}^{\prime}$ e $\vartheta_{2}^{\prime}$ maiores que a média também sugerem a atividade de ondas destes modos na região. Ao largo do estreito de Gibraltar, a literatura também relatada a ação de vórtices de água do mediterrâneo (conhecidos como meddies) em regiões de intratermoclina. Meddies são capazes de serem transportados por grandes distâncias sem serem descaracterizados, sendo reportados até mesmo ao largo das Bahamas, junto à borda oeste do Atlântico (McDowell e Rossby 1978; Bower et al. 1995). Não espera-se que o conjunto de dados sintético seja capaz de resolver apropriadamente a estrutura de meddies de subsuperfície, uma vez que tratam-se de fenômenos de mesoescala (10 a $100 \mathrm{~km}$ ). Porém, mapas de $\vartheta_{1}^{\prime}$ a $\vartheta_{3}^{\prime}$, particularmente de seus desvios-padrão (Figuras 38 a 40), curiosamente mostram feições retilíneas ligando o estreito de Gibraltar ao Caribe. Especula-se portanto que estas feições sejam respostas, mesmo que subamostradas, da ação de meddies sobre a estrutura baroclínica. 
Evidências da transferência de energia entre modos dinâmicos podem ser inferidas a partir dos mapas médios e do desvio-padrão de $\vartheta_{i}$ e $\vartheta_{i}^{\prime}$. Particularmente, mapas médios de $\vartheta_{0}^{\prime}$ (Figura 33) mostram sinais comparativamente fracos $(\sim 10 \%)$, porém bem definidos sobre diversas feições proeminentes do fundo oceânico. Isto pode corresponder a uma forma não linear de transferência de energia entre o primeiro modo baroclínico e o modo barotrópico descrito em resposta à topografia descrito em Barnier 1988. Segundo ele, uma cordilheira submarina meridional bloqueia ondas do primeiro modo provenientes da porção leste da bacia, que ao interagir com a topografia, transferem energia para ondas de Rossby barotrópicas confinadas à crista do obstáculo, cuja energia é retransferida para ondas do primeiro modo baroclínico do lado oeste da cordilheira. No oceano Índico, o formato em " $\mathrm{L}$ " da cordilheira de $90^{\circ} \mathrm{E}$ é delineado por baixos valores de $\vartheta_{i}$ e $\vartheta_{i}^{\prime}$ referentes ao terceiro modo baroclínico e por altos valores destes parâmetros referentes ao segundo (isto é emblematicamente observado nas Figuras 27 e 28), sendo possível que um mecanismo semelhante ao descrito em Barnier 1988 esteja em ação entre modos dinâmicos de ordem mais alta. Teoriza-se ainda que os desvios-padrão de $\vartheta_{i}^{\prime}$, além de constituir uma medida da intermitência de ondas de Rossby ou da coexistência entre ondas de diferentes modos, também se amplifiquem em regiões onde estejam ocorram transferências não-lineares da variância entre diferentes modos dinâmicos. Neste caso, os menores desviospadrão de $\vartheta_{i}^{\prime}$ associados ao interior dos giros subtropicais (Figuras 37 a 38) indicariam que as ondas nestas regiões tendem a ser mais lineares do que as observadas em regiões tropicais.

Foi observada uma correspondência entre as feições formadas pelos valores médios e do desvio-padrão de $\vartheta_{i}^{\prime}$ para os modos baroclínicos (mapas médios, Figuras 34 a 36, e dos desviospadrão, Figuras 38 a 40) e as formadas pelos desvios-padrão das anomalias percentuais de $R_{i}$ (Figuras 21 a 23). Esta relação é particularmente bem caracterizada para o segundo modo baroclínico, presente de maneira menos marcada para terceiro modo e em ainda menor grau para o primeiro. A semelhança implica na interligação dos mecanismos físicos por trás da variabilidade dos raios de deformação e da variabilidade da fração da estrutura vertical explicada por cada modo dinâmico. Isto é, uma onda planetária do primeiro modo parece provocar alterações preferencialmente sobre o primeiro raio interno, uma onda do segundo modo sobre o segundo modo interno, etc. Uma implicação direta da maior semelhança dos padrões formados pelas DPs e $\vartheta_{i}^{\prime}$ para o segundo e terceiro modos em relação ao primeiro é de que ondas de ordens baroclínicas superiores à 1 são mais propensas à ação de efeitos não lineares. 
Outra implicação desta semelhança diz respeito à observabilidade dos diferentes modos dinâmicos pelos altímetros orbitais. Como afirmado anteriormente, as feições formadas pelas DPs em relação ao primeiro raio interno são muito semelhantes aos padrões observados em mapas altimétricos. Nos raios internos de maior ordem, a variabilidade aparentemente se refere a níveis cada vez mais rasos da coluna de água, destacando o ciclo sazonal e outros fenômenos cuja expressão se perde ao integrar as variações da estratificação ao longo da coluna de água inteira. Os resultados apresentados sugerem que as feições destacadas pelas DPs do segundo e terceiro raios de deformação internos de fato correspondem à formas de variabilidade com estruturas verticais ligadas ao segundo e terceiro modos baroclínicos, característica que suporta a hipótese de insensibilidade dos altímetros orbitais à modos baroclínicos maiores que o primeiro.

Assim, este estudo identifica regiões com maior probabilidade de ocorrência de ondas de Rossby planetárias de diferentes modos baroclínicos, mostrando indícios de que interações nãolineares podem influenciar suas características. São apresentadas ainda evidências da baixa sensibilidade dos altímetros orbitais a modos baroclínicos maiores que o primeiro, e de possíveis fenômenos envolvendo transferências de energia entre modos dinâmicos. As exatas características dos sinais referentes a diferentes modos devem ser investigadas em trabalhos futuros para confirmar a sua natureza dinâmica, assim como a existência e os exatos efeitos das interações não-lineares teorizadas aqui. Adicionalmente, os resultados obtidos para os raios de deformação internos e para a importância relativa dos diferentes modos dinâmicos sobre o fluxo total podem ser úteis na calibração e validação de modelos de camadas oceânicos.

Do ponto de vista metodológico, as diversas etapas da análise desenvolvida atestam a consistência do conjunto de perfis sintéticos de temperatura sob diversos aspectos dinâmicos. As duas formulações propostas para o seu cálculo, particularmente a formulação básica, possuem relativamente poucos parâmetros ajustáveis além da forma de extrapolação vertical de perfis in situ e das dimensões da caixa de procura de dados para o seu cálculo, suportando a robustez do método e uma possível aplicabilidade em modelos númericos de assimilação de dados. Potenciais melhorias envolveriam (a) o aumento da profundidade dos perfis sintéticos e resolução espacial dos dados orbitais; (b) a inclusão do efeito halostérico através da utilização de perfis sintéticos de salinidade, que teoricamente poderiam ser obtidos através uma metodologia similar à descrita aqui, utilizando dados orbitais da salinidade de superfície obtidos pela nova geração de satélites oceanográficos, como o Aquarius e o SMOS (Soil Moisture and Ocean Salinity), 
aliados ao número crescente de perfis in situ de salinidade do oceano global por meio da rede de flutuadores Argo; e (c) o acoplamento do método descrito aqui à um modelo de camada de mistura, o que poderia eliminar a necessidade de utilização do método adaptado (descrito na seção 3.3.3). Outra abordagem possível do método proposto aqui envolveria a sua utilização em conjunto com plataformas in situ, como fundeios hidrográficos. Neste caso, medições discretas de temperatura poderiam ser utilizadas como condições de contorno adicionais para a inclusão de mais modos EOF no cálculo dos perfis sintéticos. Isto pode potencialmente possibilitar a obtenção de perfis verticais de temperatura de alta qualidade utilizando um número relativamente pequeno de sensores ao longo da vertical. 


\section{Referências}

Abarbanel, H. D. I. e W. R. Young, 1987:. General Circulation of the Ocean. New York: Springer-Verlag New York Inc., 291 pp.

Agarwal, N., R. Sharma, B. Basu e V. K. Agarwal, 2007:. Derivation of salinity profiles in the Indian ocean from satellite surface observations. IEEE Transactions on Geoscience and Remote Sensing Letters 4(2), 322-325.

Amante, C. e B. W. Eakins, 2009:. ETOPO1 1 Arc-Minute Global Relief Model: Procedures, Data Sources and Analysis. NOAA Technical Memorandum NESDIS NGDC-24. 19 pp.

Antonov, J. I., R. A. Locarnini, T. P. Boyer, A. V. Mishonov, e H. E. Garcia, 2006:. World Ocean Atlas 2005, Volume 2: Salinity. Ed: Sydney Levitus. NOAA Atlas NESDIS 62, U.S. Government Printing Office, Washington, D.C., 182 pp.

Barnier, B., 1988:. A numerical study of the influence of the Mid-Atlantic Ridge on nonlinear first-mode baroclinic Rossby waves generated by seasonal winds. Journal of Physical Oceanography, 18, 417-433.

Benada, R., 1997:. Merged GDR TOPEX/Poseidon Users Handbook Version 2.0. Jet Propulsion Lab. PO.DAAC. D-11007.

Bower, A. S., L. Armi, e I. Ambar, 1995:. Direct evidence of meddy formation of the southwestern coast of Portugal. Deep-Sea Research 42(9), 1621-1630.

Brandt, P., L. Stramma, F. Schott, J. Fischer, M. Dengler e D. Quadfasel, 2002:. Annual Rossby waves in the Arabian Sea from TOPEX/POSEIDON altimeter and in situ data. Deep-Sea Research II, 49, 1197-1210.

Calil, P. H. R., J. Kevin, K. J. Richards, Y. Jia e R. R. Bidigare, 2008:. Eddy activity in the lee of the hawaiian islands. Deep-Sea Research II, 55, 1179-1194.

Campos, E. J. D. e D. B. Olson, 1991:. Stationary Rossby waves in western boundary current extensions. Journal of Physical Oceanography, 21, 1202-1224.

Carnes, M. R., L. Mitchell e P. W. deWitt, 1990:. Synthetic temperature profiles derived from GEOSAT altimetry: Comparison with air-dropped expendable bathythermograph profiles. Journal of Geophysical Research, 95, 17979-17992. 
Challenor, P. G., P. Cipollini, D. Cromwell, K. L. Hill, G. D. Quartly e I. S. Robinson, 2004:. Characteristics of mid-latitude Rossby wave propagation from multiple satellite datasets. International Journal of Remote Sensing, 25, 1297-1302.

Chambers, D. P., B. D. Tapley e R. H. Stewart, 1997:. Long-period ocean heat storage rates and basin-scale heat fluxes from TOPEX. Journal of Geophysical Research, 102(C5), $10,525-10,533$.

Chelton, D. B., R. A. deSzoeke, M. G. Schlax, K. E. Naggar e N. Siwertz, 1998:. Geographical variability of the first baroclinic Rossby radius of deformation. Journal of Physical Oceanography, 28, 433-460.

Chelton, D. B. e M. Schlax, 1996: Global observations of oceanic Rossby waves. Science, 272, 234-238.

Chereskin, T. K. e D. Roemmich, 1991:. A comparison of measured and wind-derived Ekman transport at $11^{\circ} \mathrm{N}$ at the Atlantic Ocean. Journal of Physical Oceanography, 21, 869-878.

Chereskin, T. K. e D. Roemmich, 1997:. Observations of the Ekman balance at $8^{\circ} 30^{\prime}$ in the Arabian Sea during the 1995 southwest monsoon. Geophysical Research Letters, 24, $2541-2544$.

Chu, P. C., C. Fan e W. T. Liu, 1999:. Determination of vertical thermal structure from sea surface temperature. Journal of Atmospheric and Oceanic Technology, 17, 971-979.

Cipollini, P., P. G. Challenor, D. Cromwell e I. S. Robinson, 2004:. Remote sensing of extraequatorial planetary waves in the oceans. In Manual of Remote Sensing, Volume 6, Chapter 3: Remote Sensing of the Marine Environment, pp. 61-84. ASPRS.

Cipollini, P., D. Cromwell, M. S. Jones, G. D. Quartly e P. G. Challenor, 1997:. Concurrent altimeter and infrared observations of Rossby wave propagation near $34^{\circ} \mathrm{N}$ in the northeast Atlantic. Geophysical Research Letters, 24, 889-892.

De Mey, P. e A. R. Robinson, 1987:. Assimilation of altimeter eddy fields in a limited-area quasi-geostrophic model. Journal of Physical Oceanography, 17, 2280-2293.

Dewar, W. K. e M. Y. Morris, 2000:. On the propagation of baroclinic waves in the general circulation. Journal of Physical Oceanography, 30, 2637-2649. 
Emery, W., W. G. Lee e L. Magaard, 1984:. Geographical and seasonal distributions of BruntVäisälä frequency and Rossby radii in the North Pacific and North Atlantic. Journal of Physical Oceanography, 14, 294-317.

Flierl, G. R., 1978:. Models of vertical structure and the calibration of two-layer models. Dynamics of Atmospheres and Oceans, 2, 341-381.

Fu, L.-L., 2007:. Interaction of mesoscale variability with large-scale waves in the argentine basin. Journal of Physical Oceanography, 37, 417-433.

Gangopadhyay, A., A. R. Robinson e H. G. Parango, 1997:. Circulation and dynamics of the western North Atlantic. Part I: Multiscale feature models. Journal of Atmospheric and Oceanic Technology, 14, 1314-1332.

Gill, A. E., 1982:. Atmosphere-Ocean Dynamics, Volume 30 of International Geophysics Series. San Diego, Calif.: Academic Press Inc., 662 pp.

Gnanaseelan, C., B. H. Vaid e P. S. Polito, 2008:. Impact of biannual Rossby waves in Indian ocean dipole. IEEE Geoscience and Remote Sensing Letters 5(3). doi: 10.1109/LGRS.2008.919505.

Haines, K., 1991:. A direct method for assimilating sea surface height data into ocean models with adjustments to the deep circulation. Journal of Physical Oceanography, 21, 843868.

Houry, S., E. Dombrowsky, P. De Mey e J.-P. Minster, 1987:. Brunt-Väisälä frequency and Rossby radii in the South Atlantic. Journal of Physical Oceanography, 17, 1619-1626.

Isachsen, P. E., J. H. LaCasce e J. Pedlosky, 2007:. Rossby wave instability and apparent phase speeds in large ocean basins. Journal of Physical Oceanography, 37, 1177-1191. doi: 10.1175/JPO3054.1.

Killworth, P. D. e J. R. Blundell, 2004:. The dispersion relation for planetary waves in the presence of mean flow and topography. Part I: Analytical theory and one-dimensional examples. Journal of Physical Oceanography, 34, 2692-2711.

Lapeyre, G., 2009:. What vertical mode does the altimeter reflect? On the decomposition in baroclinic modes and on a surface-trapped mode. Journal of Physical Oceanography, 39, 2857-2874. doi: 10.1175/2009JPO3968.1. 
Laurindo, L. C., P. S. Polito e I. C. A. Silveira, 2010:. Three-dimensional characterization of intraseasonal Rossby waves in the tropical Atlantic. In prep.

LeBlond, P. H. e L. A. Mysak, 1978:. Waves in the Ocean. Elsevier Oceanography Series 20. New York: Elsevier Scientific Publishing Company, 602 pp.

Levitus, S. e T. P. Boyer, 1994:. World Ocean Atlas 1994. Technical Report Vol. 4, National Oceanographic Data Center, Ocean Climate Laboratory. 117 pp.

Locarnini, R. A., A. V. Mishonov, J. I. Antonov, T. P. Boyer e H. E. Garcia, 2006:. World Ocean Atlas 2005, Volume 1: Temperature. Ed: Sydney Levitus. NOAA Atlas NESDIS 61, U.S. Government Printing Office, Washington, D.C., 182 pp.

Lozier, M. S., M. S. McCartney e W. B. Owens, 1994:. Anomalous anomalies in averaged hydrographic data. Journal of Physical Oceanography, 24, 2624-2638.

Maharaj, A. M., P. Cipollini, N. J. Holbrook, P. D. Killworth e J. R. Blundell, 2007:. An evaluation of the classical and extended Rossby wave theories in explaining spectral estimates of the first few baroclinic modes in the South Pacific Ocean. Ocean Dynamics, 57, 173-187. doi: 10.1007/s10236-006-0099-5.

McDowell, S. F. e H. T. Rossby, 1978:. Mediterranean Water: an intense mesoscale eddy off the Bahamas. Science, 202, 1085-1087.

Pedlosky, J., 1986:. Geophysical Fluid Dynamics (2 ed.). Springer-Verlag, 710 pp.

Penven, P., J. R. E. Lutjeharms, P. Marchesiello, C. Roy e S. J. Weeks, 2001: Generation of cyclonic eddies by the Agulhas current in the lee of the Agulhas Bank. Geophysical Research Letters 27(6), 1055-1058.

Picaut, J. e L. Sombardier, 1993:. Influence of density stratification and bottom depth on vertical mode structure functions in the tropical Pacific. Journal of Geophysical Research 98(C8), 14727-14737. doi: 10.1029/93JC00885.

Polito, P. S. e W. T. Liu, 2003:. Global characterization of Rossby waves at several spectral bands. Journal of Geophysical Research 108(C1). 3018, doi: 10.1029/2000JC000607.

Polito, P. S. e O. T. Sato, 2003:. Patterns of sea surface height and heat storage associated to intraseasonal Rossby waves in the tropics. Journal of Geophysical Research 108(C12). 3373, doi: 10.1029/2002JC001684. 
Rossby, C. G., 1938:. On the mutual adjustment of pressure and velocity distributions on certain simple current systems II. Journal of Marine Research, 2, 239-263.

Saha, S., S. Nadiga, C. Thiaw, J. Wang, W. Wang, Q. Zhang, H. M. Van den Dool, H.-L. Pan, S. Moorthi, D. Behringer, D. Stokes, M. Peña, S. Lord, G. White, W. Ebisuzaki, P. Peng e P. Xie, 2006:. The NCEP Climate Forecast System. Journal of Climate, 19, 3483-3517.

Sandström, J. W. e B. Helland-Hansen, 1903:. Über die Berechnung von Meeresströmungen. Fishkeridirektoratets Skrifter Serie Havundersokelser, 2(4), 1-43.

Sangrà, P., A. Pascual, A. Rodríguez-Santana, F. Machín, E. Mason, J. C. McWilliams, J. L. Pelegrí, C. Dong, A. Rubio, J. Arístegui, A. Marrero-Díaz, A. Hernández-Guerra, A. Martínez-Marrero e M. Auladell, 2009:. The Canary eddy corridor: a major pathway for long-lived eddies in the subtropical North Atlantic. Deep-Sea Research, 56, 21002114. doi: 10.1016/j.dsr.2009.08.008.

Sato, O. T. e P. S. Polito, 2008:. Influence of salinity on the interannual heat storage trends in the Atlantic estimated from altimeters and Pilot Research Moored Array in the Tropical Atlantic data. Journal of Geophysical Research 113(C02008). doi: 10.1029/2007JC004151.

Sato, O. T., P. S. Polito e W. T. Liu, 2000:. The importance of in situ salinity measurements in the heat storage estimation from TOPEX/Poseidon. Geophysical Research Letters, 27(4), $549-551$.

Sato, O. T. e T. Rossby, 2000:. Seasonal and low frequency variability in the meridional heat flux at $36^{\circ} \mathrm{N}$ in the North Atlantic. Journal of Physical Oceanography, 30(3), 606-621.

Silveira, I. C. A., W. S. Brown e G. Flierl, 2000:. Dynamics of the North Brazil Current retroflection region from the Western Tropical Atlantic Experiment observations. Journal of Geophysical Research 105(12), 28559-28583.

Smith, W. H. F. e P. Wessel, 1990:. Gridding with continuous curvature splines in tension. Geophysics, 55, 293-305.

Stammer, D., 1997:. Global characteristics of ocean variability estimated from regional TOPEX/Poseidon altimeter measurements. Journal of Physical Oceanography, 27, 1743-1769. 
Tomczak, M. e J. S. Godfrey, 2005:. Regional Oceanography: an Introduction. Versão em pdf 1.1, 391 pp. Disponível em www.es.flinders.edu.au, último acesso em 04/10/2010.

Wijffels, S., E. Firing e H. Bryden, 1994:. Direct observations of Ekman balance at $10^{\circ} \mathrm{N}$ in the Pacific. Journal of Physical Oceanography, 24, 1666-1679. 